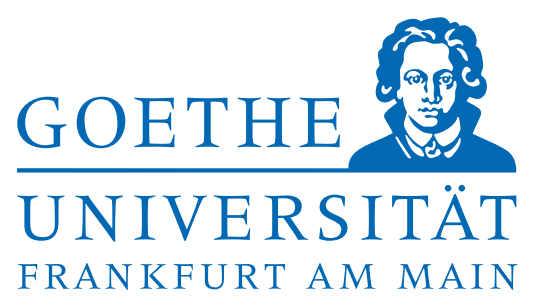

\title{
The radiation budget in a regional climate model
}

\author{
Dissertation \\ zur Erlangung des Doktorgrades \\ der Naturwissenschaften \\ vorgelegt beim Fachbereich Geowissenschaften/Geographie \\ der Johann Wolfgang Goethe-Universität \\ in Frankfurt am Main \\ von \\ Steffen Kothe \\ aus Eberswalde-Finow
}

Frankfurt (2011)

(D 30) 

Vom Fachbereich Geowissenschaften / Geographie

der Johann Wolfgang Goethe-Universität als Dissertation angenommen.

Dekan: Prof. Dr. R. Pütz

Gutachter: Prof. Dr. Bodo Ahrens

Prof. Dr. Heiko Paeth

Datum der Disputation: 
6 Abstract

$8 \quad$ Kurzzusammenfassung

\section{Chapter 1}

Introduction

12 A short history of climate modeling

14 Types of climate models

16 Parameterization

16 Evaluation

16 The earth's energy balance

18 Objectives of this thesis

\section{Chapter 2}

The radiation budget for Europe

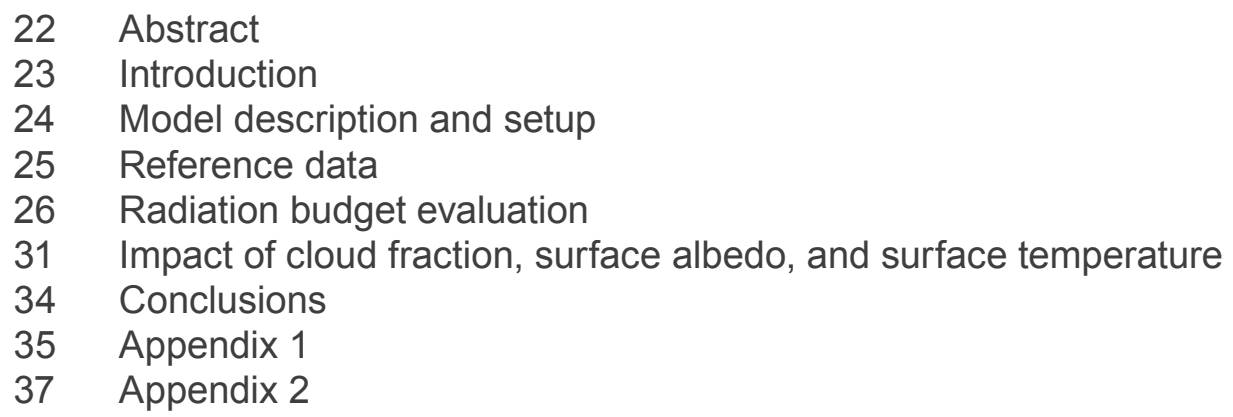

\section{Chapter 3}

The radiation budget for West Africa

42 Abstract

43 Introduction

44 Data sets and simulations

46 Radiation budget evaluation

50 Investigation of uncertainty sources

54 Conclusions

55 Appendix

\section{Chapter 4}

\section{The West African Monsoon}
60 Abstract
61 Introduction
62 Model and model setup
63 Reference data and indices
65 Results
75 Conclusions
75 Appendix 


\section{Chapter 5}

\section{Conclusions}

78 Conclusions

79 Outlook

\section{Chapter 6}

\section{Zusammenfassung}

84 Eine kurze Geschichte der Klimamodellierung

86 Arten von Klimamodellen

87 Parametrisierung

87 Evaluierung

87 Die Energiebilanz der Erde

88 Zielsetzung

90 Daten

91 Ergebnisse

93 Schlussfolgerungen

95 Ausblick

\section{Chapter 7}

Appendix

98 Abstract

99 Introduction

100 Model and model setup

101 Results

104 Discussion \& conclusions

108 References

121 Vita 


\section{Abstract}

The aim of this study is a better understanding of radiation processes in regional climate models (RCMs) in order to quantify their impact and to reduce possible errors. A first important task in finding an answer to this question was to examine the accuracy of the components of the radiation budget in regional climate simulations. To this end, the simulated radiation budgets of two regional climate simulations for Europe were compared with a satellite-based reference. In the simulations with the RCM COSMO-CLM there were some serious underand overestimations of short- and long-wave net radiation in Europe. However, taking into account the differences in the reference datasets, the results of the COSMO-CLM were quite satisfactory.

Using statistical methods, the influence of potential sources of uncertainties was estimated. Uncertainties in the cloud cover and surface albedo had a significant impact on uncertainties in short-wave net radiation, the explained variance of uncertainties in cloud cover was two to three times higher than that of uncertainties in surface albedo. Uncertainties in the cloud cover resulted in significant errors in the net long-wave radiation. However, the influence of uncertainties in soil temperature on errors in the long-wave radiation budget was low or even negligible. These results were confirmed in a comparison with simulations of the REMO and ALADIN regional climate models. It is reasonable to expect that a better parameterization of relatively simple parameters such as cloud cover and surface albedo is a means of significantly improving the simulation of radiation budget components in the COSMO-CLM.

An important question for the application of RCMs is to examine whether the results of radiation uncertainties and their impact factors are comparable if the model is applied in a region that is not the one for which it was originally created. Comparisons of the simulated radiation budgets of different RCMs for West Africa showed that problems in the simulation of short- and long-wave radiation fluxes were a widespread problem. Most of the tested models showed some considerable under- or overestimation of the short- and long-wave radiation fluxes.

Similar to Europe uncertainties in cloud cover were also in the simulations for Africa a significant factor affecting uncertainties in the simulated radiation fluxes. However, for the African simulations uncertainties in the parameterization of surface albedo were much more important than in Europe. On average, overland uncertainties in the cloud cover and surface albedo were of similar importance. Uncertainties in soil temperature simulations were of higher importance in Africa, and reached overland similar values of the mean explained variance $\left(R^{2} \approx 0.2\right)$ such as uncertainties in the cloud cover. This indicates a geographical dependence of the model error. This study confirmed the assumption that an improved parameterization of relatively simple parameters such as the surface albedo in RCMs leads to a significant improvement in the modeled radiation budget, particularly in Africa.

The influence of errors in the simulated radiation budget components on the simulation of climate processes, such as the West-African monsoon (WAM), was investigated in a next step. The evaluation of ERA-Interim and ECHAM5 driven COSMO-CLM simulations for Africa showed that the main features of the WAM were well reproduced by the model, but there were only slight improvements compared to the driving data. The index of convective activity in the model simulations was much too high and precipitation was underestimated in large parts of tropical Africa. The partly considerable differences between the ERA-Interim and ECHAM5 driven simulations demonstrated the sensitivity of the RCM to the boundary conditions and in 
particular to the sea surface temperature. An excessive northwards shift of the monsoon in the model was influenced by the land-sea temperature gradient and the strength of the Saharan heat low. Consequently, a part of the error was due to the driving data and the model itself produced another part.

By modifying the parameterization of the bare soil albedo the errors in the radiation budget and $2 \mathrm{~m}$ temperature in the Sahara region were significantly reduced. Similarly, the overestimation of precipitation and convection has been reduced in the Sahel. The effect of this modification on the examined WAM area was low. This confirmed that especially in desert regions, errors in the surface albedo were a driving factor for errors in the radiation budget. However, there are other important factors not yet sufficiently understood that have a strong influence on the quality of the simulation of the WAM.

The analysis of the actual state, the quantification of error sources and the highlighting of connections made it possible to find means to reduce uncertainties in the simulated radiation in RCMs and to have a better understanding of radiation processes. However, the magnitude of the errors found, the number of possible influencing factors, and the complexity of interactions, indicate that there is still a need for further research in this area. 


\section{KURZZUSAMMENFASSUNG}

Das Ziel dieser Arbeit war es Strahlungsprozesse in regionalen Klimamodellen (RCMs) besser zu verstehen, um deren Einfluss quantifizieren zu können und mögliche Fehler zu reduzieren. Eine erste wichtige Aufgabe zur Beantwortung dieser Frage war es zu untersuchen, wie präzise regionale Klimamodelle die Komponenten der Strahlungsbilanz simulieren können. Dazu wurden in einer ersten Studie die simulierten Strahlungsbilanzkomponenten zweier regionaler Klimasimulationen für Europa mit satellitenbasierten Daten verglichen. Die Ergebnisse zeigten in den Simulationen mit dem RCM COSMO-CLM teils erhebliche Unter- und Überschätzungen der kurz- und langwelligen Nettostrahlung in Europa. Unter Berücksichtigung der Unterschiede in den Referenzdatensätzen waren die Ergebnisse des COSMO-CLM jedoch recht zufriedenstellend.

Mithilfe statistischer Methoden wurde der Einfluss potenzieller Unsicherheitsquellen abgeschätzt. Unsicherheiten in der Wolkenbedeckung und Bodenalbedo haben einen erheblichen Einfluss auf Unsicherheiten der kurzwelligen Nettostrahlung, wobei die erklärte Varianz für Unsicherheiten in der Wolkenbedeckung zwei- bis dreimal höher war als für Unsicherheiten in der Bodenalbedo. Unsicherheiten in der Wolkenbedeckung führten zu erheblichen Fehlern in der langwelligen Nettostrahlung. Allerdings war der Einfluss von Unsicherheiten in der Bodentemperatur auf Fehler im langwelligen Strahlungsbudget gering oder sogar vernachlässigbar. Diese Ergebnisse konnten bei einem Vergleich mit Simulationen der regionalen Klimamodelle REMO und ALADIN bestätigen werden. Es ist deshalb zu erwarten, dass eine bessere Parametrisierung der relativ einfachen Parameter Wolkenbedeckung und Bodenalbedo eine wesentliche Verbesserung der Simulation der Strahlungsbilanzkomponenten im COSMO-CLM zur Folge hat.

Eine wichtige Frage bei der Anwendung von RCMs ist, ob die Ergebnisse zu Strahlungsunsicherheiten und deren Einflussfaktoren vergleichbar sind, wenn das Modell in einer anderen Region angewandt wird, als die, für die es ursprünglich erstellt wurde. Vergleiche der simulierten Strahlungsbudgets verschiedener RCMs für Westafrika zeigten, dass Probleme in der Simulation von kurz- und langwelligen Strahlungsflüssen ein verbreitetes Problem sind. Die meisten der untersuchten Modelle wiesen teils erhebliche Unter- bzw. Überschätzungen der kurz- und langwelligen Strahlungsbilanzen auf.

Ähnlich, wie für Europa, sind Unsicherheiten in der Wolkenbedeckung auch in den Simulationen für Afrika ein erheblicher Einflussfaktor auf Unsicherheiten in den simulierten Strahlungsflüssen. Für die Simulationen für Afrika waren Unsicherheiten in der Parametrierung der Bodenalbedo jedoch sehr viel wichtiger als für Europa. Über Land waren Unsicherheiten in der Wolkenbedeckung und Bodenalbedo im Durchschnitt sogar von ähnlicher Bedeutung. Auch Unsicherheiten der Bodentemperatur waren in Simulationen für Afrika von größerer Bedeutung und erreichten über Land ähnliche Werte der mittleren erklärten Varianz $\left(R^{2} \approx 0.2\right)$, wie Unsicherheiten in der Wolkenbedeckung. Dies deutet auf eine geografische Abhängigkeit der Modellfehler hin. Diese Studie bekräftigte die Annahme, dass eine verbesserte Parametrisierung von relativ einfachen Parametern, wie der Bodenalbedo, in RCMs zu einer signifikanten Verbesserung des modellierten Strahlungshaushaltes insbesondere in Afrika führt.

Wie Fehler der simulierten Strahlungsbilanzkomponenten die Simulation von Klimaprozessen, wie dem West-Afrikanischen Monsun (WAM), beeinflussen, wurde im nächsten Schritt untersucht. Die Auswertung von ECHAM5 und ERA-Interim angetriebenen COSMO-CLM Simulationen für Afrika zeigte, dass die wichtigsten Merkmale des WAM vom Modell gut wiedergege- 
ben wurden, jedoch waren die Verbesserungen gegenüber den Antriebsdaten nur geringfügig. Der Index der konvektiven Aktivität war in den Modellsimulationen viel zu hoch und der Niederschlag wurde in großen Teilen der afrikanischen Tropen unterschätzt. Die teils erheblichen Unterschiede zwischen den ECHAM5 und ERA-Interim angetriebenen Simulationen zeigten die Empfindlichkeit des RCM gegenüber den Randbedingungen und insbesondere der Meeresoberflächentemperatur. Eine zu weite nördliche Verschiebung des Monsuns im Modell wurde vom Land-See-Temperaturgradient und der Stärke des Sahara-Hitzetiefs beeinflusst. Folglich resultierte ein Teil der gefundenen Fehler aus den Antriebsdaten und ein Teil aus dem Modell selbst.

Durch die Modifikation der Parametrisierung der Albedo für bloßen Boden wurden Fehler im Strahlungshaushalt und der $2 \mathrm{~m}$ Temperatur in der Sahara Region signifikant reduziert. Ebenso wurde die Überschätzung des Niederschlags und der Konvektion in der Sahelzone verringert. Der Einfluss dieser Modifikation auf das untersuchte WAM Gebiet war jedoch gering. Dies bestätigte, dass vor allem in Wüstenregionen Fehler in der Bodenalbedo ein treibender Faktor für Fehler im Strahlungshaushalt sind. Es gibt jedoch weitere wichtige, noch nicht hinreichend verstandene Faktoren, die einen starken Einfluss auf die Qualität der Simulation des WAM haben.

Die Analyse des Istzustandes, die Quantifizierung von Fehlerquellen und das Aufzeigen von Zusammenhängen ermöglichten es Wege zu finden, Unsicherheiten in der simulierten Strahlung in RCMs zu reduzieren und Strahlungsprozesse besser zu verstehen. Die Größe der gefundenen Fehler, die Anzahl der möglichen Einflussgrößen und die Komplexität der Zusammenhänge zeigen aber, dass weiterhin Forschungsbedarf auf diesem Gebiet besteht. 



\section{Chapter 1}

INTRODUCTION

"Meteorologists are people who know very much about geophysics, climatology and thermodynamics and almost nothing about the weather of tomorrow."

Ron Kritzfeld ${ }^{1}$

\footnotetext{
1 http://zitate.net/zitat_274.html (translated from german)
} 


\subsection{A SHORT HISTORY OF CLIMATE MODELING}

Few other parameters have such a great impact on the lives of people around the world as the weather and the climate do. This is why the attempt to understand and if possible to predict the processes in the atmosphere was always very considerable. The earth's climate is determined by the general atmospheric circulation. Attempts to describe this circulation mathematically and physically remained unseccessful for a long time. Without global meteorological observations of the atmospheric circulation even the capture was nearly impossible.

The first trial of a weather forecast based on simple equations for temperature, humidity and the wind was taken by the Norwegian physicist and meteorologist Vilhelm Bjerknes at the beginning of the twentieth century. His solution method was very slow and produced poor results, since even the initial state was very vaguely given. In the 1920s, the British meteorologist Lewis Fry Richardson developed this system of equations and the numerical solution technique. An important step was the breakdown of the forecast area into individual grid cells. In his book "Weather Prediction by Numerical Process", Richardson said that with the help of tens of thousands of "computers" it should be possible to calculate a timely weather forecast. "Computers" still meant people who solved equations with pencil and paper. So, in reality the calculation of a weather forecast was useless and significantly slower than the actual weather situation.

In 1946 John von Neumann made initial attempts to use computers for numerical weather prediction at Princeton University. Mainly because the military had a strong interest in a working weather forecast, these attempts were continued at Princeton under the direction of Jule Charney. A simplification and refinement of the Richardson equations yielded promising results. The used model was based on only a few equations, and has been extended by Charney to a three-dimensional regional model. One of the biggest problems which the researchers faced at the beginning were inadequate monitoring data, which made it extremely difficult to define a sufficient initial condition or to evaluate model results. In addition to unreliable measurement instruments and a coarse monitoring network, the computational power of contemporary computers was often insufficient to create a timely regional weather forecast after compiling the input data. Accordingly, it was a much bigger problem to calculate the whole general circulation of the earth's atmosphere in a climate model. The numerical weather prediction is an initial value problem, where a fixed initial state is assumed and the accuracy of the results decreases with increasing time. In addition, environmental elements such as vegetation, oceans or ice fields are assumed to be static and hence do not contribute to the change in weather. However, climate modeling is a boundary value problem, where under given conditions such as the geography of mountains and oceans, the unchanged average of the weather, which is determined by these conditions, is calculated [Weart 2008]. Environmental elements, which are kept static in the numerical weather forecast, must be included in climate models and because the model runs are much longer than for weather forecasting, a coarser resolution is necessary.

First experiments with "General Circulation Models" (GCMs) were conducted by Norman Phillips in Princeton in 1956. With increasing computer power, the number of scientists who devoted themselves to the development of GCMs increased worldwide over the following years. The complexity of the models thus continued to grow. As programming languages became easier and program codes were better documented, access to this branch of science also improved. 
In a report by "U. S. National Academy of Sciences" in 1965, it was said on the status of current GCMs that the best models simulate the gross properties of the atmosphere in a way that they have some similarity with reality [Weart 2008]. Thus, besides the expansion of computer power, there was still much room for improvement in the models. The development of the models also increased the demand for various observational datasets of, for example, wind or humidity profiles at different heights. Such measuring systems had to be established or existing ones improved. Due to lack of global measurements in the 1960s, the current status of the full general circulation was still unclear.

Climate models increasingly became established as tools for studying the atmosphere. Thus the computing power now allowed to perform several model runs to investigate the response to changes in a parameter. Using this approach, the group of Syukuro Manabe and Richard Wetherald in 1967 found indications that a doubling of $\mathrm{CO}_{2}$ concentration leads to an increase in the Earth's global mean temperature by $2^{\circ} \mathrm{C}$. This was the first calculation of its kind on the greenhouse effect, which was recognized by scientists. In 1975, improved model calculations showed a warming of $3.5^{\circ} \mathrm{C}$ at a doubling of $\mathrm{CO}_{2}$ concentration [Weart 2008]. Even if the scientists who were responsible knew about deficits in the models, and warned against a false interpretation of results, the results impressed the field of science as well as politicians and the public.

From the mid-1950s to the mid-1970s, the power of computers increased by a factor of 1000 , which allowed for more complex models, higher resolutions and longer model runs. Another important element for the progress was that monitoring data were of a better quantity and quality. In the late 1970 s models were able to reproduce the current climate fairly realistically, which is why climate scientists had increasingly hoped to perform projections for the future with the help of climate models.

In the 1980s the first coupled ocean-atmosphere models were used. Experiments with some of these coupled models showed, among other things, the possibility of a drastic change in the thermohaline circulation as a result of a rising global mean temperature. In the late 1980s model results were certain enough to warn policymakers and the public against threats of global warming. This was the real beginning of a public debate on climate change, its consequences and a reduction of greenhouse gases, and it continues to this day. However, at that time, the number of skeptics in the scientific community was relatively large. So some inaccuracies in the initial state or the equations in GCMs were increased to become major errors. Similarly, the relatively widespread tuning of models to observational data made their behavior for future projections partly unpredictable. Another reason why some skeptics questioned the models was that the results showed a relatively good suitability for global means, but regional results were in some cases conflicting. Politicians and the public are less interested in the whole world, but want to know how much warmer, drier or wetter it will be in their region. Future projections of climate models will always be fraught with some uncertainty. A computer model cannot be verified the same as a mathematical theorem. Manabe said that every raindrop involved so much physics that it would never be possible to calculate absolutely everything.

With increasing computer power and increasing understanding of atmospheric processes, climate models have become increasingly complex. Thus, for example, vegetation and atmospheric chemistry were coupled with models that determine the likely social and economic development of people. Among other things, this meant that GCM no longer only stood for "General Circulation Model", which is based on the traditional equations for weather, but also for "Global Climate Model" or even "Global Coupled Model". Climate modeling has now reached a point at which it can now be confidently declared with a high degree of probability what will happen. Nonetheless, projections of different climate models still have a large range of results for specific regions. For some regions, such as the Arctic, the results are quite uniform and thus relatively safe, whereas some of the most populated regions on earth in particular do not permit any reliable information.

At the beginning climate models were mainly designed to explain how the atmosphere works, more than aiming at the creation of future projections. Meanwhile, there are a number of 
climate models with varying complexity depending on the application. Climate models are now indispensable tools for studying the complex physics of the atmosphere. Particularly in the area of climate change and the associated consequences for humans and the environment, climate modeling has become one of the most important information sources for science, but also for policy makers and the public. So with the help of climate models you can examine climate change as a response to emissions of greenhouse gases and aerosols and perform projections on possible changes in the future. It is always a concern that climate projections are not misunderstood as climate forecasts and that current climate models have several weaknesses that need to be improved. Models can help the people to sort countless ideas and provide clues, which are the most plausible ones [Weart 2008].

\subsection{Types of climate models}

Nowadays there are a variety of different types of climate models, which differ mainly in their complexity (Figure 1.1). The simplest models are one-dimensional models that calculate only a single parameter such as radiation. These models include the "Energy Balance Model" (EBM) or "Radiative-Convective Models" (R-CM). "Statistical Dynamical Models" (SDM) are slightly more complex. These two-dimensional models create forecasts of the large-scale circulation by solving equations that describe the change in atmospheric pressure, wind and moisture. SDMs have relatively low demands on the required computing power, but they are limited in their use for future projections [Kemp 2011]. "Earth System Models of Intermediate Complexity" (EMIC) are models that contain most of the processes of atmosphere-ocean GCM (AO-GCM). However, unlike AO-GCMs they have a reduced complexity, simplified equations and a reduced resolution. GCMs are the most complex and sophisticated models (Figure 1.2). Due to longer simulation periods GCMs generally have a coarser resolution than weather forecast models. This usually ensures an adequate reproduction of large-scale climate features, but limits an application for local processes. This restriction is reduced by using regional climate models (RCMs). RCMs have a higher resolution than GCMs and usually require less computer resources. The use of RCMs allows regional characteristics such as topography, rivers, coastlines, or complex and heterogeneous land use to be captured better than in GCMs (Figure 1.3).

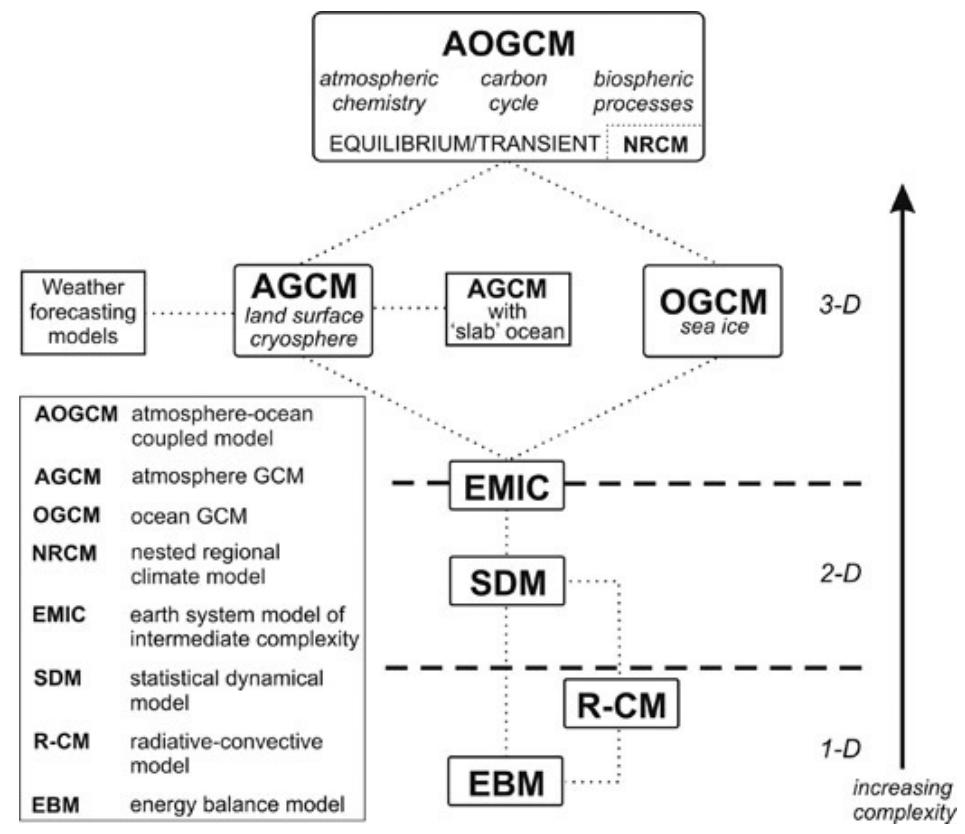

Figure 1.1 Kinds of climate models [source: Kemp 2011] 


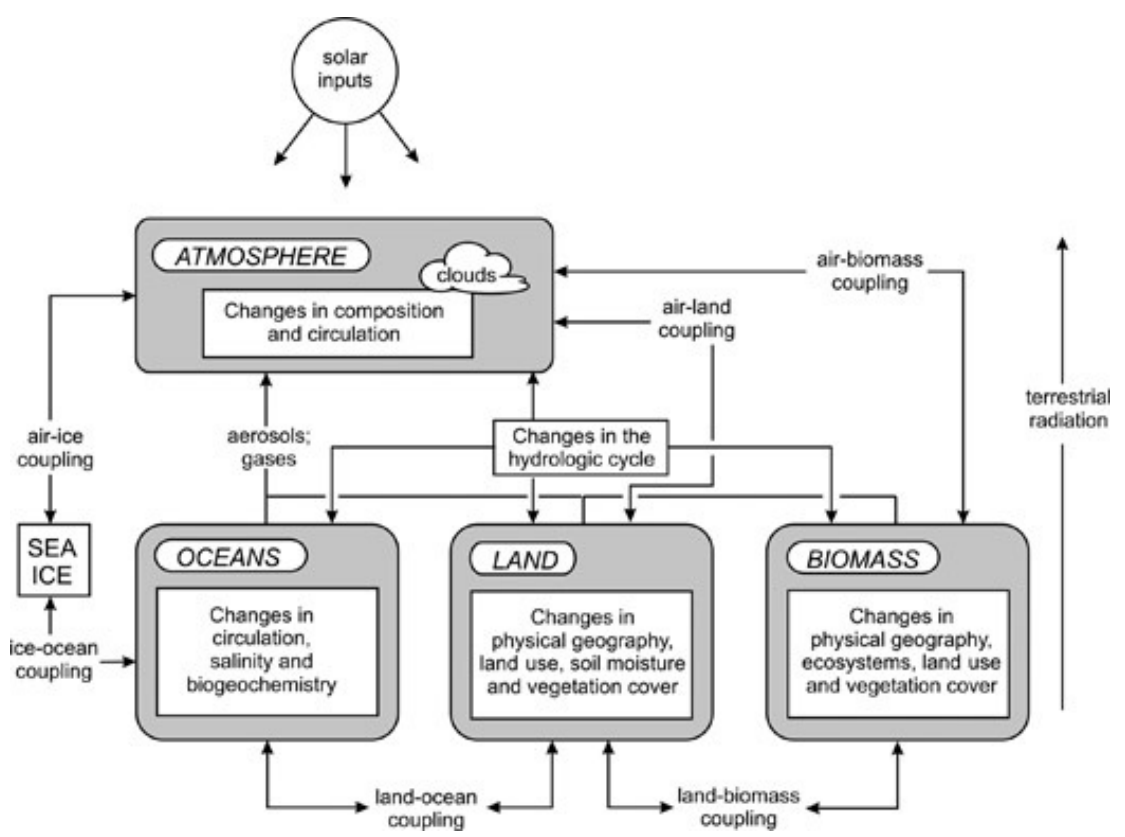

Figure 1.2 Overview of elements, processes and linkages in climate models [source: Kemp 2011]

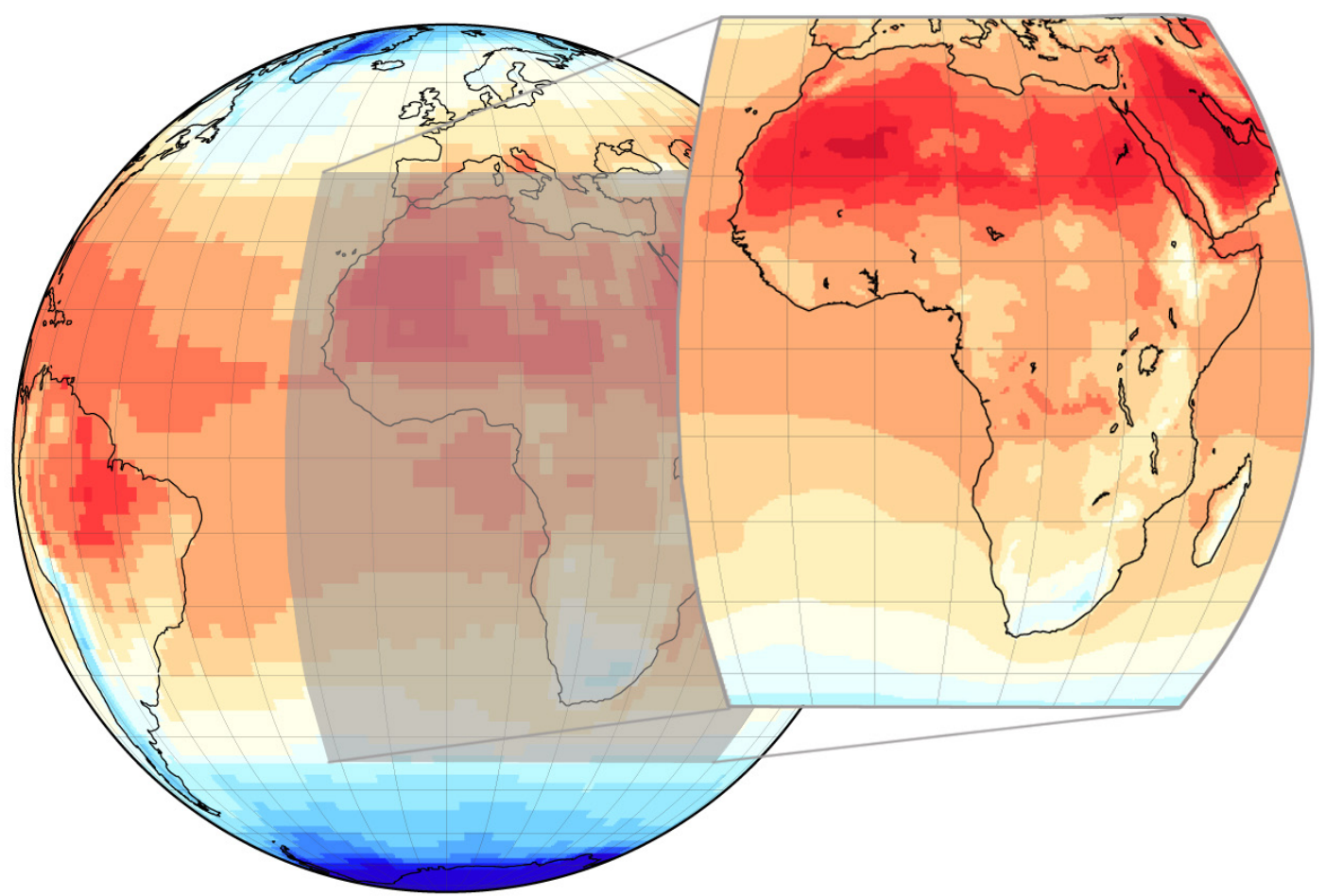

$2 \mathrm{~m}$ temperature $[\mathrm{K}]$

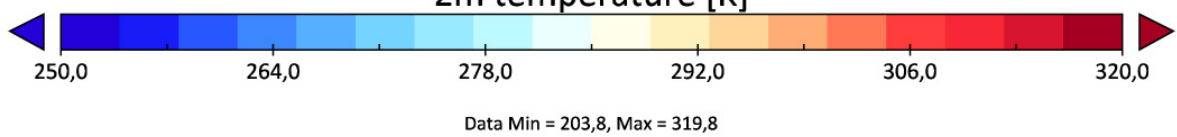

Figure $1.32 \mathrm{~m}$ temperature of July 2000 for ECHAM5 and COSMO-CLM 


\subsection{Parameterization}

Even current high-resolution climate models have a resolution, which is too coarse to calculate explicitly small-scale processes, such as turbulence in the atmospheric boundary layer, convection, interaction with small-scale topography, thunderstorms or cloud microphysics [Goosse et al. 2011]. For this reason, parameterizations have to be found for these processes. A parameterization is a set of numbers (parameters), which describes the average behavior of all existing clouds in a grid cell under given conditions [Kemp 2011]. Parameterizations typically have an empirical or theoretical basis and are intended to describe the influence of large-scale processes, which are not explicitly considered. However, they usually reproduce only first-order effects and are not valid for all possible conditions. It follows that parameterizations in climate models represent a large source of uncertainty.

\subsection{Evaluation}

Climate models always represent a compromise between the complexity of the earthatmosphere system and the constraints of factors such as availability of data, computer performance and costs for model development and model operation. These factors ultimately limit the accuracy of the model [Kemp 2011]. To assess the accuracy of a model and to identify possible sources of errors, an evaluation of the model is a very important process. The comparison of model simulations of recent years with observational data is used most often. There are now series of measurements covering a range of parameters, for example, those from station measurements, field campaigns and satellite data. Nevertheless, for many global data sets the required station density and measurement accuracy is not always given, even today. The evaluation of climate models is therefore still a problematic field. The need to evaluate model results with observational data also opened up the alternative to test model results for paleoclimates. This opened up the possibility to test models against a totally different climate than the present and to evaluate on the basis of proxy data. This results in a further field of application for GCMs, namely paleo-climatology. For future projections there is no way to prove their correctness. However, with the help of comparisons of different models and model ensembles probable error variations can be estimated.

A desired goal of this work was to improve simulated radiation processes in a regional climate model. As an extremely important tool for identification and quantification of uncertainties in climate models, the evaluation of model data is therefore an essential part of this work.

\subsection{THE EARTH'S ENERGY BALANCE}

The components of the energy balance of the earth are the radiation budget, the turbulent and latent heat flux, the soil heat flux, and heat of fusion (Figure 1.4). By far the largest proportion is formed by the radiation budget. The radiation budget of the earth is thus one of the most important parameters in meteorology. The short- and long-wave radiation budget components are the sources and sinks that describe the energy of the earth-atmosphere system. The absorbed short-wave radiation drives the weather and climate system and the biosphere. The long-wave emission from the earth represents the heat energy that is released into the atmosphere and outer space. The difference between the radiation budget at the top of the atmosphere and the radiation budget at the surface indicates a heating or cooling of the associated atmospheric column. The radiation budget is thus an important indicator of various atmospheric processes, such as the influence of clouds on the weather and climate system or on climatic changes. The description of how radiation and heat is absorbed, emitted or scattered in the atmosphere is the basis for calculating the greenhouse effect. Three-dimensional radiative 
transfer is intensive in terms of computation and memory. The calculation of the radiation in current climate models requires a large portion of the total computing time. This is partly because the radiation transport equation is a differential equation and its numerical solution is very expensive. The theoretical basis of radiation transport is now largely known and has been confirmed in the laboratory. In ideal cases radiation transport calculations are also very reliable, but application in the real atmosphere in climate models is extremely difficult because the radiative transfer depends on many atmospheric parameters, such as clouds, cloud microphysics, aerosols, or albedo, which are already hard to describe and parameterize as such.

By the application of RCMs it is possible to replace some model parameterizations by explicit descriptions, and the higher resolution of these models allows a better representation of local and regional features, which have an influence on the radiation budget components. In a study, Jaeger et al. [2008] found significant errors in the net short- and long-wave radiation of COMO-CLM simulations, which they attributed to errors in the simulated cloud cover. Several other studies of different GCMs and RCMs showed that above all, clouds are still one of the largest uncertainties in radiation modeling [e.g. Wild et al. 2001, Markovic et al. 2008]. Due to the enormous influence of the radiation budget on the results of climate simulations, these models seek to produce a reproduction of these processes that is as accurate as possible. The great importance of clouds and cloud microphysics for radiation meant that many resources were spent on developing the appropriate model parameterizations. Using RCMs with a high resolution can help to improve the simulation of clouds and cloud features, but even relatively simple parameters such as surface albedo, topography, or the description of vegetation can significantly affect the radiation budget in regional climate simulations. Besides the role of various parameters in radiation modeling thus a special focus of this work will be on regional features of the radiation budget and interactions with the land surface.

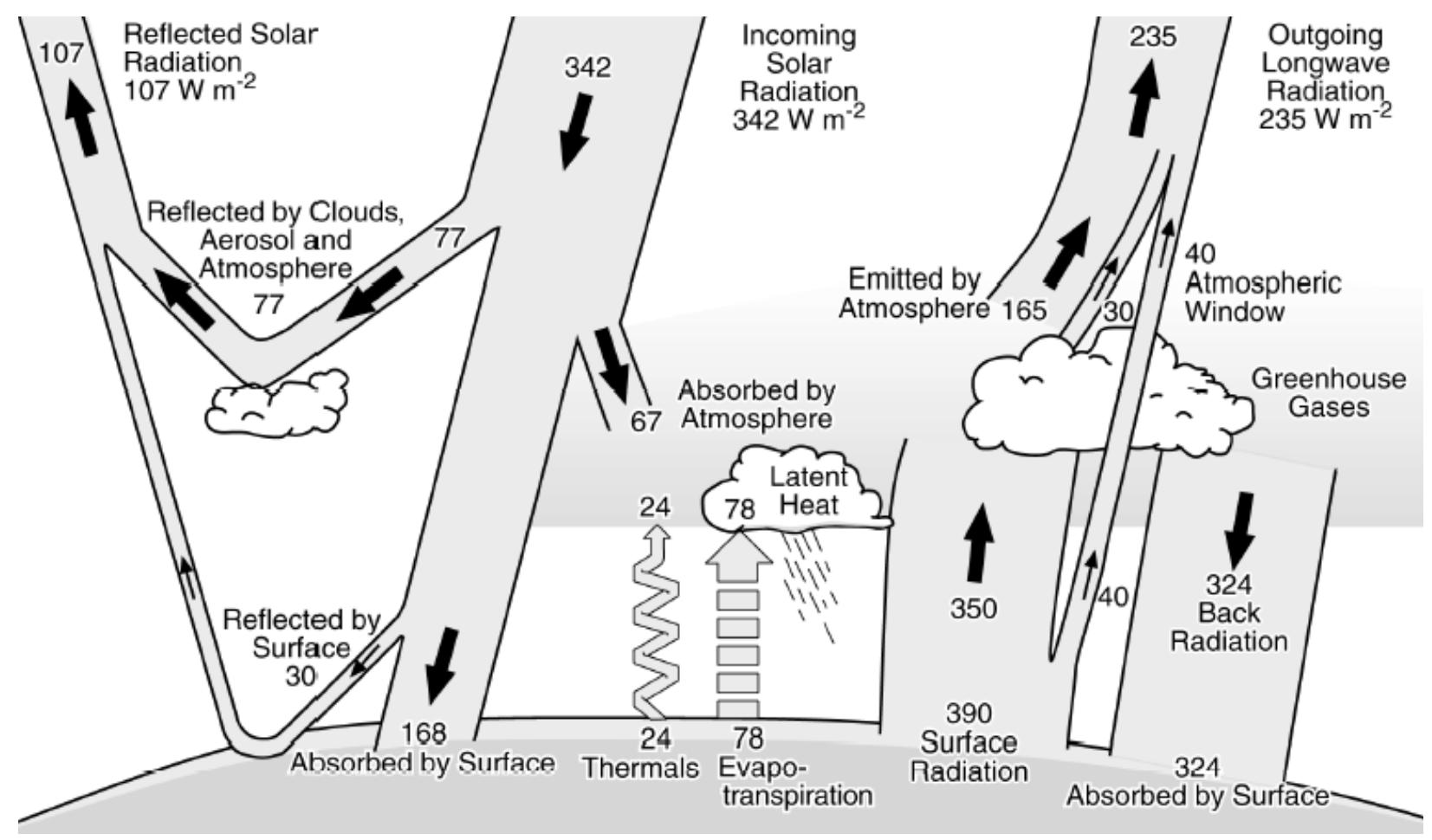

Figure 1.4 The earth's energy balance [source: Kiehl \& Trenberth 1997] 


\subsection{OBJeCtives OF thIS THESIS}

The aim of this work it is a better understanding of radiation processes in RCMs in order to quantify their impact and to reduce possible errors. This complex goal comprises a variety of questions.

- How well can RCMs (and especially the COSMO-CLM) simulate the components of the radiation budget?

To examine this question in a first step the simulated radiation budgets of two regional climate simulations for Europe were compared with satellite-based radiation data. To determine whether the regional model may offer an improvement compared to global models, the two simulations were also compared with the corresponding driving data. Europe has a large variety of climatic conditions and landscapes. There are large mountain ranges, vast forest areas, numerous urban areas, or marine areas, which affect the radiation components in a different way. Additionally, the seasonal change involves changes in parameters, such as the surface albedo, which may influence the accuracy of the simulated radiation budget.

- What are important sources of errors and uncertainties in the simulated radiation? Besides the quantification of model uncertainties it is essential for their understanding and possible approaches for improvements to determine causes of uncertainties. Statistical methods were thus used to estimate the influence of potential sources of uncertainties, such as the cloud cover, surface albedo and soil temperature. There are several other quantities, which affect radiation uncertainties, such as cloud microphysics or aerosols, but with respect to possible means for a model improvement, the main focus was on these relatively simple parameters. The two analyzed climate simulations for Europe also differed in the number of vertical layers to assess the possible added value of the higher layer number compared to the larger effort of computing resources.

- Are the results for radiation uncertainties and their impact factors comparable if the model is applied in a region (e.g. Africa) other than the one for which it was originally created (Europe)?

Many natural processes can only be represented in a simplified form in climate models. Parameterizations that have been proven in use in one application area of an RCM may therefore produce poorer results in a climatologically different area. Global climate projections suggest that the impacts of the expected climate change in the next few decades are significantly higher in Africa than in Europe, for example. In order to develop adaptation strategies for a possible climate change in African countries, it is necessary to carry out regional climate projections. To assess uncertainties of future projections, it is helpful to look at several different model runs that were carried out with different RCMs and various driving models. Since many African countries currently only have limited resources to conduct such projects a key focus of the next IPCC (Intergovernmental Panel on Climate Change; www.ipcc.ch) report will be on the impact of climate change on the African continent. Against this background, the simulated radiation budget components from nine different climate simulations for West Africa, which were realized with different RCMs and model versions, were evaluated using satellite-based radiation data and reanalysis data. The same method as that used for simulations in Europe was applied to see whether the impact of uncertainties in cloud cover, surface albedo and soil temperature in Africa is of similar importance as in Europe. Due to the different climatic conditions and landscapes differences were expected. In comparison to Europe, the climate of Africa is much more influenced by rainy seasons. Especially outside the tropics there are large areas where the cloud fraction is low in large parts of the year. Because of fewer clouds the importance of surface features, such as the albedo, is expected to be higher in Africa.

- How do errors of the simulated radiation budget components influence the simulation of climate processes, such as the West African Monsoon (WAM)?

The monsoon characterizes the lives of many millions of people in large parts of West Africa. Almost all of the annual precipitation in Westafrica falls in the months of June to September. The WAM hence affects both the growth of natural vegetation, biodiversity and ecology as well as 
agriculture and economy. The WAM is mainly a consequence of the seasonal north-south shift of the intertropical convergence zone (ITCZ), a trough of low pressure near the equator. As a result, there is a reversal of the prevailing winds in the ITCZ covered areas with the association of a shift in areas of severe rainfall in the trough of low pressure. Since the continent heats up faster than the adjacent ocean in summer the ITCZ will be deepened over land. This depression - and combined a shift of the ITCZ and a strengthening of the air inflow of moist air to the continent - results in heavy rainfalls such as the Indian and the West African monsoons.

Based on two regional climate simulations with the RCM COSMO-CLM (see www.clmcommunity.eu) it was investigated whether the model was able to simulate basic features of the WAM. The two model runs used were driven by a GCM and with reanalysis data to quantify the influence of lateral boundary conditions. This study also investigated how errors in the simulated radiation budget caused by an overestimation of the temperature in the Sahara influence the simulation of the WAM.

- Is it possible to improve the simulation of radiation and coupled processes by application of relatively simple modifications of model parameters such as the surface albedo? In recent years, great efforts were in some cases made to further improve the simulated radiation budget in climate models. A large part of the resources was spent on improving complex variables, such as the inhomogeneity of clouds, the cloud phase and the direct and indirect aerosol effect. As shown in the course of this work a relatively simple parameter such as the surface albedo also plays a considerable role in uncertainties in the simulated short-wave radiation. For example, it was found that a slight change of the angle of incidence of solar radiation by the consideration of topographic effects has demonstrable effects on the albedo for direct solar radiation and the incoming short-wave radiation at the ground. These relatively small changes induce quite large regional changes in parameters such as $2 \mathrm{~m}$ temperature or precipitation (see Appendix). An attempt was therefore made to improve the surface albedo of the COSMO-CLM with a relatively simple approach.

As part of the WAM analysis, the previous bare soil albedo was replaced by values determined from satellite data and the impact of this modification on the simulation of the WAM was examined. The previous values of the bare soil albedo were linked to the soil type. Since COSMO-CLM distinguishes only between a few soil types and the values of the soil type are based on data, which have uncertainties particularly in sparsely populated areas such as the Sahara, an improvement was expected by means of more accurate satellite data. 



\section{Chapter 2}

THE RADIATION BUDGET FOR EUROPE

This section shows the investigation of the components of the radiation budget for regional climate simulations for Europe. The study is published as: Kothe S, Dobler A, Beck A, Ahrens B (2010) The radiation budget in a regional climate model. Clim Dyn 36:1023-1036. doi:10.1007/s00382-009-0733-2 


\begin{abstract}
The long- and short-wave components of the radiation budget are among the most important quantities in climate modelling. In this study, we evaluated the radiation budget at the earth's surface and at the top of atmosphere over Europe as simulated by the regional climate model CLM. This was done by comparisons with radiation budgets as computed by the GEWEX/SRB satellite-based product and as realized in the ECMWF re-analysis ERA40. Our comparisons show that CLM has a tendency to underestimate solar radiation at the surface and the energy loss by thermal emission. We found a clear statistical dependence of radiation budget imprecision on cloud cover and surface albedo uncertainties in the solar spectrum. In contrast to cloud fraction errors, surface temperature errors have a minor impact on radiation budget uncertainties in the long-wave spectrum. We also evaluated the impact of the number of atmospheric layers used in CLM simulations. CLM simulations with 32 layers perform better than do those with 20 layers in terms of the surface radiation budget components but not in terms of the outgoing long-wave radiation and of radiation divergence. Application of the evaluation approach to similar simulations with two additional regional climate models confirmed the results and showed the usefulness of the approach.
\end{abstract}




\subsection{INTRODUCTION}

Regional climatic features such as the orography, lakes, complex coastlines, and heterogeneous land use are better captured by regional climate models (RCMs) than by global climate models (GCMs). Therefore RCMs provide better understanding of regional climatic processes [Giorgi et al. 1990, Frei et al. 2003, Leung et al. 2003, Beck et al. 2004, Dobler and Ahrens 2008]. In the present study, we evaluate CLM [the COSMO-model in climate version; see http:// www.clm-community.eu/], a regional non-hydrostatic limited-area climate model, in terms of the radiation budget.

The long- and short-wave components of the earth's radiation budget are important terms in climate modelling, describing the sources and sinks of energy in the earth-atmosphere system. These terms govern the energy balance of the earth and control daily and annual cycles. Thus, it is necessary to evaluate the radiation budget of regional climate models and to identify sources of uncertainties.

Many studies use ground station data to evaluate the results of RCMs or GCMs because of their well-known accuracy [e.g., Wyser et al. 2007, Markovic et al. 2008, Tjernström et al. 2008, Wild 2008]. For example, the accuracy of Baseline Surface Radiation Network direct solar irradiance measurements is $\pm 2 \mathrm{~W} / \mathrm{m}^{2}$ [Ohmura et al. 1998]. But, there is only a limited number of radiation stations with climatic time series of the short- and long-wave components of radiation and thus a poor spatial data coverage only. Other studies employ re-analysis data, whose main advantage is their spatial coverage and the availability of surface (SFC) and top of atmosphere (TOA) parameters [e.g., Vidale et al. 2003, Hagemann et al. 2004, Marras et al. 2007, Jaeger et al. 2008]. For ERA15 data [Gibson et al. 1997], the predecessor of the ECMWF ERA40 reanalysis [Uppala et al. 2005], Wild et al. [1998] demonstrate good agreement of ERA40 surface insolation with ground station data. Reichler and Kim [2008] investigate different re-analysis datasets and show that there are uncertainties especially in radiative quantities, but that the ERA40 dataset agrees best with ground station observations.

In the present study, we use the ERA40 and additionally the satellite-based GEWEX/SRB datasets as references. The GEWEX/SRB dataset has previously been used to evaluate model results [e.g., Shmakin et al. 2002, Winter and Eltahir 2008], and we anticipate that the additional use of the quasi-observational SRB dataset, in this study, provides more robust conclusions.

A comparison of CLM simulations and ERA15 re-analysis data indicates a significant underestimation of the net short- and long-wave radiation at the surface (downward radiation counts positive and upward radiation negative), which is attributed to an overestimation of cloud cover [Jaeger et al. 2008]. Another study that compares the surface radiation budget over North America of an RCM with ground station measurements also associates uncertainties in incoming short-wave radiation with imprecision in cloud cover simulations [Markovic et al. 2008]. For downwelling long-wave radiation, Markovic et al. [2008] conclude that all-sky errors are significantly influenced by cloud-free radiation, cloud emissivity, and cloud cover errors. Wild et al. [2001] report similar results in their comparison of the downwelling long-wave radiation of different GCMs and ground-based measurements under cloud-free and all-sky conditions. They attribute biases in all-sky conditions primarily to errors in the clear-sky downwelling long-wave radiation. Hence, besides interactions with clouds the absorption within the atmosphere has also a significant effect on uncertainties in radiation modelling. The absorption in the atmosphere is strongly determined by water vapour, which is closely linked to the temperature in the lower troposphere and thus correlated with the surface temperature.

Besides errors in cloud cover and surface temperature we expect an important impact of errors in the simulation of surface albedo on the radiation budget. Thus, in addition to quantification of errors in the simulated radiation budget components, we also investigate the impact of errors in parameters such as cloud cover, surface albedo, and surface temperature. Additionally, we compare CLM simulations using either 20 or 32 vertical atmospheric layers. Using 20 or 32 vertical layers is a relative small change in model setup, but of potentially large impact. First of all it is believed that better vertical resolution with 32 layers improves the results. But, most of 
the parameterizations in the model, for example the Tiedtke mass flux scheme [Tiedtke 1989], were originally developed and tested for smaller layer numbers. Therefore, it is of interest to evaluate both setups and check if our evaluation approach is sensitive to the differences in the simulations.

First, we provide a brief description of the model setup and datasets and afterwards present in section 2.4 comparisons of CLM20 (20 layers), CLM32 (32 layers), ERA40, and GEWEX/ SRB. In section 2.5 we then describe our investigation of the relationship between net radiation errors and errors in cloud fraction, surface albedo, and surface temperature. In the last section, we discuss the significance of our results for regional climate modelling. Attached are two appendices, which generalize our results. The first appendix applies a conceptual model and the second one applies simulations by two additional RCMs.

\subsection{MOdel AND MODEL SETUP}

The CLM is a state-of-the-art non-hydrostatic regional climate model developed for application in climate simulations up to several centuries in duration with spatial grid spacing from $50 \mathrm{~km}$ to $1 \mathrm{~km}$. The CLM is the climate version of the COSMO-model [see http://www.cosmomodel.org] that is used for operational mesoscale weather forecasting. Since completion of the first climate version of the CLM (summer of 2002), there has been a steadily growing community of users and developers [see http://www.clm-community.eu].

In this study we investigated two climate simulations done with version 2.4.11 of the CLM. Except for the horizontal resolution and number of vertical layers, the setup for these two simulations was identical to that used for the so-called CLM consortial runs [Hollweg et al. 2008]. Both simulations were driven by ERA40 at the lateral boundaries for the years 1958 to 2001. The computational domain covered Europe and parts of Northern Africa, with a grid dimension of $91 \times 97$ grid points and a grid spacing of $0.44^{\circ}$. This was the computational domain applied as a standard domain in the EU-project ENSEMBLES [Hewitt and Griggs 2004, www.ensembleseu.org]. The only difference between the two simulations was the number of atmospheric layers: 20 for CLM20 and 32 for CLM32.

Radiative transfer in the CLM is parameterized with a $\delta$-two-stream radiation scheme [Ritter and Geleyn 1992] for short- and long-wave fluxes in a plane parallel and horizontally homogeneous atmosphere. It is solved for three intervals in the solar spectrum and five intervals in the thermal spectrum. In the radiative transfer calculation of CLM, the influence of cloud water droplets, cloud ice crystals, water vapour, ozone, carbon dioxide, and other minor trace gases and aerosols is accounted for.

Radiative transfer depends strongly on input provided by other model components such as the cloud scheme. The fractional cloud cover, which significantly influences radiation, is determined by an empirical function that depends on the relative humidity, height of the model layer, and convective activity. The effective radii of the hydrometeors are prescribed. For cloud microphysics, the CLM offers four different variants. For the applied CLM simulations, we used a microphysical scheme with snow but without cloud ice or graupel. Convection is parameterized following Tiedtke [1989].

Parameters, such as soil type, soil moisture, and plant cover, determine the CLM solar surface albedo. These parameters were derived from datasets such as CORINE, GLC2000, GLOBE, or the Digital Soil Map of the World from the FAO [see Smiatek 2008]. The maximum of the surface albedo is set to 0.7 (snow cover and sea ice) and the minimum to 0.07 (water). Further details on the dynamics and physics of the model are given in Böhm et al. [2006], Steppeler et al. [2003] and in the model documentation [www.cosmo-model.org]. 


\subsection{Reference datA}

\subsubsection{ERA 40}

ERA40 is a re-analysis data product of the ECMWF (European Centre for Medium-Range Weather Forecasts). It is a global gridded dataset with a horizontal spectral resolution of T159 (about $125 \mathrm{~km}$ ) and 60 vertical levels. ERA40 produces analyses at $6 \mathrm{~h}$ intervals from 1958 to 2001 [Uppala et al. 2005]. In the present study, we used monthly means that were derived from $18 \mathrm{~h}$ forecasts starting at 00 UTC and 12 UTC from the re-analyses and discarding the leading 6 hours to account for model spin-up. In addition to monthly mean radiation fluxes, we also used monthly means of ERA40 cloud fraction, surface albedo, and surface temperature. In the evaluation of short-wave fluxes, we applied a monthly mean cloud fraction derived from daylight values (just as short-wave fluxes).

\subsubsection{GeWEX SRB}

The GEWEX/SRB (Surface Radiation Budget) project provides a satellite-based dataset of short- and long-wave radiation components at the earth surface and TOA on a global scale [Pinker and Laszlo 1992]. Here, we used version 2.81 of the dataset (which covers July 1983 to June 2005 with 3-hourly, daily, monthly/3-hourly (e.g. monthly mean 12 UTC), and monthly averages) with a global grid spacing of $1^{\circ}$ [Gupta et al. 2006]. The surface radiation fluxes were evaluated in a variety of studies with data of the BSRN (Baseline Surface Radiation Network) or the GEBA (Global Energy Balance Archive) project, which provided good agreement with monthly data, i.e., within $5 \mathrm{~W} / \mathrm{m}^{2}$ for long-wave fluxes and within $5-20 \mathrm{~W} / \mathrm{m}^{2}$ for short-wave fluxes [Gupta et al. 1999, Zhang et al. 2006, Zhang et al. 2007, Zhang et al. 2009]. In the present study, we used SRB radiation and cloud fraction data. The surface albedo was determined as the ratio of up- and downwelling solar surface fluxes. Cloud fraction data were averaged over the daylight periods for comparisons with the short-wave radiative components, and were averaged over the whole day for comparisons with long-wave radiative components. The cloud fraction data, included in SRB, originate from the ISCCP (International Satellite Cloud Climatology Project) and were already used in other climate model evaluation studies [Ahrens et al. 1998]. Monthly means were derived by averaging 3-hourly instantaneous values.

2.3.3 $\mathrm{CRU}$

For SRB, no consistent temperature dataset was available. Thus, we employed the ERA40 surface temperatures over sea and CRU (Climate Research Unit) temperatures over land. The CRU dataset (version TS 2.1) provides monthly mean global gridded surface temperature data with $0.5^{\circ}$ resolution [Mitchell and Jones 2005].

\subsubsection{Comparison OF GeWeX SRB AND ERA 40 dATA}

We compared the monthly fluxes of SRB and ERA40 in Europe (from 1983 to 2001) to estimate the uncertainty of the reference data, which was essential to know to assess the comparisons with CLM. Because of the different grid spacing of SRB $\left(1^{\circ}\right)$, ERA40 (about $125 \mathrm{~km}$ ), and CLM $\left(0.44^{\circ}\right)$, we interpolated all data to the same grid with $1^{\circ}$ grid spacing. This interpolation was performed with simple inverse distance weighting. SRB monthly means of radiation fluxes were calculated by averaging 3-hourly instantaneous values, but ERA40 and CLM monthly means were calculated by accumulated values. This yielded sampling differences, which were approximately corrected by application of a factor (the ratio of the 1-hourly and 3-hourly 
averaged local solar irradiance top-of-atmosphere assuming that the hourly average is a much better appoximation of the means from accumulated fluxes than a 3-hourly average) to the SRB data.

For surface net short-wave radiation (SNS), the comparison of SRB and ERA40 mostly showed small monthly mean differences within $\pm 10 \mathrm{~W} / \mathrm{m}^{2}$, with slightly higher values for SRB fluxes. These small differences are displayed in Fig. 2.1. This figure illustrates the biases of SRB and ERA40 in reference to the mean of SRB and ERA40. In general the difference was small, but SRB showed larger SNS values than ERA40 especially in the Mediterranean area. ERA40 realized larger TOA net short-wave radiation fluxes (TNS) than SRB.

The agreement of ERA40 and SRB for surface net long-wave radiation (SNL) was quite good, generally within about $\pm 1 \mathrm{~W} / \mathrm{m}^{2}$ (Fig. 2.1). In most parts of Europe the differences were close to zero. The SRB data had less negative values than ERA40 over the Mediterranean Sea, while ERA40 had less negative values over the Iberian Peninsula and North Africa. The difference between SRB and ERA40 for TOA long-wave radiation (TNL) was largest in the winter, with a mean difference of $-12 \mathrm{~W} / \mathrm{m}^{2}$. Thus, on average, ERA40 had higher values than SRB, except for Southern Europe and North Africa, where SRB had similar or higher values.

Therefore, there was a substantial uncertainty in the reference data, especially in the TOA fluxes (Fig. 2.1). A comparison of cloud fraction showed that SRB predicted more clouds than ERA40, with a maximum spatial mean difference of 0.1 in summer. However, regional differences could be as large as 0.25 . Throughout the year, there was a clear meridional gradient in the differences, with larger ERA40 values in northern regions and larger SRB values in southern regions (especially over the Mediterranean Sea). The SRB surface albedo was slightly larger than the ERA40 surface albedo in most parts of Europe.

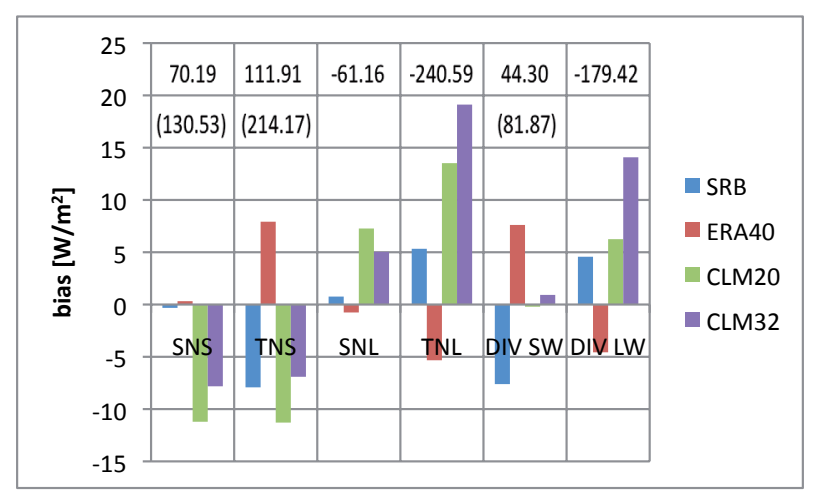

Figure 2.1 Biases of SRB, ERA40, CLM20, CLM32 relative to (ERA40 + SRB)/2 for SNS, TNS, SNL, TNL, short-wave divergence, and long-wave divergence (for the whole investigation area and time period 07/1983-12/2001). Short-wave values were derived from whole-day means just as long-wave. The numbers show the mean value of the reference in $\mathrm{W} / \mathrm{m}^{2}$. For short-wave there are in brackets the mean values for daylight means

\subsection{Radiation BUdget EVALUATION}

In this section we compared the CLM20, CLM32, GEWEX/ SRB, and ERA40 datasets by using monthly mean data from 1983 to 2001 on a $1^{\circ}$ grid. The CLM simulation domain placed limits on the area of comparison. We excluded a five-degree lateral boundary buffer zone of the CLM domain from all comparisons. Furthermore, as indicated by the comparison to ERA40 data, there were some uncertain pixels in the SRB dataset in the northern parts of the domain during winter, which were excluded from the comparisons. Because of the viewing geometry of satellites in northern regions in winter, we believed that satellite-based algorithms could produce some unrealistic values in these regions.

Figure 2.1 provides a general overview of our results. It provides the biases with reference 
to the average of SRB and ERA40 data. The short-wave components in Fig. 2.1 were derived from whole-day means just as the long-wave components. This simplifies the direct comparison of shortand long-wave biases and their potential compensation. The numbers in Fig. 2.1 show the mean values of the reference and additionally in brackets for short-wave the corresponding values for daylight means. All other shortwave values shown below were derived from daytime means. The displayed biases of short- and long-wave divergences given in the figure indicate biases in the differences between TOA and SFC fluxes.

\subsubsection{SuRfaCe NET SHORT-WAVE RADIATION (SNS)}

Figure 2.1 shows that SRB and ERA40 had a larger longterm mean SNS than CLM20 and CLM32. The underestimation by CLM was highest from April to August with spatial mean differences up to $-30 \mathrm{~W} / \mathrm{m}^{2}$. In the winter months, the underestimation decreased to differences less than $-10 \mathrm{~W} / \mathrm{m}^{2}$. Throughout the year, the largest differences (up to $-60 \mathrm{~W} / \mathrm{m}^{2}$ ) were over the Mediterranean Sea. This can be seen in Fig. 2.2 (left and middle), but the differences are smaller compared to ERA40 than to SRB. These results are consistent with those of Jaeger et al. (2008), who found summer biases in SNS of up to $-60 \mathrm{~W} / \mathrm{m}^{2}$ using 32 levels, at least compared to ERA15.

Overall, the values of CLM32 were larger than those of CLM20. The spatial mean difference ranged from less than $4 \mathrm{~W} / \mathrm{m}^{2}$ (January and December) to more than $8 \mathrm{~W} / \mathrm{m}^{2}$ (April). Again, the largest differences occured over the Mediterranean Sea in Winter and over the Atlantic Ocean in Summer (more than $25 \mathrm{~W} / \mathrm{m}^{2}$; Fig. 2.2, right). In consequence the CLM32 underestimation compared to the reference was more than $30 \%$ smaller than the CLM20 underestimation (Fig. 2.1).

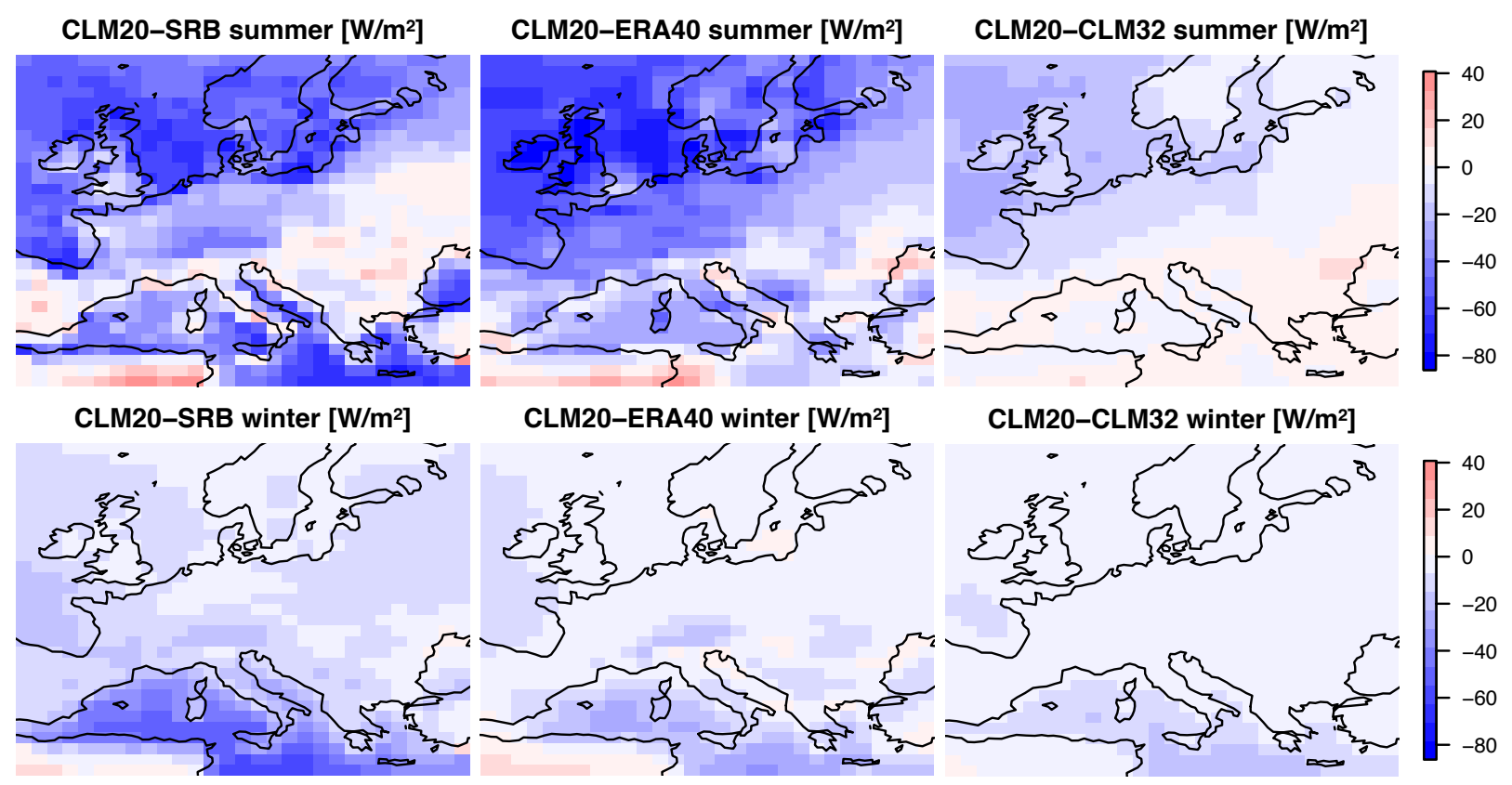

Figure 2.2 Differences of SNS [W/ $\left./ \mathrm{m}^{2}\right]$ (derived from daytime means) in summer (JJA, upper row) and winter (DJF, lower row) for CLM20 minus SRB (left), CLM20 minus ERA40 (middle), and CLM20 minus CLM32 (right). All values are means for the whole time period 07/1983-12/2001 


\subsubsection{TOA NET SHORT-WAVE RADIATION (TNS)}

The TNS reference was much more uncertain than the SNS reference as discussed above. The shown biases in Fig. 2.1 indicate that the mean TNS of CLM and SRB agrees very well, whereas ERA40 has a much higher mean. But, despite the reference uncertainty, Fig. 2.1 shows that CLM tends to underestimate TNS. The spatial mean differences were much larger compared to ERA40 (about $-11 \mathrm{~W} / \mathrm{m}^{2}$ in January and December; more than $-50 \mathrm{~W} / \mathrm{m}^{2}$ in April to June) than to SRB (about $-2 \mathrm{~W} / \mathrm{m}^{2}$ in January and December; about $-12 \mathrm{~W} / \mathrm{m}^{2}$ in April to August). In autumn and winter, the largest differences were over the Mediterranean Sea; in spring and summer, the greatest differences were in Northern Europe, in the area around the British Islands, and in Scandinavia (Fig. 2.3, left and middle). Because satellites directly observe TOA radiation, we expected SRB TNS to be more reliable than ERA40 TNS. Therefore, the CLM performance seemed to be better than the ERA40 performance.

The TNS differences between CLM20 and CLM32 were similar to the SNS differences. With an about $40 \%$ lower mean underestimation with respect to the reference (see Fig. 2.1), CLM32 yielded better results than CLM20.

\subsubsection{SuRfaCe NET LONG-WAVE RADIATION (SNL)}

Figure 2.1 indicates that the mean SNL difference between CLM and the reference data was relatively small. CLM slightly overestimates SNL indicating that CLM underestimated thermal loss of energy at the surface. ${ }^{1}$ The spatial mean difference ranged from about $2-12 \mathrm{~W} / \mathrm{m}^{2}$, whereas the mean difference compared to SRB had a minimum in winter and a maximum in September, while compared to ERA40 the largest differences occured in April and October and the minimum in July.

There was good agreement between CLM20 and CLM32, with spatial mean differences ranging from $4 \mathrm{~W} / \mathrm{m}^{2}$ (winter) to $-2 \mathrm{~W} / \mathrm{m}^{2}$ (July). The largest differences were around the British Islands (Fig. 2.4, right). Over the Mediterranean Sea, differences of about $10 \mathrm{~W} / \mathrm{m}^{2}$ occured only in winter. In summary, although the differences were small, CLM32 provided better results than did CLM20 relative to the reference (the mean difference decreased by about $30 \%$, see Fig. 2.1), except for the Mediterranean in summer.

\subsubsection{TOA NET LONG-WAVE RADIATION (TNL)}

Despite some differences in the references, CLM clearly overestimated TNL (i.e. underestimates TOA outgoing long-wave radiation). The annual cycle of the spatial mean differences to SRB data ranged from $8 \mathrm{~W} / \mathrm{m}^{2}$ (winter) to more than $12 \mathrm{~W} / \mathrm{m}^{2}$ (May). The largest differences to ERA40 data were in winter (about $20 \mathrm{~W} / \mathrm{m}^{2}$ ). Figure 2.5 (left and middle) shows that CLM20 overestimated TNL in almost the entire evaluation domain with maximum differences over the Mediterranean Sea and Scandinavia.

For TNL, CLM20 yielded smaller spatial mean TNL values (up to $7 \mathrm{~W} / \mathrm{m}^{2}$ ) than CLM32. The spatial distribution (Fig. 2.5, right) showed that the smallest differences are around the British Islands, Scandinavia, and central Europe, and that the largest differences were in the southeast part of the Mediterranean Sea. A decrease in mean overestimation of about $35 \%$ (see Fig. 2.1) for TNL showed that the results of CLM20 were better than those of CLM32.

1 Remind that downward radiation is counted positive and upward radiation is counted negative 


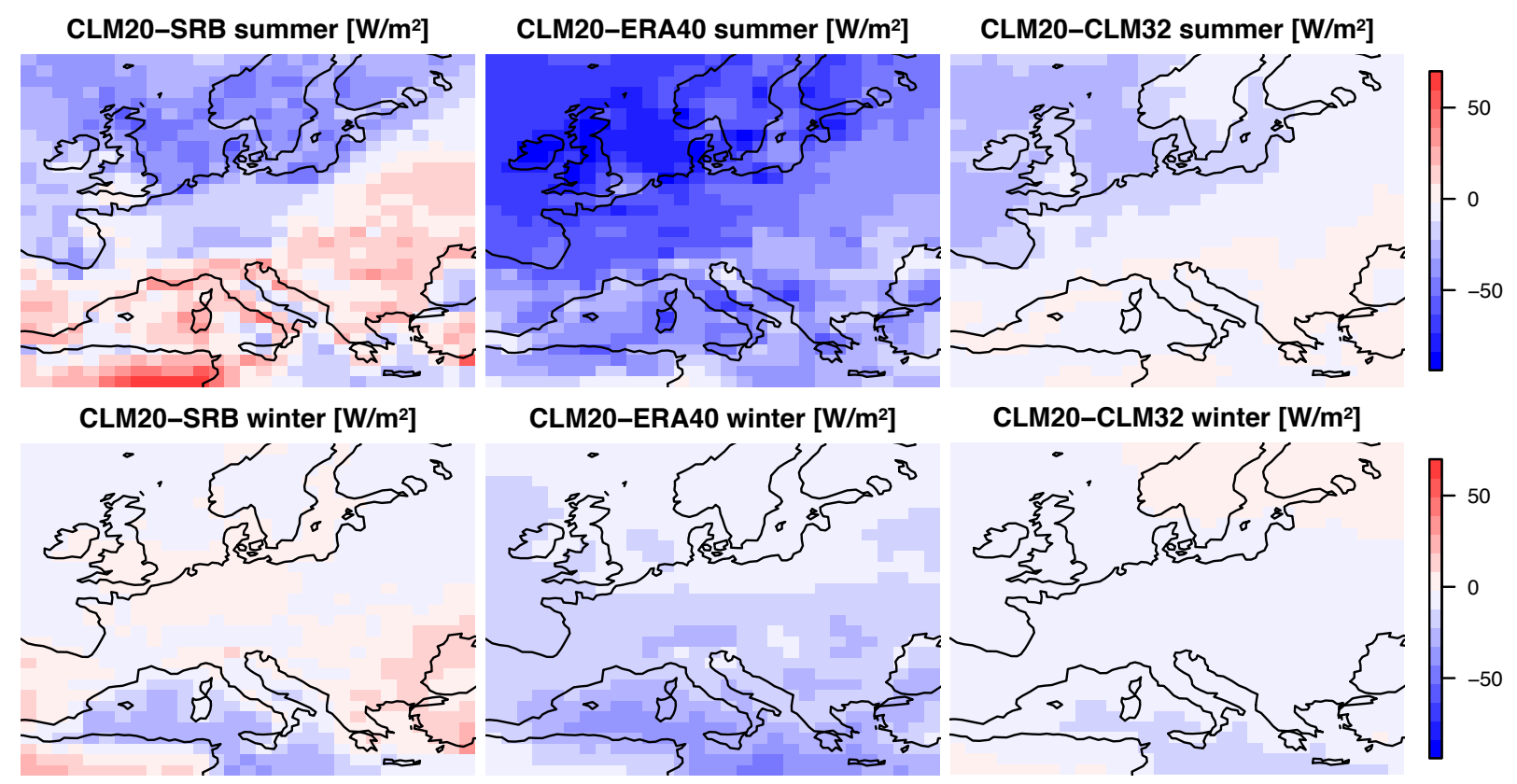

Figure 2.3 The same as Fig. 2.2 but for TNS

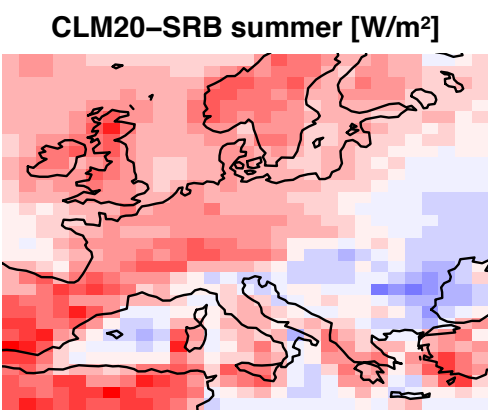

\section{CLM20-ERA40 summer [W/m²]}

CLM20-SRB winter $\left[\mathrm{W} / \mathrm{m}^{2}\right]$
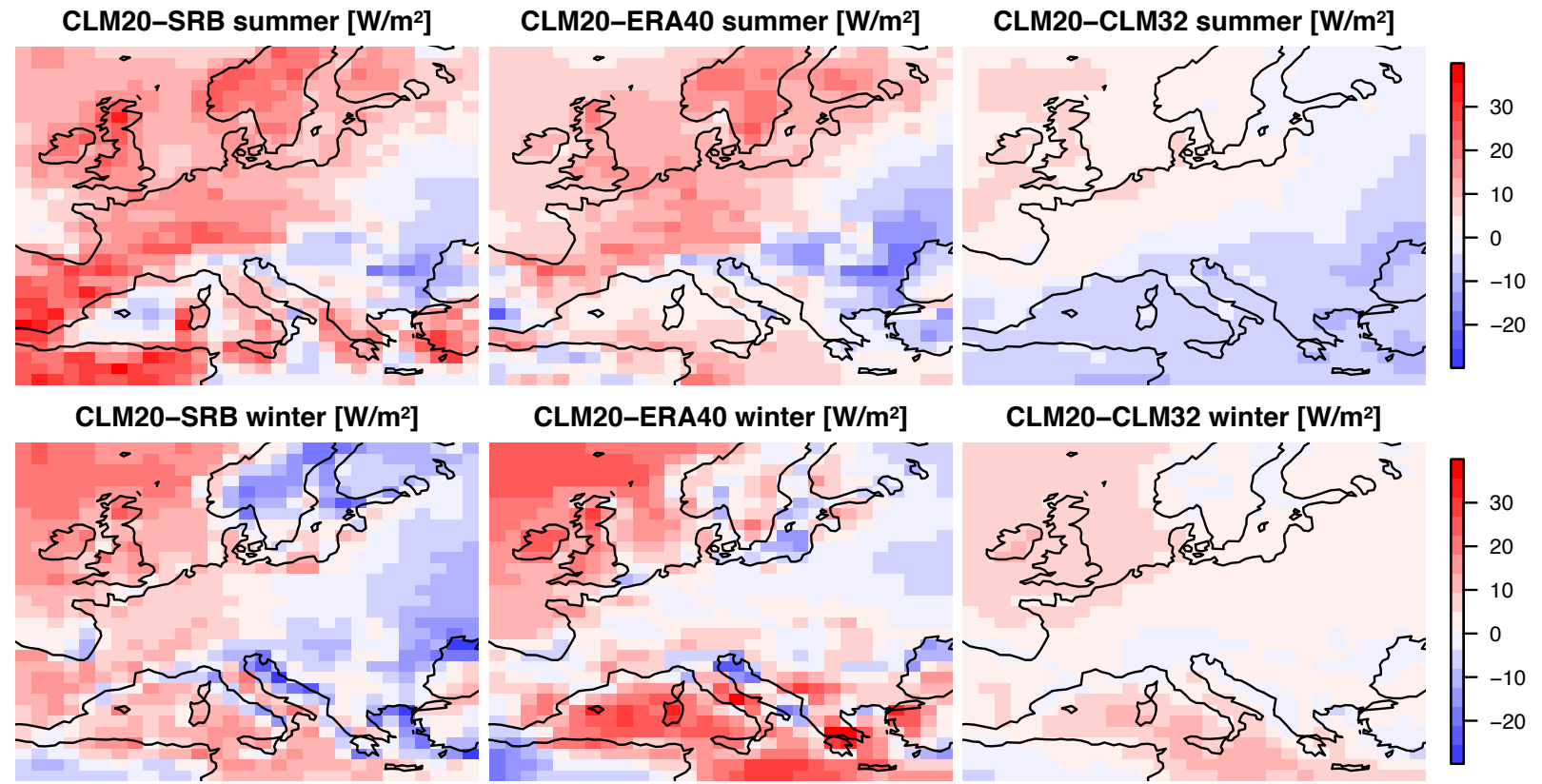

CLM20-CLM32 winter [W/m²]

Figure 2.4 Differences of SNL [W/m²] in summer (JJA, upper row) and winter (DJF, lower row) for CLM20 minus SRB (left), CLM20 minus ERA40 (middle), and CLM20 minus CLM32 (right) 


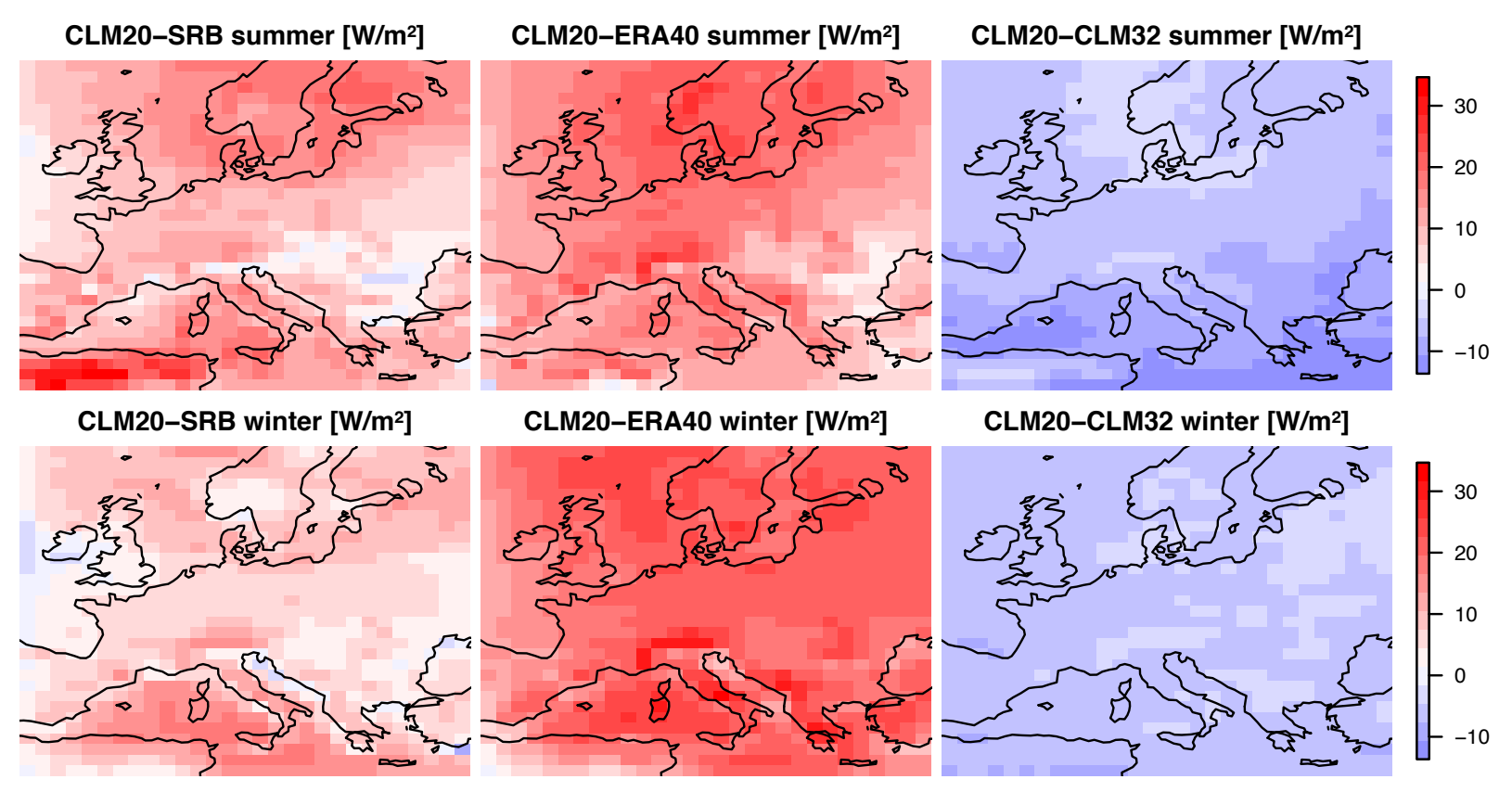

Figure 2.5 The same as Fig. 2.4 but for TNL

\subsubsection{Discussion OF COMPARISONS}

A comparison of CLM with SRB and ERA40 showed a clear underestimation of net incoming short-wave radiation and net outgoing long-wave radiation. The magnitude of the found biases was comparable to the biases of other regional climate models discussed in the Appendix 2.1 and given in Fig. 2.10. In the total radiation budget these CLM errors partly compensated. At the surface, SNS was too low, possibly because of underestimation of solar downwelling radiation caused by an overestimation of cloud cover or atmospheric absorption. Another possible reason might be an overestimation of short-wave upwelling radiation resulting from errors in the surface albedo. Similar effects could explain the large underestimation of TNS. In this context it has to be mentioned that Jaeger et al. [2008, 2009] state that clear-sky radiation and surface albedo are reasonably modelled in CLM. We discussed the potential error sources in more detail in the next section. For the short-wave divergence it was impossible to judge the quality of CLM because of a large evaluation uncertainty (Fig. 2.1).

The bias in SNL might result from an underestimation of surface emission caused by errors in surface temperature or from errors in cloud cover. The same effects might be responsible for the underestimation of TNL. Furthermore, the results showed that CLM32 had smaller errors than CLM20 in most of the radiation components (except for TNL and the divergences). But, as shown by Fig. 2.1, after integration (SNS + SNL, respectively, TNS + TNL) the errors compensate and it cannot be concluded that one model version is superior. Nevertheless, CLM32 performed better over sea (as Figs. 2.2, 2.3, 2.4, 2.5 indicate). 


\subsection{IMPACT OF CLOUD FRACTION, SURFACE ALBEDO, AND SURFACE TEMPERATURE}

Based on the results of previous studies (see discussion in Sect. 2.1), we expected that cloud fraction (CFR), surface albedo (ALB), and surface temperature (TS) are the main factors influencing the radiation components of CLM. Simple comparisons of CFR, ALB, and TS of the different datasets confirmed this expectation. For example, the spatial allocations of differences in short-wave net radiation are often co-located with differences in CFR. Especially over the ocean, there seemed to be a correlation between CFR overestimation and SNS underestimation. However, there were also regions where errors in CFR seemed not to be the main cause of errors in SNS.

The connection between errors in ALB and SNS or TNS was not as obvious as for CFR. Nevertheless, there were geographic areas with seasonally dependent correlations between underestimations of SNS and overestimations of ALB. Contrary to our expectations, there was no pronounced correlation between errors in TS and SNL or TNL.

Here, we provide a quantification of the impact of the errors $\triangle \mathrm{CFR}, \triangle \mathrm{ALB}$ and $\triangle T S$ (the difference between the respective CLM and reference values) on the net radiation fluxes. This requires that the results are comparable at different geographical latitudes. Thus, we normalised the shortwave fluxes with the factor $1 /(4 \sin \theta)$, where $\theta$ is the solar elevation angle.

Figure 2.6 (top left) shows the dependence of errors in SNS on errors in CFR and ALB. If $\triangle$ CFR $=0$, the error in SNS increases from about $-30 \mathrm{~W} / \mathrm{m}^{2}$ to about $20 \mathrm{~W} / \mathrm{m}^{2}$ as $\triangle A L B$ decreases. If $\triangle$ CFR and $\triangle A L B$ were positive (meaning that CLM predicts too many clouds and an excessively high surface albedo), SNS was underestimated. The analogous figure for TNS looks very similar (Fig. 2.6 top right).

Assuming linear relationship between the errors, the squared correlation coefficient $R^{2}$ is a measure of the explained error variance. The explained variances for SNS (Fig. 7) indicated that the error in CFR plays a more important role than the ALB error and that the combination of $\triangle A L B$ and $\triangle C F R$ is responsible for the largest part of the error in SNS. The highest values of explained variance for $\triangle A L B$ were during the winter and spring over land, whereas the contribution of $\triangle A L B$ to variance over the ocean was smaller. For $\triangle C F R$, the largest values of $R^{2}$ were during the autumn and winter. Figure 2.8 shows that the explained variance had large regional differences. For $\triangle A L B$, high values of $\mathrm{R}^{2}$ occured during winter in an area from the Alps to nearly all of Eastern Europe. These are regions with frequent winter snow cover (see for example: http://www.dwd.de/snowclim) with high albedos and albedo uncertainties. $R^{2}$ values for $\triangle$ CFR were largest in the Mediterranean Sea throughout the year and around the British Islands in spring and summer.

The sensitivity of $\triangle T N S$ to $\triangle$ CFR was similar to that of $\triangle \mathrm{SNS}$, whereas the sensitivity of $\triangle T N S$ to $\triangle$ ALB was lower. Again, the influence of errors in ALB over the sea was very low. The seasonal and regional distribution of $\mathrm{R}^{2}$ for $\triangle \mathrm{CFR}$ and $\triangle \mathrm{ALB}$ was similar to that of SNS.

A simple calculation confirmed these results for SNS and TNS (see Appendix 2.2, Table 2.2). An increase in CFR or ALB led to a negative bias in net short-wave radiation, and the $\triangle \mathrm{CFR}$ impact was in case of typical errors a multiple than that of $\triangle \mathrm{ALB}$. A similar calculation for the long-wave net radiation showed that errors in CFR had a large effect on errors in the net long-wave radiation (Appendix 2.2, Table 2.3). We assumed that TS is another important factor for net long-wave radiation, but this simple calculation showed that for typical errors the impact of TS is low compared to the impact of CFR.

This was pictured by the CLM results. Figure 2.6 (bottom left) shows a clear dependence of the error in SNL on $\triangle$ CFR and a small dependence on $\triangle T S$. As mentioned above, for SRB the ERA40 TS was used over sea and CRU TS over land. Using ERA40 TS over land instead of CRU TS changed the $R^{2}$ values only slightly (within \pm 0.02 ).

In combination, Fig. 2.6 (bottom and top panels) shows that there is a partial compensation of errors in the net short- and long-wave radiation. Whereas for SNS, a positive error in $\triangle \mathrm{CFR}$ and $\triangle A L B$ was mainly associated with a negative error in net radiation, a positive error in $\triangle C F R$ and $\triangle T S$ for SNL was associated with a positive error in net radiation. Figure 2.7 shows that for 

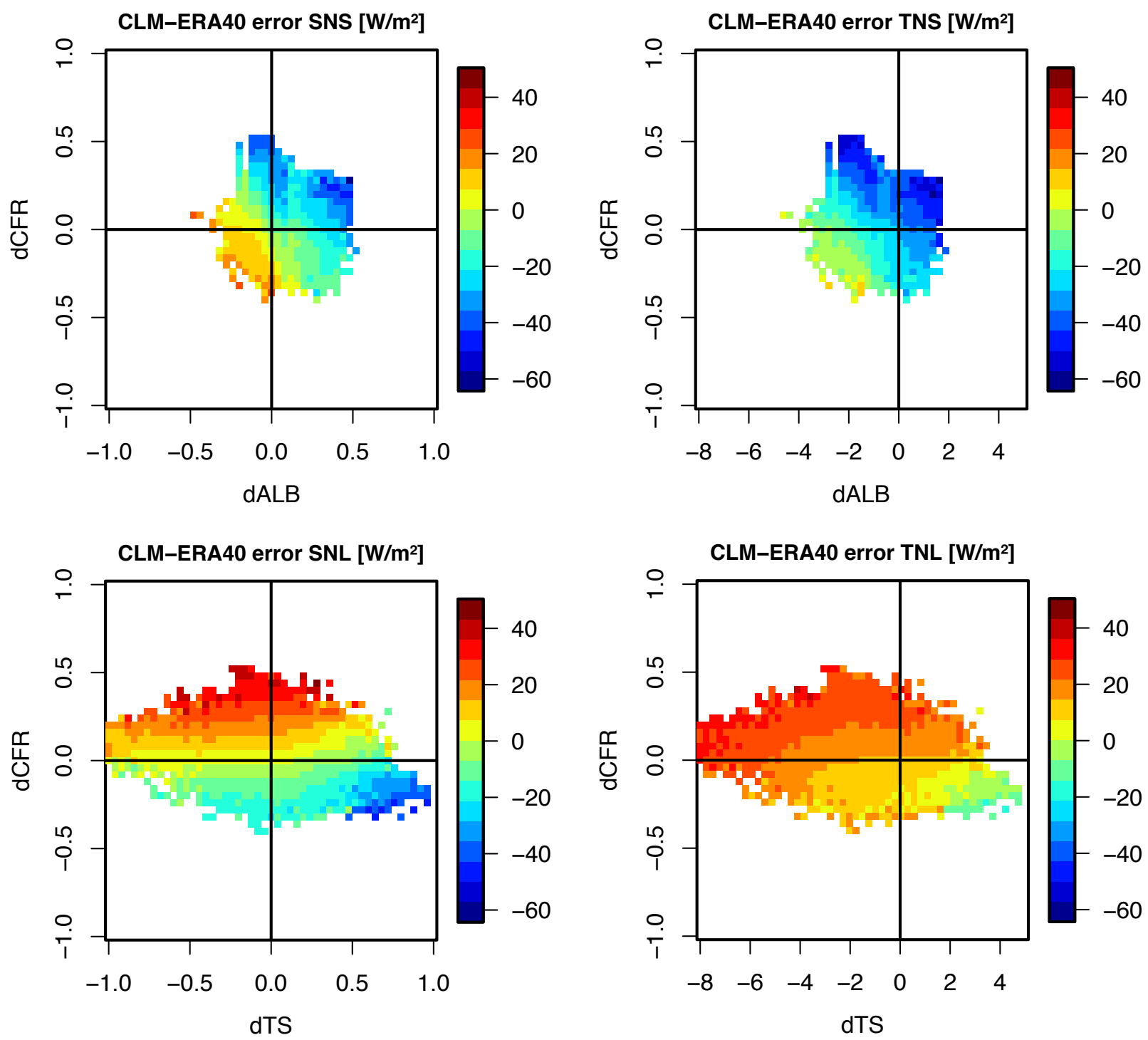

Figure 2.6 Differences of monthly means (07/1983-12/2001) of CLM minus ERA40 SNS (derived from daytime means) and TNS (upper row) against errors in ALB and CFR and for SNL and TNL (lower row) against errors in TS and CFR. In this figure, the SNS error was averaged within boxes with a side length of 0.04 units for CFR and ALB and $0.25 \mathrm{~K}$ for TS. The Figure bases on single grid points over the whole area without coast pixels

SNL, there were small values of $\mathrm{R}^{2}$ for $\triangle T S$. However, ERA40 had large values of explained variance for SNL over both land and ocean. These high levels of explained variance resulted from a high sensitivity to $\Delta$ CFR. The $\mathrm{R}^{2}$ value of about 0.15 over land for $\Delta T S$ (Fig. 2.7) with ERA40 was because of relatively large $R^{2}$ values in summer over Eastern Europe (Fig. 2.9). In all other seasons, the variance explained by $\triangle T S$ was very low. A possible reason for the higher $R^{2}$ values in case of ERA40 than in case of SRB was that the radiation fluxes and the TS reference applied in the SRB comparison might be inconsistent. Compared with SNL, the explained variance of TNL was even lower.

In summary, $\triangle C F R$ and $\triangle A L B$ explain about $50 \%$ of the error variance in the solar spectrum. In the long-wave spectrum $\triangle$ CFR was of less importance compared to shortwave (besides in the comparison against ERA40 in case of SNL), and the impact of TS errors on the radiation budget was small (except for the summer season with generally smaller cloud fractions). These results were confirmed by a investigation of two other state-of-the-art regional climate models 
(see Appendix 2.1). Obviously, there were more influential errors especially in the long-wave spectrum, but a better representation of CFR and ALB will substantially improve the computation of radiation budgets in CLM.
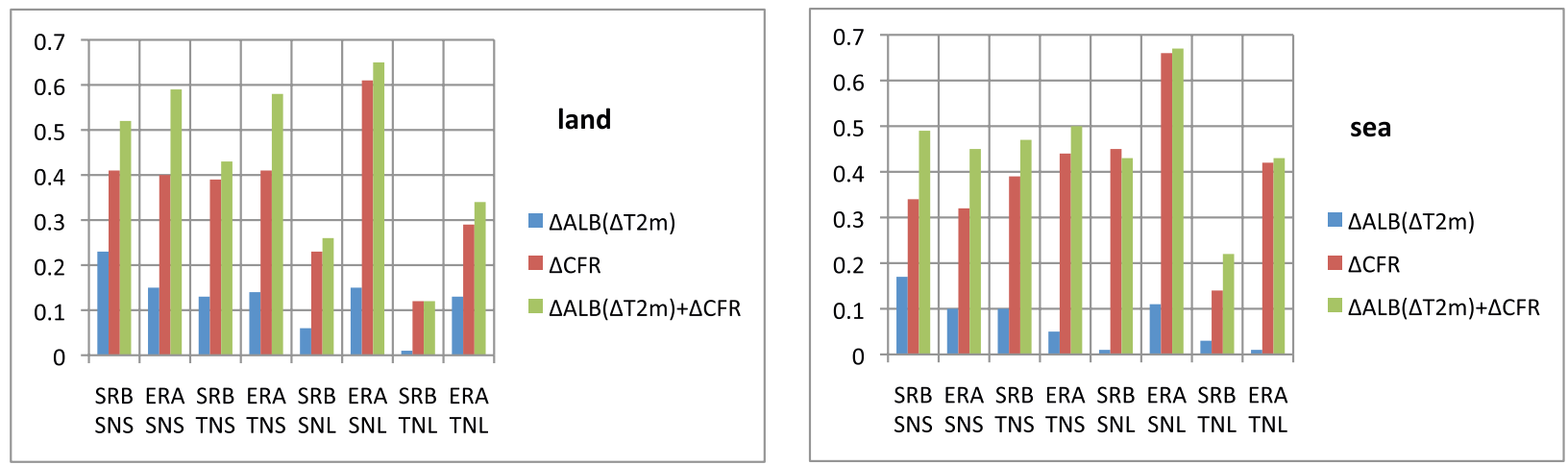

Figure 2.7 Explained variances of radiation errors relative to errors in CFR, ALB, TS and the according combinations $\triangle \mathrm{ALB}+\triangle \mathrm{CFR}$ and $\triangle \mathrm{TS}+\triangle \mathrm{CFR}$, for land (left) and sea (right). The values are means for the whole investigation area and time period 07/1983-12/2001

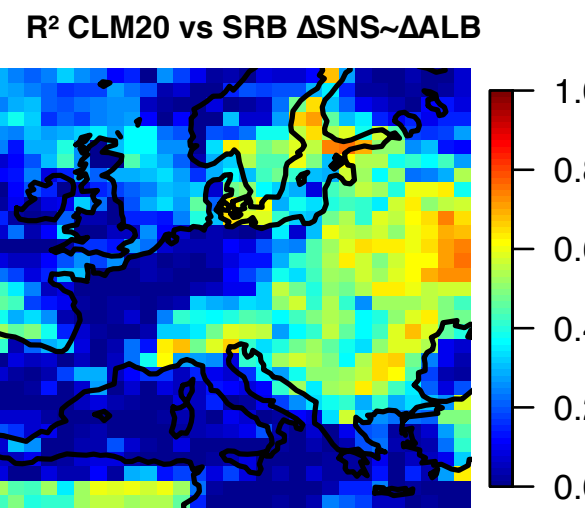

$R^{2}$ CLM20 vs SRB $\triangle$ SNS $\sim$ CFR
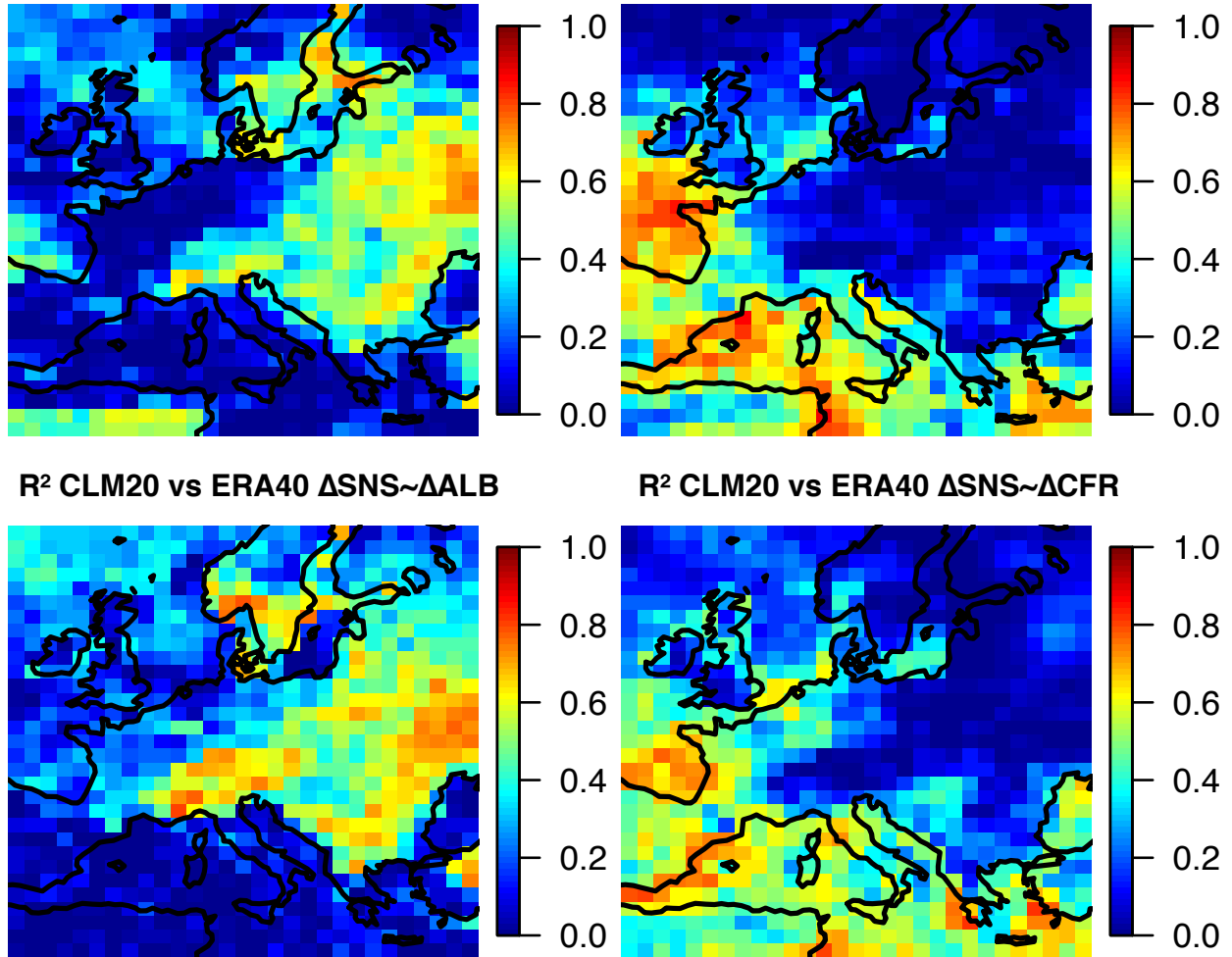

$R^{2}$ CLM20 vs ERA40 $\Delta$ SNS $\triangle$ CFR

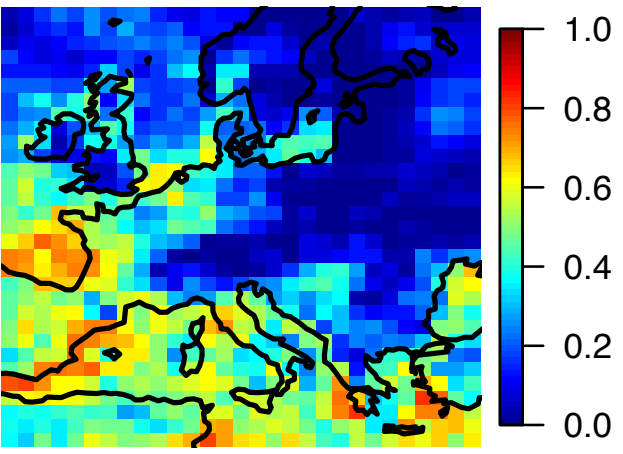

Figure 2.8 Explained variance of SNS in winter (mean 1983-2001) of errors in SNS and ALB (denoted by $\triangle$ SNS $\sim \triangle \mathrm{ALB}$ ) and errors in SNS and CFR (denoted by $\triangle \mathrm{SNS} \sim \triangle \mathrm{CFR}$ ) for SRB (top) and ERA40 (bottom) 

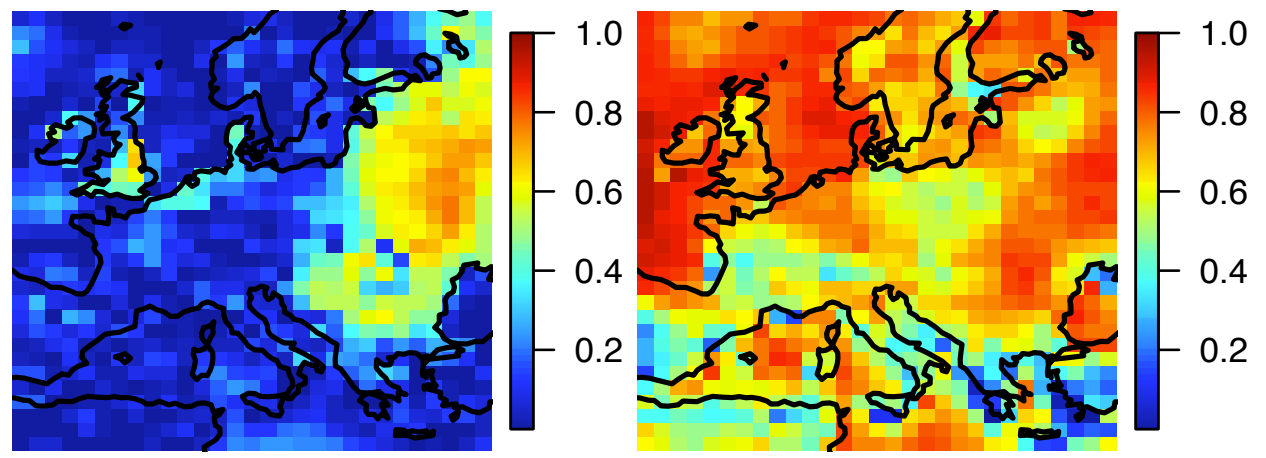

$R^{2}$ CLM20 vs ERA40 dSNL dTS

$R^{2}$ CLM20 vs ERA40 dSNL dCFR
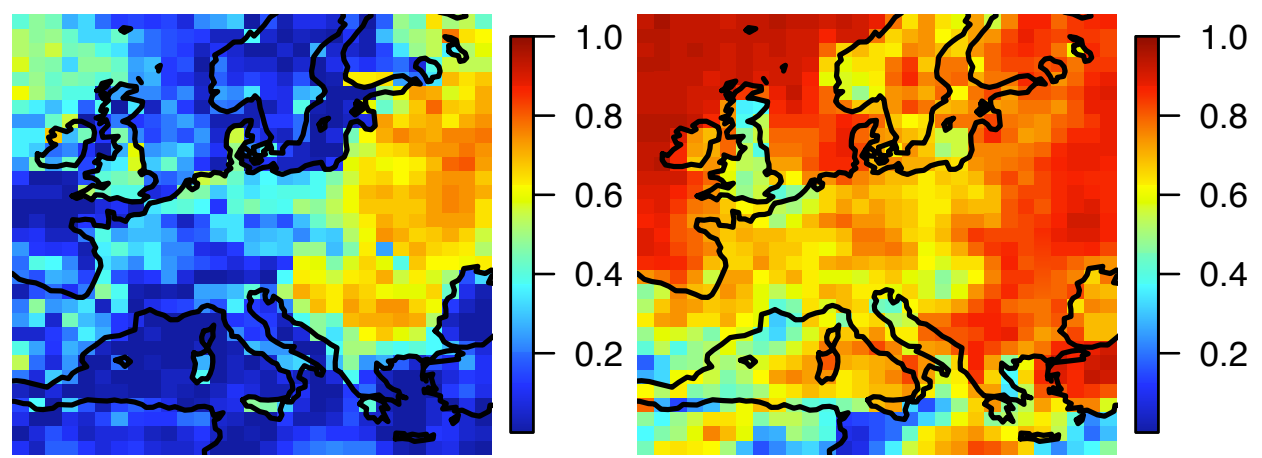

Figure 2.9 Explained variance of SNL in summer (mean 1983-2001) of errors in SNL and TS (denoted by $\triangle \mathrm{SNL} \sim \Delta \mathrm{TS}$ ) and errors in SNL and CFR (denoted by $\triangle \mathrm{SNL} \sim \triangle \mathrm{CFR}$ ) for SRB (top) and ERA40 (bottom)

\subsection{Conclusions}

The main goal of this study was to quantify uncertainties in the short- and long-wave components of the radiation budget for CLM simulations using the satellite-based GEWEX/SRB dataset and the ERA40 re-analysis dataset as references. Our comparisons showed considerable underestimations of the net short-wave radiation in large parts of Europe, es-pecially over ocean areas. Over land, the differences of CLM to SRB were smaller than to ERA40. For TNS, an overall underestimation of CLM was found, whereas SRB showed a slight overestimation in southern parts of Europe. In particular, for the TOA components, the satellite-based SRB dataset was expected to be more reliable than the ERA40 dataset. Overall, the CLM results were quite satisfactory, if the evaluation uncertainties due to the differences in the reference datasets were considered. The CLM overestimated SNL in most areas, but underestimates SNL in some parts of Eastern Europe. Overestimation of TNL was even larger, especially in comparison with ERA40. But again, these differences were not very large with respect to the difference between the reference datasets.

We also investigated the effect of the number of atmospheric layers used in CLM simulations. We found that the climate simulation with 32 layers yielded (except for TNL and long-wave divergence) better results. The use of 32 layers considerably reduced the biases (up to $40 \%$ ) in the radiation components. However, the improvement was relatively small if compared to the evaluation uncertainties and if the long- and short-wave compensation effects are considered (Fig. 2.1). Therefore, with respect to computational costs and evaluation uncertainties, the use of 20 atmospheric layers is a considerable option in terms of the radiation budget. Nevertheless, the evaluation approach applied in this paper relies on generally available data and helps in the evaluation of model differences (CLM20, CLM32, and the additional models REMO and ALADIN 
in Appendix 2.1) and will support the evaluation of CLM in other parts of the world in a future study.

Finally, we also estimated possible sources of errors with respect to possible approaches for model improvement. It was expected, that the main error sources in radiation components would be errors in CFR, ALB, and TS. For net short-wave radiation, we confirmed that $\triangle \mathrm{CFR}$ and $\triangle A L B$ are important factors; the explained variance for $\triangle C F R$ was two- to threefold higher than for $\triangle$ ALB. The large seasonal and geographic differences also had to be considered. Errors in CFR led to substantial biases in the net long-wave radiation. However, we found that $\triangle T S$ had only a small or even negligible influence on errors in the net long-wave radiation budget. In a comparison to simulations of the regional climate models REMO and ALADIN we could confirm the found relations. Thus, a better representation of cloud fraction CFR and surface albedo ALB yields a substantially better estimation of the radiation budget components by CLM. It is worth to wrestle with these relatively simple parameters compared to parameters like cloud inhomogeneity, cloud phase, direct and indirect aerosol effects, etc.

\section{Appendix 2.1 Results compared to other REgional Climate models}

To see how our results with the regional model CLM compare to results with other regional climate models, we investigated simulations with the REMO regional climate model of the Max Planck Institute for Meteorology (Hamburg, Germany) [Jacob et al. 2001, 2007] and the ALADIN in climate mode of the Centre National de Recherches Météorologiques (Toulouse, France) [Sanchez-Gomez et al. 2008; Radu et al. 2008]. These two regional climate models were applied in the EU-project ENSEMBLES [Hewitt and Griggs 2004] and we have analysed the corresponding simulations for Europe. The used simulations were ERA40 driven with a horizontal resolution of $0.5^{\circ}$. The REMO used 27 and ALADIN used 31 vertical layers, respectively.

The model bias of REMO (Fig. 2.10) relatively to SRB and ERA40 was small and for all parameters within the uncertainty range of the reference data. Opposite to CLM there was a small overestimation of TNS, which led to a larger solar divergence error than quantified for CLM. The model bias of ALADIN (Fig. 2.10) was of similar magnitude as of CLM, but in all cases with the opposite algebraic sign. Thus, ALADIN showed an overestimation of short-wave net radiation and an underestimation of long-wave net radiation. This shows that our evaluation approach is useful in identification of inter-model difference in radiation budget components.

In terms of the identification of error sources the pattern of the dependence of flux errors on errors in the explaining quantities CFR, ALB, and TS in general was similar for all investigated models and setups (CLM20, CLM32, REMO, ALADIN). Figure 2.11 (upper panels) shows a strong dependence of the SNS differences in REMO and ALADIN on errors in CFR and ALB. For SNL (Fig. 2.11, lower panels) there was also a strong dependence on errors in CFR, while there was no dependence on errors in TS. These results compare very well to the results shown for CLM in Fig. 2.6.

The explained variances (not shown) also yielded similar results as those displayed for CLM in Fig. 2.7. Errors in CFR explain two to three times more than errors in ALB of the error variance in solar fluxes. For ALADIN explained variances for errors in ALB were with a range of about $11-22 \%$ clearly higher than for errors in TS, with a range of $0-7 \%$. For REMO the values of explained variance for errors in ALB as well as for TS had a higher range than for ALADIN (for ALB 5-22\%, for TS 2-22\%). Thus, the investigation of REMO and ALADIN confirms the results with CLM that it is useful to invest some effort in relatively easily improvable parameters like CFR and ALB in further improvement of RCMs. 


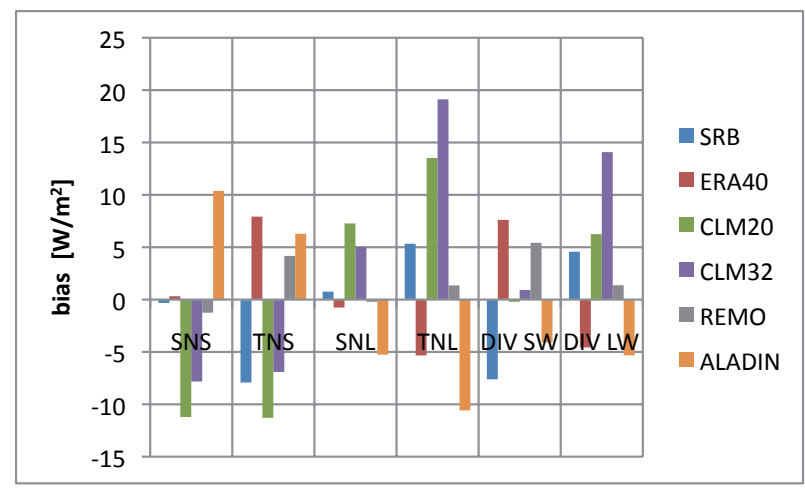

Figure 2.10 Same figure as Fig. 2.1 but additionally with biases of REMO and ALADIN
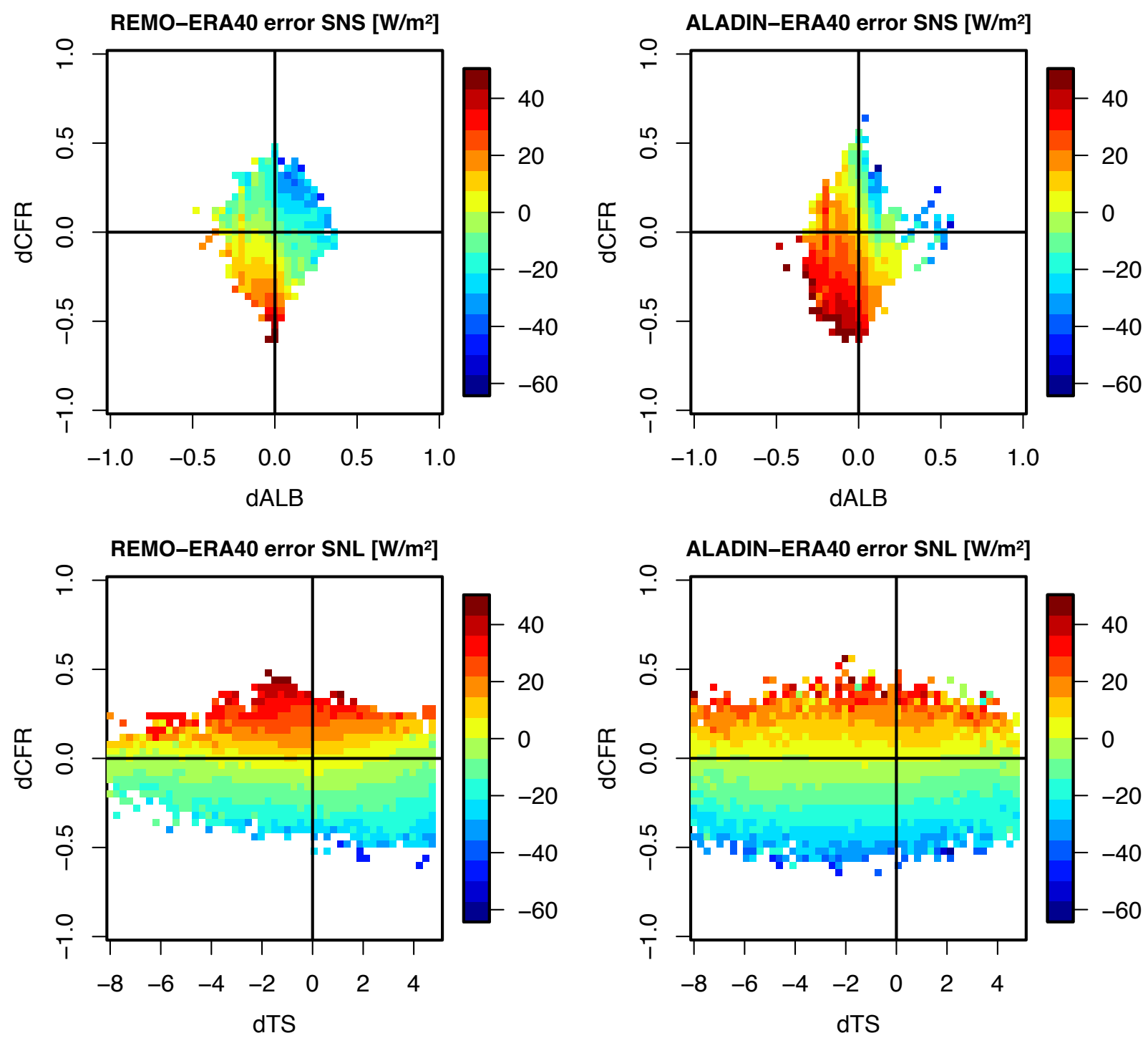

Figure 2.11 Same figure as Fig. 6 but for REMO and ALADIN and only for surface radiation components 
By the help of a simplified calculation we wanted to discuss the impact of uncertainties in CFR, ALB, or TS on radiation fluxes. In the solar spectrum a cloud albedo of one and a transparent clear-sky atmosphere were assumed. Then the shortwave radiation components (SW) can be written to:

$$
\begin{gathered}
\mathrm{SW}_{\mathrm{SFC}} \downarrow=(1-\mathrm{CFR}) \cdot \mathrm{SW}_{\mathrm{TOA}} \downarrow \\
\mathrm{SW}_{\mathrm{SFC} \uparrow=\mathrm{ALB}} \cdot(1-\mathrm{CFR}) \cdot \mathrm{SW}_{\mathrm{TOA}} \downarrow \\
\mathrm{SW}_{\mathrm{TOA}} \uparrow \stackrel{\mathrm{SW}}{=} \mathrm{SWAA}_{\mathrm{TOA}} \downarrow \cdot\left[\mathrm{ALB} \cdot(1-\mathrm{CFR})^{2}+\mathrm{CFR}\right]
\end{gathered}
$$

The indices SFC and TOA represent the surface or top of atmosphere and the arrows $\uparrow$ or $\downarrow$ represent the upwelling or downwelling fluxes. The net short-wave fluxes are given by:

$$
\begin{gathered}
\mathrm{SNS}=\mathrm{SW}_{\mathrm{SFC}} \downarrow-\mathrm{SW}_{\mathrm{SFC}} \uparrow=(1-\mathrm{ALB}) \cdot(1-\mathrm{CFR}) \cdot \mathrm{SW}_{\mathrm{TOA}} \downarrow \\
\mathrm{TNS}=\mathrm{SW}_{\mathrm{TOA}} \downarrow-\mathrm{SW}_{\mathrm{TOA}} \uparrow=\mathrm{SW}_{\mathrm{TOA}} \downarrow \cdot\left[1-\mathrm{ALB} \cdot(1-\mathrm{CFR})^{2}+\mathrm{CFR}\right]
\end{gathered}
$$

The impact of errors in CFR and ALB is nearly linear, but (a) CFR is larger than ALB on average and (b) the error in CFR typically is larger than the error of ALB. The average values are given in Tab. 2.1 and applied in simple calculations summarized in Tab. 2.2. The results show that an overestimation in CFR and ALB led to a decrease in SNS and TNS and that the impact of errors in CFR was larger than the impact of errors in ALB on average.

\begin{tabular}{ccc}
\hline Parameter & Mean & Typical error \\
\hline CFR & 0.62 & 0.06 \\
ALB & 0.14 & 0.03 \\
TS & $284 \mathrm{~K}$ & $-1.0 \mathrm{~K}$ \\
\hline
\end{tabular}

Table 2.1 Mean values and typical errors (mean errors of all data) for CFR, ALB and TS in the model simulations discussed

\begin{tabular}{cccc}
\hline$\Delta$ ALB & $\Delta$ CFR & $\Delta$ SNS & $\Delta$ TNS \\
\hline+0.03 & 0 & $-3.9 \mathrm{~W} / \mathrm{m}^{2}$ & $-1.5 \mathrm{~W} / \mathrm{m}^{2}$ \\
0 & +0.06 & $-17.6 \mathrm{~W} / \mathrm{m}^{2}$ & $-18.5 \mathrm{~W} / \mathrm{m}^{2}$ \\
+0.03 & +0.06 & $-20.9 \mathrm{~W} / \mathrm{m}^{2}$ & $-19.6 \mathrm{~W} / \mathrm{m}^{2}$ \\
\hline
\end{tabular}

Table 2.2 Example of a simplified calculation of $\triangle S N S$ and $\triangle T N S$ to test the sensitivity to uncertainties in CFR and ALB under the assumption of SW $\mathrm{SOA}_{\text {TO }} \downarrow=1367 / 4 \mathrm{~W} / \mathrm{m}^{2}$ and typical values of CFR, ALB, $\Delta$ CFR and $\triangle \mathrm{ALB}$ 
In case of long-wave radiation (LW) the single components are given by:

$$
\begin{gathered}
\mathrm{LW}_{\mathrm{SFC} \uparrow=\sigma \cdot \mathrm{TS}^{4}} \\
\mathrm{LW}_{\mathrm{SFC} \downarrow}=0.75 \cdot \sigma \cdot \mathrm{TS}^{4} \cdot\left(1+0.22 \cdot \mathrm{CFR}^{2}\right) \\
\mathrm{LW}_{\mathrm{TOA}} \uparrow=(1-\mathrm{CFR}) \cdot \sigma^{*} \cdot \mathrm{TS}^{k^{*}}+\mathrm{CFR} \cdot\left(\left(1-\varepsilon^{*}\right) \cdot \sigma^{*} \cdot \mathrm{TS}^{k^{*}}+\varepsilon^{*} \cdot \sigma^{*} \cdot \mathrm{TC}^{k^{*}}\right)
\end{gathered}
$$

The SFC components were estimated following Ångström and Bolz [see Warnecke 1997] with $\sigma$ the Stefan Boltzmann constant. The outgoing long-wave radiation $\mathrm{LW}_{\mathrm{TOA}} \uparrow$ was approximated following Corti and Peter [2009]. They estimated the parameters $\sigma^{*}$ and $k^{*}$ to $1.607 \cdot 10^{-4} \mathrm{Wm}^{-2} \mathrm{~K}^{-4}$ and 2.528 respectively, by radiative calculations. For a mid-level cloud a cloud temperature TC $=255 \mathrm{~K}$ and an effective cloud emissivity $\varepsilon^{*}=0.79$ [Allen 1970] were assumed. The choice of the cloud emissivity was important for the respective impact of CFR and TS (the higher $\varepsilon$, the higher is the impact of CFR and the lower the impact of TS). SNL and TNL are the difference of the downwelling minus the upwelling component:

$$
\begin{gathered}
\mathrm{SNL}=\mathrm{LW}_{\mathrm{SFC}} \downarrow-\mathrm{LW}_{\mathrm{SFC}} \uparrow=\sigma \cdot \mathrm{TS}^{4} \cdot\left(0.165 \cdot \mathrm{CFR}^{2}-0.25\right) \\
\mathrm{TNL}=0-\mathrm{LW}_{\mathrm{TOA}} \uparrow=-\sigma^{*} \cdot\left((1-\mathrm{CFR}) \cdot \mathrm{TS}^{\mathrm{k}^{*}}+\mathrm{CFR} \cdot\left(\left(1-\varepsilon^{*}\right) \cdot \mathrm{TS}^{\mathrm{k}^{*}}+\varepsilon^{*} \cdot \mathrm{TC}^{k^{*}}\right)\right)
\end{gathered}
$$

For the example calculations in Tab. 2.3 mean values of TS, CFR, $\Delta T S$ and $\Delta$ CFR were assumed (Tab. 2.1). The table shows that the typical impact of errors in CFR was larger than in TS because of a partly compensation of terms with TS. In Tab. 2.3 it is also to see that $\Delta T N L$ in most cases was smaller than $\triangle S N L$, while Fig. 2.1 shows a larger bias for TNL than for SNL. In combination with Fig. 2.7, where it can be seen that the explained variance for TNL was lower than for SNL, this shows that especially for TNL there were other important influencing factors besides CFR and TS. For example, Corti and Peter [2009] said that their parameterization could be improved by including a measure for the amount of absorption from water vapour, but they left it for simplification reasons.

\begin{tabular}{cccc}
\hline$\Delta \mathrm{TS}$ & $\Delta \mathrm{CFR}$ & $\Delta \mathrm{SNL}$ & $\Delta \mathrm{TNL}$ \\
\hline$-1 \mathrm{~K}$ & 0 & $0.9 \mathrm{~W} / \mathrm{m}^{2}$ & $1.1 \mathrm{~W} / \mathrm{m}^{2}$ \\
$0 \mathrm{~K}$ & +0.06 & $4.7 \mathrm{~W} / \mathrm{m}^{2}$ & $2.9 \mathrm{~W} / \mathrm{m}^{2}$ \\
$-1 \mathrm{~K}$ & +0.06 & $5.6 \mathrm{~W} / \mathrm{m}^{2}$ & $3.9 \mathrm{~W} / \mathrm{m}^{2}$ \\
\hline
\end{tabular}

Table 2.3 Example of a simplified calculation of $\triangle S N L$ and $\triangle T N L$ to test the sensitivity to uncertainties in TS and CFR under the assumption of typical values for CFR, TS, $\triangle$ CFR and $\Delta T S$ 




\section{Chapter 3}

THE RADIATION BUDGET FOR WEST AFRICA

This section shows the investigation of the components of the radiation budget for various regional climate simulations for West Africa. The study is published as:

Kothe S \& Ahrens B (2010) On the radiation budget in regional climate simulations for West Africa. J Geophys Res 115, D23120. doi:10.1029/2010JD01433 


\begin{abstract}
This paper discusses the simulated monthly radiation budget of West Africa by eight regional climate models and the impact of three uncertainty sources in the simulations: cloud fraction, surface albedo, and surface temperature. The models were driven by the European Centre for Medium-Range Weather Forecasts ERA-Interim reanalysis data within the European Union project ENSEMBLES. The simulated budgets were compared to the satellite-based Global Energy and Water Cycle Experiment Surface Radiation Budget and ERA-Interim data sets. The simulations tended to underestimate the net solar radiation and the outgoing long-wave radiation, and they showed a regionally varying over- or underestimation in all budget components (up to $75 \%$ ). The evaluation showed that uncertainty in the cloud fraction is the most important of the uncertainty sources over the ocean (with explained error variances bet-ween $25 \%$ and $60 \%$ depending on the budget component averaged over all models). Over land, the surface albedo and surface temperature were, on average, of similar importance as the cloud fraction. The latter result differed from that in a recent study for Europe, indicating that the importance of land surface on the radiation budget is regionally dependent. The relatively simple factor of surface albedo still explains a substantial part of the solar budget error variance in this study: more than $10 \%$ over ocean and more than $20 \%$ over land, peaking to more than $60 \%$ over the Sahelian and Saharan areas. It is worth improving on that in the models, in view of the complexity of other factors like cloud inhomogeneity and direct and indirect aerosol effects.
\end{abstract}




\subsection{INTRODUCTION}

The long- and short-wave components of the Earth's radiation budget, which describe the sources and sinks of energy in the atmosphere, are important terms in climate modeling. These parameters govern the energy balance of the Earth, and they control daily and annual cycles. In the present study, we evaluated simulations of different regional climate models (RCMs), which contributed to the European Union (EU) project ENSEMBLES [Hewitt and Griggs 2004; van der Linden and Mitchell 2009; http://ensembles-eu. metoffice.com], in terms of the radiation budget of West Africa.

Many previous studies have used ground station radiation measurements to evaluate climate model simulations because of their well-known accuracy [e.g., Markovic et al. 2008; Wild 2008]. However, Africa has only a limited number of radiation stations that provide climatic data. Other studies have successfully employed reanalysis data, which offer the advantages of good spatial coverage and the availability of surface (SFC) and top-of-atmosphere (TOA) parameters [e.g., Marras et al. 2007; Jaeger et al. 2008]. In the present study, we used the European Centre for Medium-Range Weather Forecasts (ECMWF) ERA-Interim reanalysis [Simmons et al. 2006] and the satellite-based Global Energy and Water Cycle Experiment (GEWEX) Surface Radiation Budget (SRB) data sets (http://gewex-srb.larc.nasa.gov/). The GEWEX SRB data set has been used to evaluate model results [e.g., Winter and Eltahir 2008; Kothe et al. 2010]. Our application of the two data sets has allowed us to draw more robust conclusions.

There have been several RCM applications in Africa that have investigated the West African monsoon system [e.g., Afiesimama et al. 2006; Druyan et al. 2008; Steiner et al. 2009]. Domínguez et al. [2010] showed for the RCM PROMES that there is a strong influence of the parameterizations of cloud fraction and radiation on the simulated West African monsoon. Various climate model evaluations have attributed errors in radiation budget components to cloud fraction errors [e.g., Markovic et al. 2008; Jaeger et al. 2008]. In addition to cloud fraction, we expected that uncertainties in the radiation budget might also result from uncertainties in surface temperature and surface albedo. In particular, surface albedo is an important parameter in climate modeling because it represents a combination of numerous surface properties, such as soil moisture, roughness length, and vegetation cover. Albedo directly describes the energy exchange between the surface and the atmosphere and, thus, influences surface temperature, evapotranspiration, energy balance, and even the photosynthesis and respiration of plants. A previous study of the West African Sahel [Charney 1975] suggested that changes in land use led to an increase in surface albedo and that this resulted in the observed decrease in rainfall. This outcome was reproduced by Abiodun et al. [2008] in an RCM study. They found that the degradation of land cover into desert can increase the surface albedo, thus reducing the shortwave net radiation. Abiodun et al. [2008] stated that desertification decreased rainfall over the Sahel region and increased it near the coast, and deforestation decreased rainfall over the entire West African region. In a similar study, Paeth et al. [2009] showed by RCM simulations that the spatial pattern and the amplitude of precipitation changes in West Africa are mainly governed by land degradation. By climate modeling experiments, Davin and de Noblet-Ducoudré [2010] showed that the global-scale replacement of forests by grassland and the resulting higher surface albedo induces a global cooling of $1.36 \mathrm{~K}$. For Europe, Kothe et al. [2010] showed that uncertainties in surface albedo are less important than cloud fraction uncertainties in explaining the errors in the short-wave radiation budget of RCMs. Kothe et al. also showed that, in Europe, surface temperature uncertainties are less important than cloud fraction uncertainties in the long-wave radiation spectrum. However, the different African climates and importance of land surface motivated a quantification of the impact of the uncertainties of cloud fraction, surface albedo, and surface temperature uncertainties on the radiation budget of western Africa. These are apparently relatively simple model parameters that have a high impact on the radiation budget. These parameters are available from the ensemble of RCM simulations performed within the ENSEMBLES project and are relatively well observed at climate scales. 
Other important sources of uncertainty are, for example, cloud inhomogeneity, aerosol effects (especially mineral dust effects), and water vapor distribution. The treatment of mineral dust in the climate simulations is a potentially important error source in the Saharan and Sahelian area [Stanelle et al. 2010]. However, the ENSEMBLES RCMs apply very simple treatments of aerosols (sometimes even neglecting aerosols like the model PROMES or simple aerosol climatologies following Tanré et al. [1984]). However, these parameters are less well quantified by observations and not available for the ensembles of RCMs investigated in this study. The RCM's parameterizations of these error sources have to be improved in future RCM development, but here we focus on the relatively simple, still important uncertainty sources: cloud fraction, surface temperature, and surface albedo. First, we provide a brief description of the used models and data sets, and then we present comparisons of the ENSEMBLES RCMs, ERAInterim, and GEWEX SRB. In section 3.4, we describe the relationship between radiation errors and cloud fraction, surface albedo, and surface temperature uncertainties. In section 3.5, we discuss the significance of our results for regional climate modeling.

\begin{tabular}{ccc}
\hline Group & Model & Reference \\
\hline DMI & HIRHAM & Christensen et al. [1998] \\
GKSS & CCLM & Böhm et al. [2006] \\
HC & HadRM & Moufouma-Okia and Rowell [2009] \\
ICTP & RegCM & Pal et al. [2007] \\
KNMI & RACMO & van Meijgaard et al. [2008] \\
METNO & HIRHAM & Haugen and Iversen [2008] \\
MPIMET & REMO & Jacob [2001] \\
SMHI & RCA & Samuelsson et al. [2010] \\
UCLM & PROMES & Dominguez et al. [2010] \\
\hline
\end{tabular}

Table 3.1 Contributing groups and the regional climate models used in nine setups for ENSEMBLES (see http://ensembles-eu.metoffice.com)

\subsection{Data SETS AND Simulations}

This section briefly introduces the ERA-Interim and GEWEX SRB reference data, which provided good performance in previous evaluation studies [e.g., Zhang et al. 2007; Troy and Wood 2009]. We also present the evaluated RCM data.

\subsubsection{ERA-INTERIM}

ERA-Interim is a global reanalysis data product of the ECMWF, with a horizontal spectral resolution of T255 (about $50 \mathrm{~km}$ at the equator) that is available for the years 1989 to 2008 [Simmons et al. 2006]. For the evaluation of RCM simulations and for identification of the 
sources of errors, we used ERA-Interim monthly mean radiation budget components, cloud fraction, surface albedo, and surface temperature. Although ERA-Interim assimilates numerous measured parameters, it is still a modeling product. Additionally, ERA-Interim was used as driving data at the lateral boundaries for the investigated model simulations. As a result, these data cannot be regarded as fully independent evaluation data.

\subsubsection{GEWEX SRB}

The GEWEX SRB project provides a satellite-based data set of 3 hourly short- and longwave radiation components at the SFC and TOA on a $1^{\circ}$ global grid [Gupta et al. 2006]. We used version 3.0 of the data set for shortwave fluxes and release 2.5 for long-wave fluxes (from July 1983 to June 2007 for short-wave fluxes and SFC net longwave flux; from July 1983 to June 2005 for outgoing long-wave radiation). The surface radiation fluxes were evaluated in a variety of studies with data from the Baseline Surface Radiation Network or the Global Energy Balance Archive project, which provided good agreement with monthly data (i.e., within $5 \mathrm{~W} / \mathrm{m}^{2}$ for long-wave fluxes and $5-20 \mathrm{~W} / \mathrm{m}^{2}$ for short-wave fluxes [Gupta et al. 1999; Zhang et al. 2007]). The same parameters were used as with the ERAInterim data. The surface albedo was derived by the ratio of short-wave up- and downwelling radiation.

\subsubsection{RCM SIMULATIONS}

The goal of the ENSEMBLES project was to develop an ensemble prediction system based on global and regional Earth system models [Hewitt and Griggs 2004]. One of the focus areas for RCM simulations was West Africa, which includes parts of northern and central Africa. Table 3.1 lists the contributing groups and associated RCMs [see http:// ensembles-eu.metoffice.com]. Table A3.1 (see appendix 3.1) summarizes the grid configurations and the most important applied parameterizations for these models.

The used simulations were driven by ERA-Interim data, and they cover the time period of 1989 to 2008. All simulations provided a grid spacing of about $50 \mathrm{~km}$. The monthly means of radiation fluxes, cloud fraction, surface albedo, and surface temperature were obtained via the ENSEMBLES data portal.

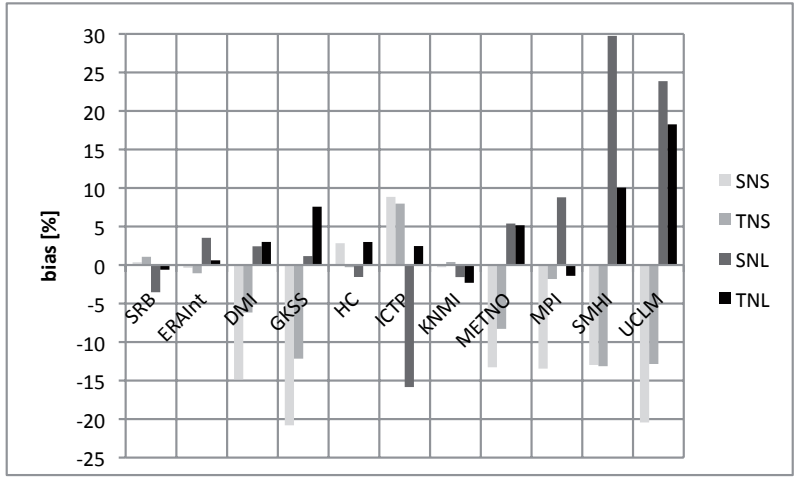

Figure 3.1 Relative differences of observed and biases of simulated surface net short-wave (SNS), topof-atmosphere net short-wave (TNS), surface net long-wave (SNL), and top-of-atmosphere net long-wave (TNL) radiation fluxes versus the arithmetic mean of ERA-Interim and SRB $\left(\mathrm{SNS}_{\text {ref }}=201.11 \mathrm{~W} / \mathrm{m}^{2}, \mathrm{TNS}_{\text {ref }}\right.$ $\left.=297.71 \mathrm{~W} / \mathrm{m}^{2}, \mathrm{SNL}_{\text {ref }}=-70.76 \mathrm{~W} / \mathrm{m}^{2}, \mathrm{TNL}_{\text {ref }}=-270.89 \mathrm{~W} / \mathrm{m}^{2}\right)$ for the time periods and area of investigation. Downward fluxes are counted positive 


\subsection{Radiation BUdget eVAluAtion}

In this section, we summarize the uncertainties in the radiation budgets of the different RCM simulations. It is the purpose of this paper to discuss common aspects of the uncertainties and their sources, not to do a model intercomparison. We compared the radiative fluxes of eight ENSEMBLES models (nine versions because HIRHAM was used by two groups; Table 3.1) and the GEWEX SRB and ERA-Interim data sets by using monthly mean data from 1990 to 2006 (1990 to 2004 for outgoing long-wave radiation). The ERA-Interim and RCM data were aggregated by inverse distance weighting to a $1^{\circ}$ grid to fit the SRB information. The area of interest extended from $28^{\circ} \mathrm{W}$ to $30^{\circ} \mathrm{E}$ and from $16^{\circ} \mathrm{S}$ to $32^{\circ} \mathrm{N}$.

Figure 3.1 displays the relative total biases with reference to the average of the SRB and ERA-Interim data and the difference of the reference data. There was some compensation of differences, but, in most areas, the SRB and ERA-Interim flux differences were small compared to the model biases (Figures 3.2 and 3.4-3.6). However, we think that SRB is better at characterizing regional features because it is less influenced by data assimilation. This is why SRB data were used as a reference in the discussed differences in Figures 3.2 and 3.4-3.6.

(a)
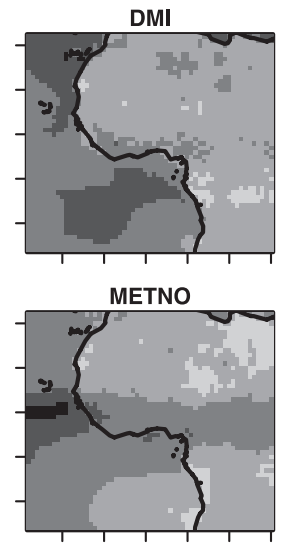

(b)
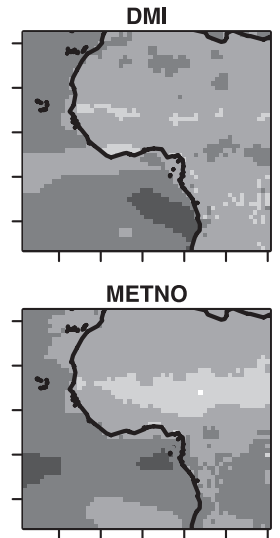

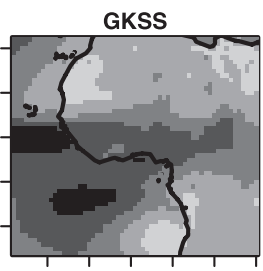

MPI
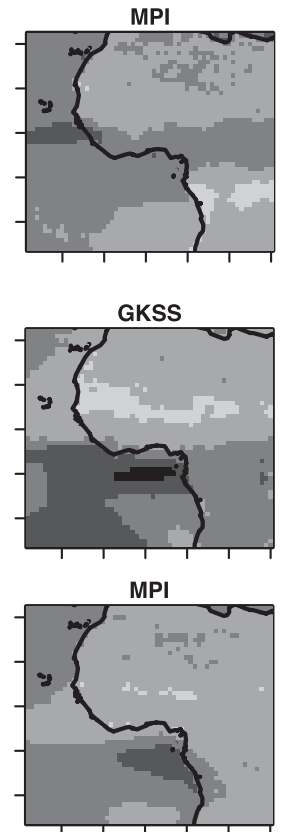
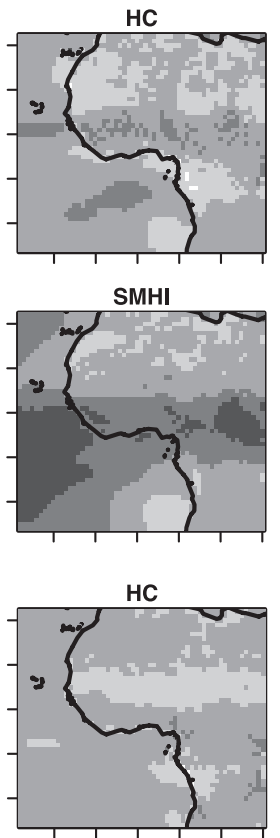

SMHI

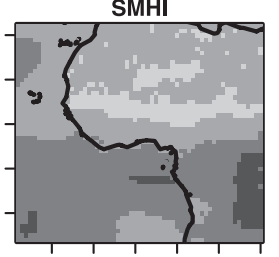

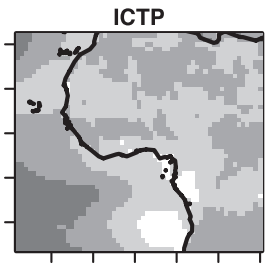
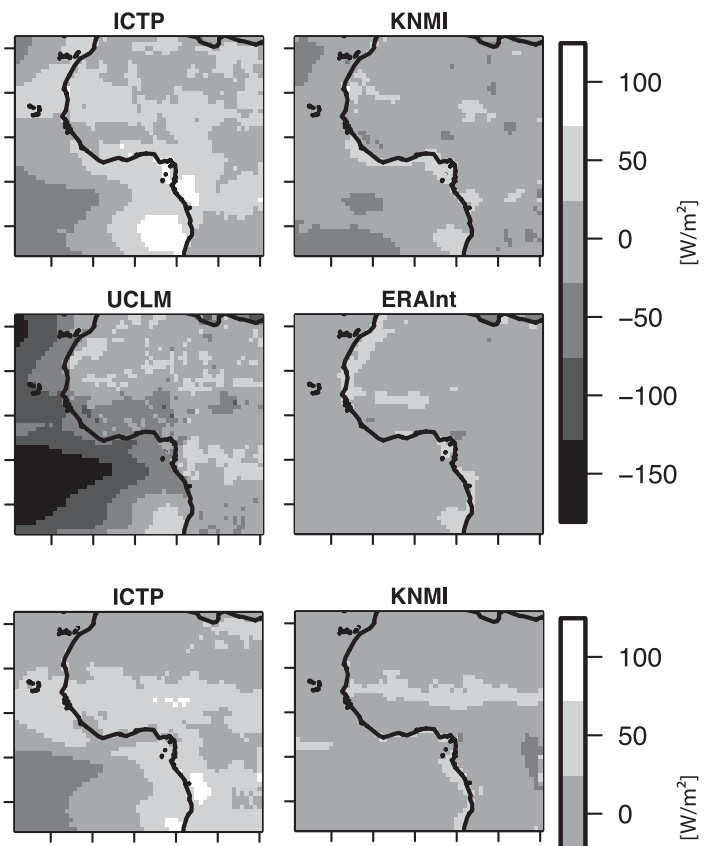

UCLM
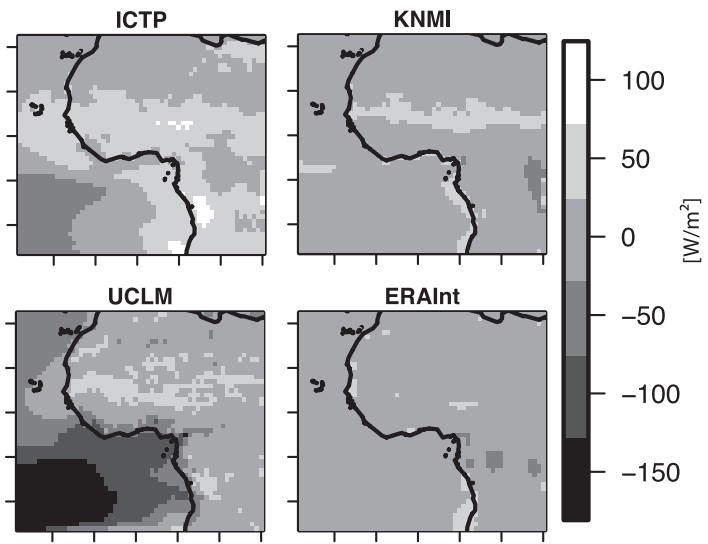

Figure 3.2 Differences in SNS $\left(\mathrm{W} / \mathrm{m}^{2}\right)$ of RCM simulations and ERA-Interim to SRB values for (a) the mean summer (June to August, 1990-2006) and (b) the mean winter (December to February, 1990-2006) 


\subsubsection{SFC NET SHORT-WAVE RADIATION}

Except in the models used by HC, ICTP, and KNMI, the long-term mean differences indicated a clear underestimation of surface net short-wave (SNS) radiation (Figure 3.1). The seasonal averaged differences showed that most models underestimated SNS in ocean areas and in parts of the intertropical convergence zone (ITCZ), and they overestimated SNS in the Sahara and Sahel (see Figure 3.2). The largest differences (GKSS and UCLM, up to $-150 \mathrm{~W} / \mathrm{m}^{2}$ ) were in summer over the equatorial ocean; the maximum overestimation (ICTP, more than $80 \mathrm{~W} / \mathrm{m}^{2}$ ) was for the region offshore of Angola (Figure 3.2a). In winter, the differences were smaller (Figure $3.2 b)$.

We used Taylor diagrams [Taylor 2001] to summarize how closely the model patterns matched the observations. The similarity between patterns was quantified by correlation, the centered RMS difference, and the amplitude of variation (represented by standard deviation). The temporal Taylor diagram, which compares the time series of area averages of SNS with reference to SRB, indicates a relatively low scatter of correlation and RMS difference (Figure 3.3, left). In contrast, the spatial Taylor diagram, which compares spatial fields of time averages, indicates a much higher scatter in both correlation (0.05-0.85) and RMS difference $\left(18-42 \mathrm{~W} / \mathrm{m}^{2}\right.$ ; Figure 3.3, right).
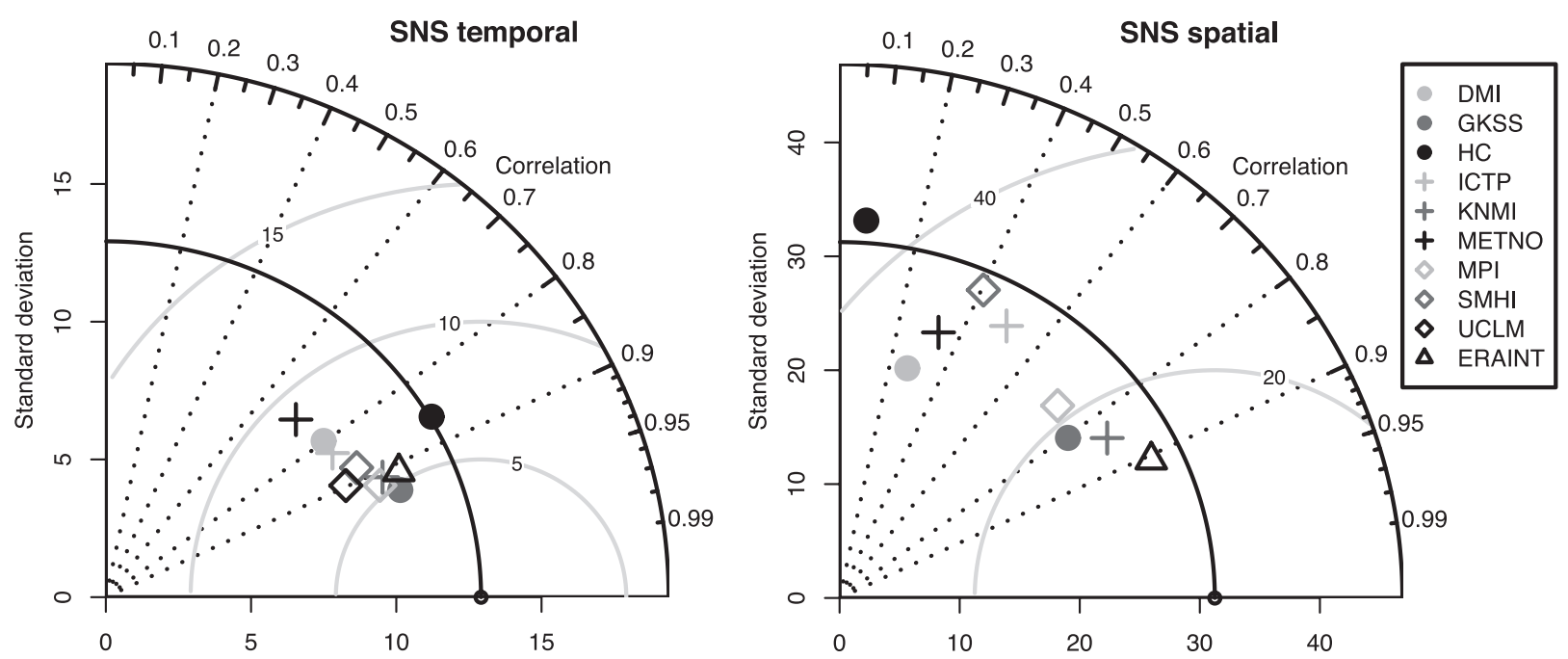

Figure 3.3 Differences in SNS $\left(\mathrm{W} / \mathrm{m}^{2}\right)$ of RCM simulations and ERA-Interim to SRB values for (a) the mean summer (June to August, 1990-2006) and (b) the mean winter (December to February, 1990-2006)

\subsubsection{TOA NET SHORT-WAVE RADIATION}

Figure 3.1 illustrates that most models underestimated TOA net short-wave (TNS) radiation. These differences, and their spatial structures and seasonal variability (Figure 3.4), were similar to the SNS results. Only the ICTP simulation showed larger overestimations (up to $150 \mathrm{~W} / \mathrm{m}^{2}$ ) in winter (Figure 3.4b). The temporal correlation (with reference to SRB) was high (0.90-0.97), and the temporal RMS difference was $4-8 \mathrm{~W} / \mathrm{m}^{2}$. The comparisons of spatial fields showed a large variation, with even a negative correlation with the SRB data for one model. The GKSS, KNMI, and MPI simulations showed the best correlations $(\approx 0.8)$ and RMS difference $\left(\approx 18 \mathrm{~W} / \mathrm{m}^{2}\right)$. 
(a)

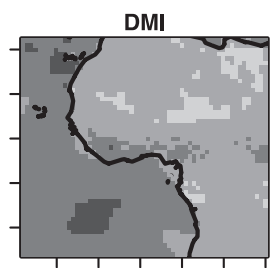

METNO

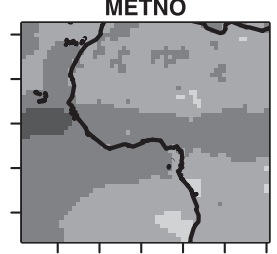

(b)

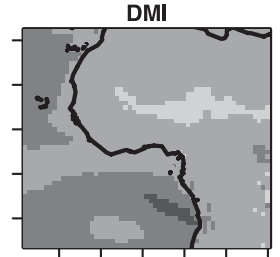

METNO

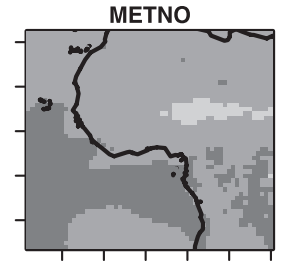

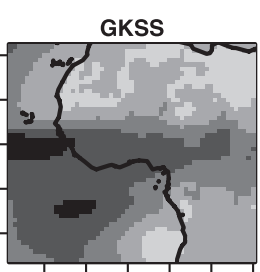

MPI

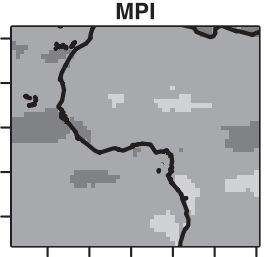

GKSS

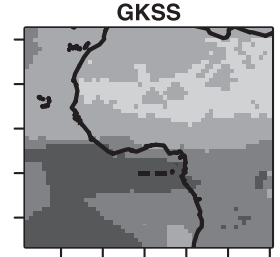

MPI

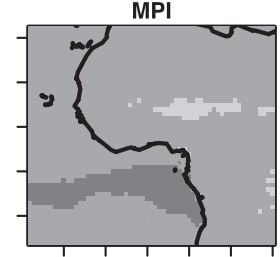

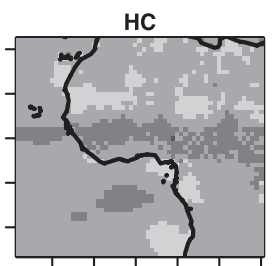

SMHI

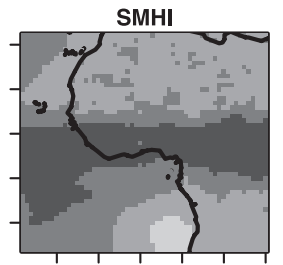

HC

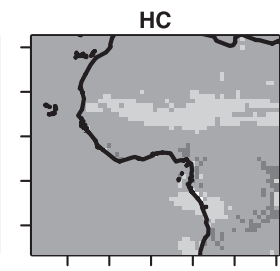

SMHI

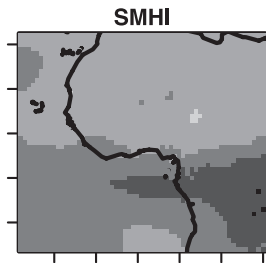

ICTP

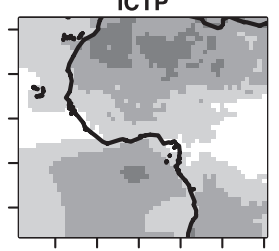

UCLM

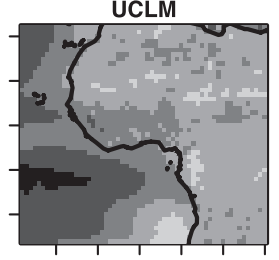

ICTP

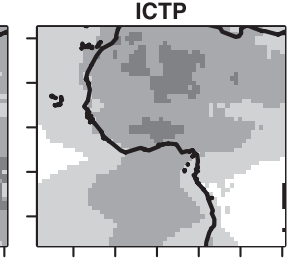

UCLM

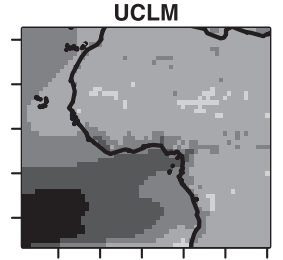

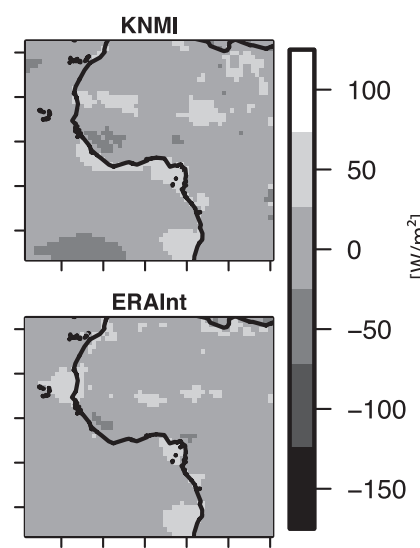
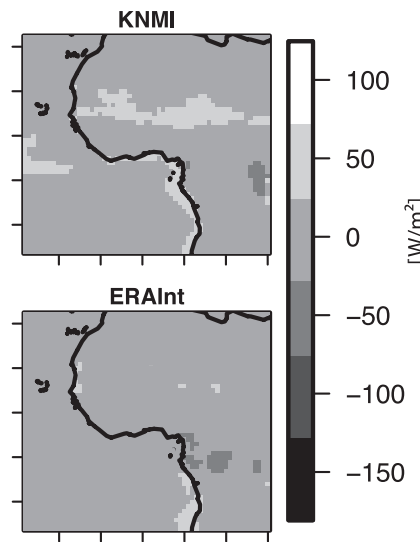

Figure 3.4 As for Figure 3.2, but for TNS

\subsubsection{SFC NET LONG-WAVE RADIATION}

Most models had small biases in SFC net long-wave (SNL) radiation (Figure 3.1). Figure 3.5 implies that these small biases partly resulted from compensating errors. There was a slight tendency to overestimate SNL in the Sahel and to underestimate SNL in central Africa during summer, whereas the opposite occurred during winter. Only SMHI and UCLM showed clear overestimations of more than $18 \mathrm{~W} / \mathrm{m}^{2}$. These two models displayed regionally strong overestimations of more than $50 \mathrm{~W} / \mathrm{m}^{2}$ in summer in the equatorial region (Figure 3.5a; remembering that downward radiation is positive).

A common feature of all simulations (except DMI) was a strong underestimation in summer (up to $60 \mathrm{~W} / \mathrm{m}^{2}$ ) in the region offshore of Angola. This area is known to develop large stratocumulus clouds, so the error may be attributable to an underestimation of the cloud fraction. In winter, the overestimations were smaller, and the regions with underestimations (especially the Sahara and Sahel) were larger. The SNL showed a temporal correlation of 0.7-0.82 with SRB for all models. The RMS difference $\left(2.5-4 \mathrm{~W} / \mathrm{m}^{2}\right)$ and standard deviation $\left(3-5 \mathrm{~W} / \mathrm{m}^{2}\right.$, for $\mathrm{SRB} \approx 4.5 \mathrm{~W} / \mathrm{m}^{2}$ ) were very similar for all models except HC (RMS difference, $5 \mathrm{~W} / \mathrm{m}^{2}$; standard deviation, $7 \mathrm{~W} / \mathrm{m}^{2}$ ). The spatial correlation was much better, varying from about 0.9 (ICTP) to 0.99 (MPI).

Although the mean difference between ERA-Interim and SRB data was low (Figure 3.1), Figure 3.5 shows regionally strong deviations in SNL between these two data sets, which resulted in a higher uncertainty of the reference in the case of SNL. 
(a)
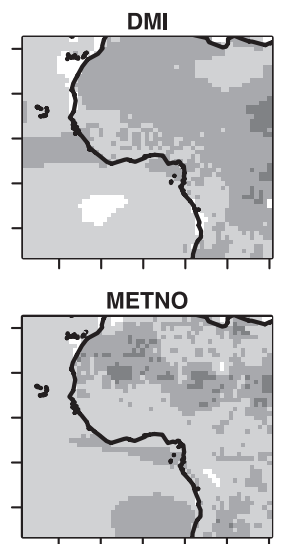

DMI

(b)

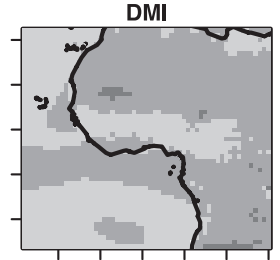

METNO

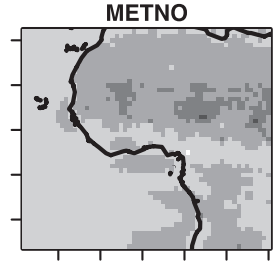

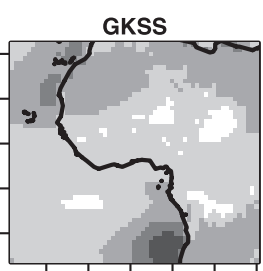

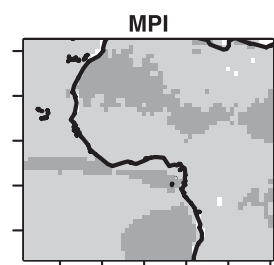

GKSS

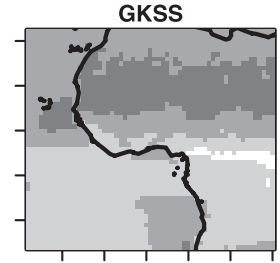

MPI

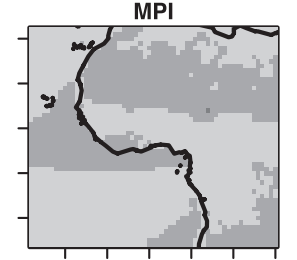

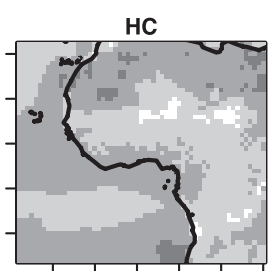

SMHI

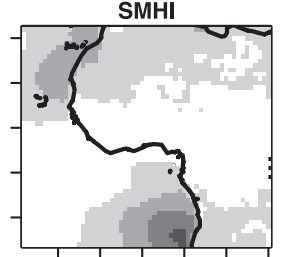

$\mathrm{HC}$

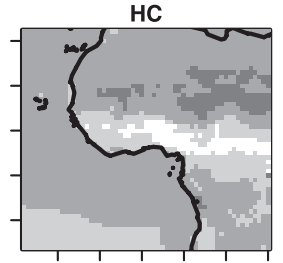

SMHI

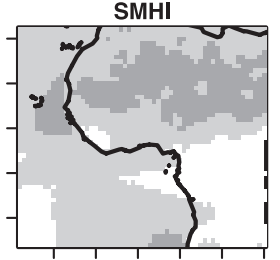

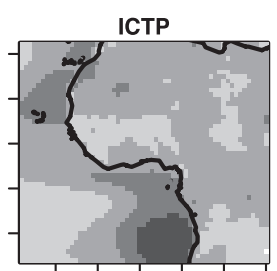

UCLM

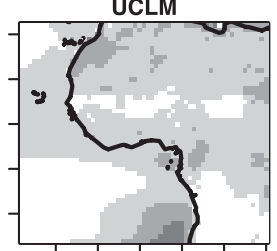

ICTP

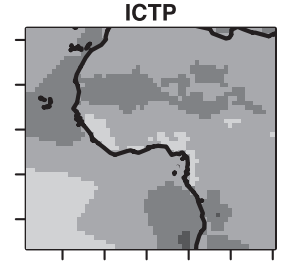

UCLM

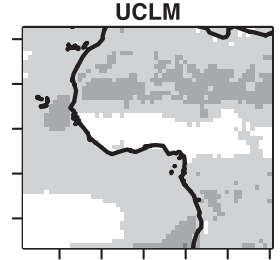

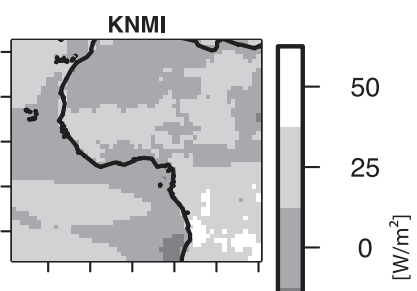
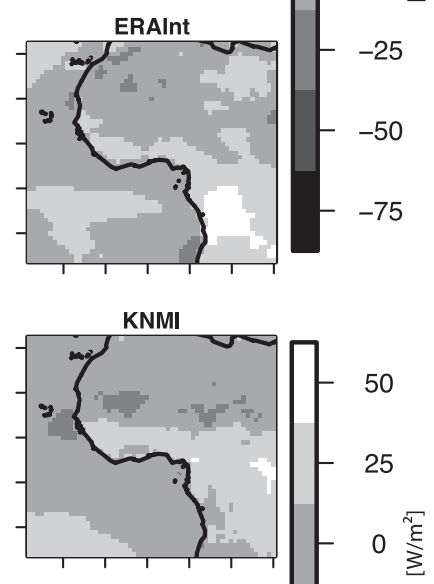

ERAlnt

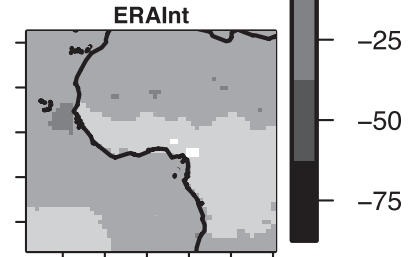

Figure 3.5 As for Figure 3.2, but for SNL

\subsubsection{TOA NET LONG-WAVE RADIATION}

Most ENSEMBLES models showed a mean overestimation of TOA net long-wave (TNL) radiation (Figure 3.1), by up to $50 \mathrm{~W} / \mathrm{m}^{2}$ in the case of UCLM. The models overestimated TNL in the Sahara and Sahel region by more than $100 \mathrm{~W} / \mathrm{m}^{2}$ in summer (Figure 3.6a), and they underestimated TNL in central Africa, with smaller differences during winter (Figure 3.6b). The temporal correlation and RMS difference in reference to SRB were good, with values up to 0.9 and about $4 \mathrm{~W} / \mathrm{m}^{2}$, respectively (except for METNO, with a correlation of 0.6 and an RMS difference of $6 \mathrm{~W} / \mathrm{m}^{2}$ ). The spatial correlations with SRB were $0.8-0.95$, and the standard deviations were $8-30 \mathrm{~W} / \mathrm{m}^{2}$ (for $\mathrm{SRB} \approx 21 \mathrm{~W} / \mathrm{m}^{2}$ ). 
(a)
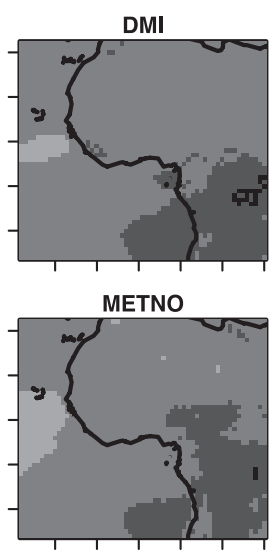

(b)

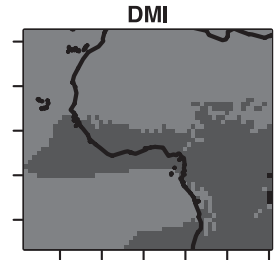

METNO

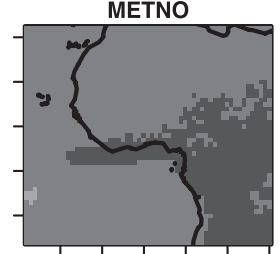

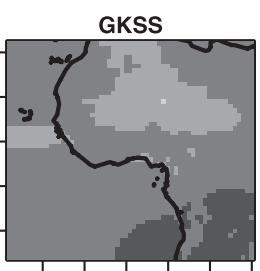

MPI

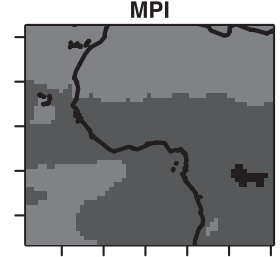

GKSS

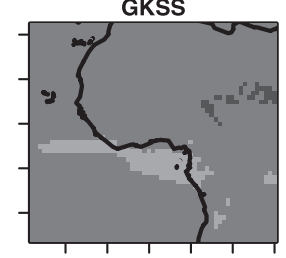

MPI

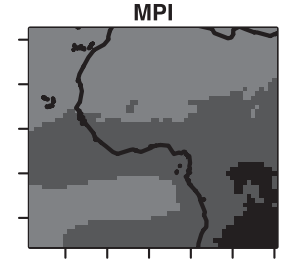

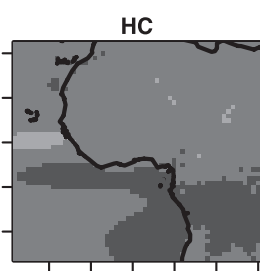

SMHI

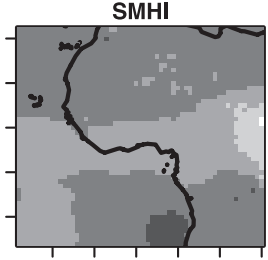

HC

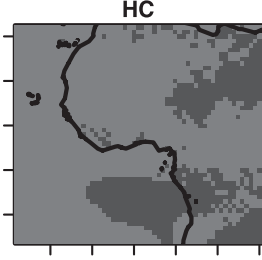

SMHI

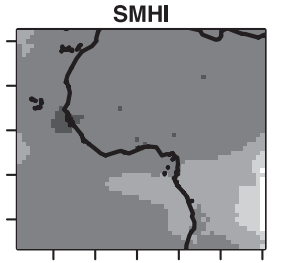

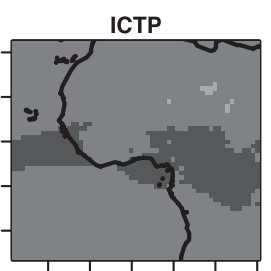

UCLM

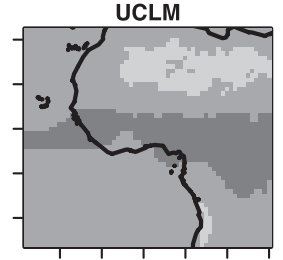

ICTP

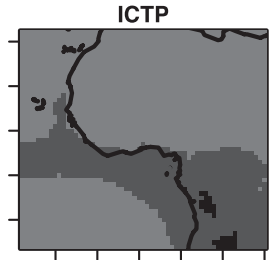

UCLM

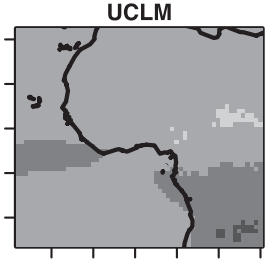

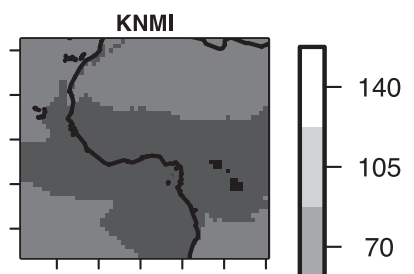
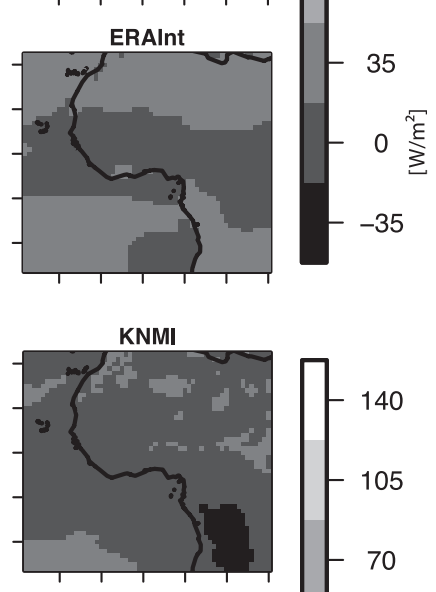

ERAInt

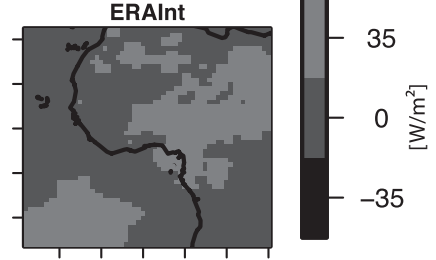

Figure 3.6 As for Figure 3.2, but for TNL and time period 1990-2004

\subsection{INVESTIGATION OF UNCERTAINTY SOURCES}

As presented in section 3.3, the simulated radiation budget components differed substantially from the ERA-Interim and SRB reference data. The parameterization of cloud fraction (CFR), surface albedo (ALB; in the short-wave spectrum), and surface temperature (TS; in the long-wave spectrum) are sources of imprecision in the simulated radiation budget components. In section 3.4.1, we compare the simulated CFR, ALB, and TS in the RCMs against the SRB and ERA-Interim data. Afterward, we look at the impact of errors in CFR, ALB, and TS on net radiation fluxes.

\subsubsection{UNCERTAINTIES OF CLOUD FRACTION, SURFACE ALBEDO, AND SURFACE TEMPERATURE}

Most models overestimated CFR (up to $70 \%$; Figure 3.7), especially over the ocean and in the equatorial region (Figure 3.8). The largest deviations in ALB were in the Sahara and Sahel regions $(\approx-0.3$ to 0.3 ; Figure 3.9). TS showed the highest deviations in central Africa and parts of the Sahara and Sahel (Figure 3.10), but in these areas the reference was also quite uncertain (mean difference between ERA-Interim and SRB data of about $-0.6 \mathrm{~K}$ ). Over the ocean, the model uncertainties of ALB and TS were comparatively low. The small relative mean differences for TS, shown in Figure 3.7, are because of error compensation in space. A visual comparison indicated correlations of uncertainties in CFR, ALB, or TS with misestimations of radiation fluxes. For example, the strong under- and overestimations of SNS in summer over oceanic regions (up to -150 and $80 \mathrm{~W} / \mathrm{m}^{2}$, respectively; see Figure $3.2 \mathrm{a}$ ) seemed to be connected to the strong over- and underestimations of CFR in the same regions (see Figure 3.8). 


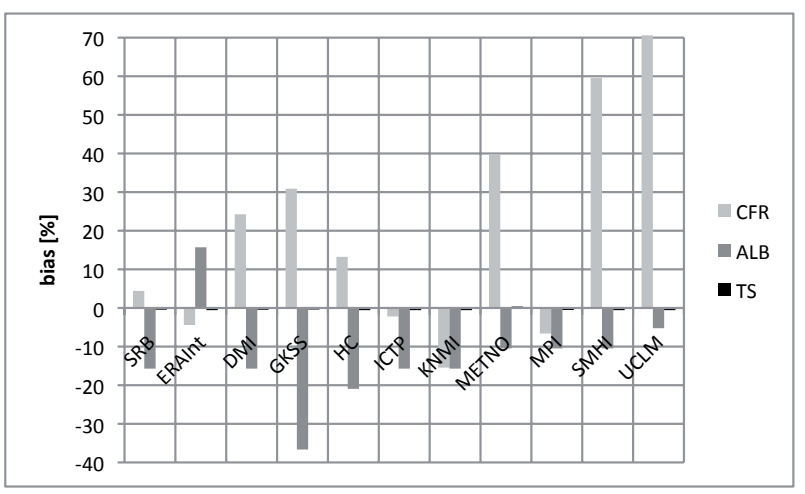

Figure 3.7 Relative differences of observed and biases of simulated CFR, ALB, and TS versus the arithmetic mean of ERA-Interim and SRB $\left(C F R_{\text {ref }}=0.45, A_{\text {ref }}=0.19\right.$, TS $\left._{\text {ref }}=298.96 \mathrm{~K}\right)$ for the time periods and area of investigation

\subsubsection{IMPACT OF CLOUD FRACTION, SURFACE ALBEDO, AND SURFACE TEMPERATURE}

Next, we quantified the impact of uncertainties in CFR, ALB, or TS (denoted as $\triangle$ CFR, $\triangle \mathrm{ALB}$ , and $\triangle T S$ ) on net radiation fluxes. Assuming a linear relationship between errors, the squared correlation coefficient $R^{2}$ is a measure of the explained variance [Ahrens 2003]. The values of explained variance for SNS indicated a strong land-sea contrast, with $\triangle$ CFR being predominant over the ocean. The impact of $\triangle A L B$ and $\triangle C F R$ over land was of equal importance (Figure 3.11, left). The spatial distributions of $R^{2}$ (not shown) gave the largest values for $\triangle A L B$ in the Sahara and Sahel regions (more than $60 \%$ ) and for $\triangle$ CFR over the ocean (especially south of the equator). The explained variances for TNS showed a similar pattern. Thus, in the case of shortwave net radiation, $\triangle A L B$ had a major impact in regions of low CFR, such as the Sahara. Over the ocean (where $\triangle A L B$ was small), the impact of $\triangle A L B$ was low.

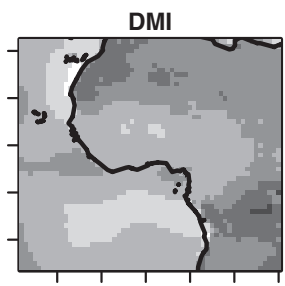

METNO

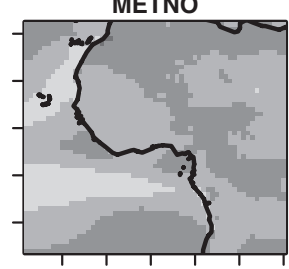

GKSS

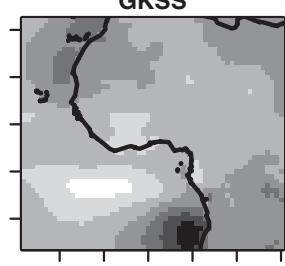

MPI

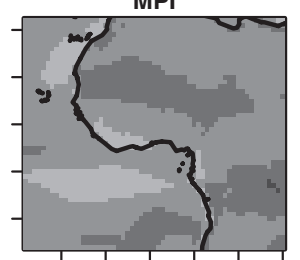

HC

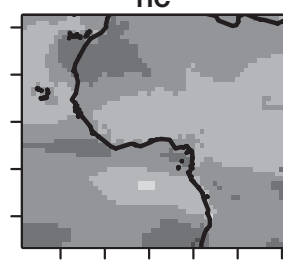

SMHI

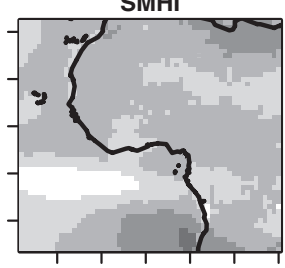

ICTP

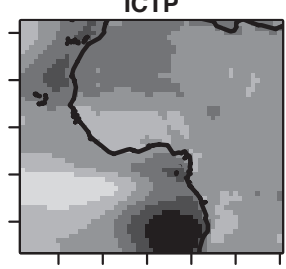

UCLM

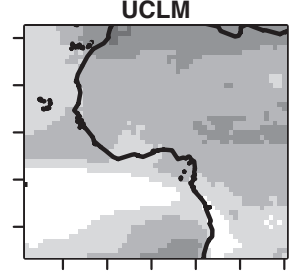

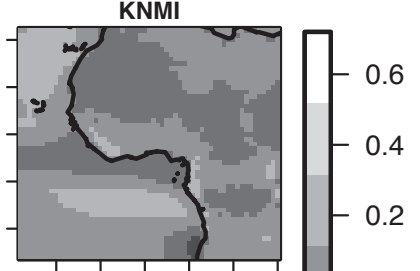

0.0

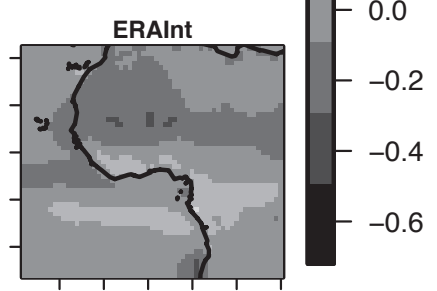

Figure 3.8 Differences in CFR of RCM simulations and ERA-Interim to SRB values for the mean summer (June to August, 1990-2006) 


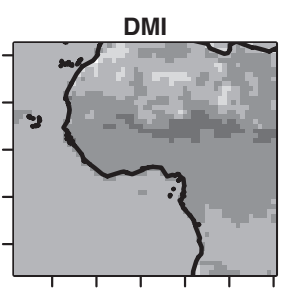

METNO

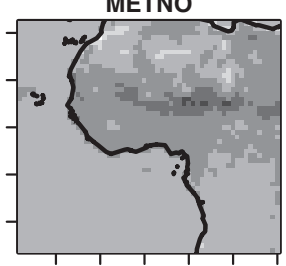

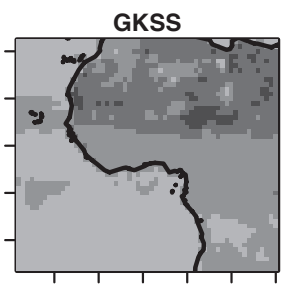

MPI

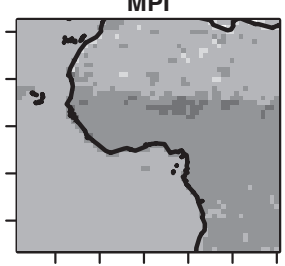

HC

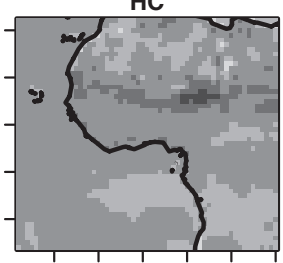

SMHI

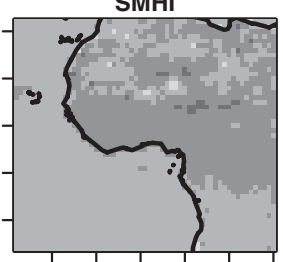

ICTP

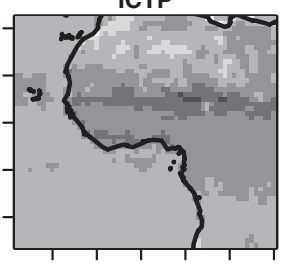

UCLM

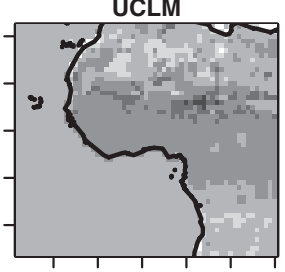

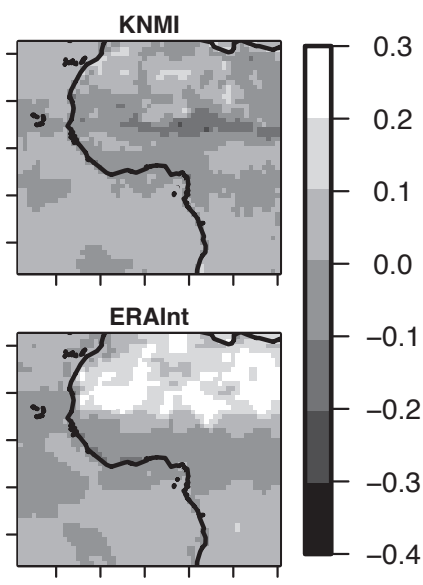

Figure 3.9 As for Figure 3.8, but for ALB

The values of the explained variance for SNL over the ocean indicated a strong impact of $\triangle C F R$ (up to 0.75 ) and a negligible impact of $\Delta T S$ (Figure 3.11). Over land, the impact of these two parameters was similar $(\approx 0.3)$. The highest $R^{2}$ values for $\Delta C F R$ occurred throughout the year over the sea (especially south of the equator), but the values of the explained variance for $\Delta T S$ showed a seasonal cycle, with the highest values in regions with the greatest solar altitude (not shown). The results for the explained variances of TNL were similar to those of SNL, but with clearly smaller $R^{2}$ values, especially for $\triangle$ CFR over the ocean (Figure 3.11). For SNS, TNS, and SNL, the differences in $\mathrm{R}^{2}$ for SRB compared to ERA-Interim were low $( \pm 0.07)$. For $\mathrm{TNL}$, especially $\triangle$ CFR, there were large differences between the two data sets (up to \pm 0.23 over land), which yielded a considerable uncertainty in $\mathrm{R}^{2}$ quantification for TNL.

The sea surface temperatures (SSTs) for most models were prescribed by the ERA-Interim forcing data. The differences between ERA-Interim and model SSTs were within $\pm 0.7 \mathrm{~K}$, and they mainly resulted from interpolation errors. As a result, the explained variances of SNL and TNL for $\triangle T$ S over the ocean were small (Figure 3.11, right) in the case of ERA-Interim. The reason for the deviations of SMHI and UCLM $\left(R^{2}\right.$ SMHI sea SNL/TNL, 0.18/0.24; $R^{2}$ UCLM sea $\mathrm{SNL} / \mathrm{TNL}, 0.08 / 0.13$ ) is that no TS was available for these two model simulations, and the $2 \mathrm{~m}$ air temperature (parameter TAS) was used instead. On a monthly basis, TAS can be presumed to be a sufficient approximation of TS, but, as seen in Figure 3.11, an influence on the results is possible.

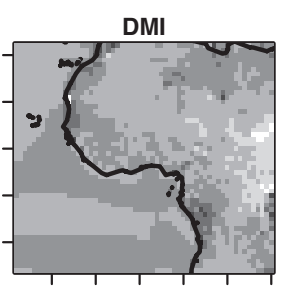

METNO

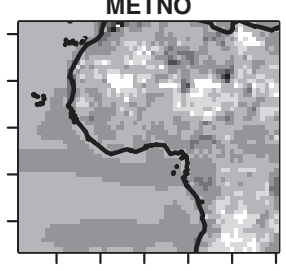

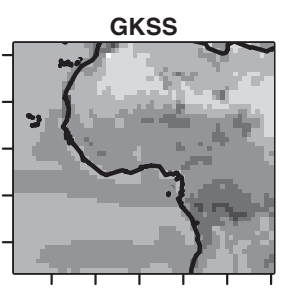

MPI

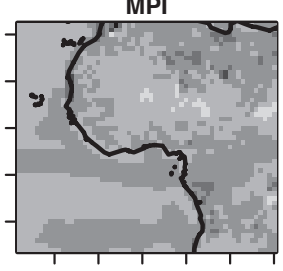

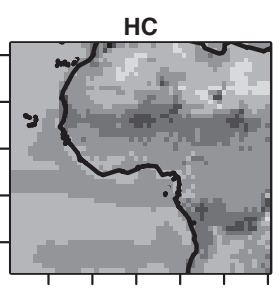

SMHI

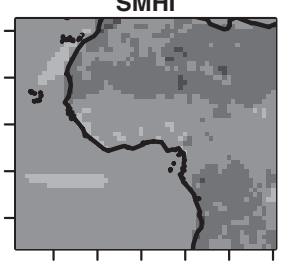

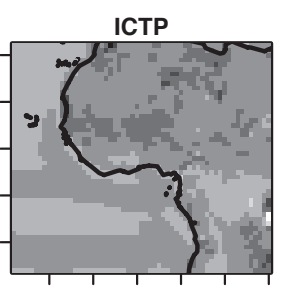

UCLM

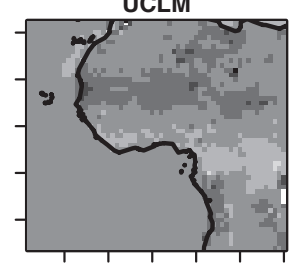

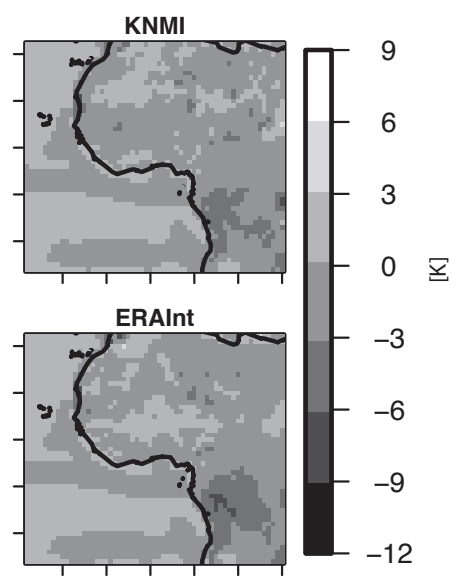

Figure 3.10 As for Figure 3.8, but for TS 
In summary, the impact of $\triangle \mathrm{CFR}$ was small over the Sahara and Sahel regions, which is not surprising because these areas are characterized by very low cloud fractions. However, the relative impact of $\triangle \mathrm{ALB}$ and $\triangle \mathrm{TS}$ over land was generally larger in West Africa than over land in Europe. Kothe et al. [2010] used three models driven by ERA-40 reanalysis data. They found that $\triangle$ CFR was most important (SNS $\mathrm{R}^{2}$ in Europe $\approx 0.43$ and in Africa $\approx 0.23$ ), that $\triangle \mathrm{ALB}$ was of modest importance (SNS $\mathrm{R}^{2}$ in Europe $\approx 0.18$ and in Africa $\approx 0.23$ ), and that $\Delta \mathrm{TS}$ had negligible impact $\left(S N L R^{2}\right.$ in Europe $\approx 0.05$ and in Africa $\approx 0.3$ ). Figure 3.11 shows the average values for Africa and Europe. Figure 3.11 also shows that there were intermodel variations of $\mathrm{R}^{2}$ but that the implications of uncertainties in the explaining variables were highly similar in all model simulations. This figure also illustrates that the sum of explained variances for $\triangle A L B$ (respectively $\triangle T S$ ) and $\triangle$ CFR does not correspond to the explained variance of $\triangle \mathrm{ALB}+\triangle \mathrm{CFR}$ (respectively $\triangle T S+\triangle C F R$ ). This result indicates the interdependences between the impacts of the uncertainty sources of CFR, ALB, and TS.

The bars in Figure 3.11 clearly show the relevance of additional sources of uncertainty. An important example over the Sahara and sub-Saharan Africa is the parameterization of mineral dust [e.g., Nicholson 2000; Yoshioka et al. 2007]. Most of the used RCMs treated aerosols (including mineral dust) as an annual averaged climatology, based on the work of Tanré et al. [1984]. This climatology describes the geographical distributions of a limited number of aerosol types, like urban, sea, land, and desert aerosols. The vertical height profiles of each aerosol type assume an exponential decay of the aerosol concentration through the troposphere or through the stratosphere for stratospheric and volcanic backgrounds [Hohenegger and Vidale 2005].

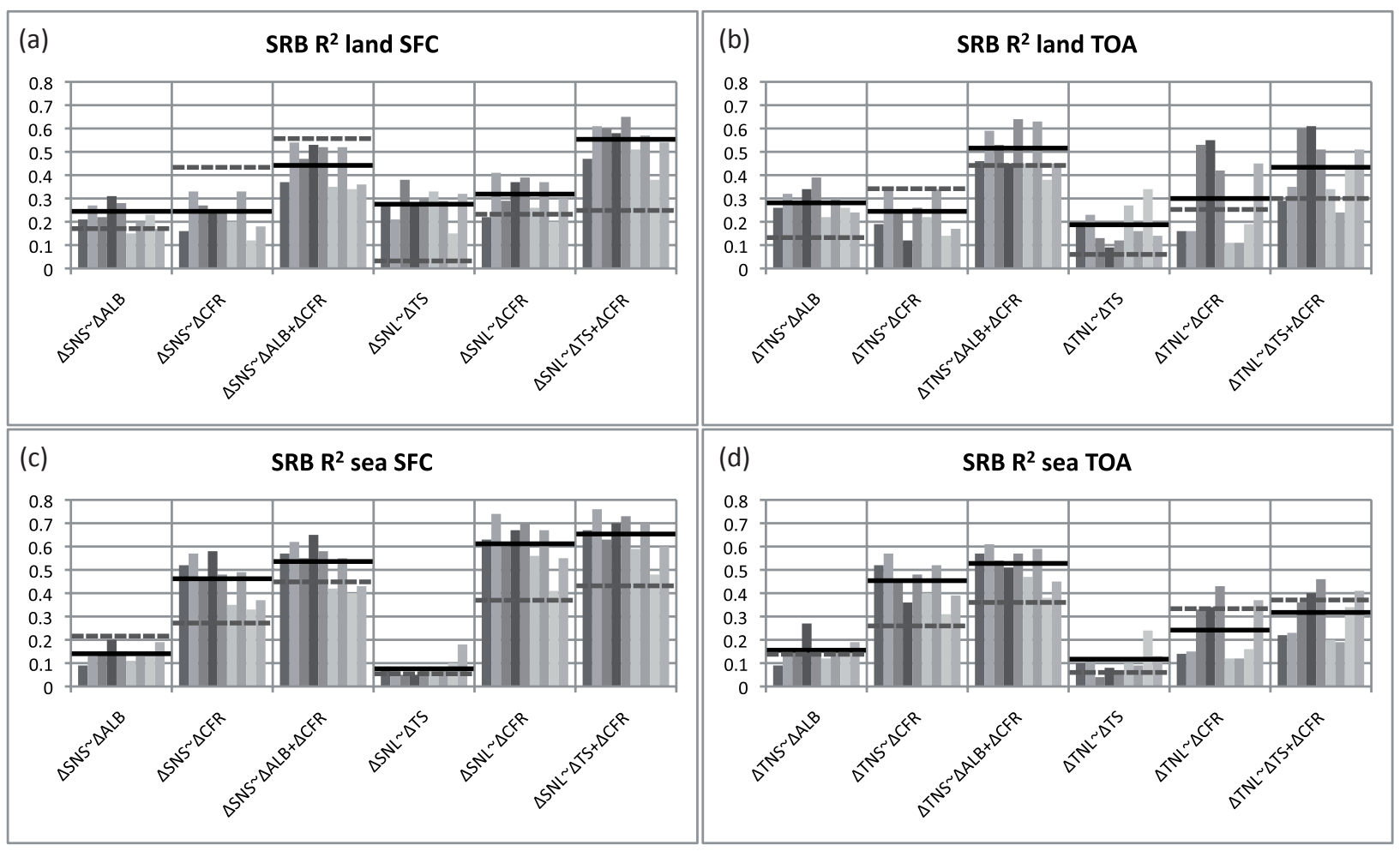

Figure 3.11 Spatially averaged explained variances of radiation errors attributable to $\triangle \mathrm{CFR}, \triangle \mathrm{ALB}$, and $\triangle T S$, and the combinations $\triangle \mathrm{ALB}+\triangle \mathrm{CFR}$ and $\triangle \mathrm{TS}+\triangle \mathrm{CFR}$, for $(\mathrm{a}, \mathrm{b})$ land and $(\mathrm{c}, \mathrm{d})$ oceanic regions. Figures 3.11a and 3.11c show the values at SFC, and Figures 3.11b and 3.11d show the values at TOA. Each shaded column refers to one RCM (in the same sequence as in Table 3.1). The horizontal black lines indicate the means of all model simulations, and dashed lines are the results of three model simulations in Europe [Kothe et al. 2010] 
Therefore, the radiative forcing uncertainty due to the aerosol parameterization probably represents a large part of the unexplained variance in Figure 3.11. Additionally, this study cannot exclude that the dust uncertainty impact is partly interpreted as an albedo uncertainty impact because of the spatial covariability of the dust concentrations and surface albedo. Other influencing factors that were not treated explicitly in this study were, for example, cloud inhomogeneity, cloud microphysics, water vapor, and ozone absorption.

Still, it is especially interesting to note that the uncertainties of ALB had a substantial impact on the radiation budget. Except for snow- and ice-covered surfaces, ALB can be considered, to a large extent, as an external parameter. Compared to CFR and TS, an improved representation of surface albedo might seem a relatively simple goal to achieve. The ENSEMBLES models used different approaches to parameterize ALB. There were RCMs like CCLM, which has a relatively simple parameterization of ALB based on a phenological dependence on soil type, soil moisture, and land use. Other RCMs, like REMO, prescribe the temporal variation of ALB as a function of vegetation phenology on a monthly time scale estimated from remotely sensed data [Rechid et al. 2008]. The difference in ALB parameterization might explain the slightly better results of MPI-REMO compared to GKSS-CCLM, especially regarding the spatial distributions (Figures 3.2 and 3.4). However, GKSS-CCLM and MPI-REMO also differed in the used land surface schemes, which were TERRA-ML [Grasselt et al. 2008] for CCLM and an approach following the work of Dümenil and Todini [1992] for REMO. The cloud fraction was calculated in a similar manner by an empirical function depending on relative humidity and height, but the cloud microphysics schemes in CCLM and REMO were different (based on the work of Kessler [1969] and Lin et al. [1983] for CCLM and Sundquist [1978] for REMO; see Table A3.1).

\section{Conclusions}

One of the goals of the present study was to quantify uncertainties in the short- and longwave components of the radiation budget simulated by several RCMs for West Africa. As references, we used the satellite-based GEWEX SRB and the ERA-Interim reanalysis data sets, which had small differences in mean flux values $\left( \pm 2 \mathrm{~W} / \mathrm{m}^{2}\right)$.

Our comparisons showed considerable uncertainties in the radiation budgets of the RCMs. In most of the investigated models, short-wave net radiation was underestimated in oceanic areas and in parts of the ITCZ and overestimated in the Sahara and Sahel regions. On average, the underestimation was $15.4 \mathrm{~W} / \mathrm{m}^{2}$ for SNS and $12.5 \mathrm{~W} / \mathrm{m}^{2}$ for TNS. In the long-wave spectrum, there was a tendency to overestimate SNL in the Sahel region and to underestimate SNL in central Africa during summer; in winter, the situation was the opposite. These tendencies yielded a small mean error of $3.4 \mathrm{~W} / \mathrm{m}^{2}$ for SNL and a larger mean error of $11.3 \mathrm{~W} / \mathrm{m}^{2}$ for TNL. There was a diversity of sources of radiative flux errors in the simulations, such as the treatment of the different cloud properties, aerosols, surface characteristics, and radiative transfer parameterization. Because of data availability, relative simplicity, and expected importance, we focused on quantifying the impacts of uncertainties in the cloud fraction $(\triangle C F R)$, surface albedo $(\triangle \mathrm{ALB})$, and surface temperature $(\triangle T S)$. We confirmed the relative importance of uncertainties in cloud fraction parameterization. For example, $\triangle$ CFR explains, on average, more than $20 \%$ over land and more than $40 \%$ over the ocean of the error variance in the net solar flux at the surface. The $\triangle T S$ was negligible over the ocean (the SST was prescribed through ERA-Interim), but it was of similar importance as $\triangle$ CFR over land (mean $\mathrm{R}^{2} \approx 0.2$ ). TS is a complex variable in the RCMs and, therefore, errors are not surprising, but the impact on the long-wave radiation budget was still clearly larger than in a former investigation over Europe [Kothe et al. 2010], which indicates the geographical dependence of the error impacts.

An important result is that the uncertainty in the parameterization of ALB in the RCMs was, on average, of similar importance as the $\triangle$ CFR over land. In the Sahara and Sahelian Africa (an area that covers $8 \%$ of the entire global land mass), $R^{2}$ was even larger than $60 \%$. This study cannot exclude that covariable uncertainties (e.g., in the dust parameterization) are partly 
mapped onto the $\triangle A L B$ impact. However, ALB is a particularly simple parameter, and a better representation of ALB in the RCMs yields a parsimonious possibility of improving the modeled radiation budgets of regional climate models for Africa.

\section{Appendix 3.1}

Table A3.1 summarizes the grid configurations and parameterizations applied in the used ENSEMBLES simulations. Because Africa is still a quite new field in regional climate modeling, there might be deficiencies in the model configurations. For example, aerosol parameterization (particularly mineral dust) is expected to be of more importance over desert regions like the Sahara than over Europe, where all of the models were developed. However, most of the RCMs apply only simple climatologies for a few types of aerosols, based on the work of Tanré et al. [1984]. The PROMES model did not even include aerosols for this simulation. Furthermore, the RCMs applied a climatological vegetation parameterization instead of a more sophisticated dynamical vegetation module. 


\begin{tabular}{|c|c|c|c|c|}
\hline & HIRHAM & CCLM & HadRM & RegCM \\
\hline Grid resolution & $0.44^{\circ}(50 \mathrm{~km})$ & $0.44^{\circ}(50 \mathrm{~km})$ & $0.44^{\circ}(50 \mathrm{~km})$ & $50 \mathrm{~km}$ \\
\hline Grid (lon*lat) & - & $115 \times 105$ & $118 \times 115$ & - \\
\hline Vertical levels & 31 & 32 & 19 & 16 \\
\hline Lateral boundarys & Davies [1976] & $\begin{array}{l}\text { Davies [1976], von } \\
\text { Storch et al. [2000] }\end{array}$ & - & Giorgi et al. [1993] \\
\hline Convection & $\begin{array}{c}\text { Mass flux } \\
\text { Tiedtke [1989], } \\
\text { Nordeng [1994] }\end{array}$ & $\begin{array}{c}\text { Mass flux } \\
\text { Tiedtke [1989] }\end{array}$ & $\begin{array}{c}\text { Mass flux } \\
\text { Gregory and } \\
\text { Rowntree [1990], } \\
\text { Gregory and Allen } \\
{[1991]}\end{array}$ & $\begin{array}{l}\text { Mass flux } \\
\text { Grell [1993] }\end{array}$ \\
\hline Microphysics & Sundquist [1978] & $\begin{array}{l}\text { Kessler [1969], } \\
\text { Lin et al. [1983] }\end{array}$ & $\begin{array}{c}\text { Smith [1990], } \\
\text { Jones et al. [1995] }\end{array}$ & Pal et al. [2000] \\
\hline Radiation & $\begin{array}{c}\text { Morcrette [1991], } \\
\text { Giorgetta and Wild } \\
\text { [1995] }\end{array}$ & $\begin{array}{c}\text { Ritter and Geleyn } \\
\text { [1992] }\end{array}$ & $\begin{array}{l}\text { Edwards and } \\
\text { Slingo [1996] }\end{array}$ & $\begin{array}{l}\text { Kiehl et al. [1996], } \\
\text { Giorgi et al. [1999] }\end{array}$ \\
\hline Land surface & $\begin{array}{c}\text { Dümenil and Todini } \\
\text { [1992] }\end{array}$ & $\begin{array}{c}\text { TERRA3D, BATS, } \\
\text { Grasselt et al. } \\
{[2008]}\end{array}$ & $\begin{array}{l}\text { MOSES I, Cox et } \\
\text { al. [1999] }\end{array}$ & $\begin{array}{c}\text { Dickson et al. } \\
\text { [1993] }\end{array}$ \\
\hline Soil thermal layers & 5 & 9 & 5 & - \\
\hline $\begin{array}{l}\text { Soil moisture } \\
\text { layers }\end{array}$ & 1 & - & 1 & 3 \\
\hline
\end{tabular}

Table A 3.1 Summary of grid configurations and most important parameterizations for the used RCMs

1 See also http://www.ecmwf.int/6315publications/library/ecpublications/pdf/tm/001-300/tm295.pdf 


\begin{tabular}{|c|c|c|c|}
\hline RACMO & REMO & $\mathrm{RCA}$ & PROMES \\
\hline $0.44^{\circ}(50 \mathrm{~km})$ & $0.5^{\circ}(55 \mathrm{~km})$ & $0.44^{\circ}(50 \mathrm{~km})$ & $50 \mathrm{~km}$ \\
\hline $114 \times 124$ & $109 \times 121$ & $102 \times 111$ & $123 \times 113$ \\
\hline 40 & 27 & 24 & 28 \\
\hline Davies [1976] & Davies [1976] & Davies [1976] & Davies [1976] \\
\hline $\begin{array}{c}\text { Mass flux } \\
\text { Tiedtke [1989] }\end{array}$ & $\begin{array}{c}\text { Mass flux } \\
\text { Tiedtke [1989], } \\
\text { Nordeng [1994] }\end{array}$ & $\begin{array}{c}\text { Mass flux } \\
\text { Kain and Fritsch [1990] }\end{array}$ & $\begin{array}{c}\text { Mass flux } \\
\text { Kain and Fritsch [1990] }\end{array}$ \\
\hline- & Sundquist [1978] & $\begin{array}{c}\text { Rasch and Kristjansson } \\
\text { [1998] }\end{array}$ & Hsie et al. [1984] \\
\hline Morcrette [1991] & $\begin{array}{c}\text { Morcrette [1989], } \\
\text { Giorgetta and Wild } \\
\text { [1995] }\end{array}$ & $\begin{array}{l}\text { Savijarvi [1990], } \\
\text { Sass et al. [1994] }\end{array}$ & $\begin{array}{l}\text { Anthes et al. [1987], } \\
\text { Stephens [1978], } \\
\text { Garand [1983] }\end{array}$ \\
\hline $\begin{array}{l}\text { TESSEL, van den Hurk } \\
\text { et al. [2000] }{ }^{1}, \\
\text { Balsamo et al. [2009] }\end{array}$ & $\begin{array}{c}\text { Dümenil and Todini } \\
\text { [1992] }\end{array}$ & $\begin{array}{l}\text { RCA land surface } \\
\text { model, } \\
\text { Bringfelt et al. [2001] }\end{array}$ & $\begin{array}{c}\text { SECHIBA, } \\
\text { Ducoudré et al. [1993] }\end{array}$ \\
\hline 4 & 5 & 2 & 7 \\
\hline 4 & 1 & 2 & 2 \\
\hline
\end{tabular}





\section{Chapter 4}

\section{THE WEST AFRICAN MONSOON}

This section shows the investigation of the simulated monsoon in regional climate simulations with COSMO-CLM for Africa. The study is submitted as:.

Kothe S, Lüthi D, Ahrens B (2011) Analysis of the West African Monsoon system in the regional climate model COSMO-CLM. Submitted to Clim Dyn 


\begin{abstract}
The West African Monsoon (WAM) is a major climatic system that has important ecological and socioeconomic impacts. This study investigated the WAM representation in regional climate simulations with the COSMO-CLM model. The regional simulations were driven by present-day climate simulations with the global climate model ECHAM5 and the re-analysis ERA-Interim. The WAM dynamics were quantified by the WAM wind shear index (WAMI). Additionally, total precipitation and outgoing long-wave radiation (an indicator of convective clouds) indices were used to assess monsoon characteristics. Although the mean values of precipitation were satisfactory, COSMO-CLM tended to significantly underestimate precipitation in some regions and overestimate precipitation in other regions. The model also significantly overestimated convective activity. An overestimation of the WAMI indicated a too intense monsoon circulation. It was assumed that a warm bias of the model in the Sahara region led to an excessive Sahara heat low during the monsoon season. By using MODIS based data for the bare soil albedo this warm bias was reduced and the simulation of the WAM improved in the Sahel region, but not in the region used to determine the WAM indices. Precipitation and convective activity, particularly along the African West coast were significantly overestimated in the ECHAM5-driven simulation with higher sea surface temperatures provided by ECHAM5 relative to ERA-Interim re-analysis. Overall, the results were very sensitive to the driving model. At the WAM scale, COSMO-CLM was able to add value to the ECHAM5 simulation, but not to the ERA-Interim data.
\end{abstract}




\subsection{INTRODUCTION}

The West African Monsoon (WAM) is a seasonal wind reversal that is mainly caused by a temperature gradient between the ocean and land surface. High temperatures over the Sahara and Sahel region induce development of a heat low, which initiates a northward displacement of the intertropical convergence zone (ITCZ) and transport of moist air over West Africa. The West African region receives most of its precipitation during the monsoon season (June to September). So, the monsoon has important socioeconomic and ecological impacts.

Observational data indicate a trend for a decrease in the amount of monsoon precipitation in West Africa over the last 30 years [e.g. Nicholson et al. 2000; Le Barbé et al. 2002], but the causes for this change are not well understood. Different climate modeling studies showed that West African climate variability is strongly connected to sea surface temperature anomalies [Rowell et al. 1995; Vizy \& Cook 2002]. Other model studies indicated a relationship between changes in land-use and precipitation [e.g. Charney 1975; Paeth et al. 2005; Abiodun et al. 2008; Paeth et al. 2009; Davin \& de Noblet-Ducoudré 2010]. However, knowledge of the interannual variability in monsoon circulation is limited [e.g. Afiesimama et al. 2006; Maloney \& Shaman 2008]. Thus, in order to make reliable future projections it is essential to improve the understanding of the factors that influence current climate WAM variability.

Global climate models (GCMs) and regional climate models (RCMs) can be useful tools to study relationships within a climate system. In the framework of the West African Monsoon Modeling and Evaluation Project (WAMME), several GCMs and RCMs were evaluated in terms of their simulated WAM characteristics. An analysis of ten WAMME GCMs by Xue et al. [2010] indicated reasonable results for simulations of the spatial distribution of mean precipitation, surface temperature, and wind components, but large discrepancies of the simulated spatial correlation, intensity, and variance of precipitation relative to observations. Phillipon et al. [2010] examined the performance of five coupled GCMs in a simulation of WAM precipitation, zonal and meridional wind, and specific humidity. They found discrepancies, especially in the simulation of precipitation in the Sahel relative to that in Guinea, and suggested that these were connected to a stronger forcing of the sea surface temperature (SST) on precipitation variability over this region. In a study of four GCMs, Losada et al. [2010] found a strong coupling of equatorial Atlantic SST mode and WAM precipitation.

Several earlier studies used GCMs to characterize the WAM [e.g. Cook \& Vizy 2006; Biasutti et al. 2009; Patricola \& Cook 2009], but due to the complex topography and strong gradients in vegetation and land-use in Africa, it is believed that RCMs will give better results than the lower resolution GCMs. Several previous studies have shown that RCMs could be used to model the Indian [e.g. Kumar et al. 2006; Dobler \& Ahrens 2010] and West African monsoon systems [e.g. Druyan et al. 2008; Steiner et al. 2009; Sylla et al. 2009]. Druyan et al. [2010] investigated five RCMs as part of the WAMME initiative and reported different accuracies in the representation of mean summer climate, seasonal mean zonal wind, and meridional moisture advection. They also showed that the RCM results were sensitive to lateral boundary conditions (LBC), especially concerning the SST. Rojas \& Seth [2003] attributed the significant overestimation of precipitation in a RCM simulation over South America to the GCM forcing data. In particular the SST, which is determined by the forcing data in RCMs, seems to be strongly coupled to WAM precipitation [e.g. Rowell et al. 1992; Rowell 2003; Messager et al. 2004]. Kothe \& Ahrens [2010] evaluated the simulated radiation budget over West Africa of several state-of-the-art RCMs, and showed that even for the same forcing data there were large differences among the models. Regarding the strong influence of surface albedo errors on errors in the radiation budget [Kothe \& Ahrens 2010] using a surface albedo parameterization basing on MODIS satellite data is a relatively simple way to improve model simulations [e.g. Liang et al. 2005; Bao \& Lü 2009]. In order to evaluate the results of climate model studies, it is necessary to know the performance of the model in simulating the mean state, the spatial distribution, and the interannual variability.

Studies of the Indian summer monsoon [Wang \& Fan 1999; Dobler \& Ahrens 2010] and the WAM [e.g. Fontaine \& Janicot 1992; Fontaine et al. 2008] showed that certain indices could 
be used to provide a detailed monsoon representation. Thus, to test the ability of the RCM COSMO-CLM to simulate the WAM system, we evaluated the model by using indices based on precipitation, outgoing long-wave radiation, as an indicator for convection, and zonal and meridional wind components. One of our goals was to investigate the ability of COSMO-CLM to improve the representation of the WAM in the applied global forcing data. This is only possible on the scale of the available reference datasets. In the present study, we used two RCM simulations that were driven by re-analysis and GCM forcing data, which differ in the SST and other characteristics. Further, we investigated time series on climatological time scales, which were much longer than that used in the WAMME project (5 yrs). In order to improve some of the model deficiencies, we modified the COSMO-CLM surface albedo parameterization by using MODIS based data for the bare soil albedo.

After introducing the RCM COSMO-CLM, we describe the indices and reference data and their application. In Section 4.4 we present the results, and our conclusions are given in Section 4.5.

\subsection{MOdel AND MODEL SETUP}

The COSMO-CLM (COnsortium for Small-scale MOdeling-Climate Limited-area Model) is a state-of-the-art non-hydrostatic RCM [see http://www.clm-community.eu]. It is the climate version of the COSMO-model [see http://www.cosmo-model.org], which several European weather services use for mesoscale weather forecasting.

In this study we investigated three climate simulations using version 4.8.8 of the COSMOCLM. The setup for these simulations was identical, but two different datasets were used as driving data at the lateral boundaries: (a) the ERA-Interim re-analysis with a resolution of $\approx 0.70^{\circ}$ (T255) for the time period 1989-2008, and (b) ECHAM5 data with a resolution of $\approx 1.88^{\circ}$ (T63) for the time period 1960-2000. The ERA-Interim (European Centre for Medium-range Weather Forecasts Re-Analysis) re-analysis product is a combination of numerical weather prediction model re-forecasting and an assimilation of diverse observational data [Simmons et al. 2006]. The data of the GCM ECHAM5 are from a more general circulation model. The applied ECHAM5 simulation is a coupled atmosphere-ocean experiment, coupled to the MPI-OM ocean model, and was the third run done in the framework of the fourth assessment report of the IPCC [Roeckner et al. 2005]. The computational domain of the COSMO-CLM simulations covered the whole African continent, with a dimension of $214 \times 221$ grid points, 32 vertical layers, and a grid spacing of $0.44^{\circ}$. The domain used for analyses in this study (Fig. 4.1) consists of the computational domain excluding a sponge zone of about ten degrees from the outer boundaries.

For numerical integration, we used a leapfrog scheme with a time step of $150 \mathrm{~s}$. Spectral nudging was not applied. The setup that we used includes a multilayer soil model [Schrodin \& Heise 2002], a radiation scheme [Ritter \& Geleyn 1992], and a Kessler-type microphysics scheme [Kessler 1969] that included ice-phase processes for cloud water, rain, and snow. Convection was parameterized as described by Tiedtke [1989]. Further details on the dynamics and physics of the model are given in Böhm et al. [2006], Steppeler et al. [2003], and in the model documentation [http://www.cosmo-model.org].

The soil albedo in COSMO-CLM is determined as a function of the soil type and the soil water content. To reduce a potential source for errors, we decoupled the bare soil albedo from the soil type by using MODIS based data for the bare soil albedo (for technical details see Appendix 4.1). As soon as a substantial vegetation cover is present the bare soil albedo loses its importance. That is why this kind of bare soil albedo modification is most important in desert regions, like the Sahara. The difference of the new and original surface albedo is illustrated in figure 4.2. Especially in the Sahel, the Sahara and the Arabian peninsula surface albedo values partly increased by more than $50 \%$. 


\subsection{REFERENCE DATA AND INDICES}

Many indices have been used to objectively describe monsoon circulation and quantify its variability. Most of these indices are based on precipitation [e.g. Shukla \& Mooley 1987;

Goswami et al. 1999], but other indices are based on the magnitude of mean summer vertical wind shear [Webster \& Yang 1992], or the outgoing long-wave radiation (OLR) as an indication of convection [Wang \& Fan 1999]. In recent years, there has been discussion about which index is best [e.g. Wang 2000; Lau et al. 2000], but most of this discussion has concerned indices defined for the South Asian summer monsoon. This complicates our choice of indices for the WAM, and limits our ability to make comparisons with previous studies. Indices proposed for the WAM based, for example, on raw OLR data, the moist static energy, or descriptors of atmospheric dynamics, such as relative vorticity in $925 \mathrm{hPa}$ [Fontaine et al. 2007]. Garric et al. [2002] used the Tropical easterly jet index or the monsoon flow index to describe the dynamics of the monsoon region and also defined the Central Sahel monsoon rainfall index. The dynamical normalized seasonality [Li \& Zeng 2002] or the hydrological onset and withdrawal index [Dalu et al. 2008] have also been used as indices for the WAM.

For this study, we chose simple indices based on precipitation, OLR, and zonal and meridional wind components. Due to disagreement in the definition of indices for the WAM, especially concerning the averaging area, we used a combination of previously defined areas [Garric et al. 2002; Afiesimama et al. 2006; Janicot et al. 2008]. Although there were differences in the characteristics of the monsoon precipitation in the Sahel and Guinea Coast regions (apparent as the number of maxima in annual precipitation), we used one single domain for all indices in order to allow comparisons. The area we used extends from $18^{\circ} \mathrm{W}$ to $15^{\circ} \mathrm{E}$ and $4^{\circ} \mathrm{N}$ to $20^{\circ} \mathrm{N}$ (Fig. 4.1), and we obtained all WAM indices by averaging the relevant data over this area. The precipitation index was calculated as the sum, and the other indices as the mean values over the monsoon season, June to September (JJAS).

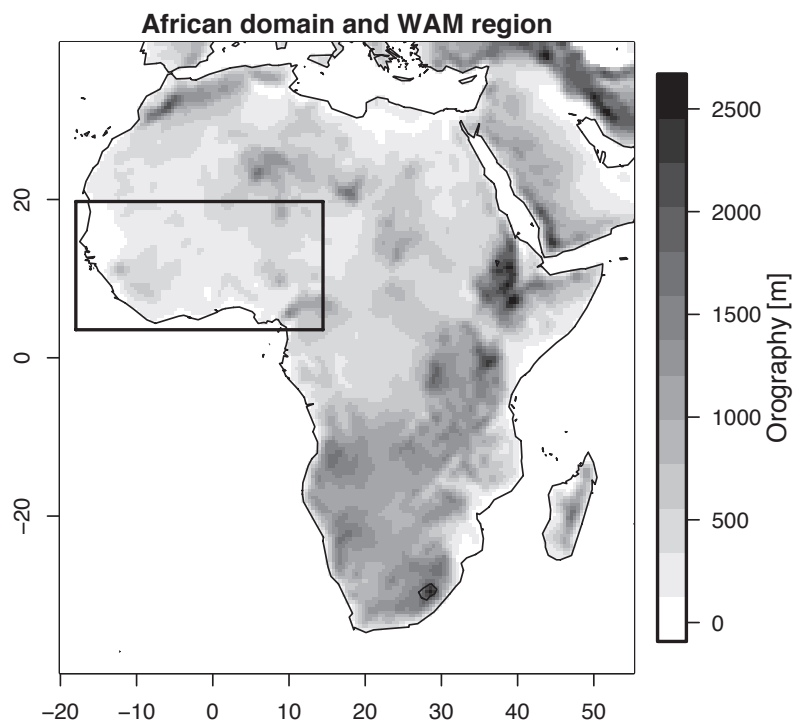

Figure 4.1 Orography for the model domain and area used for calculation of the different indices 


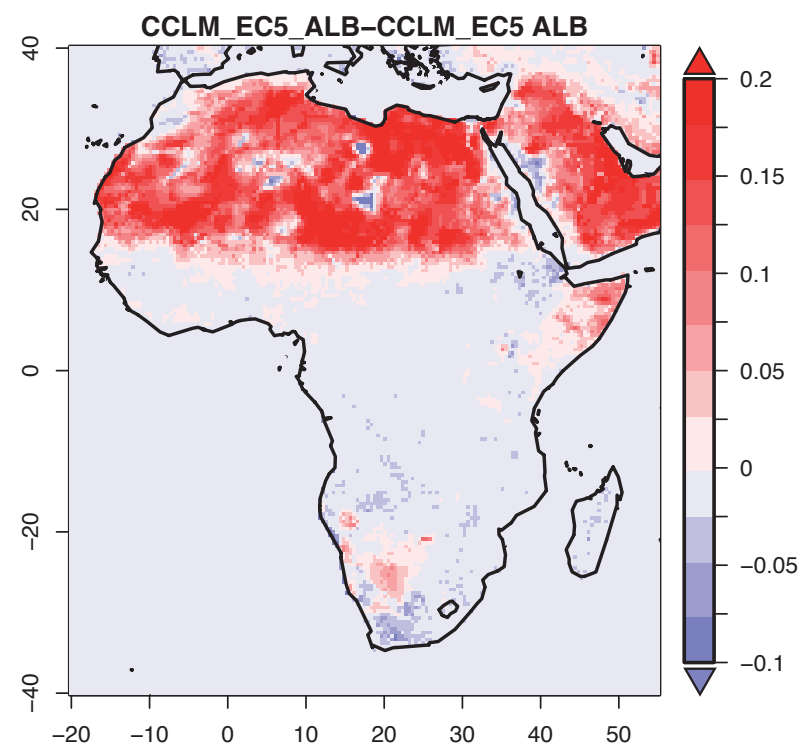

Figure 4.2 Spatial difference of mean surface albedo for the monsoon season (JJAS) for CCLM_EC5_ ALB - CCLM_EC5 1961-2000

\subsubsection{Precipitation}

We used the Global Precipitation Climatology Centre (GPCC) data product version 4 [Schneider et al. 2008] as the reference dataset for precipitation. GPCC provides a dataset of globally gridded rain gauge measurements with a spatial resolution of $0.5^{\circ}$. Dinku et al. [2008] compared this dataset over complex terrain in Africa with other globally gridded precipitation data and reported a strong agreement among datasets, with the best performance in the wet season (June to August). However, inclusion of satellite-based datasets by Negrón Juárez et al. [2009] showed that the long-term domain averages of the datasets differed by $22 \%$ in the Congo basin. This indicates an influence of the relatively low rain gauge density in Africa on uncertainty of the GPCC dataset.

\subsubsection{OUtGoING LONG-WAVE RADIATION (OLR)}

We used OLR as a measure of convection. Due to the low cloud-top temperature of high convective clouds, a low OLR value indicates high convective activity [Wang \& Fan 1999; Fontaine et al. 2008]. As a reference for OLR, we used the NASA/GEWEX SRB (Surface Radiation Budget) dataset (release 2.5, July 1983 to June 2005), a satellite-based dataset of $3 \mathrm{~h}$ short- and long-wave radiation components at the surface and top-of-atmosphere on a $1^{\circ} \mathrm{global}$ grid [Gupta et al. 2006; Zhang et al. 2007].

\subsubsection{MERIDIONAL AND ZONAL WIND COMPONENTS}

The West African Monsoon Index (WAMI) can be used to diagnose the West African monsoon cell circulation [Fontaine \& Janicot 1992; Fontaine et al. 2008]. Thus, a higher WAMI represents an enhanced southwesterly monsoon flux and a stronger Tropical Easterly Jet. Based on Fontaine et al. [2008], the WAMI is calculated as follows:

$$
\mathrm{WAMI}=\mathrm{Z}\left(\sqrt{\mathrm{U} 925^{2}+\mathrm{V} 925^{2}}\right)-\mathrm{Z}(\mathrm{U} 200)
$$


$\mathrm{U}$ and $\mathrm{V}$ denote the zonal and meridional wind components. In this study the standardization $Z$ was performed using the mean $\mu_{\text {NCEP }}$ and standard deviation $\sigma_{\text {NCEP }}$ of the NCEP reference at $925 \mathrm{hPa}$ or rather $200 \mathrm{hPa}$.

$$
Z=\frac{X-\mu_{\text {NCEP }}}{\sigma_{\text {NCEP }}}
$$

We used the re-analysis product of the National Centers for Environmental Prediction/ National Center for Atmospheric Research (NCEP/NCAR) [Kalnay et al. 1996] as reference data for the $925 \mathrm{hPa}$ and $200 \mathrm{hPa}$ meridional and zonal winds. The variables were derived for the time period 1961-2000, with a horizontal resolution of $2.5^{\circ}$. The NCEP re-analysis output variables were classified into four categories, depending on the relative influence of the observational data and model on the gridded variable [Kalnay et al. 1996]. The wind fields were classified as "category A files", which are highly influenced by observations and can be considered to be the most reliable class of NCEP output variables. A comparison of wind profile observations and NCEP re-analysis indicated good agreement at sites where nearby rawinsonde observations were assimilated into the NCEP re-analysis, but discrepancies when no rawinsonde observations were available [Schafer et al. 2003].

NCEP and ERA-Interim wind fields base on similar data sources, which is why we did not expect COSMO-CLM to perform better than ERA-Interim in comparison to NCEP data. However, the application of NCEP data instead of ERA-Interim ensures data independence as much as possible.

\subsection{ResULtS}

We investigated ECHAM5 and ERA-Interim driven COSMO-CLM Africa simulations (CCLM_EC5 and CCLM_ERA, respectively) in terms of mean values of indices, interannual variability of indices (represented by the standard deviation), spatial distribution of applied quantities, and temporal correlation of indices. To examine the impact of the modified bare soil albedo parameterization on the WAM, the analysis included an ECHAM5 driven COSMO-CLM simulation (CCLM_EC5_ALB), which used this albedo modification. We used Taylor diagrams [Taylor 2001], which quantify the similarity between patterns by correlation, centered rootmean-square difference (RMS), and amplitude of variation (represented by standard deviation), to summarize the match of model patterns and observations. In this analysis, we interpolated the specified data fields to the horizontal resolution of the appropriate reference datasets (i.e., $0.5^{\circ}$ for precipitation, $1^{\circ}$ for OLR, $2.5^{\circ}$ for wind fields). All comparisons were performed for monthly mean values or climatological means covering the monsoon periods (JJAS) of 1961 to 2000 for precipitation and wind fields, and of 1984 to 2000 for OLR. The values for ERAInterim and ERA-Interim driven COSMO-CLM simulation were derived from the period of 1990 to 2008. A simple estimation of the impact of using different averaging time periods (1961 to 2000 compared to 1990 to 2008) indicated that spatiotemporal climatological means, temporal standard deviations, and spatial correlations were comparable, with relatively small uncertainty limits $( \pm 5 \%$ for mean values, $\pm 11 \%$ for standard deviations, $\pm 0.3 \%$ for spatial correlations). In that analysis, we did a random sampling of a 19-year time series from the 40-year ECHAM5 resp. CCLM_EC5 time series, and examined changes in the mean, standard deviation, and spatial correlations. The GPCC precipitation dataset was available for the time period of 1961 to 2008 and allowed a direct comparison of different averaging periods. The mean and standard deviation of the GPCC PI time series were $136.2 \mathrm{~mm}$ and $30.3 \mathrm{~mm}$ for 1961 to 2000 , and $133.5 \mathrm{~mm}$ and $29.9 \mathrm{~mm}$ for 1990 to 2008 . In this case the difference was $2.0 \%$ for the mean and $1.3 \%$ for the standard deviation. 


\subsubsection{Precipitation Index (PI)}

Table 4.1 shows the means and standard deviations of the PI for the GPCC reference, the CCLM_EC5, CCLM_EC5_ALB and CCLM_ERA data, and the corresponding driving models (ECHAM5 and ERA-Interim). CCLM_EC5, with an underestimation of about $8.5 \%$, was closest to the reference, and CCLM_ERA had the lowest PI value. The temporal standard deviation of CCLM_EC5 was also very close to the reference, and CCLM_ERA had the highest difference relative to the GPCC reference. In the COSMO-CLM simulations, the interannual variability (temporal standard deviation) was underestimated, but the driving models overestimated this variability. Compared to CCLM_EC5 PI mean and interannual variability decreased for CCLM_EC5_ALB.

Figure $4 . \overline{3}$ shows the mean monsoon precipitation (JJAS, 1961-2000 resp. 1990-2008 for CCLM_ERA) of CCLM_EC5, CCLM_EC5_ALB, CCLM_ERA, and the differences of the simulations and the GPCC reference. The $\overline{C O S M O-C L M}$ appeared to capture the main structures, with the greatest precipitation (more than $2000 \mathrm{~mm}$ ) at the coast of Cameroon and Nigeria, along the coast of Guinea and Sierra Leone, and in the Ethiopian Highlands. The main precipitation area (more than $1000 \mathrm{~mm}$ ) was between the equator and $10^{\circ} \mathrm{N}$. However, the difference plots indicate that both simulations underestimated precipitation by more than $50 \%$ for large areas on the West coast and Central Africa. In both model simulations, the extension of the main precipitation area was too far north, and this led to a significant overestimation of precipitation in parts of the Sahel. For CCLM_EC5_ALB this overestimation was reduced.

Figure 4.4 shows the similarity of spatial patterns in terms of correlation, centered RMS, and standard deviation. Use of CCLM_EC5 resulted in a slight improvement relative to the driving model, with an increased correlation and lower RMS, while CCLM_ERA compared to ERA-Interim showed no significant improvement. CCLM_EC5_ALB spatial correlation and RMS slightly decreased compared to CCLM_EC5, but had good match with the GPCC spatial standard deviation.

\begin{tabular}{lccc}
\hline & PI $[\mathrm{mm}]$ & OLRI $\left[\mathrm{W} / \mathrm{m}^{2}\right]$ & WAMI $\times 100[1]$ \\
\hline Reference & $136(30)$ & $254(12)$ & $-0(106)$ \\
ERA & $124(32)$ & $264(11)$ & $-33(87)$ \\
CCLM_ERA & $113(25)$ & $224(9)$ & $109(103)$ \\
ECHAM5 & $116(31)$ & $232(12)$ & $-0(85)$ \\
CCLM_EC5 & $125(30)$ & $219(11)$ & $57(92)$ \\
CCLM_EC5_ALB & $116(26)$ & $225(13)$ & $55(92)$ \\
\hline
\end{tabular}

Table 4.1 Mean and standard deviations of the time series (in brackets) of monsoon indices for the monsoon season (JJAS) and corresponding time periods 
(a)

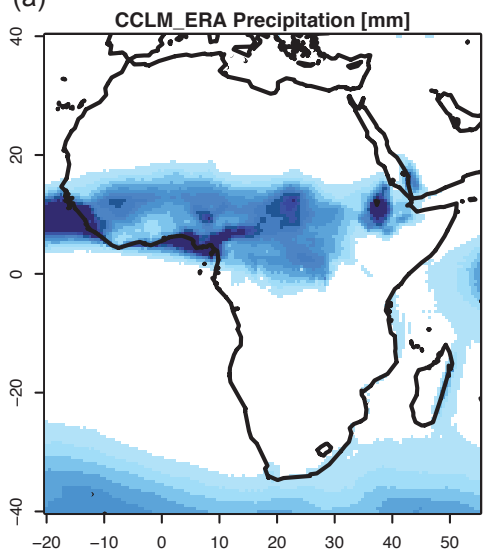

(d)

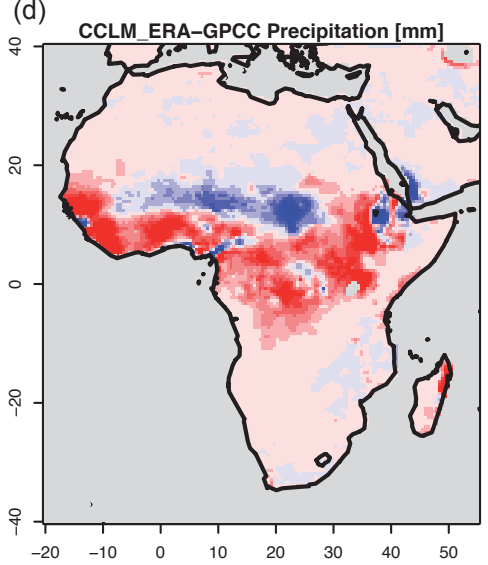

(b)

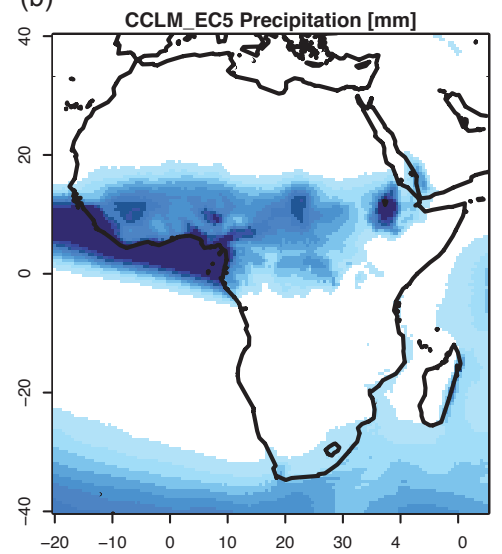

(e)

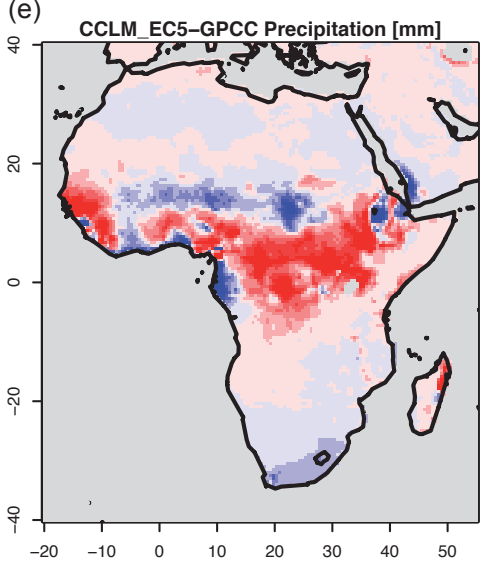

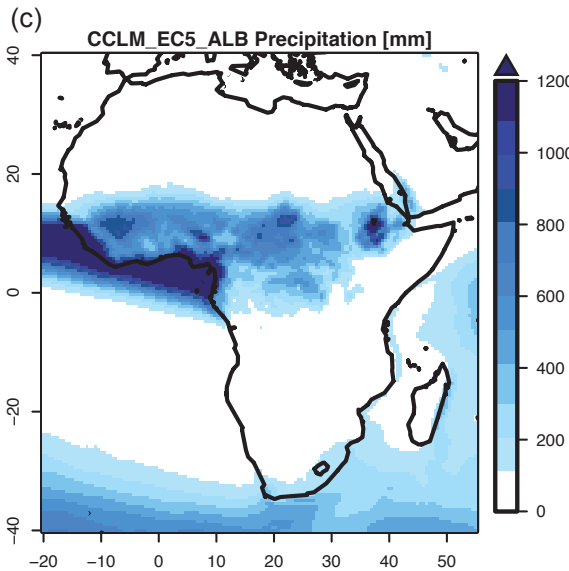

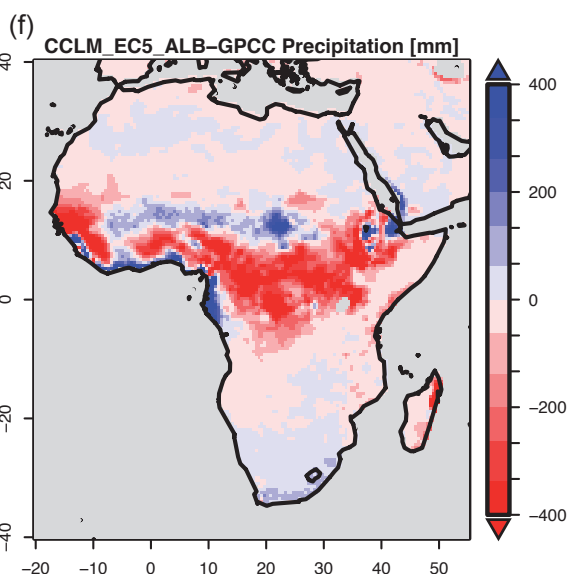

Figure 4.3 Spatial distribution of mean precipitation for the monsoon seasons (JJAS) for (a) CCLM_EC5 1961-2000, (b) CCLM ERA 1990-2008, (c) CCLM EC5 ALB 1961-2000, and the corresponding differences for GPCC 1961-2000: (d) CCLM_EC5 - GPCC, (e) CCLM_ERA - GPCC, (f) CCLM_EC5_ALB GPCC

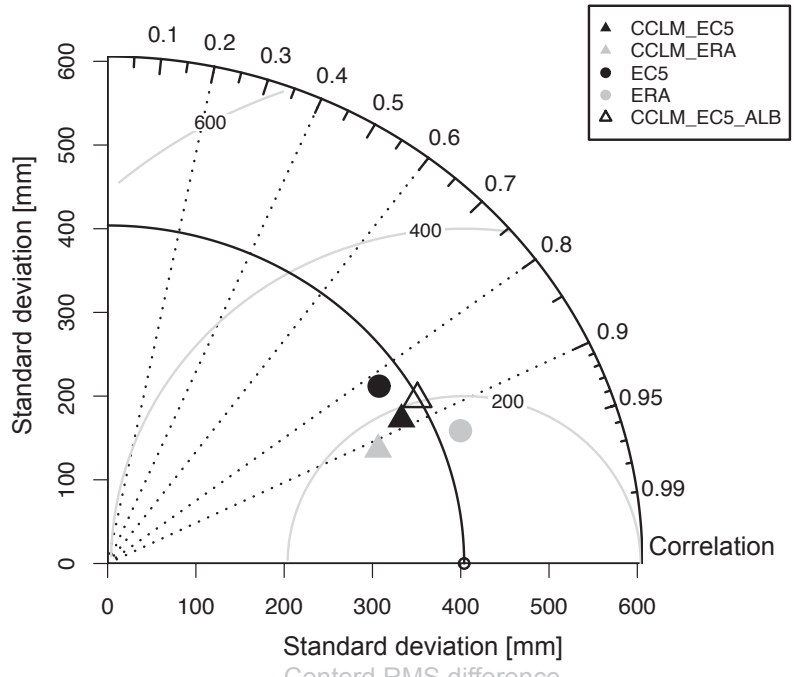

Figure 4.4 Analysis of the spatial precipitation patterns within the WAM area using a Taylor diagram for GPCC and different models 


\subsubsection{OUtGoING LONG-WAVE RADIATION INDEX (OLRI)}

We used OLR data as an indication of convection, with low values corresponding to high convective activity. Table 4.1 summarizes the spatiotemporal means and temporal standard deviations of the OLRI. To be consistent with the PI, only land pixels were considered in the averaging. For the OLRI, the driving models were closer to the reference than the simulations; there was a slight underestimation of convective activity by ERA-Interim and an overestimation by ECHAM5. CCLM_EC5 and CCLM_ERA clearly overestimated convective activity relative to the SRB and driving models. We obtained similar results for interannual variability, which was closer to the reference for the driving models. The temporal variability of these both COSMOCLM simulations was too low compared to SRB. For the CCLM_EC5_ALB simulation the overestimation of convection slightly reduced and the temporal variability of OLRI increased relative to CCLM_EC5.

Figure 4.5 shows the spatial distributions of OLR for the monsoon period (JJAS, 19842000 for CCLM_EC5 and CCLM_EC5_ALB resp. 1990-2008 for CCLM_ERA) of CCLM_EC5, CCLM_EC5_ALB, CCLM_ERA, and the corresponding differences (model - SRB reference). All model simulations (Figs. 4.5a, 4.5b and 4.5c) captured the main structural features of the SRB reference (not shown), but in the northern tropics, both simulations clearly had lower OLR values. CCLM_EC5 significantly overestimated convective activity at offshore Cameroon and Nigeria by up to $80 \mathrm{~W} / \mathrm{m}^{2}$ (Fig. 4.5e). CCLM_ERA captured convection better than CCLM_EC5. Consistent with the results for precipitation, CCLM_EC5 and CCLM_ERA simulated the

(a)

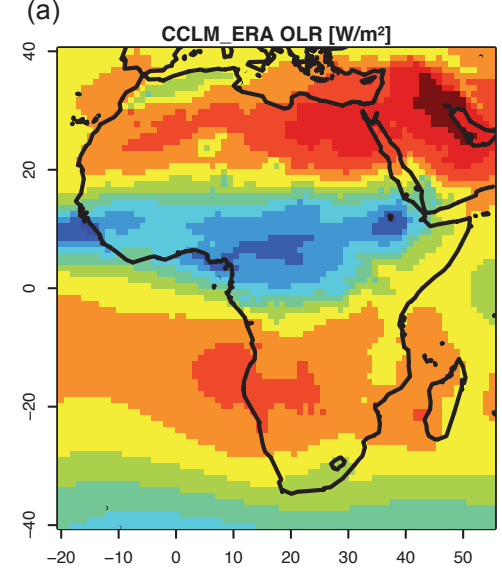

(d)

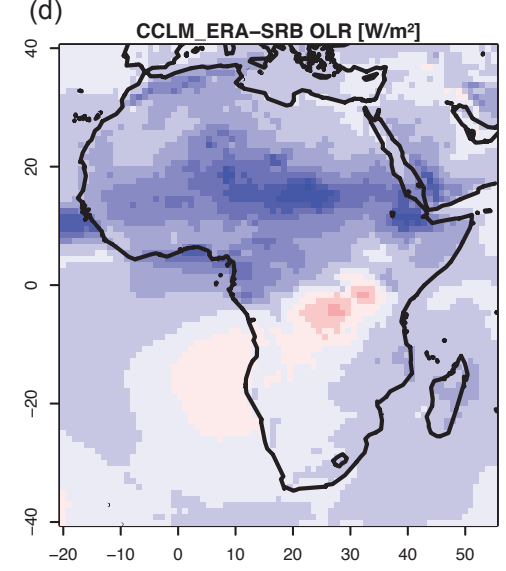

(b)

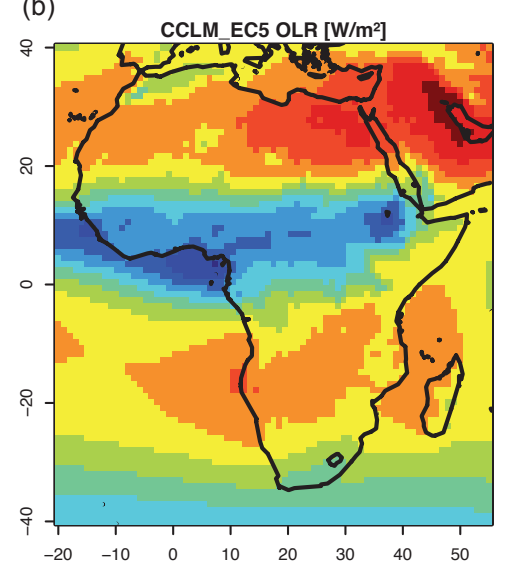

(e)

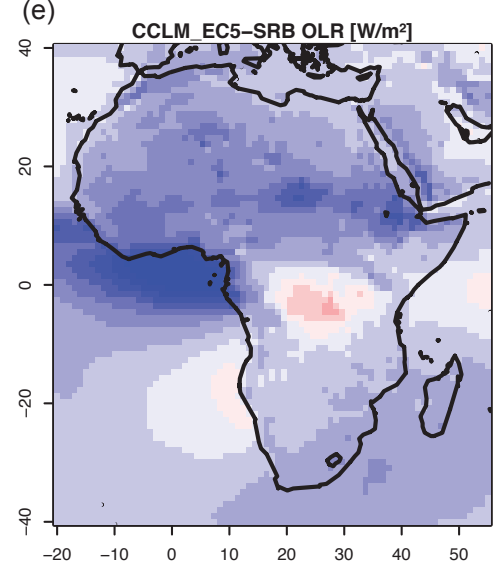

(c)

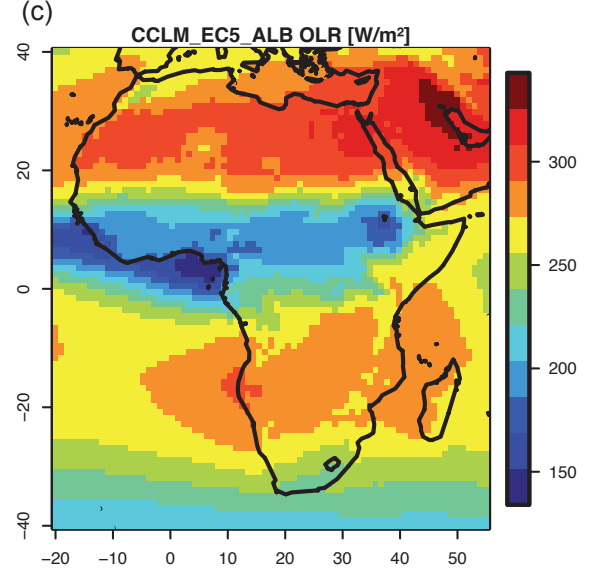

(f)

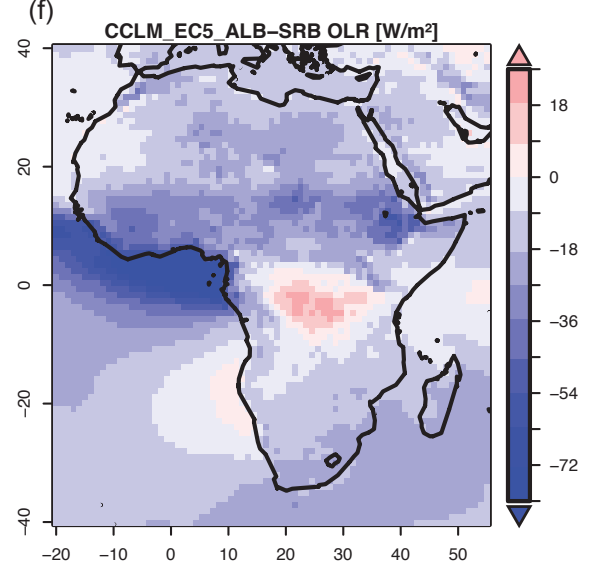

Figure 4.5 Spatial distribution of mean OLR for the monsoon seasons (JJAS) for (a) CCLM_EC5 19842000, (b) CCLM_ERA 1990-2008, (c) CCLM_EC5_ALB 1984-2000, and the corresponding differences for SRB 1984-2000: (d) CCLM_EC5 - SRB, (e) CCLM_ERA - SRB, (f) CCLM_EC5_ALB - SRB 
displacement of monsoon-related convection too far north, resulting in an overestimate of convective activity in the Sahel region. For CCLM_EC5_ALB the overestimation of convection offshore the Guinean coast was slightly enhanced, but the overestimation over land was reduced, especially in the West Sahara and Sahel by up to $20 \mathrm{~W} / \mathrm{m}^{2}$. The increase in OLR in the Sahel and Sahara despite decreasing temperatures is explained by a simultaneous decrase in total cloud cover in these regions by up to $35 \%$.

The Taylor diagram (Fig. 4.6) summarizes the spatial match relative to the SRB OLR. Compared to the driving model, the spatial variability and the RMS of CCLM_EC5 worsened, whereas CCLM_ERA had slightly better results than ERA-Interim. CCLM_ERA was relatively close to SRB, with a correlation of 0.96 , standard deviation of $28 \mathrm{~W} / \mathrm{m}^{2}$, and RMS of $6 \mathrm{~W} / \mathrm{m}^{2}$. Relative to CCLM_EC5, CCLM_EC5_ALB showed a strong decrease in spatial variability by about $10 \mathrm{~W} / \mathrm{m}^{2}$.

Figures 4.7a and 4.7b illustrate SRB and CCLM_EC5 for days with high convective activity $\left(O L R<180 \mathrm{~W} / \mathrm{m}^{2}\right)$ during the monsoon period (JJAS) of 1984-2000. These figures show that COSMO-CLM clearly overestimated the extension of the high convective activity region and the number of days with OLR $<180 \mathrm{~W} / \mathrm{m}^{2}$. This is especially true over the ocean, where CCLM EC5, relative to SRB, overestimated the days with high convective activity by a factor of up to 10 .

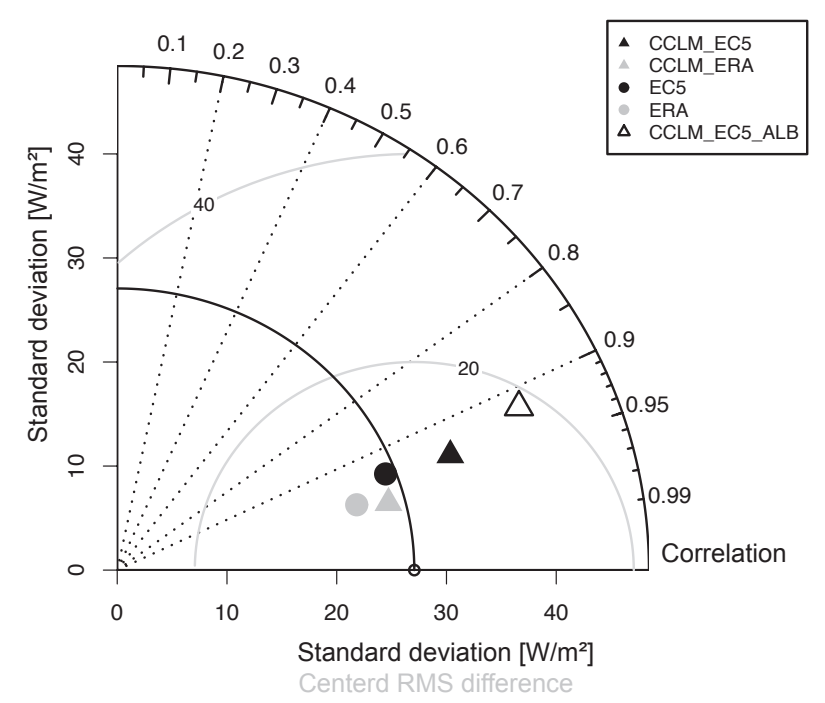

Figure 4.6 Analysis of the spatial OLR patterns within the WAM area using a Taylor diagram for SRB and different models 
(a)

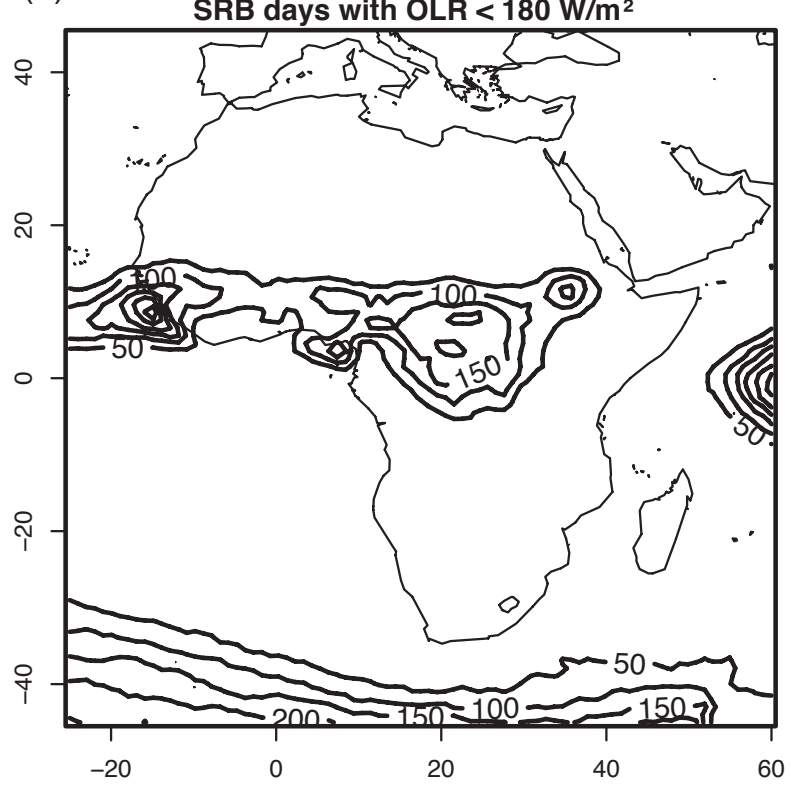

(b)

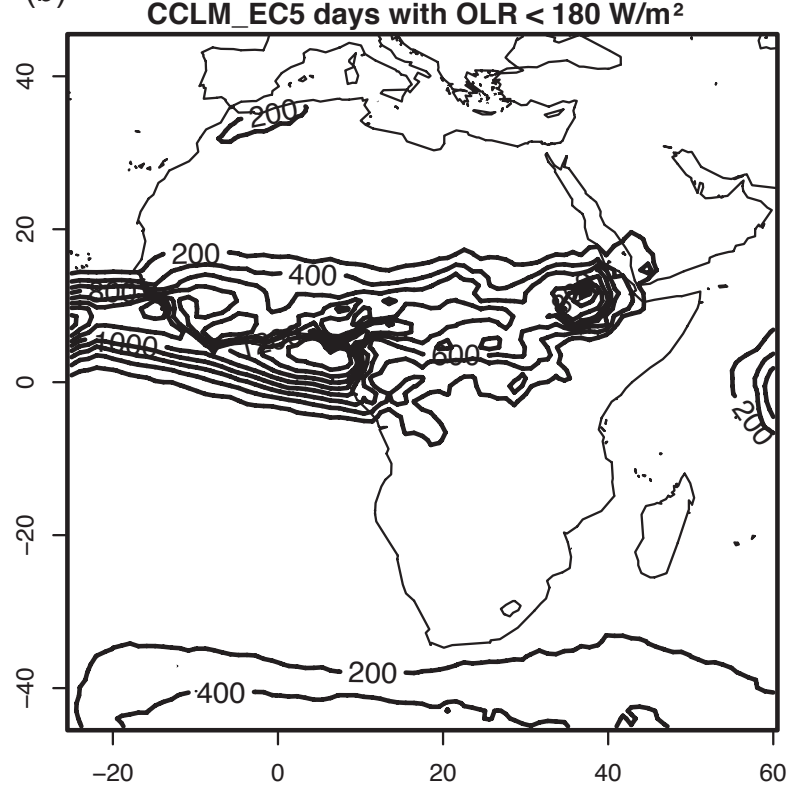

Figure 4.7 Number of days with OLR $<180 \mathrm{~W} / \mathrm{m}^{2}$ in SRB (a) and CCLM_EC5 (b) for the monsoon seasons (JJAS) of 1984-2000

\subsubsection{West African monsoon index (WAmi)}

For averaging the WAMI, we only considered land pixels. Table 4.1 shows the means and standard deviations of the calculated WAMI for all datasets. Both COSMO-CLM simulations strongly overestimated the WAMI compared to the NCEP reference, whereas the overestimation of CCLM_ERA was about twice as much as for CCLM_EC5. For ECHAM5 the WAMI was very close to the NCEP reference, but not for ERA-Interim. Both driving models underestimated the WAMI interannual variability (represented as standard deviation). The interannual variability was best captured by CCLM_ERA. NCEP and ERA-Interim are re-analysis products, and therefore strongly influenced by observational data. Thus, we expected that ERA-Interim would agree well with NCEP. Hence, the bad agreement of NCEP and ERA-Interim indicates a relatively high uncertainty of the reference. Compared to CCLM_EC5 the WAMI remained almost unchanged for CCLM_EC5_ALB.

The main moisture transport in the African monsoon region is in lower levels of the troposphere. Figure 4.8 shows the $925 \mathrm{hPa}$ zonal wind for CCLM_EC5, CCLM_EC5_ALB, CCLM_ ERA, and the corresponding differences (model - NCEP reference). The model simulations simulated the main spatial structures very well, but the values in many regions exceeded the $925 \mathrm{hPa}$ zonal wind of the NCEP reference. Figures $4.8 \mathrm{~d}$ and $4.8 \mathrm{e}$ show that the differences are greatest in the WAM region, with some differences more than $6 \mathrm{~m} / \mathrm{s}$. Thus, the COSMO-CLM overestimated the west-east component of the $925 \mathrm{hPa}$ wind. The results of CCLM_EC5_ALB were very similar to CCLM_EC5, but with a slight improvement relative to the reference of about $1 \mathrm{~m} / \mathrm{s}$ in the Sahel region.

Figure 4.9 shows that for the spatial pattern of the WAMI ERA-Interim was closest to the NCEP reference, with a correlation of 0.94. The correlation of CCLM_ERA and NCEP was smaller (0.87). The correlation for CCLM_EC5 and ECHAM5 was similar with 0.79, but for standard deviation and RMS CCLM_EC5 yielded better results. Thus, in case of CCLM_EC5, use of the COSMO-CLM did improve the driving model at the scale of investigation. Such an improvement was not found for CCLM_ERA. Relative to CCLM_EC5 there was a slight improvement in spatial correlation and RMS for CCLM_EC5_ALB. 
(a)

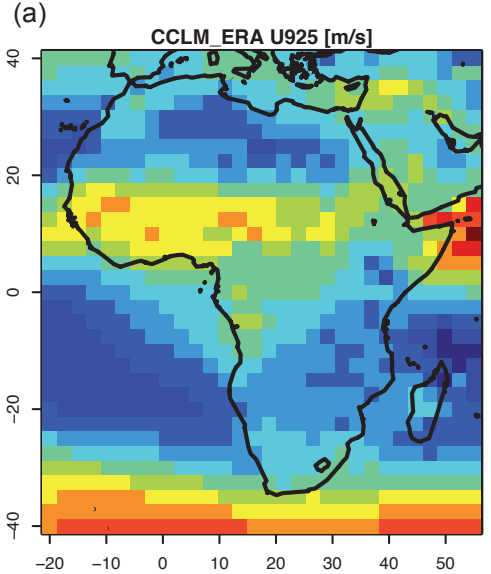

(d)

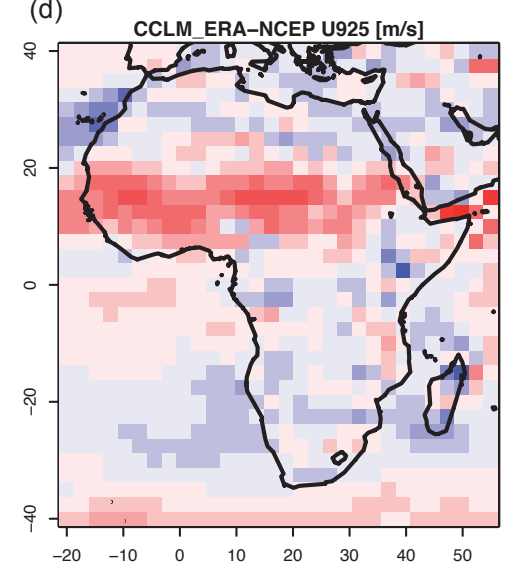

(b)

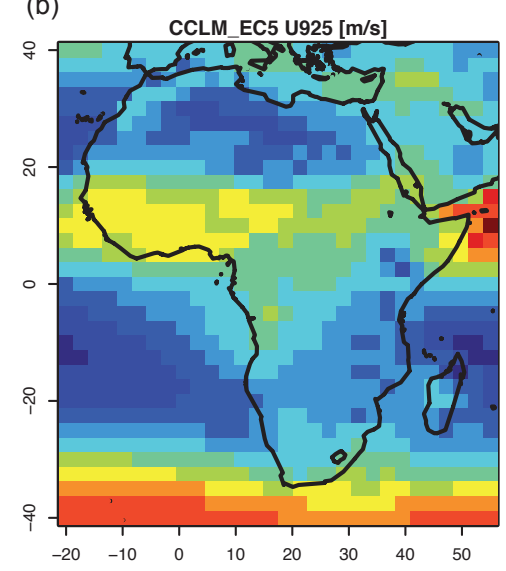

(c)

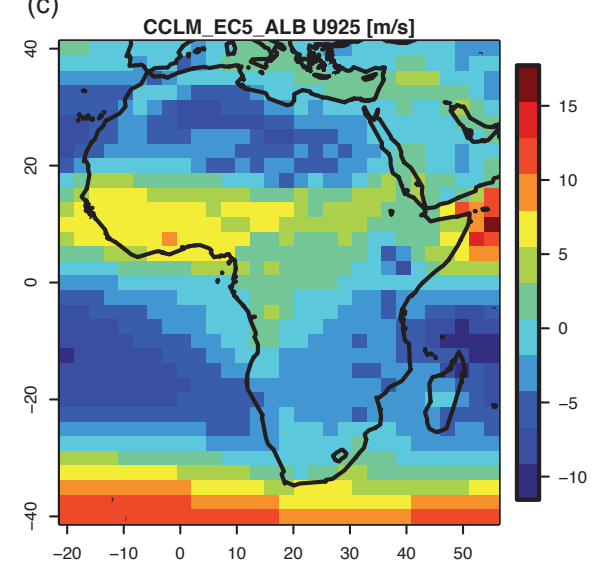

(e)

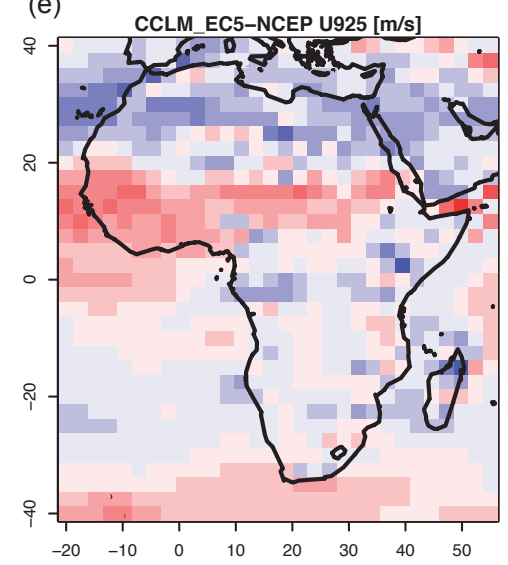

(f) CCLM_EC5_ALB-NCEP U925[m/s]

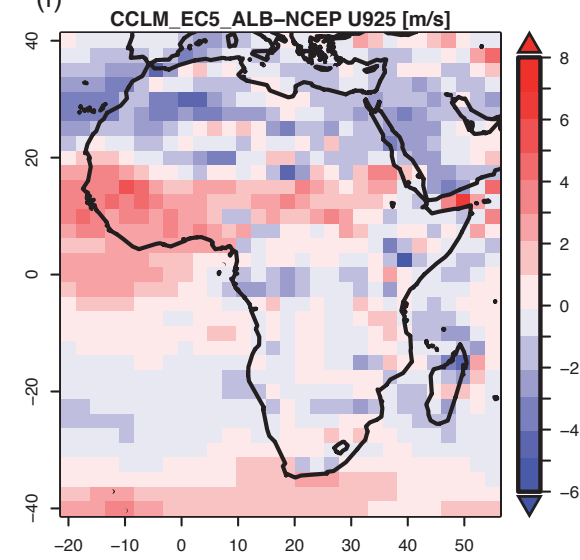

Figure 4.8 Spatial distribution of mean $925 \mathrm{hPa}$ zonal wind for the monsoon seasons (JJAS) for (a) CCLM_EC5 1961-2000, (b) CCLM_ERA 1990-2008, (c) CCLM_EC5_ALB 1961-2000, and the corresponding differences for NCEP 1961-2000: (d) CCLM_EC5 - NCEP, (e) CCLM_ERA - NCEP, (f) CCLM_EC5 - NCEP

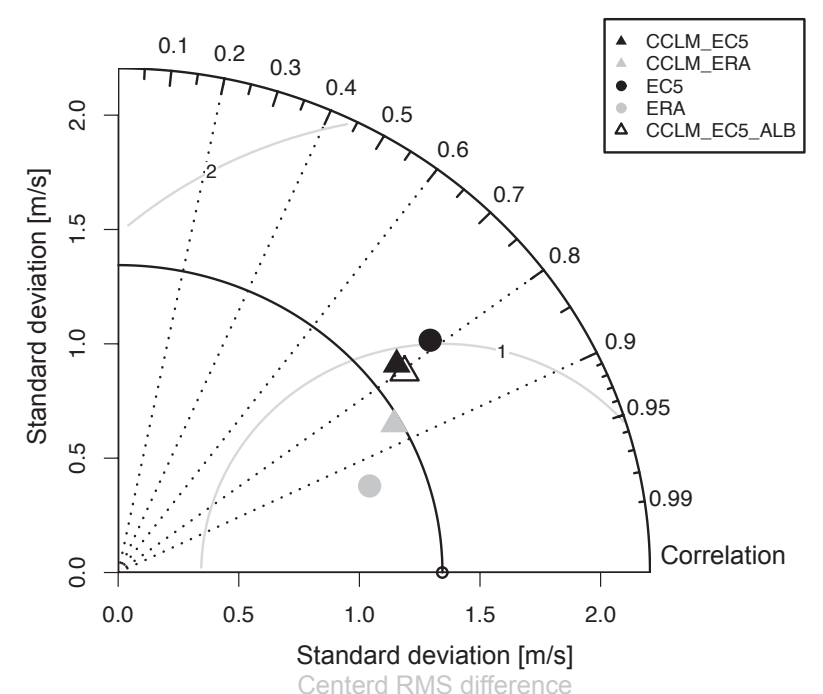

Figure 4.9 Analysis of the spatial WAMI patterns within the WAM area using a Taylor diagram for NCEP and different models 


\subsubsection{INDEX CORRELATIONS}

We examined the pairwise temporal correlations of the indices to investigate the covariability of monsoon predictors that describe different aspects of the monsoon (Table 4.2). PI and OLRI had the highest correlation with 0.91 for the reference and smaller values for the models (smallest correlation of 0.80 for CCLM_ERA). All correlations for PI and OLR were close to the reference, with slightly lower values (0.8) for the COSMO-CLM runs. As expected, most WAM precipitation was of convective origin.

The connection between PI and WAMI was not as distinctive as that for PI and OLRI. The reference value of 0.58 was clearly higher than the values of the COSMO-CLM results and of the driving models. This indicates deficiencies in the physical parameterization of the connection between precipitation and monsoon flow in the driving models and in the COSMO-CLM.

CCLM_EC5 (0.58), CCLM_EC5_ALB (0.64) and CCLM_ERA (0.58) overestimated the correlation between WAMI and OLRI compared to the reference (0.53), possibly because COSMO-CLM produces too strong convective activity. ERA-Interim and especially ECHAM5 underestimated the connection of monsoon flow and convection. ECHAM5 and the corresponding CCLM_EC5 run produced a slight improvement of the driving model, especially for the correlation of $\mathrm{PI}$ and WAMI.

\begin{tabular}{lccc}
\hline & PI \& WAMI & PI \& OLRI & WAMI \& OLRI \\
\hline Reference & 0.58 & 0.91 & 0.53 \\
ERA & 0.36 & 0.88 & 0.48 \\
CCLM_ERA & 0.30 & 0.80 & 0.58 \\
ECHAM5 & 0.25 & 0.86 & 0.37 \\
CCLM_EC5 & 0.39 & 0.83 & 0.58 \\
CCLM_EC5_ALB & 0.46 & 0.82 & 0.64 \\
\hline
\end{tabular}

Table 4.2 Correlations of the different indices within the reference datasets and within the models for the monsoon season (JJAS) and corresponding time periods

\subsubsection{Discussion}

Our results showed significant differences between COSMO-CLM simulations and the references. In particular, the COSMO-CLM simulations and the driving models underestimated the PI. The spatial distribution of precipitation differences showed that this underestimation was reduced due to compensating errors in the WAM region. In large parts of the African tropics, precipitation was underestimated by up to $50 \%$, and larger overestimations occurred along the Western coastlines and the Ethiopian Highlands. An overestimation of precipitation in the Sahel region resulted from a northerly overextension of the monsoon system in the model simulations. An improvement of the representation of precipitation in the driving data only occurred for the ECHAM5-driven COSMO-CLM simulation. The spatial correlation, mean, and interannual variability of PI of CCLM_EC5 were better than the corresponding values of ECHAM5. For CCLM_ERA such an improvement did not occur.

Both COSMO-CLM simulations failed to improve the forcing data in terms of means and interannual variability of OLRI (representing convective activity). CCLM_EC5 and CCLM_ERA 
clearly overestimated convective activity in the WAM region. The ECHAM5-driven simulation underestimated OLR by more than $80 \mathrm{~W} / \mathrm{m}^{2}$ in the Gulf of Guinea. A northerly overextension of the developing monsoon system in CCLM_EC5 and CCLM_ERA led to overestimations of convective activity in the Sahel. Overall, CCLM_EC5 gave no significant improvement relative to ECHAM5, but for CCLM_ERA there was an improvement of the match of spatial patterns.

Both COSMO-CLM simulations successfully captured the interannual variability of the WAMI, but strongly overestimated the mean compared to the NCEP reference. ECHAM5s mean WAMI agreed well with NCEP, whereas ERA-Interim underestimated it. Both forcing datasets also underestimated the interannual variability of the WAMI. The differences between ERA-Interim and NCEP indicated a stronger uncertainty of the reference data. Nevertheless, the match of spatial patterns was only improved by CCLM_EC5 and not by CCLM_ERA. One reason for this was an overestimation of CCLM_ERA $925 \mathrm{hPa}$ zonal wind by more than $6 \mathrm{~m} / \mathrm{s}$ in the WAM region.

A comparison of the pairwise correlation of indices confirmed the expected strong relationship between precipitation and convection, and this was reproduced well by all of the datasets. CCLM_EC5, CCLM_ERA, ECHAM5, and ERA-Interim had more problems in reproducing the correlation of precipitation and the monsoon flow, and this reached a value of 0.58 for the reference. CCLM_EC5 and CCLM_ERA slightly overestimated the correlation of monsoon flow and convective activity, possibly due to a tendency of COSMO-CLM to pro-duce too much convection. Compared to the forcing data CCLM_EC5 improved the index correlations, whereas the results for CCLM_ERA were not better than for ERA-Interim.

An obvious feature of the spatial distribution plots was the overestimation of precipitation and convective activity of COSMO-CLM relative to the references in the Sahel region. This indicated a northerly overextension of the monsoon system in the model. A comparison of CCLM_EC5 and CCLM_ERA 2m air temperatures (T2M) with observational data of the Climate Research Unit (CRU) [New et al. 2002] indicated a strong warm bias of the RCM results in the whole Sahara region by up to $6 \mathrm{~K}$ (Fig. 4.10a). Corresponding to this bias, comparisons of CCLM_EC5 and CCLM_ERA with NCEP [Kalnay et al. 1996] indicated that mean sea level pressure (MSLP) was underestimated by up to $3 \mathrm{hPa}$ in parts of the Sahara during the monsoon season.

Thus, the shift of the WAM seemed to be mainly driven by a warm bias in the Sahara, which resulted in an intensification of the Sahara heat low and an increased temperature gradient

(a)

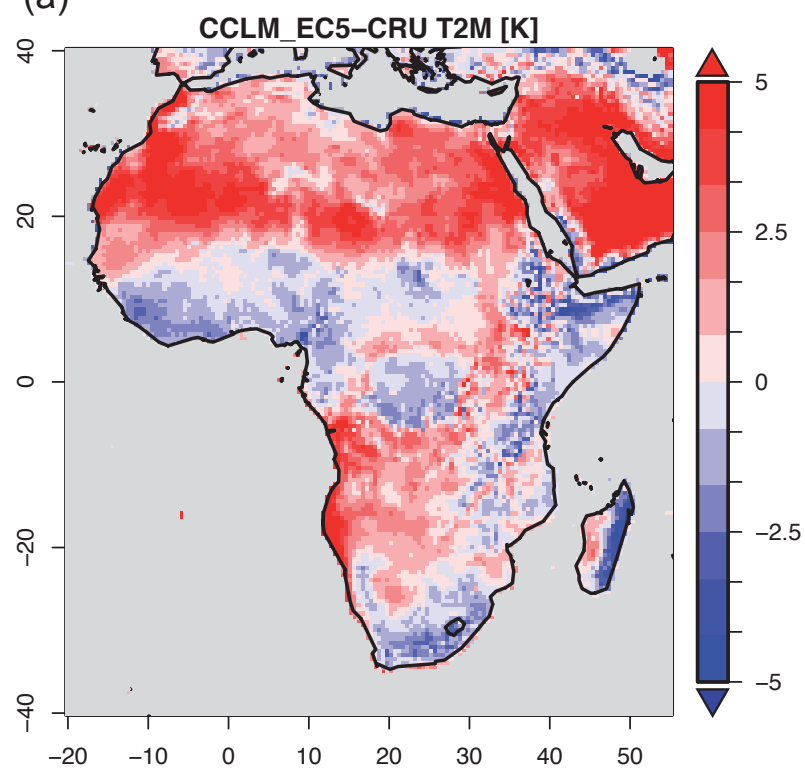

(b)

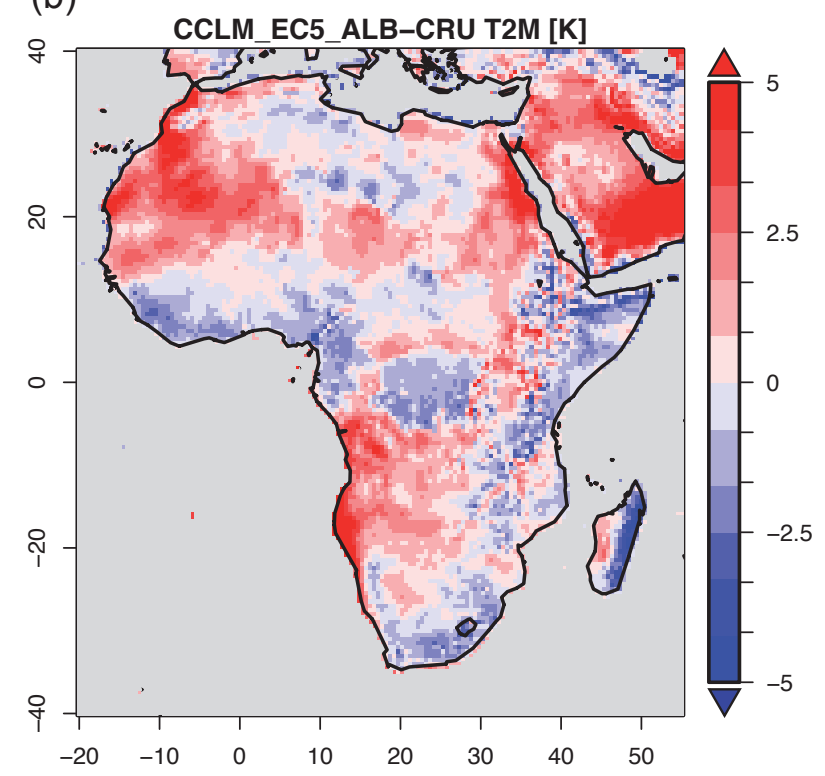

Figure 4.10 Spatial differences of mean $2 \mathrm{~m}$ temperature for the monsoon seasons (JJAS) for (a) CCLM EC5 - GPCC $2 m$ temperature 1961-2000, and (b) CCLM_EC5_ALB - GPCC $2 m$ temperature 1961-2000 
between the ocean and land-surface. In an earlier study of models in the third Coupled Model Intercomparison Project (CMIP3) dataset, Biasutti et al. [2009] confirmed that there was a strong correlation between the low-level Sahara low and precipitation in the Sahel. They suggested that variations in the Sahara low can force precipitation anomalies. The Sahara low is mainly driven by solar radiation, so the T2M and MSLP uncertainties in the COSMO-CLM could be a result from uncertainties in the surface albedo and corresponding uncertainties in net radiation fluxes [Kothe \& Ahrens 2010]. Kothe \& Ahrens [2010] showed for ERA-Interim driven simulations of West Africa with eight different RCMs in nine versions that discrepancies in the simulated radiation budget components were a common problem of all RCMs. Thus, all investigated simulations had significant uncertainties in the radiation fluxes in the Sahara and Sahel region.

To verify the hypothesis that uncertainties in the simulation of the WAM are strongly dependent on uncertainties in the simulated Sahara heat low, induced by errors in the simulated radiation budget, we modified the parameterization of the bare soil albedo in the COSMO-CLM with the aim to improve the simulated radiation budget especially in the desert regions of Africa. The resulting increase of the surface albedo of up to 0.2 in desert regions (Fig. 4.2) led to a strong decrease of the warm bias by up to $3 \mathrm{~K}$ (Fig. 4.10b). However, the influence on the error in surface pressure in the Sahara region was low (up to $0.4 \mathrm{hPa}$ ). So, the change in bare soil albedo had low influence on errors in the index region, but it reduced the strong warm bias in the Sahara region. The overestimation of precipitation and convection in the Sahel region was reduced by this modification, but it did not help improving the simulated WAM as quantified by different indices. So, the warm bias over the Sahara and the resulting overestimation of the Sahara heat low in the monsoon period is of less importance for the simulation of the WAM than originally assumed.

Other uncertainties, such as the strong overestimation of convective activity over the Gulf of Guinea by CCLM_EC5, might be caused by differences in the driving models. For example, the sea surface temperature (SST) in COSMO-CLM was prescribed by the driving model [see Dobler \& Ahrens 2010]. A comparison of ECHAM5 and ERA-Interim SSTs indicated much higher SSTs (up to $6 \mathrm{~K}$ ) for ECHAM5 from the Benguela stream up to the Gulf of Guinea. In CCLM_EC5, these higher SSTs led to an increased latent heat release and stronger convective activity. Overall, the results indicated a relatively strong sensitivity to the driving model. Except for the mean OLRI, the differences between CCLM_EC5 and CCLM_ERA were clearly larger than the differences between ECHAM5 and ERA-Interim. This indicates that a small change in the input can cause a larger change in the output.

Additionally, the difference in T2M and SST of ECHAM5 and ERA-Interim led to different temperature gradients in CCLM_EC5 and CCLM_ERA. Compared to CCLM_EC5, the ERAInterim driven COSMO-CLM simulation had lower SSTs over the Gulf of Guinea and higher T2M values over the Sahara. This increased the temperature gradient between the ocean and land surface, the primary driving factor for the WAM, and caused an increased gradient in surface pressure fields, which led to a more intense monsoon system. This explains the higher WAMI values of CCLM_ERA (Table 4.1) and worse performance in index correlations, whereas a smaller gradient might be one reason for better results of the ECHAM5-driven simulation.

Our study showed that errors in the surface albedo had strong influence on errors in the surface radiation budget and so in T2M. But, the results also indicated that there have to be other important factors influencing the simulation of the WAM. For example it is obvious that the model had a problem in simulating convection. A lot of work had been done in the last years in the field of convection schemes [e.g. Braconnot et al. 2007; Zanis et al. 2009], but without simulations on a convection resolving resolution these schemes will be a potential source for errors. 


\subsection{Conclusion}

In this study, we evaluated three climate simulations of Africa done with the RCM COSMOCLM in order to quantify the ability of the model to reproduce the main WAM features. Our evaluation also included the driving models, to see if the COSMO-CLM provides added value to the coarsely resolved forcing data by ECHAM5 and ERA-Interim. We expected to obtain better results, due to the better characterization of small-scale processes by RCMs.

We found that COSMO-CLM was able to reproduce the main WAM features. However, at the grid-scales of the used reference data $\left(0.5^{\circ}\right.$ to $2.5^{\circ}$ depending on parameter), the RCM produced only slight improvements relative to the forcing data. The convective activity of COSMO-CLM, measured by an OLR based index, was much too high, and precipitation was underestimated in large parts of the African tropics. CCLM_EC5 strongly overestimated convection in particular over the Gulf of Guinea. CCLM_ERA overestimated the WAMI much more than CCLM_EC5. This indicates the sensitivity of the RCM to LBC, and in particular SST. A northerly overextension of the monsoon system in the model was influenced by the land-sea temperature gradient and the strength of the Sahara heat low. Radiation fluxes are the main drivers of the Sahara heat low, and the SST is prescribed by LBC. Thus, errors are largely inherited from the forcing datasets, and the model itself generates additional errors. Errors in the simulated radiation budget in the Sahara region are a common feature of most RCMs [Kothe \& Ahrens 2010] as well as the sensitivity to LBC [e.g. Rojas \& Seth 2003; Messager et al. 2004]. By modifying the surface albedo parameterization, errors in the radiation budget components and in T2M decreased in the Sahara region. This reduced the overestimation of precipitation and convection in the Sahel region, but had minor influence on errors in the regarded WAM region. This confirms that especially in desert regions errors in the surface albedo are a very strong driver for errors in the radiation budget. But, there are additional important not yet wellunderstood factors, which strongly influence the simulation quality of the WAM.

Appendix 4.1

The soil albedo in COSMO-CLM is determined using a coefficient depending on the soil type, which is multiplied with the soil water content in the top soil layer. The final surface albedo over land is a mixture of soil albedo, vegetation albedo and eventually snow albedo depending on the fraction of each. The COSMO-CLM differs between seven soil types basing on the Digital Soil Map of the World [see www.fao.org].

The coupling of soil type and bare soil albedo is an unnecessarily limitation of the dynamic range of the albedo. So, we decoupled the bare soil albedo from the soil type by using a soil albedo treatment adopted from the Community Land Model [Lawrence \& Chase 2007]. Thereby in a first step bare soil color was calculated from MODIS data. So, MODIS reflectance values were not used directly. In a next step albedo values for dry and saturated soils were assigned by four lookup tables for two spectral bands (visible and near infrared). Since the radiation scheme in COSMO-CLM did not distinguish between different spectral bands for the albedo a weighted mean of the albedo values for the two bands was calculated with a weighting factor of 0.53 for the near infrared band (according to the relative contribution of solar energy from this band). The treatment of wet soils was changed with respect to the original scheme. With the prescribed albedo fields a linear interpolation between dry and saturated values based on the relative saturation was applied, where the pore volume and air dryness point were used to determine the relative saturation. 



\section{Chapter 5}

Conclusions

In this chapter the main findings of this thesis are briefly summarized. 


\section{Conclusions}

In simulations with the RCM COSMO-CLM, the results of this study revealed some serious underestimates of the short-wave net radiation in large parts of Europe and in particular over marine areas. However, taking into account the differences in the reference datasets, the results of the COSMO-CLM were quite satisfactory. The model overestimated the net long-wave radiation at the surface and also at the top of the atmosphere in many parts of Europe. With regard to the differences between the reference data these differences were also not very large.

It was found that an increase in the number of atmospheric layers in the COSMO-CLM simulations from 20 to 32 gave better results (except for the long-wave net radiation at the top of the atmosphere and the long-wave divergence). The use of 32 layers reduced the errors in the radiation components by up to $40 \%$. However, considering the uncertainties of the references and the long- and short-wave compensation effects, the improvement was relatively small. In view of the lower demands on processing power, the use of 20 atmospheric layers is an appreciable option for the simulation of the radiation budget.

The assessment of possible sources of errors showed that uncertainties in cloud cover and surface albedo had a significant impact on uncertainties in the net short-wave radiation the explained variance of uncertainties in cloud cover was two to three times higher than for uncertainties in the albedo. Uncertainties in the cloud cover resulted in significant errors in the net long-wave radiation. However, the influence of uncertainties in soil temperature on errors in the long-wave radiation budget was low or even negligible. These results were confirmed in a comparison with simulations of the RCMs REMO and ALADIN. It is reasonable to expect that a better parameterization of relatively simple parameters such as cloud cover or surface albedo significantly improves the simulation of radiation budget components in the COSMO-CLM.

Comparisons of the simulated radiation budgets of different RCMs for West Africa showed that problems in the simulation of short- and long-wave radiation fluxes were a widespread problem. Most of the tested models showed some considerable under- or overestimations of the short- and long-wave radiation budgets.

As in Europe, uncertainties in cloud cover were also a significant factor affecting uncertainties in the simulated radiation fluxes in simulations for Africa. However, for the African simulations uncertainties in the parameterization of the surface albedo were much more important than for Europe. Overland uncertainties in the cloud cover and surface albedo were on average even of similar importance. Uncertainties in the soil temperature were of greater importance for African simulations. While these were negligible over the ocean, they reached overland similar values of the mean explained variance $(\approx 0.2)$ such as uncertainties in the cloud cover. This indicates a geographical dependence of the model error. This second study also confirmed the assumption that an improved parameterization of the surface albedo in RCMs leads to an improvement in the modeled radiation budget, particularly in Africa.

To investigate how the application of this assumption effects the simulation of the WAM, the current albedo for bare soil in COSMO-CLM was replaced by values that were based on satellite measurements. Previously, the ECHAM5 and ERA-Interim driven climate simulations for Africa were evaluated to determine the ability of the model to reproduce the main features of the WAM.

It was found that the main features of the WAM were reproduced well by the COSMO-CLM, but the improvements compared to the driving data were only marginal. The index of convective activity in the model simulations was much too high and precipitation was underestimated in 
large parts of tropical Africa. The differences between the ERA-Interim and ECHAM5 driven simulations, in some cases considerable, demonstrated the sensitivity of the RCM to boundary conditions and in particular to the sea surface temperature. An excessive northerly shift of the monsoon in the model was influenced by the land-sea temperature gradient and the strength of the Saharan heat low. Consequently, some of the errors found resulted from the driving data and the model itself produced additional errors.

By modifying the parameterization of the bare soil albedo, the errors in the radiation budget and $2 \mathrm{~m}$ temperature in the Sahara region were significantly reduced. Similarly, the overestimation of precipitation and convection was reduced in the Sahel. However, the effect of this modification on the examined WAM area was low. This confirmed that especially in desert regions, the error in the surface albedo is a driving factor for errors in the radiation budget. But, there are other important factors which are not yet sufficiently understood that have a strong influence on the quality of the simulated WAM.

The present study provides a helpful contribution to a better understanding of radiation processes in RCMs. A detailed investigation of the actual condition demonstrated that RCM simulations have partly substantial errors in the simulated components of the radiation budget. Cloud cover, the surface albedo and the soil temperature were identified as three important sources of uncertainties on radiation modeling. The quantification of the influence of these variables revealed a regional dependence on the one hand and secondly, that even relatively simple parameters can have a quite decisive impact. The investigation of the simulated WAM exemplary showed that there are significant interactions between uncertainties in the simulated radiation and atmospheric processes. Based on this knowledge model simulations for Africa were improved by the modification of the surface albedo.

The analysis of the actual state, the quantification of error sources and the highlighting of connections made it possible to find ways to reduce uncertainties in the simulated radiation in RCMs and to have a better understanding of radiation processes. However, the magnitude of the errors found, the number of possible influencing factors, and the complexity of interactions, indicate that there is still a need for further research in this area.

\subsection{OUtLOOK}

For the investigation of sources of uncertainties, the main focus of this study was on cloud cover, surface albedo and the soil temperature. These variables explained a large part of the uncertainties found in the radiation budget, but by far not all. Therefore, further efforts should be made to quantify additional sources of uncertainties. It is not excluded, for example, that some of the radiation uncertainties in the Sahara are not due to the surface albedo, but due to errors in the parameterization of aerosols. However, the model data available, allowed no detailed investigation of this assumption.

In the COSMO-CLM simulations for Africa a strong overestimation of convection was observed, whose causes are not precisely known. Part of this overestimation is attributable to errors in the SST of the driving model. Additionally, an inaccurate parameterization of convection, a lack of interaction between atmosphere and ocean, or errors in the simulation of daily cycles of different parameters, are possible sources of errors.

The analysis, presented in the appendix, to the influence of topography on the radiation budget, showed some interesting results, and could be improved and expanded for example by considering sub-scale effects.

The investigations of other possible sources of errors are connected with the simulation of the WAM. The results of this study showed that the relationship between radiation uncertainties in the Sahara and the WAM, is lower than expected. Because of the enormous importance of the WAM for the African continent, further improvements of the simulation of the WAM should be sought. In particular, the mentioned uncertainties in the convection parameterization are probably in strong connection with the quality of the simulated WAM. 
Working with the COSMO-CLM was associated with a detailed insight into the source code of the model. Since the creation of the first version of the model code various people modified it continuously. This resulted in addition to a constant improvement of the model, to an increasingly complex network of programs, which is overlooked only by a few people in its entirety. As a result, individual processes that are not the main focus of current science, can be easily overlooked and forgotten. So, in today's RCMs there are various equations, which could be replaced with less effort by newer and expanded knowledge. The example of the surface albedo showed that relatively simple changes to a quantity, which was not noticed for a long time, can cause a quite remarkable improvement. So, in addition to working on complex variables such as the parameterization of clouds and convection, a steady maintenance of the model code should be done to track such potentials. 




\section{Chapter 6}

\section{ZUSAMMENFASSUNG}

In diesem Kapitel wird die vorliegende Arbeit ausführlich zusammengefasst. Vorrangestellt soll eine Einführung Informationen über die Hintergründe und Motivation liefern.

„Das schönste Glück des denkenden Menschen ist, das Erforschliche erforscht zu haben und das Unerforschliche zu verehren."

Johann Wolfgang von Goethe ${ }^{1}$

1 http://zitate.net/zitat_3359.html 


\subsection{EINE KURZE GESCHICHTE DER KLIMAMODELLIERUNG}

Kaum ein anderer Parameter hat einen derart großen Einfluss auf das Leben der Menschen weltweit, wie das Wetter und Klima. Aus diesem Grund war das Bestreben die Abläufe in der Atmosphäre zu verstehen und wenn möglich vorherzusagen stets sehr groß. Das Klima der Erde wird durch die allgemeine atmosphärische Zirkulation bestimmt. Versuche diese Zirkulation mathematisch und physikalisch zu beschreiben, waren lange Zeit erfolglos. Ohne weltweite meteorologische Beobachtungen war selbst die Erfassung der atmosphärischen Zirkulation nahezu unmöglich.

Den ersten Versuch einer Wettervorhersage, basierend auf einfachen Gleichungen für die Temperatur, Feuchte und den Wind, unternahm der norwegische Physiker und Meteorologe Vilhelm Bjerknes zu Beginn des zwanzigsten Jahrhunderts. Seine Lösungsmethode war jedoch sehr langsam und produzierte unzureichende Ergebnisse, da schon der Anfangszustand überaus ungenau vorgegeben war. In den 1920er Jahren entwickelte der britische Meteorologe Lewis Fry Richardson dieses Gleichungssystem und den numerischen Lösungsansatz weiter. Ein wichtiger Schritt war dabei die Aufteilung des Vorhersagegebietes in einzelne Gitterzellen. In seinem Buch "Weather Prediction by Numerical Process“ meint Richardson, dass es mit Hilfe von mehreren Zehntausend "Computern" möglich sein sollte eine zeitnahe Wettervorhersage zu berechnen. Mit „Computern“ waren dabei jedoch noch Menschen gemeint, die mit Papier und Stift Gleichungen lösen. In der Realität war die Berechnung einer Wettervorhersage deshalb unbrauchbar und deutlich langsamer als der tatsächliche Wetterverlauf.

Im Jahre 1946 unternahm John von Neumann an der Princeton-Universität erste Versuche Computer zur numerischen Wettervorhersage zu nutzen. Da vor allem das Militär großes Interesse an einer funktionierenden Wettervorhersage hatte, wurden diese Versuche in Princeton unter der Leitung von Jule Charney weiter vorangetrieben. Eine Vereinfachung und Verfeinerung der Richardson Gleichungen lieferte vielversprechende Ergebnisse. Das verwendete Modell, das nur auf wenigen Gleichungen basierte, wurde durch Charney zu einem dreidimensionalen regionalen Modell erweitert. Eines der größten Probleme, dem sich die Wissenschaftler zu Beginn gegenübersahen, waren mangelhafte Beobachtungsdaten, die es überaus schwierig machten einen hinreichenden Anfangszustand zu definieren oder Modellergebnisse zu evaluieren. Neben unzuverlässigen Messgeräten und einem groben Messnetz war die Rechenleistung der damaligen Computer oft nicht ausreichend, um nach Zusammenstellung der Eingangsdaten eine zeitnahe regionale Wetterprognose zu erstellen. Dementsprechend war es ein unweit größeres Problem die gesamte allgemeine Zirkulation der Erdatmosphäre in einem Klimamodell zu berechnen. Bei der numerischen Wettervorhersage handelt es sich um ein AnfangswertProblem, bei dem von einem festen Anfangszustand ausgegangen wird und die Genauigkeit der Ergebnisse mit zunehmender Zeit abnimmt. Zudem werden Umweltelemente, wie die Vegetation, Ozeane oder Eisfelder als statisch angenommen und tragen somit nicht zur Änderung des Wetters bei. Bei der Klimamodellierung hingegen handelt es sich um ein Grenzwert-Problem, wo bei vorgegebenen Bedingungen, wie zum Beispiel der Geografie von Bergen und Ozeanen, der unveränderliche Durchschnitt des Wetters berechnet wird, dass durch diese Bedingungen bestimmt wird [Weart 2008]. Umweltelemente, die in der numerischen Wettervorhersage statisch gehalten werden, müssen in Klimamodellen enthalten sein und wegen der im Vergleich zur Wettervorhersage deutlich längeren Modelläufe ist in der Regel eine gröbere Auflösung erforderlich. 
Erste Experimente mit „General Circulation Models“ (GCMs) wurden 1956 in Princeton von Norman Phillips durchgeführt. Mit wachsender Computerleistung nahm die Zahl der Wissenschaftler, die sich der Weiterentwicklung von GCMs widmeten, weltweit in den folgenden Jahren stetig zu. Auch die Komplexität der Modelle stieg damit weiter an. Weil Programmiersprachen zunehmend einfacher wurden und Programmcodes besser dokumentiert wurden, verbesserte sich zusätzlich der Zugang zu diesem Zweig der Wissenschaft.

In einem Bericht der „U.S. National Academy of Sciences“ hieß es 1965 zum Stand aktueller GCMs, dass die besten Modelle die groben Eigenschaften der Atmosphäre so simulieren, dass sie einige Ähnlichkeit mit der Wirklichkeit haben [Weart 2008]. Neben der Erweiterung der Computerleistung war also auch noch viel Raum für die Verbesserung der Modelle. Die Weiterentwicklung der Modelle verstärkte zudem die Nachfrage nach diversen, möglichst globalen Messwerten, von zum Beispiel Windprofilen oder der Feuchte in verschiedenen Höhen. Derartige Messnetze mussten zum Teil erst eingerichtet oder bestehende erheblich verbessert werden. So war aufgrund fehlender globaler Messungen der aktuelle Status der vollständigen allgemeinen Zirkulation in den 1960er Jahren noch immer unklar.

Klimamodelle etablierten sich zunehmend als Werkzeuge zur Erforschung der Atmosphäre. So ließ es die Rechenleistung mittlerweile zu, mehrere Modelläufe durchzuführen, um durch deren Vergleich die Reaktion auf Änderungen eines Parameters zu erforschen. Mithilfe dieser Vorgehensweise fand die Gruppe um Syukuro Manabe und Richard Wetherald 1967 Hinweise darauf, dass eine Verdopplung der $\mathrm{CO}_{2}$ Konzentration in der Erdatmosphäre zu einem Anstieg der globalen Mitteltemperatur von $2^{\circ} \mathrm{C}$ führt. Dies war die erste von Wissenschaftlern anerkannte Berechnung dieser Art zum Treibhauseffekt. 1975 ergaben Berechnungen mit einem verbesserten Modell eine Erwärmung von $3,5^{\circ} \mathrm{C}$ bei einer Verdopplung des $\mathrm{CO}_{2}$ Gehalts [Weart 2008]. Auch wenn die verantwortlichen Wissenschaftler von Defiziten in den Modellen wussten und vor einer falschen Interpretation der Resultate warnten, beeindruckten diese Ergebnisse die Wissenschaft, aber auch Politiker und die Öffentlichkeit.

Von Mitte der 1950er bis Mitte der 1970er Jahre steigerte sich die Leistungsfähigkeit von Computern etwa um einen Faktor 1000, was komplexere Modelle, höhere Auflösungen und längere Modelläufe ermöglichte. Ein weiteres wichtiges Element für den Fortschritt waren Beobachtungsdaten in höherer Quantität und Qualität. Ende der 1970er Jahre waren die Modelle so weit entwickelt, dass sie das gegenwärtige Klima einigermaßen realistisch reproduzieren konnten, weshalb Klimaforscher zunehmend die Hoffnung hatten, mit Hilfe von Klimamodellen Projektionen für die Zukunft durchführen zu können.

In der 1980er Jahren wurden erste gekoppelte Ozean-Atmosphäre Modelle eingesetzt. Experimente mit einigen dieser gekoppelten Modelle zeigten unter anderem die Möglichkeit einer drastischen Änderung der thermohalinen Zirkulation durch eine ansteigende globale Mitteltemperatur. Ende der 1980er war man sich in den Modellergebnissen sicher genug, um Politik und Öffentlichkeit vor einer Bedrohung durch die globale Erwärmung zu warnen. Dies war der eigentliche Beginn einer öffentlichen Debatte um die Klimaänderung, deren Folgen und eine Reduktion von Treibhausgasen, die bis zum heutigen Tag anhält. Jedoch war zu dieser Zeit auch die Zahl der Skeptiker innerhalb der wissenschaftlichen Gemeinde relativ groß. So können sich etwa Ungenauigkeiten im Anfangszustand oder den Gleichungen in GCMs zu großen Fehlern steigern. Ebenso machte das relativ verbreitete Anpassen von Modellen an Beobachtungsdaten deren Verhalten bei Zukunftsprojektionen teils unvorhersehbar. Ein weiterer Grund, warum manche Skeptiker die Modelle infrage stellten war, dass die Ergebnisse für globale Mittel relativ gute Übereinstimmungen zeigten, regional aber teils gegensätzliche Ergebnisse produzierten. Vor allem Politiker und die Öffentlichkeit sind weniger an der ganzen Erde interessiert, sondern wollen wissen wie viel wärmer, trockener oder feuchter es bei innen wird. Insbesondere Zukunftsprojektionen mit Klimamodellen werden immer mit einer gewissen Unsicherheitskomponente behaftet sein. Ein Computermodell kann nicht in dem Sinne bewiesen werden, wie es bei einem mathematischen Theorem möglich ist. So erklärte Manabe zum Beispiel, dass in jedem Regentropfen so viel Physik beteiligt ist, dass es niemals möglich sein wird absolut alles zu berechnen. 
Mit zunehmender Computerleistung und zunehmendem Verständnis atmosphärischer Prozesse, wurden Klimamodelle immer komplexer. So wurden zum Beispiel die Vegetation und die atmosphärische Chemie mit Modellen gekoppelt, die die zu erwartende soziale und wirtschaftliche Entwicklung der Menschen bestimmen sollen. Das führte unter anderem dazu, dass GCM nicht länger nur für "General Circulation Model“ stand, das auf den traditionellen Gleichungen für das Wetter basiert, sondern auch für "Global Climate Model“ oder gar „Global Coupled Model“. Die Klimamodellierung hat heute einen Punkt erreicht, an dem sie zuversichtlich erklären kann, was mit großer Wahrscheinlichkeit passieren wird. Dennoch zeigen Projektionen verschiedener Klimamodelle noch immer eine große Reichweite der Ergebnisse für spezifische Regionen. Für einige Regionen, wie die Arktis, sind die Ergebnisse recht einheitlich und damit relativ sicher, wohingegen insbesondere die am stärksten bevölkerten Regionen der Erde zum

Teil keine verlässlichen Informationen zulassen.

Erste Klimamodelle sollten erklären, wie die Atmosphäre funktioniert, und waren weniger zur Erstellung von Zukunftsprojektionen gedacht. Mittlerweile gibt es eine Vielzahl von Klimamodellen mit unterschiedlicher Komplexität, je nach Anwendungsgebiet. Klimamodelle sind heutzutage unerlässliche Werkzeuge zur Erforschung der komplexen physikalischen Vorgänge in der Atmosphäre. Insbesondere im Bereich der Klimaänderung und der damit verbundenen Folgen für Mensch und Umwelt, hat sich die Klimamodellierung zu einer der wichtigsten Informationsquellen für die Wissenschaft, aber auch für politische Entscheidungsträger und die Öffentlichkeit entwickelt. So kann man mit Hilfe von Klimamodellen Klimaänderungen als Antwort auf Emissionen von Treibhausgasen und Aerosolen untersuchen und Projektionen über mögliche Änderungen in der Zukunft durchführen. Dabei ist aber immer zu bedenken, dass Klimaprojektionen nicht als Klimaprognosen missverstanden werden und dass auch heutige Klimamodelle noch diverse Schwachstellen haben, die es zu verbessern gilt. Modelle können den Menschen jedoch helfen unzählige Ideen und Möglichkeiten zu sortieren und Hinweise geben, welche am plausibelsten sind [Weart 2008].

\subsection{Arten von KLimamodellen}

Heutzutage gibt es eine Vielzahl verschiedener Arten von Klimamodellen, die sich vor allem in ihrer Komplexität unterscheiden (Abbildung 1.1). Die einfachsten Modelle sind eindimensionale Modelle, die nur einen einzelnen Parameter, wie zum Beispiel die Strahlung, berechnen. Zu diesen Modellen zählen „Energy Balance Models“ (EBM) oder auch „Radiative-Convective Models" (R-CM). Ein wenig komplexer sind "Statistical Dynamical Models“ (SDM). Diese zweidimensionalen Modelle erstellen Prognosen der großräumigen Zirkulation durch das Lösen von Gleichungen, die die Änderungen des atmosphärischen Drucks, des Windes und der Feuchtigkeit beschreiben. SDMs stellen relative geringe Anforderungen an die benötigte Rechenleistung, sind für Zukunftsprojektionen aber nur begrenzt einsetzbar [Kemp 2011]. „Earth System Models of Intermediate Complexity“ (EMIC) sind Modelle, die die meisten Prozesse von AtmosphäreOzean GCMs (AO-GCMs) enthalten. Im Vergleich zu AO-GCMs weisen sie aber eine reduzierte Komplexität, Vereinfachungen in den Gleichungen und eine reduzierte Auflösung auf. GCMs sind die komplexesten und anspruchsvollsten Modelle (Abbildung 1.2). GCMs haben wegen längerer Modelllaufzeiten in der Regel eine gröbere Auflösung als Wettervorhersagemodelle. Dies gewährleistet meist eine adäquate Wiedergabe großskaliger Klimaeigenschaften, schränkt jedoch die Anwendung für lokale Prozesse ein. Diese Einschränkung möchte man durch die Anwendung von regionalen Klimamodellen (RCMs) reduzieren. Im Vergleich zu GCMs haben RCMs deshalb eine höhere Auflösung und beanspruchen meist weniger Computerressourcen. Der Einsatz von RCMs erlaubt es zum Beispiel regionale Eigenschaften wie die Orographie, Flüsse, komplexe Küstenlinien oder heterogene Landnutzung besser zu erfassen als in GCMs (Abbildung 1.3). 


\subsection{Parametrisierung}

Selbst aktuelle hochauflösende Klimamodelle haben eine zu grobe Auflösung um kleinskalige Prozesse, wie zum Beispiel Turbulenzen in der atmosphärischen Grenzschicht, Konvektion, Interaktion mit kleinräumiger Topografie, Gewitter oder Wolkenmikrophysik explizit zu berechnen. Aus diesem Grund müssen Parametrisierungen für diese Prozesse gefunden werden. Unter einer Parametrisierung versteht man eine Reihe von Zahlen (Parametern), die zum Beispiel das durchschnittliche Verhalten aller in einer Gitterzelle vorhandenen Wolken unter gegebenen Bedingungen beschreiben [Goosse et al. 2011]. Parametrisierungen haben in der Regel eine empirische oder theoretische Grundlage und sollen den großskaligen Einfluss der nicht explizit berücksichtigten Prozesse beschreiben [Kemp 2011]. Sie reproduzieren jedoch meist nur Effekte erster Ordnung und sind nicht für alle möglichen Bedingungen gültig. Daraus ergibt sich, dass Parametrisierungen in der Klimamodellierung eine große Quelle für Unsicherheiten darstellen.

\subsection{Evaluierung}

Klimamodelle stellen immer einen Kompromiss zwischen der Komplexität des Systems Erde-Atmosphäre und den Einschränkungen durch Faktoren wie Verfügbarkeit von Daten, Computerleistung und Kosten für Modellentwicklung und -betrieb dar. Diese Faktoren schränken letztendlich die Genauigkeit des Modells ein [Kemp 2011]. Um diese Genauigkeit einzuschätzen und um mögliche Fehlerquellen zu identifizieren, ist eine Evaluierung des Modells ein überaus wichtiger Bestandteil der Modellentwicklung. Der Vergleich von Modellsimulationen der letzten Jahre mit Beobachtungsdaten wird am häufigsten angewendet. Mittlerweile stehen Messreihen für eine Vielzahl von Parametern, zum Beispiel aus Stationsmessungen, Messkampagnen oder Satellitendaten, zur Verfügung. Dennoch ist für viele globale Datensätze die notwendige Stationsdichte und Messgenauigkeit auch heute nicht immer gegeben. Die Evaluierung von Klimamodellen ist also noch immer ein problematisches Gebiet. Aus der Notwendigkeit Modellergebnisse anhand von Beobachtungsdaten zu evaluieren ergab sich auch die Alternative Modellergebnisse an Paleoklimata zu testen. Dies bot die Möglichkeit Modelle an einem völlig anderem Klima als dem heutigen zu testen und anhand von Proxydaten zu evaluieren. Daraus entwickelte sich die Paleoklimatologie als ein weiteres Anwendungsgebiet von GCMs. Bei Zukunftsprojektionen gibt es keine Möglichkeit deren Richtigkeit zu beweisen. Mit Hilfe von Vergleichen verschiedener Modelle und Modellensembles können jedoch wahrscheinliche Fehlervariationen abgeschätzt werden.

Ein angestrebtes Ziel dieser Arbeit war die Verbesserung simulierter Strahlungsprozesse in einem regionalen Klimamodell. Als ein überaus wichtiges Werkzeug zur Identifizierung und Quantifizierung von Unsicherheiten in Klimamodellen ist die Evaluierung von Modelldaten deshalb ein wesentlicher Bestandteil dieser Arbeit.

\subsection{Die energiebiLANZ DeR ERDE}

Zu den Komponenten der Energiebilanz der Erde zählen die Strahlungsbilanz, der turbulente und latente Wärmefluss, der Bodenwärmefluss und die Schmelzwärme (siehe Abbildung 1.4). Den bei weitem größten Anteil bildet jedoch die Strahlungsbilanz. Daher stellt die Strahlungsbilanz der Erde einen der wichtigsten Parameter in der Meteorologie dar. Die kurzwelligen und langwelligen Komponenten der Strahlungsbilanz beschreiben die Quellen und Senken der Energie des Systems Erde-Atmosphäre. Die absorbierte kurzwellige Einstrahlung treibt das Wetter- und Klimasystem sowie die Biosphäre an. Die langwellige Ausstrahlung der Erde repräsentiert die Wärmeenergie, die an die Atmosphäre und den Weltraum abgegeben wird. Die Differenz zwischen der Strahlungsbilanz am Oberrand der Atmosphäre und der Strahlungsbilanz am Erdboden lässt deshalb auf eine Erwärmung beziehungsweise Abkühlung der zugehörigen Atmosphärensäule schließen. 
Die Strahlungsbilanz ist somit ein bedeutender Indikator für verschiedene atmosphärische Prozesse, wie zum Beispiel den Einfluss von Wolken auf das Wetter- und Klimasystem oder

auch klimatische Veränderungen. Die Beschreibung wie Strahlung und Wärme innerhalb der Atmosphäre absorbiert, emittiert oder gestreut werden, ist die Grundlage zur Berechnung des Treibhauseffektes. Dreidimensionaler Strahlungstransport ist jedoch sehr rechen- und speicherintensiv. Die Berechnung der Strahlung erfordert in aktuellen Klimamodellen einen großen Teil der gesamten Rechenleistung. Dies liegt zum Teil daran, dass die Strahlungstransportgleichung eine Differenzialgleichung ist, deren numerische Lösung sehr aufwendig ist. Die theoretischen Grundlagen des Strahlungstransportes sind heute weitestgehend bekannt und im Labor bestätigt. Für ideale Fälle sind Strahlungstransportrechnungen zudem sehr zuverlässig. Die Anwendung auf die reale Atmosphäre in Klimamodellen ist allerdings äußerst schwierig, da der Strahlungstransport von vielen atmosphärischen Parametern, wie zum Beispiel Wolken, Wolkenmikrophysik, Aerosolen oder der Bodenalbedo abhängt, die für sich allein schon schwierig zu beschreiben und zu parametrisieren sind.

Die Anwendung von RCMs ermöglicht es einige Modell-Parametrisierungen durch explizite Beschreibungen zu ersetzen, und die höhere Auflösung dieser Modelle erlaubt eine bessere Darstellung der lokalen und regionalen Besonderheiten, die einen Einfluss auf die Komponenten der Strahlungsbilanz haben. Jaeger et al. [2008] fanden in einer Studie signifikante Fehler in der kurz- und langwelligen Nettostrahlung von COSMO-CLM Simulationen, die sie auf Fehler in der simulierten Bewölkung zurückführten. Mehrere andere Studien zeigten für verschiedene GCMs und RCMs, dass vor allem Wolken nach wie vor eine der größten Unsicherheiten in der Strahlungsmodellierung sind [z.B. Wild et al. 2001, Markovic et al. 2008]. Aufgrund des enormen Einflusses der Strahlungsbilanz auf die Ergebnisse von Klimasimulationen wird eine möglichst korrekte Wiedergabe dieser Prozesse in Modellen angestrebt. Die große Wichtigkeit von Wolken und Wolkenmikrophysik für die Strahlung führte dazu, dass viele Ressourcen für die Weiterentwicklung der entsprechenden Modellparametrisierungen aufgebracht wurden. Die Verwendung von RCMs mit hoher Auflösung kann dazu beitragen die Simulation von Wolken und Wolkeneigenschaften zu verbessern, aber auch relativ einfache Parameter, wie die Bodenalbedo, Topografie, oder die Beschreibung von Vegetation, können erhebliche Auswirkungen auf die Strahlungsbilanz in regionalen Klimasimulationen haben. Daher liegt neben der Rolle verschiedener Parameter bei der Modellierung der Strahlungsbilanz ein besonderer Schwerpunkt dieser Arbeit auf regionalen Besonderheiten der Strahlungsbilanz und Interaktionen mit der Landoberfläche.

\subsection{ZieLSETZUNG}

Das Ziel dieser Arbeit ist es Strahlungsprozesse in RCMs besser zu verstehen, um deren Einfluss quantifizieren zu können und mögliche Fehler zu reduzieren. Dieses komplexe Ziel umfasst diverse Fragestellungen.

- Wie gut können RCMs (und im Speziellen das COSMO-CLM) die Komponenten der Strahlungsbilanz simulieren?

Zur Untersuchung dieser Frage wurden in einem ersten Schritt die simulierten Strahlungsbilanzkomponenten zweier regionaler Klimasimulationen für Europa mit satellitenbasierten Daten verglichen. Um festzustellen, ob das regionale Modell eine Verbesserung gegenüber globalen Modellen bieten kann, wurden die beiden Simulationen zudem mit den entsprechenden Antriebsdaten verglichen. In Europa gibt es eine Vielzahl verschiedener klimatischer Bedingungen und Landschaften. Es gibt große Bergketten, ausgedehnte Waldgebiete, zahlreiche urbane Gebiete oder Meeresgebiete, die die Strahlungskomponenten in unterschiedlicher Weise beeinflussen. Darüber hinaus bewirken die jahreszeitlichen Änderung Veränderung von Parametern, wie zum Beispiel der Bodenalbedo, was die Genauigkeit der simulierten Strahlung beeinflussen kann.

- Was sind wichtige Quellen für Fehler und Unsicherheiten in der simulierten Strahlung? Neben der Quantifizierung von Modellunsicherheiten ist es für deren Verständnis und mög- 
liche Verbesserungsansätze entscheidend Ursachen für Unsicherheiten zu bestimmen. Mithilfe statistischer Methoden wurde deshalb der Einfluss potenzieller Unsicherheitsquellen, wie der Wolkenbedeckung, Bodenalbedo oder Bodentemperatur, abgeschätzt. Es gibt diverse andere Größen, die Strahlungsunsicherheiten beeinflussen können, wie zum Beispiel Wolkenmikrophysik oder Aerosole, aber im Hinblick auf Möglichkeiten zur Verbesserung des Modells, lag der Schwerpunkt auf diesen relativ einfachen Parametern. Die beiden untersuchten Klimasimulationen für Europa unterschieden sich zudem in der Anzahl der verwendeten vertikalen Schichten, um den eventuellen Mehrwert der höheren Schichtenanzahl gegenüber dem größeren Aufwand von Rechenressourcen bewerten zu können.

- Sind die gefundenen Ergebnisse zu Strahlungsunsicherheiten und deren Einflussfaktoren vergleichbar, wenn das Modell in einer anderen Region (zum Beispiel Afrika) angewandt wird, als die, für die es ursprünglich erstellt wurde (Europa)?

Viele natürliche Prozesse können in Klimamodellen nur in vereinfachter Form dargestellt werden. Dies kann dazu führen, dass Parametrisierungen, die sich in einem Anwendungsgebiet eines RCMs bewährt haben, in einem klimatologisch verschiedenen Gebiet zu weniger guten Ergebnissen führen. Globale Klimaprojektionen deuten darauf hin, dass die in den nächsten Jahrzehnten zu erwartenden Klimaänderungen deutlich größere Auswirkungen in Afrika als zum Beispiel in Europa haben werden. Zur Entwicklung von Anpassungsstrategien an mögliche Klimaänderungen in afrikanischen Ländern ist es notwendig regionale Klimaprojektionen durchzuführen. Um Unsicherheiten in den Zukunftsprojektionen abschätzen zu können, ist es hilfreich eine Anzahl verschiedener Modelläufe, die mit verschiedenen RCMs und verschiedenen Antriebsmodellen durchgeführt wurden, zu betrachten. Da viele afrikanische Länder derzeit nur begrenzte Ressourcen zur Verfügung haben, um derartige Projekte durchzuführen, wird ein Hauptfokus des nächsten IPCC (Intergovernmental Panel on Climate Change; siehe www. ipcc.ch) Berichts auf den Auswirkungen von Klimaänderungen auf den afrikanischen Kontinent liegen. Vor diesem Hintergrund wurden die simulierten Strahlungsbilanzkomponenten von neun verschiedenen Klimasimulationen für Westafrika, die mit verschiedenen RCMs und Modellversionen realisiert wurden, mit satellitenbasierten Daten und Reanalysedaten evaluiert. Die selbe Methode, die angewandt wurde, um Unsicherheitsquellen der Strahlungsbilanz für Simulationen in Europa zu finden, wurde hier verwendet, um zu sehen, ob der Einfluss von Unsicherheiten in der Wolkenbedeckung, Bodenalbedo oder Bodentemperatur in Afrika von ähnlicher Bedeutung wie in Europa ist. Aufgrund der unterschiedlichen klimatischen Bedingungen und Landschaften waren Unterschiede zu erwarten. Im Vergleich zu Europa ist das Klima in Afrika zum Beispiel viel mehr beeinflusst durch Regenzeiten. Besonders außerhalb der Tropen gibt es große Bereiche mit einer sehr geringen Wolkenbedeckung in einem großen Teil des Jahres, weshalb angenommen wird, dass die Bedeutung von Oberflächeneigenschaften, wie etwa der Albedo, in Afrika voraussichtlich höher ist.

- Wie beeinflussen Fehler der simulierten Strahlungsbilanzkomponenten die Simulation von Klimaprozessen, wie dem Westafrikanischen Monsun (WAM)?

Der Monsun prägt in großen Teilen Westafrikas das Leben vieler Millionen Menschen. Nahezu der gesamte Jahresniederschlag fällt dort in den Monaten Juni bis September. Damit werden sowohl das Wachstum der natürlichen Vegetation, die Biodiversität und Ökologie als auch Ackerbau und Wirtschaft entscheidend vom WAM beeinflusst. Der WAM ist überwiegend eine Folge der jahreszeitlich bedingten Nord-Süd-Verschiebung der intertropischen Konvergenzzone (ITCZ), einer Tiefdruckrinne in Äquatornähe. In der Folge kommt es zu einer Richtungsumkehr der vorherrschenden Winde in den von der ITCZ überstrichenen Gebieten. Damit einher geht eine Verlagerung der Gebiete mit starken Niederschlägen in der Tiefdruckrinne. Da das Festland sich im Sommer schneller aufheizt als der angrenzende Ozean, wird die Tiefdruckrinne über Land vertieft. Diese Vertiefung - und damit eine Verlagerung der ITCZ und eine Verstärkung des Einströmens feuchter Luft auf das Festland - führt zu den starken Regenfällen beispielsweise während des Indischen oder Westafrikanischen Monsuns.

Anhand zweier regionaler Klimasimulationen mit dem RCM COSMO-CLM (siehe www.clmcommunity.eu) wurde untersucht, ob das Modell in der Lage ist die grundlegenden Merkmale 
des WAM zu simulieren. Die zwei verwendeten Modellläufe wurden zum einen von einem GCM und zum anderen mit Reanalysedaten angetrieben, um den Einfluss der lateralen Randbedingungen quantifizieren zu können. Innerhalb dieser Studie sollte zudem untersucht werden, wie sich eine durch Fehler in der simulierten Strahlungsbilanz bewirkte Überschätzung der Temperatur im Bereich der Sahara auf die Simulation des WAM auswirkt.

- Ist es möglich, durch die Modifizierung relativ einfacher Modellparameter, wie der

Bodenalbedo, die Simulation der Strahlung und damit gekoppelter Prozesse zu verbessern? In den letzten Jahren wurden teils große Anstrengungen unternommen, um die simulierte Strahlungsbilanz in Klimamodellen weiter zu verbessern. Ein großer Teil der Ressourcen wurde dabei verwendet, um komplexe Größen, wie die Inhomogenität von Wolken, die Wolkenphase oder den direkten und indirekten Aerosoleffekt, zu verbessern. Wie im Verlauf dieser Arbeit gezeigt wird, hat aber auch ein relativ einfacher Parameter, wie die Bodenalbedo, einen teils erheblichen Anteil an Unsicherheiten in der simulierten kurzwelligen Strahlung. Es zeigte sich zum Beispiel, dass eine geringe Änderung des Einfallswinkels der solaren Strahlung durch die Berücksichtigung topografischer Effekte auf die Albedo für direkte solare Strahlung und die einfallende kurzwellige Strahlung am Boden nachweisbare Auswirkungen hat. Diese relativ kleinen Veränderungen induzieren relativ große regionale Veränderungen in Parametern wie der $2 \mathrm{~m}$ Temperatur oder dem Niederschlag (siehe Appendix). Durch einen relativ einfachen Ansatz wird deshalb versucht die Bodenalbedo des COSMO-CLM zu verbessern.

Im Rahmen der Untersuchung des WAM wurde die bisherige Albedo für bloßen Boden durch Werte ersetzt, die aus Satellitendaten bestimmt wurden und anschließend wurde die Auswirkung dieser Modifikation auf die Simulation des WAM analysiert. Die bisherigen Werte der Albedo für bloßen Boden waren an den Bodentyp gekoppelt. Da im COSMO-CLM nur zwischen wenigen Bodentypen unterschieden wird und die Werte für den Bodentyp zudem auf Daten beruhen die insbesondere in dünn besiedelten Gebieten, wie der Sahara, Unsicherheiten aufweisen, ist eine Verbesserung durch genauere Satellitendaten erwartet worden.

\subsection{DATEN}

Im folgenden Abschnitt werden kurz die wichtigsten Informationen zu den verwendeten Modelldaten und den zur Evaluierung verwendeten Datensätzen zusammengefasst. Insbesondere sollen die wichtigsten Eigenschaften des RCM COSMO-CLM beschrieben werden.

\subsubsection{Modelldaten}

Das COSMO-CLM (COnsortium for Small-scale MOdeling-Climate Limited-area Model) ist ein nicht-hydrostatisches RCM [siehe http://www.clm-community.eu]. Es ist die Klimaversion des COSMO-Modells [siehe http://www.cosmo-model.org], das von mehreren europäischen Wetterdiensten für die mesoskalige Wettervorhersage verwendet wird.

In dieser Arbeit wurden Klimasimulationen mit verschiedenen Versionen des COSMO-CLM verwendet, alle Simulationen wurden jedoch mit einer horizontalen Auflösung von $0.44^{\circ}$ durchgeführt. Detaillierte technische Einzelheiten über die Dynamik und die Physik des Modells sind in Böhm et al. [2006], Steppeler et al. [2003], und in der Modelldokumentation [siehe http://www. cosmo-model.org] zu finden.

Für die Randbedingungen an den Modellgrenzen wurden verschiedene globale Modell- oder Reanalysedaten verwendet. Die Simulationen für Europa wurden durch die ERA-40 Reanalyse angetrieben. ERA40 ist ein Reanalyse Produkt des ECMWF (European Centre for Mediumrange Weather Forecasts) auf einem globalen Gitter, mit einer horizontalen Auflösung von $\approx 125$ km (T159), für den Zeitraum von 1958 bis 2001 [Uppala et al. 2005]. Die Simulationen für Afrika wurden angetrieben durch die ERA-Interim Reanalyse sowie durch Daten des GCM ECHAM5. Die ERA-Interim Reanalyse hat eine Auflösung von $\approx 0,70^{\circ}$ (T255) und deckt den Zeitraum 
von 1989 bis 2010 ab. ERA-Interim, wie auch ERA-40 Daten sind eine Kombination aus numerischer Wettervorhersage und einer Angleichung an unterschiedlichste Beobachtungsdaten [Simmons et al. 2006]. Die Daten des GCM ECHAM5 haben eine Auflösung von $\approx 1,88^{\circ}$ (T63) und umfassen den Zeitraum von 1960 bis 2000. Die verwendete ECHAM5 Simulation ist ein gekoppeltes Atmosphäre-Ozean Experiment, gekoppelt an das MPI-OM Ozean-Modell und war der dritte Lauf, der im Rahmen des vierten Sachstandsberichts des IPCC [Roeckner et al. 2005] durchgeführt wurde.

Für den Vergleich verschiedener Modellergebnisse in Westafrika wurden neun ERA-Interim getriebene RCM Simulationen verwendet, die im Rahmen des EU-Projekts ENSEMBLES [Hewitt and Griggs 2004; van der Linden and Mitchell 2009; siehe http://ensembles-eu.metoffice. com] erstellt wurden.

\subsubsection{EVALUIERUngsdaten}

Zur Evaluierung der Modellergebnisse sollten Daten verwendet werden, die zum einen auf einem globalen Gitter verfügbar sind und zum anderen höchstmögliche Qualität garantieren. Für Größen wie den Niederschlag und die $2 \mathrm{~m}$ Temperatur stehen Beobachtungsdatensätze zur Verfügung. Global gerasterte Beobachtungen der Strahlungsbilanzkomponenten sind als Produkte von Satellitenmessungen verfügbar, sind aber keine reinen Beobachtungsdaten, da zur Bestimmung dieser Daten Strahlungstransportmodelle notwendig sind. Messungen der Windkomponenten, vor allem in größeren Höhen, sind global nur für wenige Radiosondenstationen verfügbar, weshalb zur Evaluierung dieser Größen Reanalysedaten verwendet wurden. In dieser Arbeit wurden folgende Datensätze genutzt:

- Als Referenzdatensatz für den Niederschlag wurden Daten des Global Precipitation Climatology Centre (GPCC) Produkt Version 4 [Schneider et al. 2008] verwendet. GPCC liefert einen Datensatz von global gerasterten Niederschlagsmessungen mit einer räumlichen Auflösung von $0,5^{\circ}$.

- Beobachtungsdaten der Climate Research Unit (CRU) [New et al. 2002] wurden verwendet, um die Qualität der vom Modell simulierten $2 \mathrm{~m}$ Temperatur zu evaluieren. Der CRU Datensatz ist auf einem globalen Gitter mit $0,5^{\circ}$ horizontaler Auflösung verfügbar.

- Als Referenz für die Komponenten der Strahlungsbilanz dienten Daten des NASA/GEWEX SRB (Surface Radiation Budget) Projektes des NASA Langley Research Centers. Die darin enthaltenen Produkte bieten für den Zeitraum von Juli 1983 bis Juni 2007 einen satellitengestützten Datensatz von 3-stündigen Werten der kurz- und langwelligen Strahlungskomponenten an der Oberfläche und dem Oberrand der Atmosphäre auf einem globalen Gitter mit $1^{\circ}$ horizontaler Auflösung [Gupta et al 2006; Zhang et al 2007].

- Zur Evaluierung des meridionalen und zonalen Windes in $925 \mathrm{hPa}$ und $200 \mathrm{hPa}$ wurde das Reanalyseprodukt des National Centers for Environmental Prediction/National Center for Atmospheric Research (NCEP/NCAR) [Kalnay et al. 1996] als Referenzdatensatz genutzt. Die verwendeten Variablen für den Zeitraum 1961-2000 hatten eine horizontale Auflösung von 2,5.

\subsection{ERGEBNISSE}

In einer ersten Studie [Kothe et al. 2010] wurden die kurz- und langwelligen Komponenten der Strahlungsbilanz zweier mit ERA40 angetriebener COSMO-CLM Simulationen für Europa evaluiert. Als Referenzen dienten der satellitenbasierte GEWEX/SRB Datensatz sowie die ERA40 Reanalyse. Die Vergleiche zeigten erhebliche Unterschätzungen der kurzwelligen Nettostrahlung am Boden in großen Teilen Europas und vor allem über Meeresgebieten. Über Land waren die Unterschiede von COSMO-CLM zu SRB kleiner als relativ zu ERA40. Die kurzwellige Nettostrahlung am Oberrand der Atmosphäre wurde vom Modell verbreitet unterschätzt, die Vergleiche mit SRB zeigten jedoch auch eine leichte Überschätzung in Teilen Südeuropas. Mit 
Ausnahme einiger Teile Osteuropas überschätzte COSMO-CLM die langwellige Nettostrahlung am Boden in den meisten Bereichen. Die Überschätzung der langwelligen Nettostrahlung am Oberrand der Atmosphäre war besonders im Vergleich mit ERA40 sogar noch größer.

Die beiden untersuchten Simulationen unterschieden sich in der Anzahl der atmosphärischen Schichten, um den Einfluss dieses Parameters abschätzen zu können. Die Auswertung zeigte, dass die Simulation mit 32 Schichten, außer für die langwellige Nettostrahlung am Oberrand der Atmosphäre und die langwellige Divergenz, bessere Ergebnisse lieferte. Die Verwendung von 32 Schichten reduzierte die gefundenen Fehler in den Strahlungskomponenten um bis zu $40 \%$.

Neben der Quantifizierung von Fehlern wurden auch mögliche Fehlerquellen abgeschätzt. Es wurde angenommen, dass die wichtigsten Ursachen für Fehler in den Strahlungskomponenten Fehler in der Wolkenbedeckung, der Bodenalbedo und der Bodentemperatur sein würden. Für die kurzwellige Nettostrahlung wurde bestätigt, dass Unsicherheiten in der Wolkenbedeckung und Bodenalbedo wichtige Einflussfaktoren sind. Die erklärte Varianz für Unsicherheiten in der Wolkenbedeckung war zwei- bis dreimal höher als für Unsicherheiten in der Bodenalbedo. Die Ergebnisse zeigten jedoch große jahreszeitliche und geografische Unterschiede. Unsicherheiten in der Wolkenbedeckung führten zu erheblichen Fehlern in der langwelligen Nettostrahlung. Allerdings hatten Unsicherheiten der Bodentemperatur nur einen kleinen oder sogar vernachlässigbaren Einfluss auf Fehler in der langwelligen Nettostrahlung. Die gefundenen Zusammenhänge zwischen Unsicherheiten in der Wolkenbedeckung, der Bodenalbedo und der Bodentemperatur zu Unsicherheiten in den Nettostrahlungsflüssen konnten bei Vergleichen mit Simulationen der RCMs REMO und ALADIN bestätigt werden.

Ein wichtiges Ziel der zweiten Studie [Kothe \& Ahrens 2010] war es zu sehen, inwieweit die für Europa gefunden Ergebnisse zu Unsicherheiten in den Nettostrahlungsflüssen und deren Unsicherheitsquellen für Simulationen in Westafrika vergleichbar sind. Verglichen wurden hierzu Simulationen von acht verschiedenen RCMs in neun Versionen, die im Rahmen des EU-Projekts ENSEMBLES erstellt wurden. Als Referenzdaten dienten der GEWEX/SRB Datensatz sowie die ERA-Interim Reanalyse.

Die Vergleiche zeigten erhebliche Unsicherheiten in den Strahlungsbudgets der RCMs. In den meisten der untersuchten Modelle wurden die kurzwelligen Strahlungsflüsse in Ozeangebieten und in Teilen der intertropischen Konvergenzzone unterschätzt und in den Sahara und Sahel Regionen überschätzt. Im Durchschnitt betrug die Unterschätzung für die kurzwellige

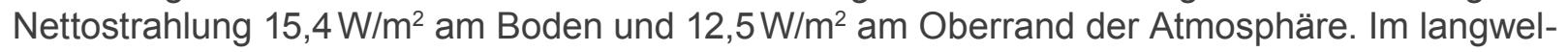
ligen Spektrum gab es eine Tendenz dazu die Nettostrahlung am Boden in der Sahelzone zu überschätzen und in Zentralafrika im Sommer zu unterschätzen. Im Winter war dieser Zusammenhang umgekehrt. Die mittleren Fehler für die langwellige Nettostrahlung betrugen $3,4 \mathrm{~W} / \mathrm{m}^{2}$ am Boden und $11,3 \mathrm{~W} / \mathrm{m}^{2}$ Oberrand der Atmosphäre.

Unsicherheiten in der Wolkenbedeckung waren in den RCM Simulationen ebenso ein wichtiger Einflussfaktor auf Unsicherheiten in den Strahlungsflüssen, wie sie es in Europa waren. So erklärten sie für die kurzwellige Nettostrahlung am Boden im Durchschnitt mehr als $20 \%$ der Fehlervarianz über Land und mehr als $40 \%$ über dem Ozean. Unsicherheiten in der Bodentemperatur waren über dem Ozean vernachlässigbar, hatten über Land aber ähnliche Bedeutung wie Unsicherheiten in der Wolkenbedeckung (mittlere erklärte Varianz $\approx 0,2$ ). Der Einfluss von Unsicherheiten in der Bodentemperatur auf Unsicherheiten im langwelligen Strahlungsbudget war damit deutlich größer als in der Untersuchung von Simulationen für Europa [Kothe et al. 2010]. Ein weiteres wichtiges Ergebnis ist, dass Unsicherheiten in der Parametrisierung der Bodenalbedo in den RCMs im Durchschnitt über Land von ähnlicher Bedeutung waren wie Unsicherheiten in der Wolkenbedeckung. In der Sahara und Sahelzone (ein Bereich, der $8 \%$ der gesamten globalen Landmasse bedeckt) war die erklärte Varianz für Unsicherheiten in der Bodenalbedo sogar größer als $60 \%$.

In einer dritten Studie [Kothe et al. 2011] wurden drei COSMO-CLM Klimasimulationen für Afrika ausgewertet, um festzustellen, ob das Modell fähig ist die wichtigsten Merkmale des WAM zu reproduzieren. Für die Simulationen wurden zwei verschiedene Antriebsmo- 
delle (ECHAM5 und ERA-Interim) verwendet, um den Einfluss des antreibenden Modells zu quantifizieren.

Die Analysen ergaben signifikante Unterschiede zwischen den COSMO-CLM Simulationen und den Referenzen. Die COSMO-CLM Simulationen und die treibenden Modelle unterschätzen den Niederschlagsindex PI. In weiten Teilen der afrikanischen Tropen wurde der Niederschlag um bis zu $50 \%$ unterschätzt, und größere Überschätzungen traten entlang der Westküsten und im äthiopischen Hochland auf. Eine Überschätzung der Niederschläge in der Sahelzone resultierte aus einer zu weiten nördlichen Verschiebung des Monsunsystems in den Modellsimulationen. Eine Verbesserung des simulierten Niederschlags gegenüber den Antriebsdaten konnte nur für die ECHAM5 angetriebene COSMO-CLM Simulation (CCLM_EC5) festgestellt werden. Die räumliche Korrelation, der Mittelwert und die interannuelle Variabilität des PI waren für CCLM_EC5 besser als die entsprechenden Werte für ECHAM5. Für die ERA-Interim angetriebene COSMO-CLM Simulation (CCLM_ERA) war eine solche Verbesserung nicht eingetreten.

Die COSMO-CLM Simulationen konnten die Antriebsdaten hinsichtlich der Mittel und der Variabilität des Index für die langwellige Ausstrahlung OLRI (Maß für die konvektive Aktivität) nicht verbessern. CCLM_EC5 und CCLM_ERA überschätzten die konvektive Aktivität in der Untersuchungsregion deutlich. Die ECHAM5 getriebene Simulation unterschätzte die abgestrahlte langwellige Strahlung (OLR) um mehr als $80 \mathrm{~W} / \mathrm{m}^{2} \mathrm{im}$ Golf von Guinea. Eine nördliche Verschiebung des Monsunsystems in CCLM_EC5 und CCLM_ERA führte zu Überschätzungen der konvektiven Aktivität in der Sahelzone. Insgesamt gab es in CCLM_EC5 keine signifikante Verbesserung gegenüber ECHAM5, für CCLM_ERA gab es jedoch eine Verbesserung der Übereinstimmung von räumlichen Mustern der OLR.

Alle COSMO-CLM Simulationen konnten die interannuelle Variabilität des Westafrikanischen Monsunindex (WAMI) wiedergeben, überschätzten aber den Mittelwert im Vergleich zur NCEP Referenz. Die Übereinstimmung von räumlichen Mustern wurde nur durch CCLM_EC5 und nicht durch CCLM_ERA verbessert. Ein Grund dafür war eine Überschätzung des zonalen Windes in $925 \mathrm{hPa}$ in CCLM_ERA von mehr als $6 \mathrm{~m} / \mathrm{s}$ in der Untersuchungsregion.

Zur Überprüfung der Hypothese, dass Unsicherheiten in der Simulation des WAM aus Unsicherheiten in der Simulation des Sahara-Hitzetiefs resultieren, die induziert wurden durch Fehler in der simulierten Strahlung, wurde die Parametrisierung der Albedo im COSMO-CLM mit dem Ziel modifiziert, den simulierten Strahlungshaushalt besonders in den Wüstenregionen Afrikas zu verbessern. Der daraus resultierende Anstieg der Bodenalbedo um bis zu 0,2 in Wüstenregionen führte zu einem starken Rückgang der Temperaturüberschätzung um bis zu $3 \mathrm{~K}$. Der Einfluss auf den Fehler im Bodendruck in der Sahara war jedoch niedrig (bis zu 0,4 hPa). Die Änderung der Albedo hatte somit geringen Einfluss auf die Fehler in der Untersuchungsregion, konnte aber die Überschätzung der Temperatur, des Niederschlags und der Konvektion in der Sahel Region reduzieren.

\subsection{SCHLUSSFolgerungen}

Die Ergebnisse dieser Arbeit zeigten in den Simulationen mit dem RCM COSMO-CLM teils erhebliche Unterschätzungen der kurzwelligen Nettostrahlung in großen Teilen Europas und insbesondere über Meeresgebieten. Unter Berücksichtigung der Unterschiede in den Referenzdatensätzen waren die Ergebnisse des COSMO-CLM jedoch recht zufriedenstellend. Das Modell überschätzte die langwellige Nettostrahlung am Boden wie auch am Oberrand der Atmosphäre in vielen Teilen Europas. In Bezug auf die Differenz zwischen den Referenzdatensätzen waren diese Unterschiede aber ebenfalls nicht sehr groß.

Es zeigte sich, dass eine Erhöhung der Anzahl der atmosphärischen Schichten in den COSMO-CLM Simulationen von 20 auf 32 bessere Ergebnisse lieferte (außer für die langwellige Nettostrahlung am Oberrand der Atmosphäre und die langwellige Divergenz). Der Einsatz von 32 Schichten reduziert die Fehler in den Strahlungskomponenten um bis zu $40 \%$. Berücksichtigt man jedoch die Unsicherheiten der Referenzen und die lang- und kurzwelligen Kompensations- 
effekte, dann war die Verbesserung relativ gering. Im Hinblick auf die günstigeren Anforderungen an Rechenleistung ist die Verwendung von 20 Atmosphärenschichten deshalb eine nennenswerte Option bei der Simulation der Strahlungsbilanz.

Die Abschätzung möglicher Fehlerquellen ergab, dass Unsicherheiten in der Wolkenbedeckung und Bodenalbedo einen erheblichen Einfluss auf Unsicherheiten der kurzwelligen Nettostrahlung haben, wobei die erklärte Varianz für Unsicherheiten in der Wolkenbedeckung zweibis dreimal höher war als für Unsicherheiten in der Bodenalbedo.

Unsicherheiten in der Wolkenbedeckung führten zu erheblichen Fehlern in der langwelligen Nettostrahlung. Allerdings war der Einfluss von Unsicherheiten in der Bodentemperatur auf Fehler im langwelligen Strahlungsbudget gering oder sogar vernachlässigbar. Diese Ergebnisse konnten bei einem Vergleich mit Simulationen der regionalen Klimamodelle REMO und ALADIN bestätigen werden. Es ist deshalb zu erwarten, dass eine bessere Parametrisierung der relativ einfachen Parameter Wolkenbedeckung und Bodenalbedo eine wesentliche Verbesserung der Simulation der Strahlungsbilanzkomponenten im COSMO-CLM zur Folge hat.

Vergleiche der simulierten Strahlungsbudgets verschiedener RCMs für Westafrika zeigten, dass Probleme in der Simulation von kurz- und langwelligen Strahlungsflüssen ein verbreitetes Problem sind. Die meisten der untersuchten Modelle wiesen teils erhebliche Unter- bzw. Überschätzungen der kurz- und langwelligen Strahlungsbilanzen auf.

Ähnlich wie für Europa sind Unsicherheiten in der Wolkenbedeckung auch in den Simulationen für Afrika ein erheblicher Einflussfaktor auf Unsicherheiten in den simulierten Strahlungsflüssen. Für die Simulationen für Afrika waren Unsicherheiten in der Parametrisierung der Bodenalbedo jedoch sehr viel wichtiger, als für Europa. Über Land waren Unsicherheiten in der Wolkenbedeckung und Bodenalbedo im Durchschnitt sogar von ähnlicher Bedeutung. Auch Unsicherheiten der Bodentemperatur waren in Simulationen für Afrika von größerer Bedeutung. Während diese über dem Ozean vernachlässigbar waren, erreichten sie über Land ähnliche Werte der mittleren erklärten Varianz $(\approx 0.2)$ wie Unsicherheiten in der Wolkenbedeckung. Dies deutet auf eine geografische Abhängigkeit der Modellfehler hin. In dieser zweiten Studie wurde zudem die Annahme bekräftigt, dass eine verbesserte Parametrisierung der Bodenalbedo in RCMs zur Verbesserung des modellierten Strahlungshaushaltes insbesondere in Afrika führt.

Um zu untersuchen, wie sich die Anwendung dieser Annahme auf die Simulation des WAM auswirkt, wurde die bisherige Albedo für bloßen Boden im COSMO-CLM durch Werte ersetzt, die auf Satellitenmessungen basierten. Zuvor wurden die ECHAM5 und ERA-Interim angetriebenen Klimasimulationen für Afrika ausgewertet, um die Fähigkeit des Modells die wichtigsten Merkmale des WAM zu reproduzieren, festzustellen.

Es zeigte sich, dass die wichtigsten Merkmale des WAM im COSMO-CLM gut wiedergegeben wurden, jedoch waren die Verbesserungen gegenüber den Antriebsdaten nur geringfügig. Der Index der konvektiven Aktivität in den Modellsimulationen war viel zu hoch und Niederschlag wurde in großen Teilen der afrikanischen Tropen unterschätzt. Die teils erheblichen Unterschiede in den ECHAM5 und ERA-Interim angetriebenen Simulationen zeigten die Empfindlichkeit des RCM gegenüber den Randbedingungen und insbesondere der Meeresoberflächentemperatur. Eine zu starke nördliche Verschiebung des Monsuns im Modell wurde vom Land-See-Temperaturgradient und der Stärke des Sahara-Hitzetiefs beeinflusst. Folglich resultierte ein Teil der gefundenen Fehler aus den Antriebsdaten und ein Teil aus dem Modell selbst.

Durch die Modifikation der Parametrisierung der Albedo für bloßen Boden wurden die Fehler im Strahlungshaushalt und der $2 \mathrm{~m}$ Temperatur in der Sahara Region signifikant reduziert. Ebenso wurde die Überschätzung des Niederschlags und der Konvektion in der Sahelzone verringert. Der Einfluss dieser Modifikation auf das untersuchte WAM Gebiet war jedoch gering. Dies bestätigte, dass vor allem in Wüstenregionen Fehler in der Bodenalbedo ein treibender Faktor für Fehler im Strahlungshaushalt sind. Es gibt jedoch weitere wichtige noch nicht hinreichend verstandene Faktoren, die einen starken Einfluss auf die Qualität der Simulation des WAM haben.

Die vorliegende Arbeit liefert einen hilfreichen Beitrag zum besseren Verständnis von Strahlungsprozessen in RCMs. Eine detaillierte Studie des Istzustandes zeigte, dass RCM Simulati- 
onen teils erhebliche Fehler in den simulierten Komponenten der Strahlungsbilanz aufweisen. Unsicherheiten in der Wolkenbedeckung, der Bodenalbedo und der Bodentemperatur wurden als drei wichtige Unsicherheitsquellen in der Strahlungsmodellierung identifiziert. Die Quantifizierung des Einflusses dieser Größen offenbarte zum einen eine regionale Abhängigkeit und zum anderen, dass auch relativ einfache Parameter eine durchaus entscheidende Wirkung haben können. Die Untersuchung des simulierten WAM zeigte beispielhaft, dass es relevante Wechselwirkungen zwischen Unsicherheiten in der simulierten Strahlung und atmosphärischen Prozessen gibt. Auf diesem Wissen aufbauend konnten Modellsimulationen für Afrika durch die Modifikation der Bodenalbedo teils deutlich verbessert werden.

Die Analyse des Istzustandes, die Quantifizierung von Fehlerquellen und das Aufzeigen von Zusammenhängen ermöglichten es Wege zu finden Unsicherheiten in der simulierten Strahlung in RCMs zu reduzieren und Strahlungsprozesse besser zu verstehen. Die Größe der gefundenen Fehler, die Anzahl der möglichen Einflussgrößen und die Komplexität der Zusammenhänge zeigen aber, dass weiterhin Forschungsbedarf auf diesem Gebiet besteht.

\subsection{Ausblick}

Bei der Untersuchung von Unsicherheitsquellen lag der Hauptfokus dieser Arbeit auf der Wolkenbedeckung, der Bodenalbedo und der Bodentemperatur. Diese Größen erklärten einen großen Teil der gefundenen Unsicherheiten im Strahlungsbudget, aber bei Weitem nicht alles. Es sollten deshalb weitere Anstrengungen unternommen werden, um zusätzliche Unsicherheitsquellen zu quantifizieren. Es ist zum Beispiel nicht auszuschließen, dass ein Teil der Strahlungsunsicherheiten in der Sahara nicht auf die Bodenalbedo, sondern auf Fehler in der Parametrisierung von Aerosolen zurückzuführen ist. Die vorhandenen Modelldaten ließen jedoch keine detaillierte Untersuchung dieser Vermutung zu.

In den COSMO-CLM Simulationen für Afrika war ebenfalls eine teils starke Überschätzung von Konvektion beobachtet worden, deren Ursachen nicht genau bekannt sind. Ein Teil dieser Überschätzung kann auf Fehler in der SST des antreibenden Modells zurückgeführt werden. Weiterhin sind aber auch eine ungenaue Parametrisierung der Konvektion, eine fehlende Interaktion von Atmosphäre und Ozean oder Fehler in der Simulation von Tagesgängen verschiedener Parameter, denkbare Fehlerquellen.

Die im Appendix vorgestellte Betrachtung zum Einfluss der Topografie auf das Strahlungsbudget zeigte einige interessante Ergebnisse und könnte zum Beispiel durch die Betrachtung subskaliger Effekte verbessert und erweitert werden.

Die Untersuchungen von weiteren möglichen Fehlerquellen stehen gleichzeitig in Verbindung mit der Simulation des WAM. Die Ergebnisse dieser Arbeit zeigten, dass der Zusammenhang zwischen Strahlungsfehlern in der Sahara und dem WAM geringer ist als erwartet wurde. Aufgrund der enormen Wichtigkeit des WAM für den afrikanischen Kontinent, sollte eine weitere Verbesserung der Simulation des WAM angestrebt werden. Insbesondere die erwähnten Unsicherheiten in der Konvektionsparametrisierung stehen vermutlich in großem Zusammenhang mit der Qualität des simulierten WAM.

Die Arbeit mit dem COSMO-CLM war verbunden mit einem detaillierten Einblick in den Quellcode des Modells. Seit der Erstellung der ersten Version dieses RCMs wurde der Modellcode stetig durch diverse Personen bearbeitet. Dies führte neben einer konstanten Verbesserung des Modells aber zu einem immer komplexer werdenden Programmgeflecht, das nur noch von wenigen Personen in seiner Gesamtheit überblickt wird. Daraus resultiert, dass einzelne Prozesse, die nicht im Hauptfokus der aktuellen Wissenschaft stehen, leicht übersehen und vergessen werden können. So gibt es in heutigen RCMs diverse Gleichungen, die mit geringer Anstrengung durch neuere und erweiterte Erkenntnisse ersetzt werden könnten. Am Beispiel der Bodenalbedo war zu sehen, dass relativ einfache Änderungen an einer lange nicht beachteten Größe, durchaus ein beachtenswertes Verbesserungspotenzial haben können. So sollte neben der Arbeit an komplexen Größen, wie der Parametrisierung von Wolken oder Konvektion, eine stetige Pflege des Modellcodes stattfinden, die derartige Potenziale aufspürt. 



\section{Chapter 7}

Appendix

In this section the influence of topography on the simulated radiation in a regional climate model is investigated. 


\begin{abstract}
Many regional climate models use the assumption of horizontal planes to solve the radiation transport. Use of this assumption neglects the influence of sloping topography on the surface albedo (PALB) and on the short-wave incoming radiation at the surface (SIS). In this study a simple model modification was used to quantify this impact. By analyzing five-year ERA-Interim driven regional climate simulations for Africa, it was shown that the change of sun inclination angle by regarding sloping topography leads to direct changes in PALB and SIS, which affects several other climatological parameters. Relatively small changes in PALB and SIS were the trigger for changes in $2 \mathrm{~m}$ temperature, precipitation, cloud cover, and surface net short-wave radiation, whose strength depended on the regarded time-scale, decreasing with longer averaging periods. So, the strongest effects were not directly related to areas with the highest orography and were subject to several feedbacks.
\end{abstract}




\section{A1 InTROdUCTION}

Kothe \& Ahrens [2010] showed that in the Sahelian and Saharan area in some cases more than $60 \%$ of the solar budget error variance was explained by uncertainties in the surface albedo. Thus, especially in regions with low cloud fraction and vegetation, the surface albedo is a very important parameter in the simulation of radiation. Furthermore, Kothe et al. [2011] demonstrated for regional climate simulations with the COSMO-CLM that a warm bias in the Sahara region, induced by errors in the simulated radiation budget components, had strong influence on the simulated precipitation in the Sahel. In consequence the improvement of the surface albedo parameterization in climate models yields a relatively simple method of improving model simulations for the African continent.

There are various reasons for uncertainties of the surface albedo in climate models. Several regional climate models (RCMs) determine the surface albedo by a relatively simple function of soil moisture and a soil type specific background albedo value. Especially in sparsely populated regions of the world the defaults for background albedo or soil type can be uncertain or wrong. Kothe et al. [2011] showed for an RCM that the replacement of the soil-type based bare soil albedos by Moderate Resolution Imaging Spectroradiometer (MODIS) based bare soil albedos led to a warm bias reduction in the Sahara region of locally more than $3 \mathrm{~K}$. Another approach to improve the albedo parameterization in RCMs is the use of MODIS Bidirectional Reflectance Distribution Function (BRDF) and albedo data [e.g. Wang et al. 2004; Liang et al. 2005; Wang et al. 2007; Bao \& Lü 2009]. The use of satellite-based data can give a more sophisticated base for empirical surface albedo parameterizations, but particularly with respect to future climate projections the goal of climate modelers should be a physically based form of parameterization. There is uncertainty as to whether parameterizations based on current measurements will still be valid in future.

Another way of improving the simulated radiation is the consideration of topographic effects. A lot of numerical weather prediction (NWP) models and RCMs use the assumption of horizontal planes to solve the radiation transport and neglect by that the influence of the slope of surfaces, the orientation of slopes, or shadowing effects on radiation budget components and the surface albedo. Several studies proved the influence of topography on radiation budget components as well as on the surface albedo for high-resolution weather and climate models [e.g. Müller \& Scherrer 2005; Aguilar et al. 2010; Lai et al. 2010; Lee et al. 2010]. For high-resolution (40 m) simulations over complex terrain the results of Lai et al. [2010] showed that the impact of topographic effects on surface short-wave radiation is of importance for mesoscale land and atmospheric models. However, they also showed that these effects decrease as the grid box size increases.

By using a relatively simple modification we investigate the impact of topographic effects on surface albedo (PALB) and on the short-wave incoming radiation at the surface (SIS) in an RCM for a $50 \mathrm{~km}$ grid and different averaging time periods. In section A2 we will give a brief introduction to the RCM COSMO-CLM and detailed information about its surface albedo parameterization and the modifications used. The following section shows some results for five-year simulations for Africa using different model setups. Finally, the results are discussed in section A4. 
This section gives an overview of the RCM COSMO-CLM, with a detailed view to the albedo parameterization, and a brief description of theoretical background of the used modifications.

\section{A2.1 THE COSMO-CLM}

In this study we investigated four climate simulations using version 4.8.14 of the COSMO-CLM. The simulations were driven at the lateral boundaries the ERA-Interim reanalysis with a resolution of $\approx 0.70^{\circ}$ (T255) for the time period 1989-1993. The ERA-Interim (European Centre for Medium-range Weather Forecasts Re-Analysis) re-analysis product is a combination of numerical weather prediction model re-forecasting and an assimilation of diverse observational data [Simmons et al. 2006]. To avoid a spin-up, the simulations were initialized with climatological fields for soil temperature, soil water content, and canopy water amount. The computational domain of the COSMO-CLM simulations covered the whole African continent, with a dimension of $214 \times 221$ grid points, 35 vertical layers, and a grid spacing of $0.44^{\circ}$. The domain used for analyses in this study consists of the computational domain excluding a sponge zone of about five degrees from the outer boundaries. For numerical integration, we used a leapfrog scheme with a time step of $180 \mathrm{~s}$.

\section{A2.2 Albedo parameterization}

The soil albedo in COSMO-CLM is determined using a coefficient depending on the soil type, which is multiplied with the soil water content in the upper soil layer. The final surface albedo over land is a mixture of soil albedo, vegetation albedo and eventually snow albedo depending on the fraction of each. The COSMO-CLM differs between seven soil types basing on the Digital Soil Map of the World [see www.fao.org].

The albedo for direct short-wave radiation over land is calculated following Hou et al. [2002] by multiplying the surface albedo with a zenith angle dependency function. There are two zenith angle dependency functions for strong (bare soil) and weak (vegetation) dependencies, which are combined depending on the fraction of each. Over sea the albedo for direct short-wave radiation is determined by an empirical equation following Taylor et al. [1996].

\section{A2.3 Consideration of topographic EfFEcts}

Taking into account the topography, sun incidence angle changes relative to the inclination of the surface (Fig. A1). The zenith angle is determined relative to the normal level and changes according to the inclination. This change is dependent on the solar elevation Ts, the solar azimuth Ps, the surface orientation Pn and the slope of the surface Tn, and was described by Kondratiev [1977] as follows:

$$
\cos \alpha^{\prime}=\cos T_{n} \cdot \sin T_{s}+\sin T_{n} \cdot \cos T_{s} \cdot \cos \left(P_{s}-P_{n}\right)
$$

Based on these considerations the following topographic correction for SIS was derived:

$$
\mathrm{SIS}^{\prime}=\mathrm{SIS} \cdot \frac{\cos \alpha^{\prime}}{\cos \alpha}
$$

PALB and SIS are functions of the sun zenith angle. By consideration of sloping topography 
the inclination of solar radiation at the surface changes following Eq. 1 and induces by these changes in PALB and SIS. A negative value for Eq. 1 can be considered as a shadowing effect, where no direct radiation reaches the surface. In this case cos $\alpha^{\prime}$ is set to zero.
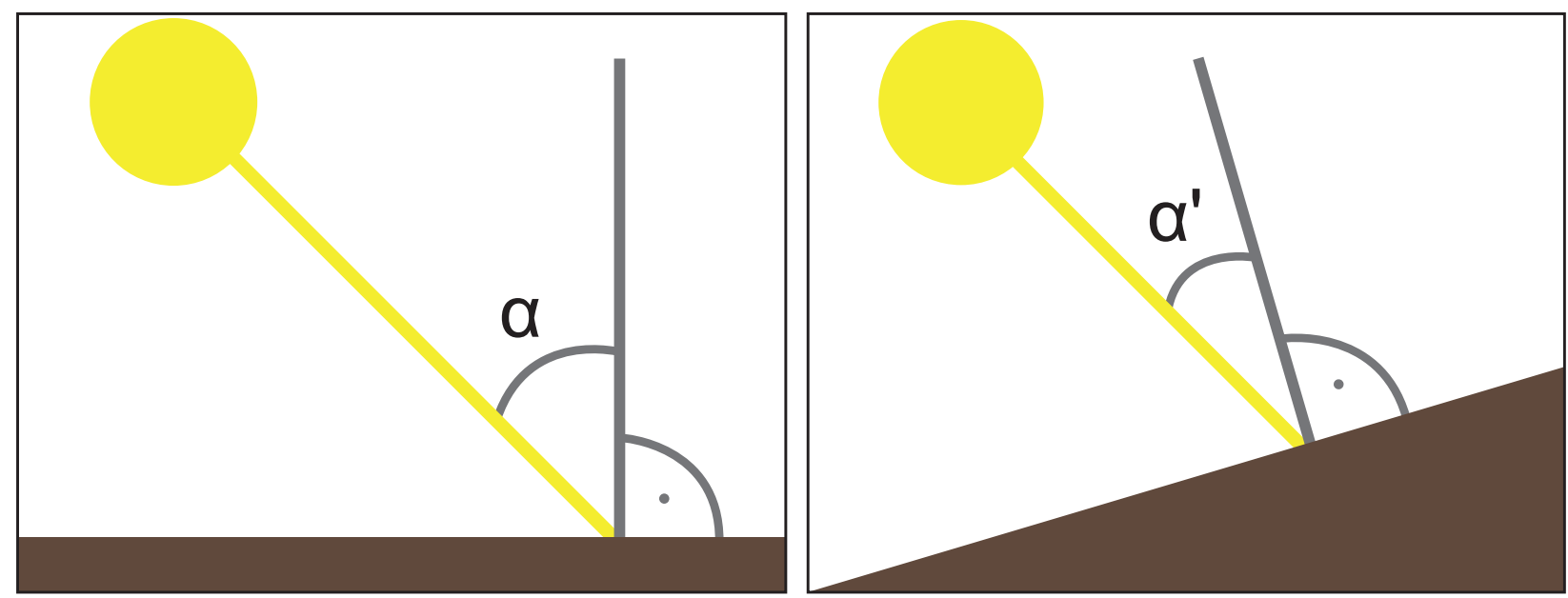

Figure A1 Incidence of solar parallel radiation: Simplified only for horizontal planes (left) and enhanced including sloping topography (right)

\section{A3 Results}

A primary aim of this study is to investigate whether or not the grid-scale topography has a significant influence on PALB and SIS. A secondary aim is to analyze whether a possible impact improves the simulations with COSMO_CLM for Africa and if it is worth using these modifications for regional climate model applications. Due to its importance for the West African Monsoon and due to the availability of observational data the main focus of this study is on the $2 \mathrm{~m}$ temperature (T2M) and precipitation (PREC). The direct impact of the model modifications is analyzed by looking at the surface short-wave net radiation (SNS), and PALB. We used the Global Precipitation Climatology Centre (GPCC) data product version 4 [Schneider et al. 2008] as the reference dataset for precipitation. GPCC provides a dataset of globally gridded rain gauge measurements with a spatial resolution of $0.5^{\circ}$. Observational data of the Climate Research Unit (CRU) [New et al. 2002] on a $0.5^{\circ}$ global grid were used to evaluate T2M. As a reference for SNS, we used the NASA/GEWEX SRB (Surface Radiation Budget) dataset (release 2.5), a satellite-based dataset on a $1^{\circ}$ global grid [Gupta et al. 2006; Zhang et al. 2007].

In the following subsections the results of four COSMO-CLM versions are shown. The only differences of these four model versions were: (A) no zenith angle dependence included; (B) with zenith angle dependence, but without topographic correction; (C) with zenith angle dependence and topographic correction for PALP, but without topographic correction for SIS; (D) with zenith angle dependence and full topographic correction.

\section{A3.1 Albedo for diRect parallel radiation (palb)}

Figure A2 shows the changes in PALB due to the consideration of topography. However, the overall changes in PALB were largest in regions with a high surface albedo, such as desert regions. Besides the slope of the terrain, the magnitude of the surface albedo was thus also important for changes in PALB. 


\section{A3.2 2M temperature (T2M)}

Figure A3 shows the differences of the simulated T2M to the CRU reference. Due to higher differences between $B$ and the reference, the color bar for the first column has another scaling than the one for the second to fourth column. The second column shows the difference of B-A, which illustrates the influence of the zenith angle dependence. Particularly in the North and South of Africa the addition of a zenith angle dependence of PALB increased T2M and decreased it in Central Africa. The impact of topography on PALB is illustrated in the third row by the difference $\mathrm{C}-\mathrm{B}$. In the Sahara region the topographic zenith angle correction led to a slight T2M decrease. The influence of the full topographic correction is displayed in column four by the difference D-B. Compared to the third column this shows that the corrections of PALB and SIS had local compensating or intensifying effects.

The graphics in Fig. A4 show different averaging intervals for T2M. Each of the four graphics has a different color bar interval to show that the influence of the topographic correction strongly depended on the regarded time period. For any instantaneous T2M field the differences could be stronger than $\pm 10 \mathrm{~K}$, while the annual mean had differences between $\pm 1 \mathrm{~K}$. The magnitude of these differences is in general representative for the respective time intervals.

The application of a zenith angle dependent PALB also influenced the diurnal temperature range (DTR). For the topographic corrected simulations the impact on the long-term annual mean of DTR is low with values up to $\pm 0.5 \mathrm{~K}$ (not shown).

\section{A3.3 Precipitation (PReC)}

The differences in PREC were quite patchy (Fig. A5, columns 2 to 4). Regarding the topographic correction (columns 3 and 4 ) the differences reached values of up to $\pm 17 \%$ for annual means, $\pm 36 \%$ for winter means, and $\pm 10 \%$ for summer means compared to the GPCC references. The spatial patterns of PREC were however not significantly improved.

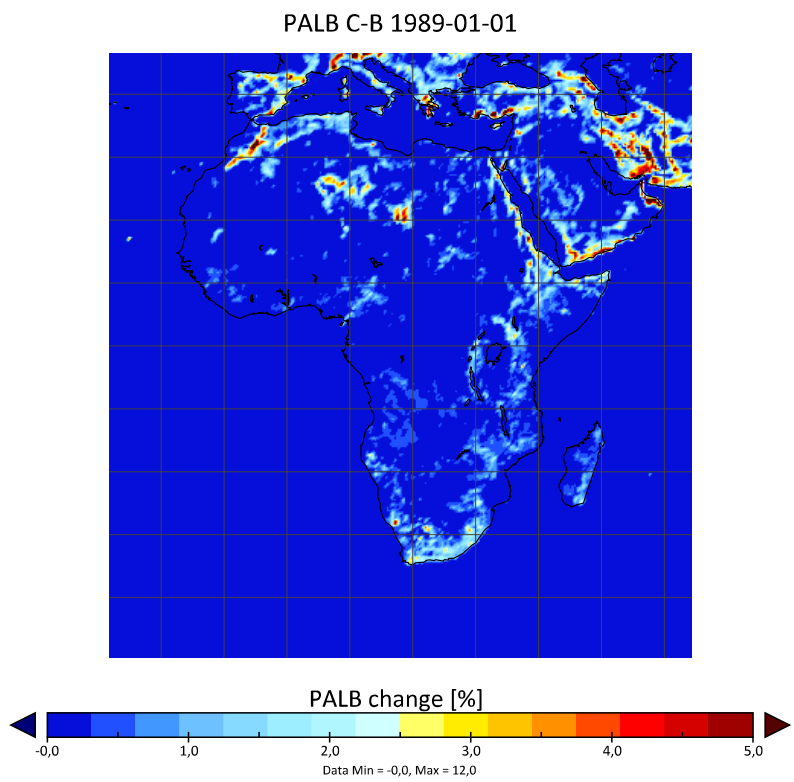

Figure A2 Maximum relative change of PALB modulus for C-B on 1989-01-01 

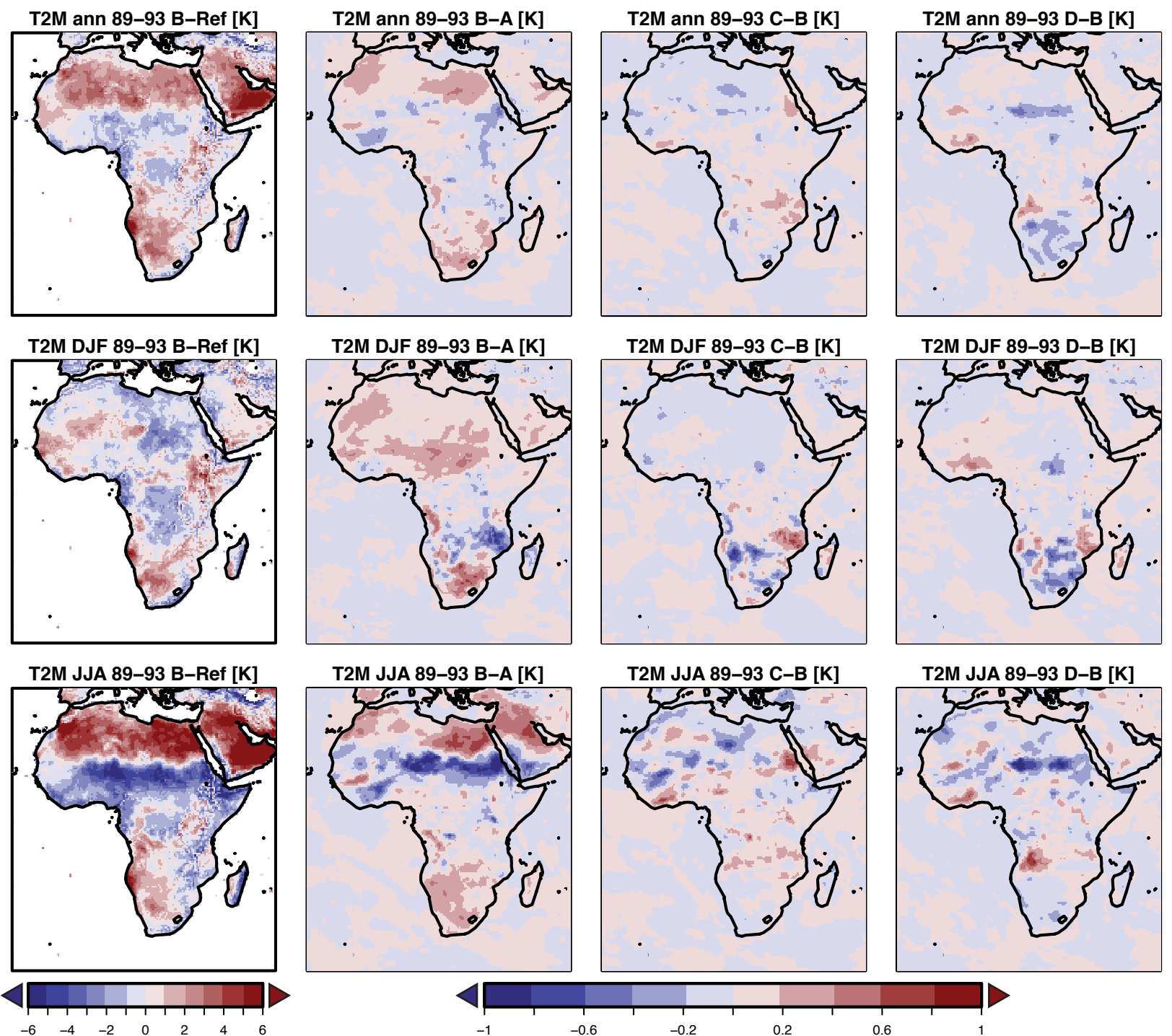

Figure A3 Difference plots of T2M for the period 1989-1993. The first column is $B$ minus reference (CRU), second is $B-A$, third is $C-B$, fourth is $D-B$. The upper row shows annual means, mid row shows winter (DJF) means, lower row shows summer (JJA) means

\section{A3.4 SuRface Net SHORT-WAVE RADIATION (SNS)}

The first column of Fig. A6 shows that there were quite large differences, in some cases of more than $50 \%$ in the simulated SNS. Compared to these differences, the differences resulting from the topographic correction (columns 3 and 4 ) and the zenith angle dependence (column 2 ) were relatively small with maximum values of about $\pm 10 \mathrm{~W} / \mathrm{m}^{2}$. The topographic correction yielded no significant improvement in case of long-term spatial fields. 

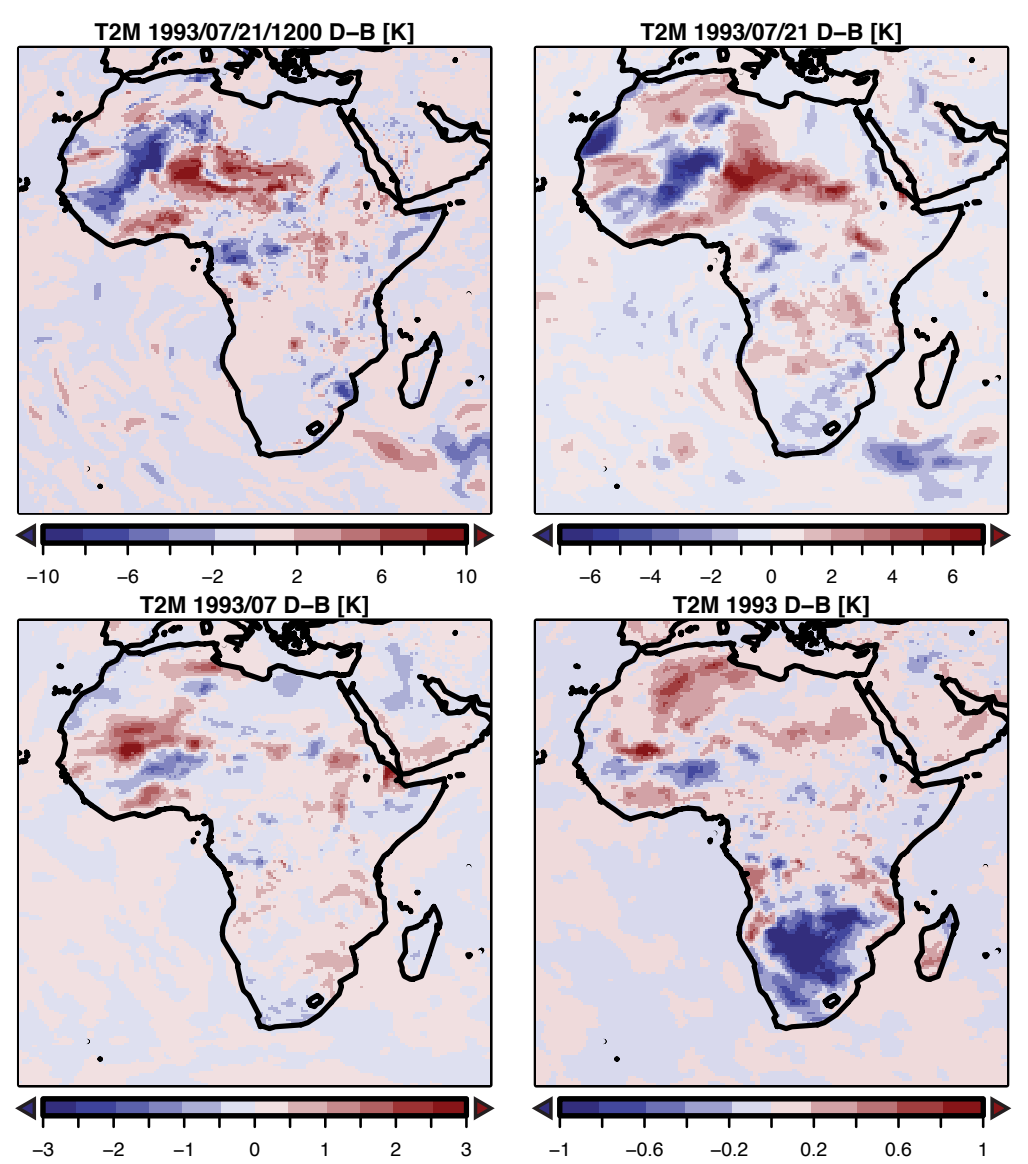

Figure A4 T2M differences between D minus B for: 93/07/21 noon (top left), 93/07/21 daily mean (top right), 93/07 monthly mean (bottom left), 1993 annual mean (bottom right)

\section{A4 Discussion \& Conclusions}

The results shown in section A3 illustrate that relatively small changes in PALB and SIS were able to trigger substantial changes in T2M, PREC, and SNS. For long-term means the magnitude of these changes was small compared to the ascertained differences to observational data. For T2M the modifications of PALB and SIS induced changes of long-term annual means between $\pm 1 \mathrm{~K}$, and for single monthly means between $\pm 3 \mathrm{~K}$. The changes for PREC long-term annual mean sum were between $\pm 400 \mathrm{~mm}$, and $\pm 250 \mathrm{~mm}$ for long-term seasonal mean sums. For long-term annual means of SNS the differences were between $7 \mathrm{~W} / \mathrm{m}^{2}$, but for long-term seasonal means there were values up to $\pm 20 \mathrm{~W} / \mathrm{m}^{2}$.

An obvious feature of these results was that differences were clearly stronger for shorter averaging periods. This indicated that topography linked changes in PALB and SIS had impact on T2M, PREC, and SNS in the whole domain. These impacts were not directly linked to topographic features, so compensating effects led to reduced differences for longer averaging time periods. For example in many cases changes in T2M and SNS were related to changes in cloud fraction (CFR) (not shown), a spatial and temporal highly variable parameter. The sensitivity of the model results to small changes in PALB or SIS was also visible in the difference between C and $D$ (Fig. A3, A5, A6, columns 3 and 4). Main structural features in $C$ and $D$ were mainly similar, but there were also areas were the effects of the PALB and SIS modifications compensated or intensified each other.

Our analysis showed that the change in PALB intensified itself by different feedbacks. The induced changes in PREC and T2M led to a change in soil moisture. Even after a few months of simulation the change in PALB induced by changes in soil moisture exceeded the 
PREC ann 89-93 B-Ref [mm]

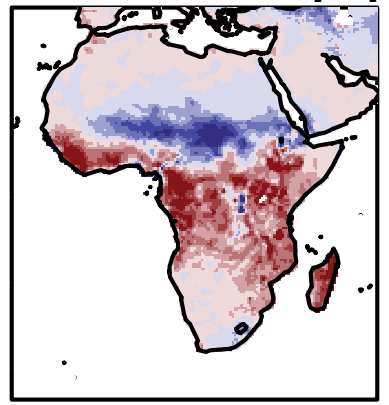

PREC DJF 89-93 B-Ref [mm]

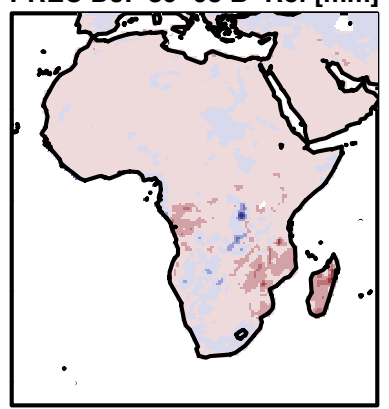

PREC JJA 89-93 B-Ref [mm]

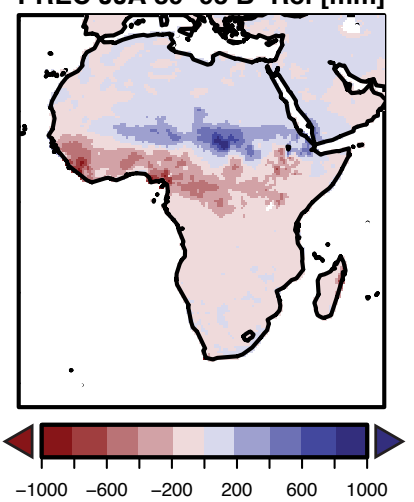

PREC ann 89-93 B-A [mm]

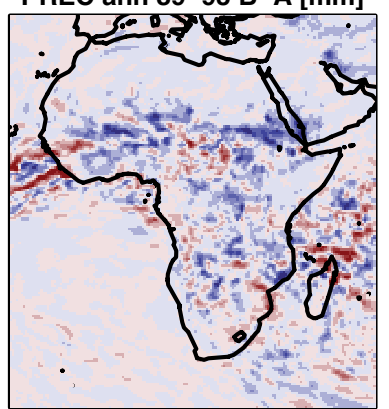

PREC DJF 89-93 B-A [mm]

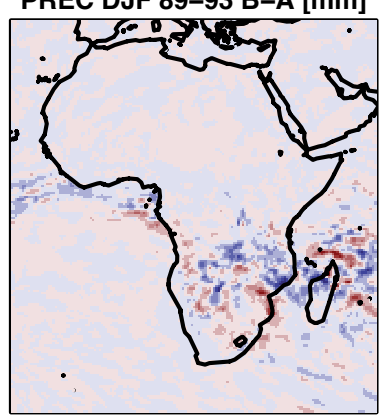

PREC JJA 89-93 B-A [mm]
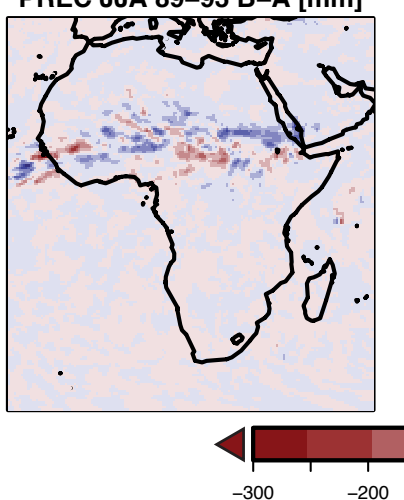

PREC ann 89-93 C-B [mm]

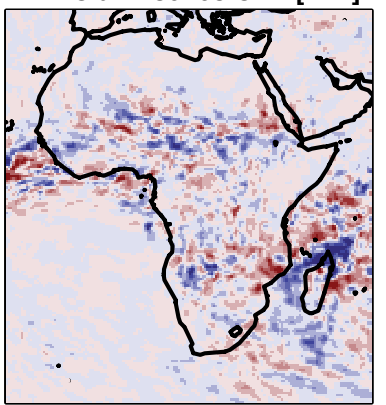

PREC DJF 89-93 C-B [mm]

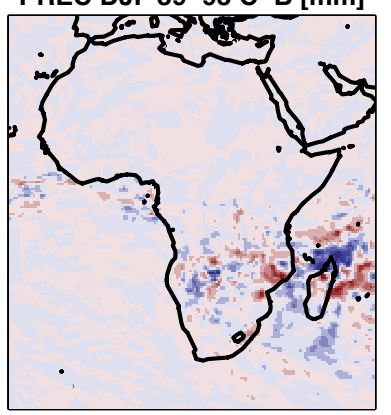

PREC JJA 89-93 C-B [mm]
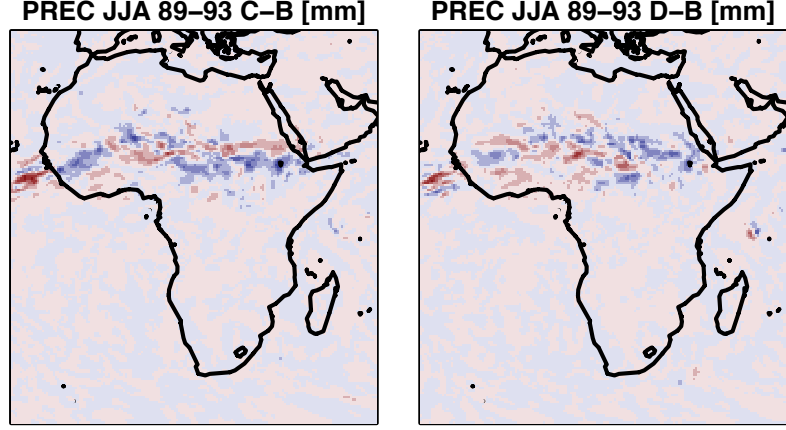

PREC JJA 89-93 D-B [mm]

PREC DJF 89-93 D-B [mm]

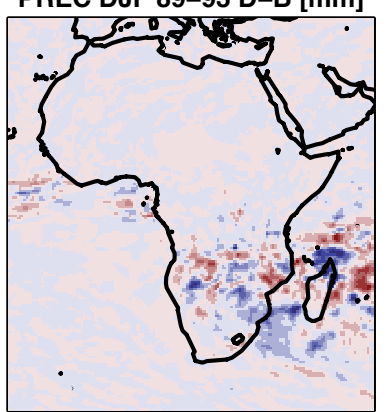

PREC ann 89-93 D-B [mm]
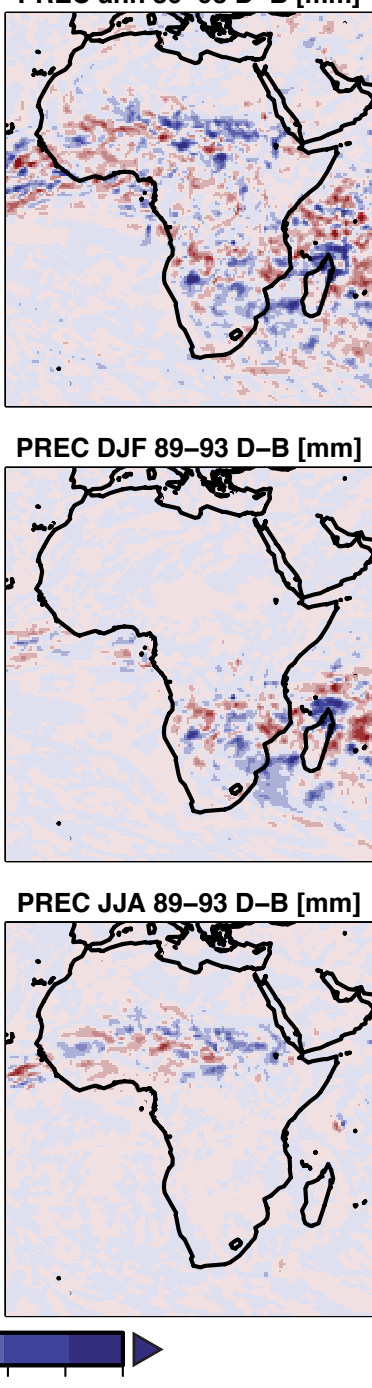

Figure A5 Difference plots of PREC for the period 1989-1993. The first column is B minus reference (GPCC), second is $B-A$, third is $C-B$, fourth is $D-B$. The upper row shows annual mean sums, mid row shows winter (DJF) mean sums, lower row shows summer (JJA) mean sums

changes induced by topography. Depending on the aspect of sloping planes the maximum change in PALB was about $1 \%$ per $1^{\circ}$ of slope. But, due to the aspect of sloping planes the changes in PALB can partly compensate in the course of the day, while changes induced by soil moisture changes do not. In addition the magnitude of the slopes and the resulting magnitude of the changes in PALB and SIS were dependent on the horizontal resolution. For the $0.44^{\circ}$ grid used, maximum slopes were found in the Ethiopian Highlands, at the coast of South Africa, or in the Atlas mountains, reaching values between four to nine degrees. For higher horizontal resolutions slopes and resulting changes in PALB will increase.

For climatologic applications the impact induced by topographic effects on PALB and SIS was thus relatively small. However, the changes ascertained were in general in the right direction and previous model errors were slightly improved. It was shown that the zenith angle dependence of PALB had a clear impact on model results, but that in some cases errors were enhanced by this dependence. The applied modifications concerning topographic effects on PALB and SIS were able to counteract some of these errors with negligible additional computing time. 
SNS ann 89-93 B-Ref $\left[\mathrm{W} / \mathrm{m}^{2}\right]$

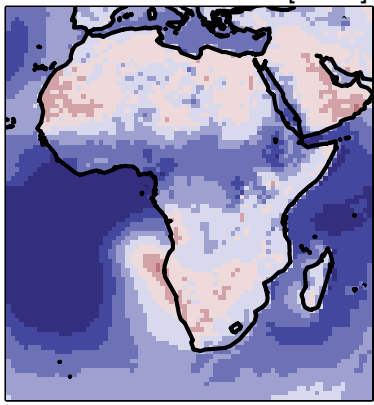

SNS DJF 89-93 B-Ref [W/m²]

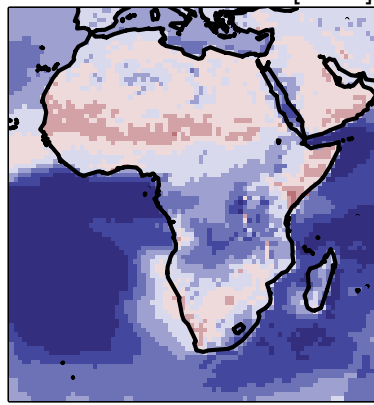

SNS JJA 89-93 B-Ref [W/m²]
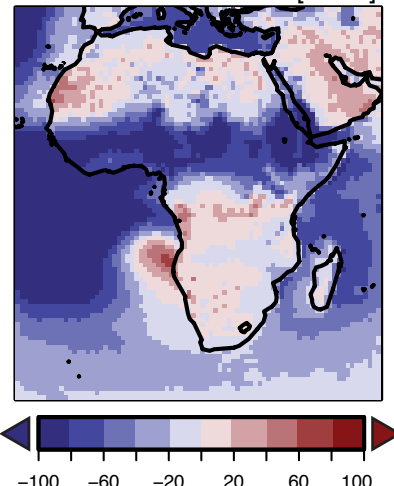

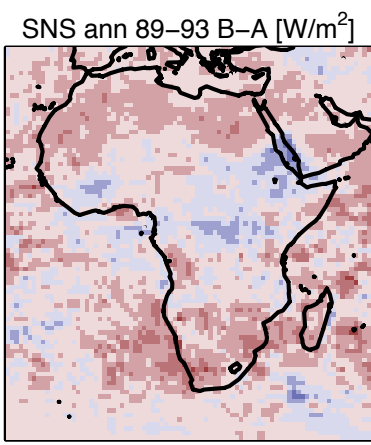

SNS DJF 89-93 B-A [W/m²]

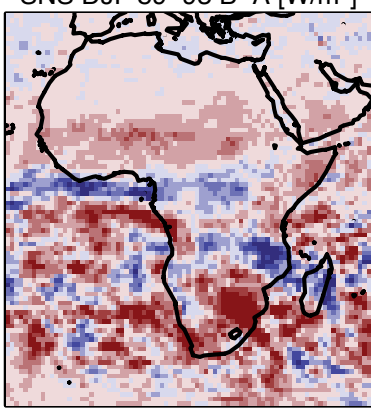

SNS JJA 89-93 B-A [W/m²]
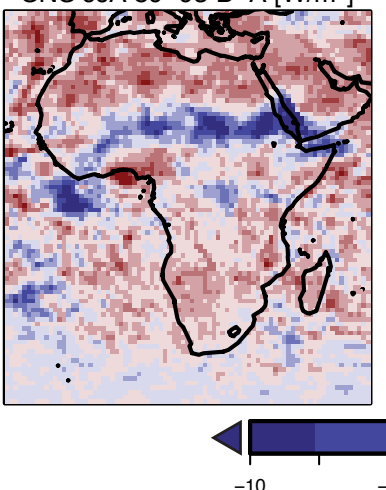

SNS ann 89-93 C-B $\left[\mathrm{W} / \mathrm{m}^{2}\right]$

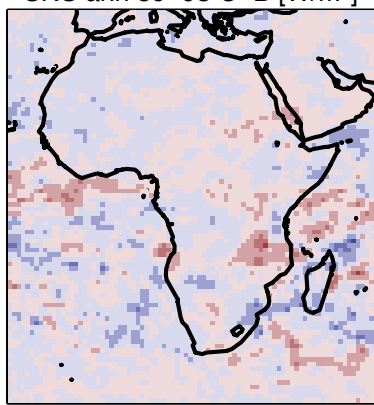

SNS DJF 89-93 C-B [W/m²]

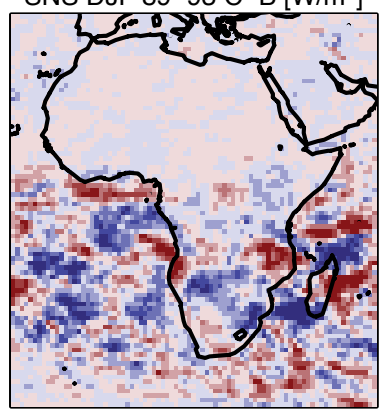

SNS JJA 89-93 C-B [W/m²]

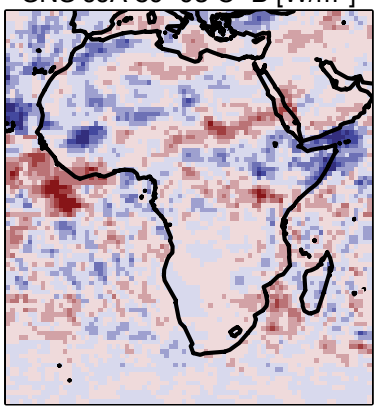

SNS ann 89-93 D-B [W/m²]

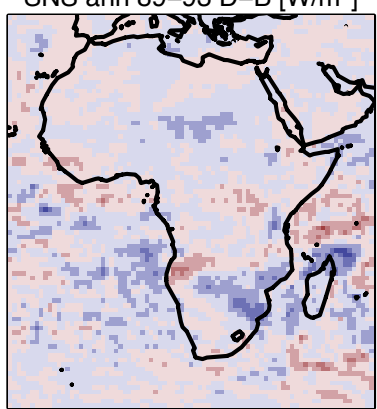

SNS DJF 89-93 D-B [W/ $\left./ \mathrm{m}^{2}\right]$

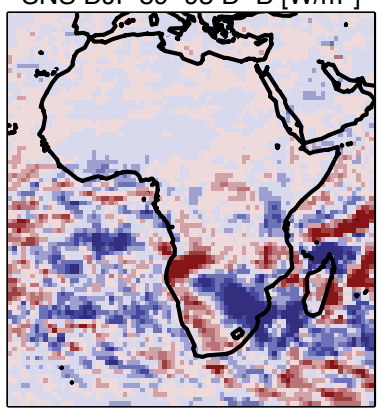

SNS JJA 89-93 D-B [W/m²]
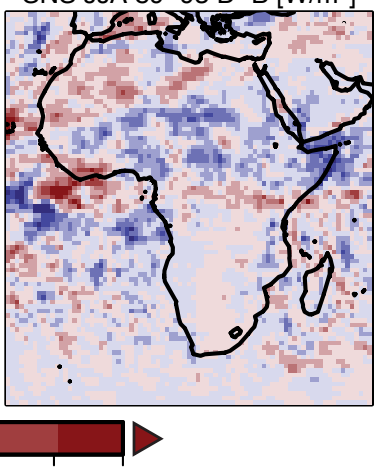

Figure A6 Difference plots of SNS for the period 1989-1993. The first column is B minus reference (SRB), second is $B-A$, third is $C-B$, fourth is $D-B$. The upper row shows annual means, mid row shows winter (DJF) means, lower row shows summer (JJA) means 



\section{REFERENCES}

Abiodun BJ, Pal JS, Afiesimama EA, Gutowski WJ, Adedoyin A (2008) Simulation of West African monsoon using RegCM3 Part II: impacts of deforestation and desertification. Theor Appl Climatol 93: 245261. doi:10.1007/s00704-007-0333-1

Afiesimama EA, Pal JS, Abiodun BJ, Gutowski WJ, Adedoyin A (2006) Simulation of West African monsoon using the RegCM3. Part I: model validation and interannual variability. Theor Appl Climatol 86:2337. doi:10.1007/s00704-005-0202-8

Aguilar C, Herrero J, Polo MJ (2010) Topographic effects on solar radiation distribution in mountainous watersheds and their influence on reference evapotranspiration estimates at watershed scale. Hydrol Earth Syst Sci 7:2479-2494. Retrieved from http://www.hydrol-earth-syst-sci-discuss.net/7/2373/2010/

Ahrens B, Karstens U, Rockel B, Stuhlmann R (1998) On the validation of the atmospheric model REMO with ISCCP data and precipitation measurements using simple statistics. Meteorol Atmos Phys (68):127142. doi:10.1007/BF01030205

Ahrens B (2003) Evaluation of precipitation forecasting with the limited area model ALADIN in an alpine watershed. Meteorol Z 12:245-255

Allen J (1971) Measurements of cloud emissivity in the 8-13 I waveband. J Appl Meteorol 10:260-265 Beck A, Ahrens B, Stadelbacher K (2004) Impact of nesting strategies in dynamical downscaling of reanalysis data. Geophys Res Lett 31:L19101. doi:10.1029/2004GL020115

Anthes RA, Hsie E-Y, Kuo Y-H (1987) Description of the Penn State/NCAR mesoscale model version 4 (MM4). Natl Cent for Atmos Res Tech Note 282. Boulder, Colo

Balsamo G, Viterbo P, Beljaars A, van den Hurk B, Hirschi M, Betts AK, Scipal K (2009) A revised hydrology for the ECMWF model: Verification from field site to terrestrial water storage and impact in the Integrated Forecast System. J Hydrometeorol 10:623-643

Bao Y, Lü S (2009) Improvement of surface albedo parameterization within a regional climate model (RegCM3). Hydrol Earth Syst Sci Discuss 6:1651-1676. doi:10.5194/hessd-6-1651-2009

Biasutti M, Sobel AH, Camargo SJ (2009) Role of the Sahara low in summertime Sahel rainfall variability in the CMIP3 models. J Climate 22:5755-5771. doi:10.1175/2009JCLI2969.1

Böhm U, Kücken M, Ahrens W, Block A, Hauffe D, Keuler K, Rockel B, Will A (2006) CLM—the climate version of LM: brief description and long-term applications. COSMO Newsl 6:225-235

Braconnot P, Hourdin F, Bony S, Dufresne JL, Grandpeix JY, Marti O (2007) Impact of different convective cloud schemes on the simulation of the tropical seasonal cycle in a coupled ocean-atmosphere model. Clim Dyn 29:501-520. doi: 10.1007/s00382-007-0244-y

Bringfelt B, Räisänen J, Gollvik S, Lindström G, Graham LP, Ullerstig A (2001) The land surface treatment for the Rossby Centre Regional Atmospheric Climate Model version 2 (RCA2). Rep Meteorol Climatol 98:40. Swed Meteorol and Hydrol Inst. Norrköping, Sweden

Charney JG (1975) Dynamics of deserts and drought in the Sahel. Q J R Meteorol Soc 101:193-202. doi:10.1002/qj.49710142802 
Christensen OB, Christensen JH, Machenhauer B, Botzet M (1998) Very high resolution regional climate simulations over Scandinavia - Present climate. J Clim 11:3204-3229

Cook KH, Vizy EK (2006) Coupled Model Simulations of the West African Monsoon System: Twentiethand Twenty-First-Century Simulations. J Climate 19:3681-3703. doi: 10.1175/JCLI3814.1

Corti T, Peter T (2009) A simple model for cloud radiative forcing. Atmos Chem Phys Discuss 9:85418560 Dobler A, Ahrens B (2008) Precipitation by a regional climate model and bias correction in Europe and South Asia. Meteorol Z 17(4):499-509

Cox PM, Betts RA, Bunton CB, Essery RLH, Rowntree PR (1999) The impact of new land surface physics on the GCM simulation of climate and climate sensitivity. Clim Dyn 15:183-203

Dalu GA, Gaetani M, Baldi M (2008) A hydrological onset and withdrawal index for the West African monsoon. Theor Appl Climatol 96:179-189. doi:10.1007/s00704-008-0022-8

Davies HC (1976) A lateral boundary formulation for multi-level prediction models. Q J R Meteorol Soc 102:405-418

Davin EL, de Noblet-Ducoudré N (2010) Climatic Impact of Global-Scale Deforestation: Radiative versus Nonradiative Processes. J Climate. 23:97-112. doi:10.1175/2009JCLI3102.1

Dickinson RE, Henderson-Sellers A, Kennedy PJ (1993) Biosphere - atmosphere transfer scheme (BATS) version 1e as coupled to the NCAR community climate model. Tech Note NCAR-TN-387 +STR 72. Natl Cent Atmos Res. Boulder, Colo

Dinku T, Connor SJ, Ceccato P, Ropelewski CF (2008) Comparison of global gridded precipitation products over a mountainous region of Africa. Int J Climatol 28:1627-1638. doi: 10.1002/joc.1669

Dobler A, Ahrens B (2010) Analysis of the Indian summer monsoon system in the regional climate model COSMO-CLM. J Geophys Res 115. doi:10.1029/2009JD013497

Domínguez M, Gaertner MA, de Rosnay P, Losada T (2010) A regional climate model simulation over West Africa: Parameterization tests and analysis of land surface fields. Clim Dyn 35:249-265. doi:10.1007/s00382-010-0769-3

Druyan LM, Fulakeza M, Lonergan P (2008) The impact of vertical resolution on regional model simulation of the West African summer monsoon. Int J Climatol 28:1293-1314. doi:10.1002/joc.1636

Druyan LM, Feng J, Cook KH, Xue Y, Fulakeza M, Hagos SM, Konaré A, Moufouma-Okia W, Rowell DP, Vizy EK, Ibrah SS (2010) The WAMME regional model intercomparison study. Clim Dyn 35:175-192. doi:10.1007/s00382-009-0676-7

Ducoudré N, Kaval K, Perrier A (1993) Sechiba, a new set of parameterizations of the hydrologic exchanges at the land-atmosphere interface within the LMD atmospheric general circulation model. J Clim $6: 248-273$

Dümenil L, Todini E (1992) A rainfall-runoff scheme for use in the Hamburg climate model. in Advances in Theoretical Hydrology. A Tribute to James Dooge. European Geophysical Society Series on Hydrological Sciences 1. edited by O'Kane JP. 129-157. Elsevier, Amsterdam

Edwards JM, Slingo A (1996) Studies with a flexible new radiation code. I: Choosing a configuration for a large scale model. Q J R Meteorol Soc 122:689-719 
Fontaine B, Janicot S (1992) Wind-Field Coherence and Its Variations over West Africa. J Climate 5:512524. doi: 10.1175/1520-0442(1992)005<0512:WFCAIV>2.0.CO;2

Fontaine B, Louvet S, Roucou P (2007) Fluctuations in annual cycles and interseasonal memory in West Africa: rainfall, soil moisture and heat fluxes. Theor Appl Climatol 88:57-70. doi:10.1007/s00704-0060246-4

Fontaine B, Louvet S, Roucou P (2008) Definition and predictability of an OLR-based West African monsoon onset. Int J Climatol 28:1787-1798. doi:10.1002/joc.1674

Frei C, Christensen JH, Déqué M, Jacob D, Jones RG, Vidale PL (2003) Daily precipitation statistics in regional climate models: evaluation and intercomparison for the European Alps. J Geophys Res 108(D3):4124. doi:10.1029/2002JD002287

Garand L (1983) Some improvements and complements to the infrared emissivity algorithm including a parameterization of the absorption in the continuum region. J Atmos Sci 40:230-244

Garric G, Douville H, Déqué M (2002) Prospects for improved seasonal predictions of monsoon precipitation over Sahel. Int J Climatol 22:331-345. doi:10.1002/joc.736

Gibson JK, Kallberg P, Uppala S, Nomura A, Hernandez A, Serrano E (1997) ERA description. ECMWF ERA15 Project Report Series, 1

Giorgetta M, Wild M (1995) The water vapour continuum and its representation in ECHAM4. 162:38. Max-Planck-Inst für Meteorol, Hamburg, Germany

Giorgi F, Marinucci MR, Visconti G (1990) Use of a limited area model nested in a general circulation model for regional climate simulation over Europe. J Geophys Res 95(18):413-418 431

Giorgi F, Marinucci MR, Bates GT, DeCanio G (1993) Development of a second generation regional climate model (REGCM2). Part II: Cumulus cloud and assimilation of lateral boundary conditions. Mon Weather Rev 121:2814-2832

Giorgi F, Huang Y, Nishizawa K, Fu C (1999) A seasonal cycle simulation over eastern Asia and its sensitivity to radiative transfer and surface processes. J Geophys Res 104:6403-6423. doi:10.1029/ 1998JD200052

Goosse H, Barriat PY, Lefebvre W, Loutre MF, Zunz V (July 2011) Introduction to climate dynamics and climate modeling. Online textbook available at http://www.climate.be/textbook

Goswami BN, Krishnamurthy V, Annamalai H (1999) A broad scale circulation index for the interannual variability of the Indian summer monsoon. Q J R Meteorol Soc 125:611-633. doi: 10.1002/qj.49712555412

Grasselt R, Schüttemeyer D, Warrach-Sagi K, Ament F, Simmer C (2008) Validation of TERRA-ML with discharge measurements. Meteorol Z 17:763-773. doi:10.1127/0941-2948/2008/0334

Gregory D, Allen S (1991) The effect of convective downdraughts upon NWP and climate simulations, paper presented at the Ninth Conference on Numerical Weather Prediction. Am Meteorol Soc. Denver, Colo, 14-18 October 1991

Gregory D, Rowntree PR (1990) A mass-flux convection scheme with representation of cloud ensemble characteristics and stability dependent closure. Mon Weather Rev 118:1483-1506 
Grell GA (1993) Prognostic evaluation of assumptions used by cumulus parameterizations. Mon Weather Rev 121:764-787

Gupta SK, Ritchey NA, Wilber AC, Whitlock CH, Gibson GG, Stackhouse PW (1999) A climatology of surface radiation budget derived from satellite data. J Clim 12:2691-2710

Gupta SK, Stackhouse PW, Mikovitz JC, Cox SJ, Zhang T (2006) Surface radiation budget project completes 22-year data set. GEWEX WCRP News 16(4):12-13

Hagemann S, Machenhauer B, Jones R, Christensen O, Déqué M, Jacob D, Vidale P (2004) Evaluation of water and energy budgets in regional climate models applied over Europe. Clim Dyn 23(5):547-567

Haugen JE, Iversen T (2008) Response in extremes of daily precipitation and wind from a downscaled multi-model ensemble of anthropogenic global climate change scenarios. Tellus 60A:411-426. doi:10.1111/j.1600-0870.2008.00315.x

Hewitt CD, Griggs DJ (2004) Ensembles-based predictions of climate changes and their impacts. Eos 85:566. doi:10.1029/2004EO520005

Hohenegger C, Vidale PL (2005) Sensitivity of the European climate to aerosol forcing as simulated with a regional climate model. J Geophys Res 110:D06201. doi:10.1029/2004JD005335

Hollweg HD, Fast I, Hennemuth B, Keup-Thiel E, Lautenschlager M, Legutke S, Schubert M, Wunram C (2008) Ensemble simulations over Europe with the regional climate model CLM forced with IPCC AR4 global scenarios. Technical Report No. 3, Max Planck Institute for Meteorology, Hamburg, Germany

Hou Y-T, Moorthi S, Campana KA (2002) Parameterization of solar radiation transfer in the NCEP models. NCEP Office Note 441

Hsie E-Y, Anthes RA, Keyser D (1984) Numerical simulation of frontogenesis in a moist atmosphere. J Atmos Sci 41:2581-2594

Jacob D, Andrae U, Elgered G, Fortelius C, Graham LP, Jackson SD, Karstens U, Koepken C, Lindau R, Podzun R, Rockel B, Rubel F, Sass HB, Smith RND, Van den Hurk BJJM, Yang X (2001) A comprehensive model intercomparison study investigating the water budget during the BALTEX-PIDCAP period. Meteorol Atmos Phys 77:19-43

Jacob $D$ (2001) A note to the simulation of the annual and inter-annual variability of the water budget over the Baltic Sea drainage basin. Meteorol Atmos Phys 77:61-73

Jacob D, Bärring L, Christensen OB, Christensen JH, de Castro M, Déqué M, Giorgi F, Hagemann S, Hirschi M, Jones R, Kjellström E, Lenderink G, Rockel B, Sànchez ES, Schär C, Seneviratne SI, Somot S, van Ulden A, van den Hurk B (2007) An inter-comparison of regional climate models for Europe: design of the experiments and model performance. Clim Change 81(1):31-52. doi:10.1007/s10584-006-9213-4

Jaeger EB, Anders I, Lüthi D, Rockel B, Schär C, Seneviratne SI (2008) Analysis of ERA40-driven CLM simulations for Europe. Meteorol Z 17(4):349-367

Jaeger EB, Stöckli R, Seneviratne SI (2009) Analysis of planetary boundary layer fluxes and land-atmosphere coupling in theregional climate model CLM. J Geophys Res 114:D17106. doi: 10.1029/2008JD011658 
Janicot S, Thorncroft CD, Ali A, Asencio N, Berry GJ, Bock O, Bourles B, Caniaux G, Chauvin F, Deme A, Kergoat L, Lafore J-P, Lavaysse C, Lebel T, Marticoréna B, Mounier F, Nédélec P, Redelsperger J-L, Ravegnani F, Reeves CE, Roca R, de Rosnay P, Schlager H, Sultan B, Tomasini M, Ulanovsky A, and ACMAD forecasters team (2008) Large-scale overview of the summer monsoon over West Africa during the AMMA field experiment in 2006, Ann Geophys 26:2569-2595. doi:10.5194/angeo-26-2569-2008

Jones RG, Murphy JM, Noguer M (1995) Simulation of climate change over Europe using a nested regional climate model. I. Assessment of control climate, including sensitivity to location of lateral boundaries. Q J R Meteorol Soc 121:1413-1449

Kain J, Fritsch JM (1990) A one dimensional entraining/detraining plume models and its application to convective parameterization. J Atmos Sci 47:2784-2802

Kalnay E, Kanamitsu M, Kistler R, Collins W, Deaven D, Gandin L, Iredell M, Saha S, White G, Woollen J, Zhu Y, Chelliah M, Ebisuzaki W, Higgins W, Janowiak J, Mo KC, Ropelewski C, Wang J, Leetmaa A, Reynolds R, Jenne R, Joseph D (1996) The NCEP/NCAR 40-year reanalysis project. Bull Amer Meteor Soc 77:437-471. doi:10.1175/1520-0477(1996)077\%3C0437:TNYRP\%3E2.0.CO;2

Kemp D (July 2011) http://www.libraryindex.com/pages/3216/Climate-Models-Uncertainty.html - Climate Models and Uncertainty - Model Types, General circulation models, Evaluation and Reliability, Models of intermediate complexity, energy balance models

Kessler E (1969) On the Distribution and Continuity of Water Substance in Atmospheric Circulations. Meteorol Monogr 10:88

Kiehl JT, Hack JJ, Bonan GB, Boville BA, Briegleb BB, Williamson DL, Rasch PJ (1996) Description of the NCAR community climate model (CCM3). Natl Cent for Atmos Res Tech Note NCAR/TN420+STR:152. Boulder, Colo

Kiehl JT, Trenberth KE (1997) Earth's Annual Global Mean Energy Budget. Bull Amer Meteor Soc 78:197-208

Kondratiev KY (1977) Radiation regime of inclined surfaces. WMO Tech. Note 152:82

Kothe S, Dobler A, Beck A, Ahrens B (2010) The radiation budget in a regional climate model. Clim Dyn 36:1023-1036. doi:10.1007/s00382-009-0733-2

Kothe S, Ahrens B (2010) On the Radiation Budget in Regional Climate Simulations for West Africa. J Geophys Res 115:D23120. doi:10.1029/2010JD014331

Kothe, S, Lüthi D, Ahrens B (2011) Analysis of the West African Monsoon system in the regional climate model COSMO-CLM. Submitted to Clim Dyn

Kumar KR, Sahai AK, Kumar KK, Patwardhan SK, Mishra PK, Revadekar JV, Kamala K, Pant GB (2006) High-resolution climate change scenarios for India for the 21st century. Curr Sci 90:334-345

Lai Y-J, Chou M-D, Lin P-H (2010) Parameterization of topographic effect on surface solar radiation, J Geophys Res 115. doi:10.1029/2009JD012305

Lau K-M, Kim K-M, Yang S, Dynamical and boundary forcing characteristics of regional components of Asian summer monsoon. J Climate 13:2461-2482. doi:10.1175/15200442(2000)013<2461:DABFCO>2.0.CO;2 
Lawrence PJ, Chase TN (2007) Representing a new MODIS consistent land surface in the Community Land Model (CLM 3.0). J Geophys Res 112. doi:10.1029/2006JG000168

Le Barbé L, Lebel T, Tapsoba D (2002) Rainfall Variability in West Africa during the Years 1950-90. J Climate 15:187-202. doi:10.1175/1520-0442(2002)015\%3C0187:RVIWAD\%3E2.0.CO;2

Lee W-L, Liou KN, Hall A (2011) Parameterization of solar fluxes over mountain surfaces for application to climate models. J Geophys Res 116. doi:10.1029/2010JD014722

Leung LR, Mearns LO, Giorgi F, Wilby RL (2003) Regional climate research. Bull Am Meteorol Soc 84:89-95 Markovic M, Jones CG, Vaillancourt PA, Paquin D, Winger K, Paquin-Ricard D (2008) An evaluation of the surface radiation budget over North America for a suite of regional climate models against surface station observations. Clim Dyn 31(7-8):779-794

Li J, Zeng Q (2002) A unified monsoon index. Geophys Res Lett 29(8):1274. doi:10.1029/2001GL013874

Liang X-Z, Xu M, Gao W, Kunkel KE, Slusser J, Dai Y, Min Q, Houser PR, Rodell M, Schaaf CB, Gao F (2005) Development of land surface albedo parameterization bases on Moderate Resolution Imaging Spectroradiometer (MODIS) data. J Geophys Res 110. doi:10.1029/2004JD005579

Lin Y-L, Farley RD, Orville HD (1983) Bulk parameterization of the snow field in a cloud model. J Clim Appl Meteorol 22:1065-1095

Losada T, Rodríguez-Fonseca B, Janicot S, Gervois S, Chauvin F, Ruti P (2010) A multi-model approach to the Atlantic Equatorial mode: impact on the West African monsoon. Clim Dyn 35:29-43. doi:10.1007/ s00382-009-0625-5

Maloney ED, Shaman J (2008) Intraseasonal Variability of the West African Monsoon and Atlantic ITCZ. J Climate 21:2898-2918. doi: 10.1175/2007JCLI1999.1

Markovic M, Jones CG, Vaillancourt PA, Paquin D, Winger K, Paquin-Ricard D (2008) An evaluation of the surface radiation budget over North America for a suite of regional climate models against surface station observations. Clim Dyn 31:779-794

Marras S, Jimenez P, Jorba O, Perez C, Baldasano JM (2007) Presentday climatic simulations run with two GCMs: a comparative evaluation against ERA40 reanalysis data. American Geophysical Union, Fall Meeting 2007

Messager C, Gallée H, Brasseur O (2004) Precipitation sensitivity to regional SST in a regional climate simulation during the West African monsoon for two dry years. Clim Dyn 22:249-266. doi:10.1007/ s00382-003-0381-x

Mitchell TD, Jones PD (2005) An improved method of constructing a database of monthly climate observations and associated highresolution grids. Int J Climatol 25:693-712

Morcrette JJ (1989) Description of the radiation scheme in the ECMWF model. Tech Memo 165. Eur Cent for Med-Range Weather Forecasts, Reading, UK

Morcrette J-J (1991) Radiation and cloud radiative properties in the ECMWF forecasting system. J Geophys Res 96:9121-9132. doi:10.1029/89JD01597

Moufouma-Okia W, Rowell DP (2009) Impact of soil moisture initialisation and lateral boundary conditions on regional climate model simulations of the West African Monsoon. Clim Dyn 35:213-229. doi:10.1007/s00382-009-0638-0 
Müller MD, Scherrer D (2005) A grid and subgrid scale radiation parameterization of topographic effects for mesoscale weather forecast models. Mon Wea Rev 133:1431-1442

Negrón Juárez RI, Li W, Fu R, Fernandes K, de Oliveira Cardoso A (2009) Comparison of Precipitation Datasets over the Tropical South American and African Continents. J Hydrometeorol 10:289-299. doi:10.1175/2008JHM1023.1

New M, Lister D, Hulme M, Makin I (2002) A high-resolution data set of surface climate over global land areas. Clim Res 21:1-25. doi:10.3354/cr021001

Nicholson SE (2000) Land surface processes and Sahel climate. Rev Geophys 38:117-139. doi:10.1029/1999RG900014

Nicholson SE, Some B, Kone B (2000) An analysis of recent rainfall conditions in west africa, including the rainy seasons of the 1997 el niño and the 1998 la niña years. J Climate 13:2628-2640. doi: 10.1175/15 20-0442(2000)013<2628:AAORRC>2.0.CO;2

Nordeng TE (1994) Extended versions of the convective parametrization scheme at ECMWF and their impact on the mean and transient activity of the model in the tropics. Res Dept Tech Memo 206:41. Eur Cent for Medium-Range Weather Forecasts, Reading, UK

Ohmura A, Dutton EG, Forgan B, Fröhlich C, Gilgen H, Hegner H, Heimo A, König-Langlo G, McArthur B, Müller G, Philipona R, Pinker R, Whitlock CH, Dehne K, Wild M (1998) Baseline Surface Radiation Network (BSRN/WCRP): new precision radiometry for climate research. Bull Am Meteorol Soc 79(10):2115-2136

Paeth H, Born K, Podzun R, Jacob D (2005) Regional dynamical downscaling over West Africa: model evaporationaluation and comparison of wet and dry years. Meteorl Z 14:349-367. doi: 10.1127/09412948/2005/0038

Paeth H, Born K, Girmes R, Podzun R, Jacob D (2009) Regional climate change in tropical and northern Africa due to greenhouse forcing and land use changes. J Climate 22:114-132. doi:10.1175/2008JCLI2390.1

Pal JS, Small EE, Eltahir EAB (2000) Simulation of regional scale water and energy budgets: Representation of sub-grid cloud and precipitation processes within RegCM. J Geophys Res 105:29.579-29.594. doi:10.1029/2000JD900415

Pal JS et al (2007) The ICTP RegCM3 and RegCNET: Regional climate modeling for the developing world. Bull Am Meteorol Soc 88:1395-1409

Patricola CM, Cook KH (2009) Northern African climate at the end of the twenty-first century: an integrated application of regional and global climate models. Clim Dyn 35:193-212. doi:10.1007/s00382-0090623-7

Philippon N, Doblas-Reyes FJ, Ruti PM (2010) Skill, reproducibility and potential predictability of the West African monsoon in coupled GCMs. Clim Dyn 35:53-74. doi:10.1007/s00382-010-0856-5

Pinker RT, Laszlo I (1992) Modeling surface solar irradiance for satellite applications on a global scale. J Appl Meteorol 31:194- 211 Radu R, Déqué M, Somot S (2008) Spectral nudging in a spectral regional climate model. Tellus 60A(5):885-897. doi:10.1111/ j.1600-0870.2008.00343.x

Rasch PJ, Kristjánsson JE (1998) A comparison of the CCM3 model climate using diagnosed and predicted condensate parameterizations. J Clim 11:1587-1614 
Rechid D, Raddatz TJ, Jacob D (2008) Parameterization of snowfree land surface albedo as a function of vegetation phenology based on MODIS data and applied in climate modeling. Theor Appl Climatol 95:245-255. doi:10.1007/s00704-008-0003-y

Reichler T, Kim J (2008) Uncertainties in the climate mean state of global observations, reanalyses, and the GFDL climate model. J Geophys Res 113:D05106. doi:10.1029/2007JD009278

Ritter B, Geleyn JF (1992) A comprehensive radiation scheme for numerical weather prediction models with potential applications in climate simulations. Mon Wea Rev 120:303-325. doi:10.1175/15200493(1992)120<0303:ACRSFN>2.0.CO;2

Roeckner E (2005) IPCC MPI-ECHAM5_T63L31 MPI-OM_GR1.5L40 20C3M_all run no.3: atmosphere 6 HOUR values MPImet/MaD Germany. World Data Center for Clim. CERA-DB „EH5T63L31_OM_20C3M_3_6H“ http://cera-www.dkrz.de/WDCC/ui/Compact.jsp?acronym=EH5T63L31_OM_20C3M_3_6H

Rojas M, Seth A (2003) Simulation and sensitivity in a nested modeling system for tropical South America. Part II: GCM boundary forcing. J Climate 16:2454-2471

Rowell DP, Folland CK, Maskell K, Owen JA, Ward MN (1992) Modelling the influence of global sea surface temperatures on the variability and predictability of seasonal Sahel rainfall. Geophys Res Lett 19:905-908

Rowell DP, Folland CK, Maskell K, Ward MN (1995) Variability of summer rainfall over tropical north Africa (1906-92): Observations and modelling. Q J R Meteorol Soc 121:669-704. doi:10.1002/qj.49712152311

Rowell DP (2003) The impact of Mediterranean SSTs on the Sahelian rainfall season. J Climate 16:849862

Samuelsson P, Jones C, Willén U, Ullerstig A, Gollvik S, Hansson U, Kjellström E, Nikulin G, Wyser K (2010) The Rossby Centre Regional Climate Model RCA3: Model description and performance. Tellus A. doi:10.1111/j.1600-0870.2010.00478.x

Sanchez-Gomez E, Somot S, Déqué M (2008) Ability of an ensemble of regional climate models to reproduce the weather regimes during the period 1961-2000. Clim Dyn 33(5):723-736. doi: 10.1007/s00382008-0502-7

Sass BH, Rontu L, Räisänen P (1994) HIRLAM-2 radiation scheme: Documentation and tests. HIRLAM Tech Rep 16:43. Sveriges Meteorol och Hydrol Inst, Norrköping, Sweden

Savijärvi H (1990) Fast radiation parameterization schemes for mesoscale and short-range forecast models. J Appl Meteorol 29:437-447

Schafer R, Avery SK, Gage KS (2003) A Comparison of VHF Wind Profiler Observations and the NCEP-NCAR Reanalysis over the Tropical Pacific. J Appl Meteorol 42:873-889. doi:10.1175/15200450(2003)042<0873:ACOVWP>2.0.CO;2

Schneider U, Fuchs T, Meyer-Christoffer A, Rudolf B (2008) Global Precipitation Analysis Products of the GPCC. DWD internet publication. GPCC

Schrodin E, Heise E (2002) A New Multi-Layer Soil Model. Tech. Rep. 2, COSMO Newsl.

Shmakin AB, Milly PCD, Dunne KA (2002) Global modeling of land water and energy balances. Part III: interannual variability. J Hydrometeorol 3:311-321 
Shukla J, Mooley DA (1987) Empirical prediction of the summer monsoon rainfall over India. Mon Wea Rev 115:695-703

Simmons A, Uppala S, Dee D, Kobayashi S (2006) ERA-interim: new ECMWF reanalysis products from 1989 onwards. ECMWF Newsl No. 110:25-35

Smiatek G, Rockel B, Schättler U (2008) Time invariant data preprocessor for the climate version of the COSMO model (COSMO-CLM). Meteorol Z 17(4):395-405

Smith RNB (1990) A scheme for predicting layer clouds and their water content in a general circulation model. Q J R Meteorol Soc 116:435-460

Stanelle T, Vogel B, Vogel H, Bäumer D, Kottmeier C (2010) Feedback between dust particles and atmospheric processes over West Africa in March 2006 and June 2007. Atmos Chem Phys Disc 10:75537599. doi:10.5194/acpd-10-7553-2010

Steiner AL, Pal JS, Rauscher SA, Bell JL, Diffenbaugh NS, Boone A, Sloan LC, Giorgi F (2009) Land surface coupling in regional climate simulations of the West African monsoon. Clim Dyn. doi:10.1007/ s00382-009-0543-6

Stephens, GL (1978) Radiation profiles in extended water clouds. II: Parameterizaton schemes. J Atmos Sci 35:2123-2132

Steppeler J, Dom G, Schättler U, Bitzer HW, Gassmann A, Damrath U, Gregoric G (2003) Meso-gamma scale forecasts using the nonhydrostatic model LM. Meteorol Atmos Phys 82:75-96. doi:10.1007/s00703001-0592-9

Sundquist $\mathrm{H}$ (1978) A parameterization scheme for non-convective condensation including precipitation including prediction of cloud water content. Q J R Meteorol Soc 104:677-690

Sylla M, Coppola E, Mariotti L, Giorgi F, Ruti P, Dell'Aquila A, Bi X (2009) Multiyear simulation of the African climate using a regional climate model (RegCM3) with the high resolution ERA-interim reanalysis. Clim Dyn 35:231-247. doi:10.1007/s00382-009-0613-9

Tanré D, Geleyn JF, Slingo J (1984) First results of the introduction of an advanced aerosol-radiation interaction in the ECMWF low resolution global model, in Aerosols and Their Climatic Effects. edited by Gerber and Deepak A. 133-177. A Deepak, Hampton, Va

Taylor JP, Edwards JM, Glew MD, Hignett P, Slingo A (1996) Studies with a flexible new radiation code. II: Comparisons with aircraft short-wave observations. Q J R Meteorol Soc 122:839-861. doi:10.1002/ qj.49712253204

Taylor KE (2001) Summarizing multiple aspects of model performance in a single diagram. J Geophys Res 106:7183-7192. doi:10.1029/2000JD900719

Tiedtke M (1989) A comprehensive mass flux scheme for cumulus parameterization in large-scale models. Mon Wea Rev 117:1779-1800. doi:10.1175/1520-0493(1989)117<1779:ACMFSF>2.0.CO;2

Tjernström M, Sedlar J, Shupe MD (2008) How well do regional climate models reproduce radiation and clouds in the arctic? An evaluation of ARCMIP simulations. J Appl Meteorol Climatol 47:2405-2422

Troy TJ, Wood EF (2009) Comparison and evaluation of gridded radiation products across northern Eurasia. Environ Res Lett 4:045008. doi:0.1088/1748-9326/4/4/045008 
Uppala SM, Kallberg PW, Simmons AJ, Andrae U, Bechtold VD, Fiorino M, Gibson JK, Haseler J, Hernandez A, Kelly GA, Li X, Onogi K, Saarinen S, Sokka N, Allan RP, Andersson E, Arpe K, Balmaseda MA, Beljaars ACM, Berg LVD, Bidlot J, Bormann N, Caires S, Chevallier F, Dethof A, Dragosavac M, Fisher M, Fuentes M, Hagemann S, Holm E, Hoskins BJ, Isaksen L, Janssen PAEM, Jenne R, Mcnally AP, Mahfouf JF, Morcrette JJ, Rayner NA, Saunders RW, Simon P, Sterl A, Trenberth KE, Untch A, Vasiljevic D, Viterbo P, Woollen J (2005) The ERA40 re-analysis. Q J R Meteorol Soc 612:2961-3012

Vidale PL, Lüthi D, Frei C, Seneviratne SI, Schär C (2003) Predictability and uncertainty in a regional climate model. J Geophys Res 108(D18):4586. doi:10.1029/2002JD002810

Vizy EK, Cook KH (2002) Development and application of a mesoscale climate model for the tropics: Influence of sea surface temperature anomalies on the West African monsoon. J Geophys Res 107:4023. doi:10.1029/2001JD000686

van den Hurk BJ, Viterbo P, Beljaars AC, Betts AK (2000) Offline validation of the ERA40 surface scheme. ECMWF Tech Memo 295. Eur Cent for Medium-Range Weather Forecasts, Reading, UK

van der Linden P, Mitchell JFB (2009) ENSEMBLES: Climate change and its impacts: Summary of research and results from the ENSEMBLES project. 160. Met Off Hadley Cent, Exeter, UK

van Meijgaard E, van Ulft LH, van de Berg WJ, Bosveld FC, van den Hurk BJ, Lenderink G, Siebesma AP (2008) The KNMI regional atmospheric climate model RACMO, version 2.1. KNMI Tech Rep 302:43. R Neth Meteorol Inst, De Bilt, Netherlands

von Storch H, Langenberg H, Feser F (2000) A spectral nudging technique for spectral downscaling purposes. Mon Weather Rev 128:3664-3673

Wang B, Fan Z (1999) Choice of south Asian summer monsoon indices. Bull Amer Meteor Soc 80:629638. doi:10.1175/1520-0477(1999)080\%3C0629:COSASM\%3E2.0.CO;2

Wang B (2000) Reply to comments on "Choice of south Asian summer monsoon indices“. Bull Amer Meteor Soc 81:822-824

Wang Z, Zeng X, Barlage M, Dickinson RE, Gao F, Schaaf CB (2004) Using MODIS BRDF and Albedo Data to Evaluate Global Model Land Surface Albedo. J Hydrometeor 5:3-14.

doi: 10.1175/1525-7541(2004)005<0003:UMBAAD>2.0.CO;2

Wang Z, Zeng X, Barlage M (2007) Moderate Resolution Imaging Spectroradiometer bidirectional reflectance distribution function-based albedo parameterization for weather and climate models, J Geophys Res 112. doi:10.1029/2005JD006736

Warnecke G (1997) Meteorologie und Umwelt: Eine Einführung. Springer, Heidelberg

Weart, S R (2008) The Discovery of Global Warming. Revised and Expanded Edition edition. Harvard University Press, ISBN 067403189X

Webster PJ, Yang S (1992) Monsoon and ENSO: Selectively interactive systems. Q J R Meteorol Soc 118:877-926. doi:10.1002/qj.49711850705

Wild M, Ohmura A, Gilgen H, Morcrette JJ (1998) The distribution of solar energy at the earth's surface as calculated in the ECMWF re-analysis. Geophys Res Lett 25(23):4373-4376

Wild M, Ohmura A, Gilgen H, Morcrette JJ, Slingo A (2001) Evaluation of downward longwave radiation in general circulation models. J Clim 14:3227-3239 
Wild M (2008) Short-wave and long-wave surface radiation budgets in GCMs: a review based on the IPCC-AR4/CMIP3 models. Tellus A 60(5):932-945

Winter JM, Eltahir EA (2008) Evaluating regional climate model version 3 Over the Midwestern United States. American Geophysical Union, Spring Meeting 2008

Wyser K, Jones C, Du P, Girard E, Willén U, Cassano J, Christensen J, Curry J, Dethloff K, Haugen J, Jacob D, Køltzow M, Laprise R, Lynch A, Pfeifer S, Rinke A, Serreze M, Shaw M, Tjernström M, Zagar M (2008) An evaluation of Arctic cloud and radiation processes during the SHEBA year: simulation results from eight Arctic regional climate models. Clim Dyn 30(2-3):203-223

Xue Y, De Sales F, Lau W K-M, Boone A, Feng J, Dirmeyer P, Guo Z, Kim K-M, Kitoh A, Kumar V, Poccard-Leclercq I, Mahowald N, Moufouma-Okia W, Pegion P, Rowell DP, Schemm J, Schubert SD, Sealy A, Thiaw WM, Vintzileos A, Williams S, Wu M-L (2010) Intercomparison and analyses of the climatology of the West African Monsoon in the West African Monsoon Modeling and Evaluation project (WAMME) first model intercomparison experiment. Clim Dyn 35:3-27. doi:10.1007/s00382-010-0778-2

Yoshioka M, Mahowald NM, Conley AJ, Collins WD, Fillmore DW, Zender CS, Coleman DB (2007) Impact of desert dust radiative forcing on Sahel precipitation: Relative importance of dust compared to sea surface temperature variations, vegetation changes, and greenhouse gas warming. J Clim 20 1445-1467

Zanis P, Douvis C, Kapsomenakis I, Kioutsioukis I, Melas D, Pal JS (2009) A sensitivity study of the Regional Climate Model (RegCM3) to the convective scheme with emphasis in central eastern and southeastern Europe. Theor Appl Climatol 97:327-337. doi: 10.1007/s00704-008-0075-8

Zhang Y, Rossow WB, Stackhouse PW (2006) Comparison of different global information sources used in surface radiative flux calculation: radiative properties of the near-surface atmosphere. $\mathrm{J}$ Geophys Res 111:D13106. doi:10.1029/2005JD006873

Zhang Y, Rossow WB, Stackhouse PW (2007) Comparison of different global information sources used in surface radiative flux calculation: radiative properties of the surface. J Geophys Res 112:D01102. doi:10.1029/2005JD007008

Zhang T, Stackhouse PW, Gupta SK, Cox SJ, Mikovitz JC (2009) Validation and analysis of the release 3.0 of the NASA GEWEX surface radiation budget dataset. AIP Conf Proc 1100:597.

doi: $10.1063 / 1.3117057$ 


\section{Publications of Steffen Kothe}

Kothe S, Dobler A, Beck A, Ahrens B (2010) The radiation budget in a regional climate model. Clim Dyn 36:1023-1036. doi:10.1007/s00382-009-0733-2

Kothe S, Ahrens B (2010) On the Radiation Budget in Regional Climate Simulations for West Africa. J Geophys Res 115:D23120. doi:10.1029/2010JD014331

Kothe S, Lüthi D, Ahrens B (2011) Analysis of the West African Monsoon system in the regional climate model COSMO-CLM. Submitted to Clim Dyn

\section{Confernce PROCEedings}

Ahrens B, Kothe S (2011) On the radiation budget in regional climate simulations for West Africa. Talk at Conference on the Coordinated Regional Climate Downscaling Experiment - CORDEX, Trieste, 21-26 March 2011

Dobler A, Kothe S, Ahrens B (2011) Representation of monsoon systems in a regional climate model, EGU General Assembly 2011, Vienna, Austria, Poster

Kothe S, Ahrens B, Casanova S, Hollmann R, Müller R, Nitsche H (2008) Determination of surface radiation anomalies. EGU General Assembly 2008, Vienna, Austria, Poster

Kothe S (2008) Die Strahlungsbilanz im regionalen Klimamodell CLM. CM-SAF workshop June 2008, Offenbach, Germany, invited talk

Kothe S, Ahrens B, Casanova S, Hollmann R, Müller R, Nitsche H (2008) A satellite based reference climatology for the surface radiation budget. 2008 EUMETSAT Meteorological Satellite Conference, Darmstadt, Germany, Poster

Kothe S, Ahrens B, Nitsche H, Hechler P (2008) A conceptual approach for climate monitoring with merged satellite and in situ data, 8th Annual Meeting of the EMS/7th ECAC, Amsterdam, Netherlands, oral presentation

Kothe S, Ahrens B (2009) Assessment of radiation budget in a regional climate model, EGU General Assembly 2009, Vienna, Austria, Poster

Kothe S, Dobler A, Ahrens B (2009) Assessment of the radiation budget in a regional climate model for Europe and Africa, IMPETUS Africa Conference, Cologne, Germany, Poster

Kothe S, Ahrens B (2009), Some ideas on CCLM evaluation in Africa, 4th CLMCommunity Assembly, Karlsruhe, Germany, oral presentation

Kothe S, Ahrens B (2009) Die Strahlungsbilanz in einem regionalen Klimamodell, 8. Deutsche Klimatagung, Bonn, Germany, oral presentation

Kothe S, Ahrens B (2010) The West African Monsoon in a regional climate model, COSMO/CLM User Seminar, Langen, Germany, oral presentation

Kothe S, Ahrens B (2010) The radiation budget in regional climate simulations for Africa, EGU General Assembly 2010, Vienna, Austria, oral presentation 
Kothe S, Ahrens B (2010) The West African Monsoon in the Regional Climate Model COSMO-CLM, 10th Annual Meeting of the EMS/8th ECAC, Zurich, Switzerland, oral presentation

Kothe S, B. Ahrens (2010), Possible Evaluation Strategies for the IPCC-AR5 COSMO-CLM Simulations for Africa, 5th CLM-Community Assembly, Berlin, Germany, oral presentation

Kothe S, Ahrens B (2010) The West African Monsoon in the Regional Climate Model COSMO-CLM, 10th Annual Meeting of the EMS / 8th ECAC, Zurich, Switzerland, oral presentation

Kothe S, Ahrens B (2010) Der westafrikanische Monsun im regionalen Klimamodel COSMO-CLM, DACH Meteorologentagung 2010, Bonn, Germany, oral presentation

\section{MISCELLANEOUS}

Kothe S, Ahrens B (2008) Begutachtung des wissenschaftlichen Feinkonzepts und des gegenwärtigen Standes des Programms SAT-KLIM - Abschlussbericht, available via DWD homepage

Kothe S, Ahrens B, Casanova S (2008) Entwicklung einer hochaufgelösten Referenzklimatologie für Strahlungsbilanzkomponenten am Erdboden für Europa - Abschlussbericht, available via DWD homepage

Kothe S, Ahrens B (2008) Erstellung einer Referenzklimatologie der Strahlungsbilanzkomponenten am Erdboden mit Hilfe von GEWEX/SRB-Daten und Produkten des CM-SAF - Abschlussbericht, available via DWD homepage

Kothe S, Ahrens B (2010) Der Monsun - Segen, Fluch und Forschungsobjekt. Natur und Museum 140:264-267 
seit $10 \mid 2008$

seit $10 \mid 2007$

$10|2001-09| 2007$

$07|2000-10| 2001$

$06 \mid 2000$

\section{CURRICULUM VITAE}

*02. März 1981 in Eberswalde

Familienstatus

verheiratet, keine Kinder

\section{Steffen Kothe}

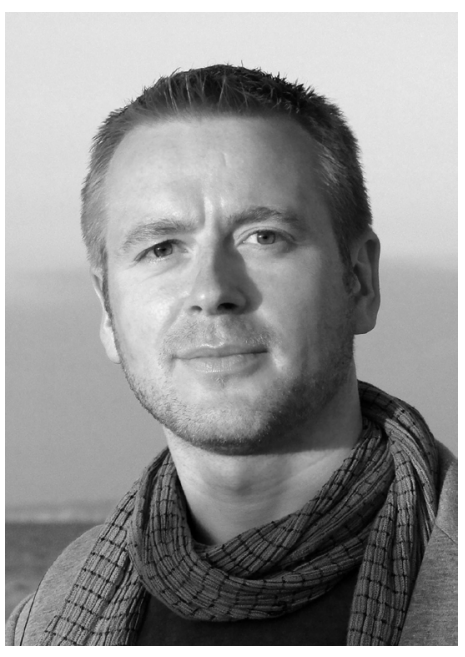

Aktuelle Tätigkeit

Wissenschaftlicher Mitarbeiter am LOEWE Biodiversität und Klima

Forschungszentrum in Frankfurt am Main

Doktorand am Institut für Atmosphäre und Umwelt

der Goethe-Universität Frankfurt

Thema der Dissertation:

"Die Strahlungsbilanz in einem regionalen Klimamodell“

(Betreuer: Prof. Dr. Bodo Ahrens)

\section{Studium}

Studium der Meteorologie an der Freien Universität Berlin Abschluss als Diplom-Meteorologe

Thema der Diplomarbeit:

„Untersuchung des Tagesgangs mikrophysikalischer Wolkenparameter mariner Stratokumulusbewölkung mit MSG/SEVIRI-Daten“

(Erstprüfer: Prof. Dr. Jürgen Fischer, Zweitprüfer: Prof. Dr. Ralf Bennartz)

Wehrdienst

Wehrdienst als Soldat im Stabsdienst

Schulbildung

Abitur am Bertolt-Brecht-Gymnasium, Bad Freienwalde

Frankfurt am Main, August 2011 